

\section{D. $3.10^{\circ}$}

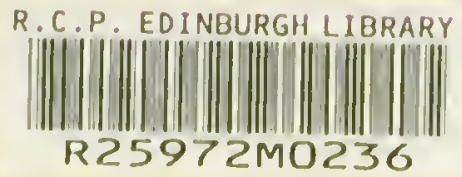




Digitized by the Internet Archive in 2016

https://archive.org/details/b21948914_0002 



\section{OEUVRES}

D E

\section{I G Q - D' A Z Y R.}

ÉLOGES HISTORIQUES. 



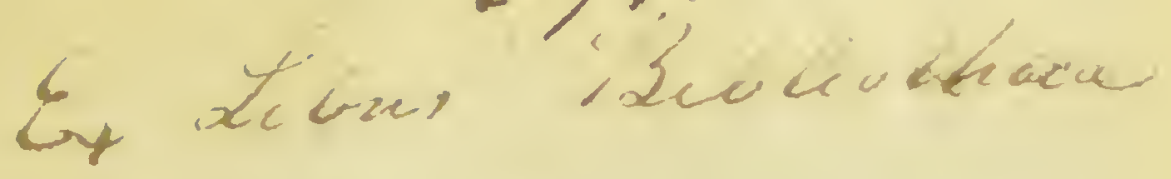

\section{OEUVRES \\ ton \\ $\mathrm{V}$

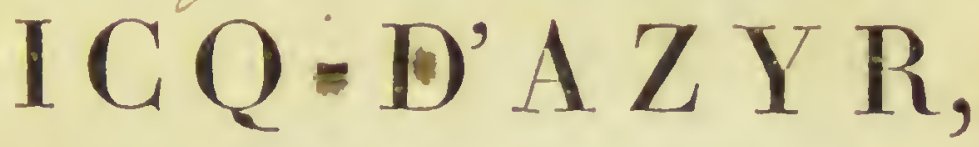 \\ $\mathrm{DE}$ \\ 172 casiare iac:}

RECUEILLIES ET PUIIRES AVEC DIS NOTES ET UX Discours suR sa Vib ET SES OUVRAGES,

par Jace. L. MOREAU (de la Sirthe),

Doctenr médecin, Sous - bibliothécaire de l'École de midecine, Membre aljoint de la Socicté de cette Éco!e, membre de la Sociéti philomathique, des Suciétés de médecine de Paris, de Mompellice, eic.

ORNÉS D'UN YOLUME DE PRA XCUES, GRAND IN-4.

ET D'UN FRONTISPICE ALLÉGORICUE.

TOME SECOND.

DE L'IMPRIMERIE DE BAUDOUIN.

A PARIS,

Chez L. DUPRAT-DUVERGER, rue des GrandsAngustins, N. ${ }^{\circ} 24$.

AN XIII. -1805. 



\section{ÉLOGES HISTORIQUES.}

SUITE DE LA SECONDE SECTIOX.

\section{POULLETIER DE LA SAILE.}

$\mathrm{F}$

naxçors - Paul - Lyon Poulietier de ra Satree, maitre des requêtes, ancien président au grand conseil, associé libre de la Société de nédecine, naquit, le 3o septembre 1719, de Pierre Poulletier, intendant de la géuéralité de Lyon et conseiller d'état, et d'HenrietteGuillamme de lat Vienx-Ville.

La ville de Lyon le tinıt sur les fonds de baptème, et lui domna son nom.

M. Poulletier fut enroyé à Paris pour y étudier en droit. Les professenrs les plus habiles enseignoient alors la médecine dans cette capitale : sa curiosité le porta près d'cux; son penchant l'y retint; et tandis que, pour obéir it son père, il donnoit quelques moznens à la jurisprudence qui n'avoit point d'attraits pour lui, toutes ses journées étoient remplies par l'étude de notre art. Il y trouvoit la nature et l'homme liés par des rapports nécessaires, invariables, et importans à connoître pour tous ccux qui font quelque cas des recherches vraiment utiles à l'humanité.

T. 2. 
Souvent on a viu des inédecins célèbres employer leur crédit pour faire obtenir à leurs fils des places distinguées dans la magistrature; ils clierchent à s'élever en agissant ainsi : M. Poulletier suivit une ronte contraire; il repoussa les dignités auxquelles il étoit conduit par sa naissance, et il ne crut point descendre en préférant de s'asseoir parmi nous. L'usage quill a fait de son temps montre assez qu'il eut raison.

Maintenant que le passé le justifie, on loıe sa générosité; mais lorsqu'au commencement de sa carrière il s'écarta des routes de l'ambition et de la fortune pour se livrer à un gôt qui paroissoit bizarre, on accusa d'extravagance ce qu'avoit tracć la sagesse; et chacun plaignit M. l'intendant de Lyon d'avoir un fils qui vouloit se faire médecin.

Persécuté par ses parens et par ses amis, il fallnt bien que M. Poulletier acceptît la cliarge de nuâ̂tre des lequêtes qu'on lui destinoit depuis long-temps. Mais lorsqu'à peine sorti de sa première jennesse, on le pressil d'exercer un de ces grands emplois sur lesquels repose le sort de tout un peuple: cNon, dit-il, je n'ai point assez méditć sur des devoirs que je sais an-dessus de mes forces, et je n’ai point assez vécu pour inspirer la confrance qui est nécessaire au snecés ». Il se sul tonjours gré de ce refus. Il se félicitoit de sêtre conservé pur dans $11 n$ agge oil l'ou a tant à espérer et à crandre de ce pue pent la sédnclion. "Qu'cest-ce, ajouloil-il, qu'mu magistrat cufant, qui sait at peinc halluntice les lois, ot que l'on envoie ponr communder atux lommes? 
PHYS. ET CHIM. - POULLETIER. 3 et combien je serois coupable si j'avois pu contribuer à donner un tel cxemple! »

Cette conduite déroila tout-á-coup le caractère de M. Poulleticr. Son père lıi-ı̂̉ıe conçut ponr hui plıs que de l'estime. «Mon fils, hil dit-il nu jou', montrezmoi donc conment vous passez rotre temps? et si vous n'eutreprencz rien pour votre fortnne, 'que je sois an' moins dans la confidence de votre bonheur $»$ ! « Tous comnoîtrez, répondit le jenne philosophe, le fruit de nes économies et de mes veilles. Ici j'il rassemblé les viacles du petit nombre de siecles dont on a gardé le sonvenir; j'y étudie les hommes sans aroir rien à craindro d'cux, puisqu'ils ne me sont présens que par lit pensée; là j'interroge la nature par la roie de l'analyse, et tont, jnsçu'ì son silence, y est éloụnent pour moi. Plns loin, je descends daus les replis les phus secrets des corps aniunés; je compare leurs organes avec leurs affections; et cette science, reponssante ponr la phipart patrce qu'clle atteste notre néant et nos uisères, a des charmes ponr noi, qui n'en snis point effrayé. Ailleurs, des végétaux salutaires qui croissent sous mes yeux m'offrent des fenilleś, des fleurs et des fruits que je consacre an sonlagennent des malades. Ainsi, tonjours occupé, mais toujours libre, l“uutrigue ct l'envie ne penvent nue blesser, parce qu'elles ne sauroient m'atteindre. Dites-moi, mon père, s'il cst possible de mieux employer les biens que je tiens de vous, et prononcez ( entre le monde et noi ? ”

Une autre fois, M. Poulletier rassembla le bon et vertucux de Jnssien, le savant Astruc, le bouillant 
Rouelle, Boulduc, Macquer, Levret, Sue, et il plaça son père au milieu d'eux. Étonné de tant de savoir, ému snr-tout par ce zèle de la vérité qui brilloit dans leurs discours, et comparant ces hommes avec ceux dont il étoit ordinairement euvironné, M. l'intendant de Lyon fut touché jusqu'aux larmes. Il félicita son frls, loin de le blâmer, d'avoir fait un tel choix; et peu s'en fallut qu'il ne quittât lui-même l'administration et les affaires pour demander à être admis dans cette société, près de laquelle il vint plus d'une fois chercher des consolations et des lumières. Depuis ce moment, M. Poulletier snivit librement ses goûts, et nul obstacle ne l'interrompit dans ses travaux.

Il avoit formé le plan de plusienrs ouvrages, qu'il ne ponvoit achever sans a voir fait l'essai de différens remèdes, et sans s'être accoutımé lui-même à la pratique de notre art. A ses projets d'instruction se joignirent des vues de bienfaisance plus louables encore. M. Poulletier établit dans les faubonrgs de Paris trois hospices où les panvres étoient reçus et traités à ses dépens. Là, sous la direction des médecins et des chirurgiens les plus habiles, il apprit à connoitre la nature et les diverses périodes des maladies. Les jours - étoient employés à la visite de ces maisons: les muits l'étoient à l'étude, et toul son temps se passoil à bien faire.

Il en est des formules de nos médicanens comme de celles de nos arrêts et de nos lois. T'untes portent l'empreinte du siècle quni les dicta. Quel siécle en effet que

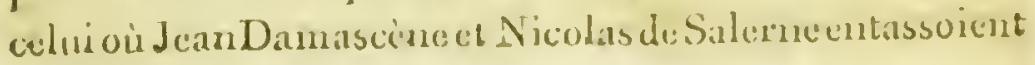


PIIYS. ET CHIM. - POULLETIER. 5 les recettes des Arabes dans d'énormes antidotaires? Que celıi où Nicolas, prévôt de Tours, et Bauderon, prétendoient communiquer toutes les propriétés à leurs remèdes en y faisant entrer tontes les drogues.

Ce fut ell 15ła que la première Pharmacopée parut à Nuremberg. Quariute-luit années après, la Faculté de médecine de Paris publia le premier Recueil de ses formules, qu'elle a corrigées plusieurs fois, et qu'elle a rendues sur-tont plins complites en 1758 . Le College des nrédecins cle.Londres n'r pas apporté inoins de zìle dans la rédaction de son Dispensaive, dont l'élition, enrichie des rotes du docten Pembertou, étoit très-estinéc. M. Ponlletier se chargea de la traduire en français, et il y ajonta un Dictionnaire de matière médicale, avec des notes trèseélendues qui servent de supplément à l'ourrage.

On re sait ce qu'on doit le plus loner dans ce travail, ou des comnoissances chimiques que rauteur y a développées, on de l'exactitude avec laquelle il y a décrit les procédés de la plarmacie, science trop étrangère à la plupart des médecins, ou dé l'ìmpartialité dont il y at donné des prenves.

Plusieurs articles importans aroient étŕ onbliés, soit dans le catalogue des médicamens, soit dans la manipulation des drogues. Quelques erreurs avoient été commises; duanciennes formules très-inutiles aroient été conservées $=\mathbf{M}$. Poulletier a relevé et corrigé toutes ces fautes.

Les membres du Collége de médecine de Eondres remarquent sur-tout, et l'on me sauroit trop rêpéter 
qu'il n'y a point de pliss grand obstacle aux progrès de notre art que l'nsage où l'on est de réumir un grand nombre de drogues dans ses formules. On ignore, en se conduisant ainsi, anquel des moyens le succès peut être dû; et, faute d'isoler les faits, le jugement demenre à jamais incertain.

All reste, si, malgré les travaux des compagnies les plus savantes, nons n'avons point encore une Pharmacopée telle que nous pourrions la désirer, il ne faut en accuser que la difficulté même du sujet. Démêler dans les anciennes compositions les substances vraiment actives, et les conserver; chercher dans les écrits et dans la pratique des médecins les plus fameux quels remèdes ont le mieux rénssi, et quel changement il seroit à propos d'y faire; consulter l'empirisme et profiter de ses hasards, en le jugeant par l'observation, sans le soumettre aux théories du moment; rejeter les nombreux mélanges que l'on emploie sans motif's, comme on les fait sans raison; donner aux médicamens une force constante et dont ou puisse calculer les résultats; les rédnire à $n$ état de simplicité qui ne laisse point de doute sur leurs effets, et ne s'écarter jalmais des règles que la climie prescrit; c'est-ì-dire, joindre à me connoissance parfaite de l'histone de la médecine nne étude profonde des sciences qui lui sont accessoires; ì un tact délić, nu esprit juste; à me prudence consonnuće, celte liardiesse sans laquelle on ne va point au but : voila quels tilens et quelles qualités loivent rénuir ceux qui se chargent de rédiger nos lormules. 
PHYS. ET CHIM. - POULLETIER. 7

Déja les déconvertes de Bergman et de Schéele ont produit dans ce genre me révolution untile. Lues médecins de Stockholm ont donné l'exemple. Ceux de Wirtcmberg, de Genc̀ve, d'Edimbourg et de Loudres, l'ont suivi. La Faculté de nıédecine de Paris est maintenaut occupéc de la mène réforme. Ne doit-on pas espérer que, forcés par les progrés des lumières, tours les colléges de médecine efficcrout enfin de leurs dispensaires ces recettes informes, assemblinges monstrenx de substances qui se combattent, dout les vertus se détruisent, et que lignorance a consacrées? Les partisans nombrenx de ces ancienues superstitions citerout des siècles de succis ; ils diront que lon détruit tonjours saus édifier, ct 'ju'ou ne substitue rien à ce qu'ou lenr enleve. Vaines déclanrations trop sonvent répétées par les détractenrs des sciences! Lors(pue les témbebres se dissipent, le jour, au meme iustant et sans nul effort, en prend lạ place, et la vérité, quoi qu'on en dise, est, connme la lumière, un des plus beanx préseus que l'on puisse offrir à l'humnanité.

Les auteurs de la Plarmacopée de Londres avoient parlé sans inénagenent de Fernel, l'un des plus illıstres médecins de l'Ecole française. M. Poulletier en a fait de justes plaintes, eu blìmant cette jalousie nationale qui a douné taut de torts aux Anglais envers nous, et qui suffiroit seule pour faire réroquer en doute leur prétendue supériorité.

La plupart des personnes riches qui se livrent à l'ćtude des sciences on des lettres semblent se plaire ì commencer un grand non bre d'écrits, que le plus 
souvent elles ne finissent jamais. C'est qu'abandonnées all plaisir de produire, elles se dispensent des soins qu'exigeroit l'achèvement de leurs ourrages; enfans de la pensée que l'on conçoit avec joie, mais qui ne croissent qu'au milieu des sollicitudes paternelles, et qui ne parviennent que difficilement à leur maturité.

M. Poulletier a fourni un grand exemple à l'appui de cette remarque; il a laissé sur toutes les parties de la médecine des mannscrits dont il n'y a qu'un très-petit nombre auxquels il ait mis la dernière main.

Parmi ceux-là doit être compté un Essai sur les accidens qui sont causés par l'épancliement de l'air ou des gaz dans les différentes cavités dn corps lummain. En faisant diverses expériences sur ce sujet, ił a observé (que les intestins grêles sont plus irritables que les gros, et que dans cenx-ci la partie la plus élevée est celle qui jonit an plus haut degré de cette force.

Ce traité de M. Ponlletier, quoique complet ì l'époque où il a été écrit, anra besoin d'm supplément lorsque nous le donnerons an public. La chimie moderne a découvert trois gaz différenis dans l'estomae et dans les intestins des animanx; savoir, l'air fixe ou acide carbonique qui est dî à la fermentation des alimens, le gaz inflammable, et le gaz liépatique on sulfuré.

On distingne encore parmi les manuscrits de M. PonlJetiex, dont M. Jeanroi, qui étoit son ami, est naintenant le dépositaire: 1.0 les procès-verhanx des exprériences qu'il a faites avec $M$. Vercher et Bertiaudi sur la sensibilité; 2.0 des remarques sur la naniere de dissondre l'extrémité d'une sonde de plomb restée dans 
la vessie, en y injectant dn mercure; $3 .^{\circ}$ me table des différentes longueurs du conduit intestinal dans les différeus âges: d'où l'on tire nu résultat curienx; satroir, que la longuenr des iutestins, comparée avec celle du corps, est plus grande dans les cufans quedaus les adultes et daus les vieillards; 4.0 des recherches sur l'ahsorption des vaisseanx lyn plratiques lans les gros intestius, qui démontreut la possililité de gućrir des manx trìsgraves par le noyen des laveneus médicanentenx; $50^{\circ}$ un exposé des effets qui sont résultís de l'application de la pierre à cantere sur différentes parties des cadarres, on clle a formé des escarres entour's de ccrcles rouges; 6.0 enfur des réflexious judicienses sur les antispasıuodiques, qui u'opèrent janıais pluss sûrement qu'en augnentant une excrétion quelconque, sur-tout celle de l'insensible transpiration.

Dans d'autres caliers sont rassemblés des extraits, des anecdotes, des formules, des sommaires de tous les genres, qu'il y trouroit au besoin.

Pour savoir ce que la mort de nos confrères doit causer de regrets, il fautroit, comme nous, aroir pénétré dauss leurs laboratoires, dans leurs bibliothèques; if fandroit s'y être assis, comure nous, an milieu des écrits auxquels ils ont coulié leurs dernières pensées; il fandroit y aroir vir ce qu'ils n'ont gu'esquissé, et ce qur'ils avoient encore à dire. Combien de fois, entouré de ces débris, ai-je formé des væux pour qu'il me fut possible de rassembler autour de moi tons mes lecteurs et de leur communiquer en ce moinent toutes mes impressions! Venez, leur aurois-je dit; apprenez ce que 
conte un pende gloire, et jugez, par ce qui reste, de tout que vous avez perdu!

Une remarque que j'ai faite en examinant les registres et les manuscrits des savans dont $j$ 'ai publié les éloges, c'est qu'il y en a eu peu ou j'aic aperçu les traces d'une méthode qu'ils eussent adoptée ou suivie pour classer les premiers résultats de leurs travaux. Comme il existe un art de combiner les jdées et de former les jugemens, je demande pourquoi l'on ne s'efforceroit pas anssi d'en trouver un pour ordonner ses sọvenenir's. Locke saroit, à l'aide d'une disposition, qui maintenant est très-connne, retrouver à volonté dans ses caliers les faits et les anecdotes qu'il avoit pris soin d'y recueillir ; mais ce moyen ne pent s'appliquer à tons les cas. L'homme qui lit on qui observe, qui médite on qui écrit, a sous les yenx une galerie de tableaux, dont les scènes, les tcmps, les liens, et la toile même qui les reçoit, varient à clıqque instant du jour : il voit fuir des images auxquelles d'autres impressions succèdent. Tous les détails, toutes les muances dont se composent ces vérilés déliées et fines qui font le charme du discours, s'effaccut ì mesure qu'une étude nouvelle vient à s'enparer de son esprit; et toujours ce qu'il oublie surpasse infininent ce qu'il a retenu.

Pour établir quel pue proportion entre l'instruclion ot les lectures; pour assurer à l'homme la jonissance de tontes ses pensées, jedemande qu'il s'accontume dìs sa jenuesse aे se reudre conpte des graudes émotions quo lo plasir on la doulcur lui anm fort éprouver q qu'il ne lise ancun live baus en tirer des résullats; qu’il ne 
PHYS. ET CHIM. - POULLETIER. 17 laisse échapper sans les écrire, ancune vérité importante, ancun fiit digne d'être remarqué. Je demande que ces notes, réflexions ou extraits, soicnt inscrits sur des feuilles dont chacune ne contienne que des observations dı mème genre, et qui soient toutes sépariées les mues des antres, afin qu'elles puissent entrer dans tontes les combinaisous dont on aurabesoinr. Il fant que ces pièces soient rangées dans un ordre analytique, quisera, pour ainsi dire, l'alphabetlr de la mémoire; il faut enfin qque ce répertoire, riche de tant de contributions, soil visité chaque anuée dans tontes ses parties par celui quil'aura formé. Une seule phrase, nu not lir rappelleront de nombrentes idées; il verra se renouer les fils de ses différens souvenirs; il retrouvera toutes ses méditations, toute sa vie, tout son ètre; il se contenuplera tont eutier; et chaqne fois qu'il fera cette revue su' lıi-même, il en sortira plus exercé, plus confiant, plus fort, et sûr de marcher ver's des succès nouveaux.

Au nombre des livres que M. Poulletier préféroit étoient sur-tout cenx de Morgagni. Les notes et les observations qu'il a rassemblées sur les causes et le siége des maladies, suffiroient pour servir de commentaire à une édition nouvelle des traités de cet auteur sur le mème sujet. Il regardoit ce genre d'étude comme un de ceux qui devoient le plus contribuer à l'avancement de notre art. Van Helmont reprochait aux médecins de son temps de n'y chercher que des prétextes pour excuser leurs funtes (1). Bonnet et Morgagni, plus

(1) Ad inveniendum excusationes in peccalis. 
généreux, ont publié les leurs; ils en ont montré les sources, et ils ont mis ceux qui les lisent dans l'henreuse impossibilité de les commettre.

Les recueils de M. Poulletier sur les diverses consestions du cervean sont les plus complets de tous. Il résulte de ses recherches, comme de celles de M. Walter, que ces congestions enlèvent la plus grande partie du genre humain. Presque toutes les maladies lentes et la plupart des maladies aiguës se terminent en effet par une sorte d'apoplexie, daus laquelle le cerveau, surcliargé de sucs, perd son mouvement, s'affaisse et succombe. C'est cette même lymphe qui alimente la vie, dont l'épanchement causc la mort. C'est elle qui, s'écliappant de ses vaisseaux, répand un nuage cutre le monde et nos organes. Ici l'imagination s'cffraic; mais le philosophe, plus calme, dit, que s'il n'est pas très-doux de rivre, il n'est pas non plus très-donloureux de mourir.

Le temps est un des grands ćlémens des choses; nuais cet élément si précieux est prodigué de toutes parts, et il scmble qu'on n'en doune à l'étude que ce que le monde ne pent en dissiper. M. Ponlleticr, qui avoit vil an commencement dı siècle les gens de lettres plus éloignés des distractions de la société, ct moins occupés de leurs plaisirs que de lenr gloire, se plaignoit sans cesse de ce désordie, qui, pour des jonissances éplı́mires, détruit l'espoir de l'avenir. Exact observateur de ces principes, son tenıps suffisoit ì peinc à ses travanx lorsque le gont de la chimie se joiguit is ceux 'yu'il avoit montrés jusqu'alors. Il ne se contenta point de line, il roulut opérer; il étoit l'ani de M. Macquer, 
PHYS. ET CHIM. - POULLETIER. 13 il en devint l'émule; et le Dictionnaire de chimie se grossit de ses recherches.

On y lit les expériences de M. Poulletier sur la soucie et le varech. On y tronve son analyse de la magnésic, ¿qu'il a combinée avec l'acide sulfurique pour former le sel d'epsom, et ses essais sur l'eau de la mer.

M. Poulletier a été le premier qui ait finit en France l'analyse de la substance osseuse, qu'il a traitée par les acides vitriolique et nitresux, et dont il a tiré l'acide phosphorique et la terre calcaire, comme Schéele et Galun l'avoient annoncé. Plus de mille expériences répétées avec M. Macquer rienuent à l'appui de l'opinion que Schéele a établie; ınais il n'a rien dit de plus. Schéele ne se plaisoit que dans des routes inconnues; M. Poulletier au contritre craignoit de s'y cugager: plusienrs fois il a tem dans ses mains des vérités importantes qui lui ont échappé, parce qu'il n’a pas osé y croire, ou parce qu'il n'a pas eu le conrage de les dire. Fidile à l'ancien plan, il a fait plus d'efforts pour s'y renfermer, qu'il n'en auroit fallu ponr en sortir. Il redontoit les constructions nourelles, et il travailloit avec M. Macquer à réparer et ì finir l'édifice, lorsque, plns hardis, les chimistes modernes s'occupoient à le détruire pour le recommencer.

M. Ponlletier a travaillé long-temps sur le sel sédatif.

Les expériences qu'il a faites sur la bile, et que l'auteur de l'Essai pour serrir à l'histoire de la putréfaction a publiées, prouvent que cette humenr est de nature savonnense; vérité que M. Cadet a mise, quelques années uprès, daus tout son jour. 


\section{ELOGES HISTORIOUES.}

Vers l'amnée 1758, M. Poullctier fit la découverte de la matière blanche cristalline et très-légère qui compose en grande partie les concrétions biliaires humnaines, dont elle se dégage par le moyen de l'esprit de vin. II l'a vue se sublimer en fumce blanche. Il en forma aveci les acides minéraux une espèce de bitume, et il ne le trouva point dans les pierres biliaires du bœuf. M. de Fourcroy a retiré cette même substance en grande massé des corps humains altérés par la putréfaction, et il a fait voir qu'elle est analogue an blanc de baleine. C'est une des vérités que les commissaires de la Société de médecine doivent à l'examen des corps ensevelis dans le terrain des Saints - Innocens, dont ils ont dirigé l'exhumation.

Le travail le" plus complet que M. Poulletier ait exécuté en chimie est l'analyse de la farine : des expériences de Beccari et de Keissel Meyer qu'il a répétées et perfectionnées, il a tiré les résultats suivans qui lıi apjartiement. Il s'est assuré que la farine délayce dan's l'eau, que le pain azyme et la pâte ancienue ne fonrnissent point de inatière glutineuse; que l'on retire des sels ammoniacanx du gluten, eu le traitant lentenent avec les acides; etc., gu'il existe dans la farine une maticre mucoso-sucrée qui se dissont dans l'ean lorsqu'on lave la pâte ponr en séparer le gluten et l'aunidon. Ces reclierclies, vraiment intéressantes, ont été pnhlices avec éloge par M. Macquer, que M. Ponlletier a beancoup aidé daus ses travanx sins lui avoir tonjours permis de le citer.

M. Ponlleticr avoit commencó on 1786 mu travail 
PHYS. ET CHIM. - POULLETIER. 15 qu'il faisoit en commun avec M. de Fourcroy sur l'analyse des pierres urinaires. Dès 1750 it aroit clierclié à déconvrir le fondant de ces concrétions; mais it n'avoit pas réfléchi qu'il falloit en déterminer la nature avant que de travailler a les dissondre. Il les supposoit composées de terre calcaire : et des essais dirigés d'aprés cette vne ne ponvoient rénssir, puisquinn acide concret et insoluble en est, comme Schéele l'a démontré, le principal élément.

On se souvieut qu'en 1779 des voleurs ayaut imaginé de meler diverses préfurations des plantes narcotiqnes aux alinens et sur-tout anx boissons, it se commit alor's de nomlreux empoisonnemens. M. Poulletier fitt prié, conjointement avec 'juelques autres membres de la Socité de nuédecine, d'analy:ser les liqueurs snspectes que l'on aroit trouvées entre les mains de ces malleurenx. Les magistrats firent très-satisfaits de ces recherches, dont nons supprimons à dessein les détails. Sur un pareil sujet on rue doit rien écrire dont les méchıus puissent faire quelque profit. Notre nation est d'ailleurs, en ce genre, d'une ignorance et d'nne maladresse qui lui font homeur, et qu'il fandroit accroître encore, si le nual que l'on sait pouvoit être oublié.

Jamais l'influence du caractére d'un anteur sur ses ourrages ne fint plns marquée que dans les prodnctions de M. Poulletier. 11 tenoit fortement à ses prenières idées, et tout ce qui n'étoit point d'accord arec elles trouvoit difficilement grace anprès de lui. Il avoit été trompé tant de fois, que, pour ne plns l'être, il aroit 


\section{6 ELOGES HISTORIQUES.}

pris le parti d'opposer le doute à presque toutes les assertions; et ce doute se montroit daus ses gestes, comme dans les inflexions de sa voix; il étoit répandu sur toute sa personne. On se blessoit peu de cette méfiance qui sembloit n'être que générale, quoiqu'elle füt souvent persomnelle; car tous ceux qu'il estimoit avoient de grands droits sur lui : s'ils erroient, il erroit volontier avec.eux, et il les défendoit avec courage. L'habitude qu'il avoit contractée de croire difficilement ce que les autres disoient avoir vu, le portoit à croire difficilement anssi ce qu'il voyoit lui-même. Il craignoit toujours d'être égaré par quelque prestige. Tant d'inquiétude lui ôtoit cette liberté d'esprit sans laquelle on ne s'élève point à de hautes conceptions : aussi ses immenses travaux ont produit pelı de découvertes. Il apportoit parmi nous un grand zèle; ses doutes, ses contradictions y étoient souvent utiles et jamais incommodes, parce que sans avoir rien de choquant ils plaisoient, ils instruisoient même par leur piquante originalité : dans nos scrutins il sembloit quelquefois renoncer à son caractère, et ses avis alors n'avoient pas tonte la singularité de ses opinions.Il nous a laissé l'exemple d'une vie remplie par le travail et par la vertu, et je crois lıi rendre un hommage digne de sá probité sévère en parlant ici le langage de la vérité.

M. Poulletier ne se pernit jamais qu'mu senl délassement, l'étude de la mussique. L'art de la composition ne lui étoit point étranger; il avoit nis en cliant plusienr's morceaux des opéras de Quinanlt et de Métastase; mais son gont étoit demenré le mèno : et la nusiquo 
PHYS. ET CHIM. - POULLETIER. 17 a tant changé que se restreignant au plaisir d'en entendre, il avoit en la sagesse de renoncer depuis loug-temps à en filire.

M. Ponlletier a vécu célibataire sans aroir épronvé aucun des inconvéniens auxquels cet état expose. NI. et madame de Thurique, ses neven et nièce, avec lesquels il demeuroit, ont été la consolation et l'appui de sa vieillesse; et, graces à leur's tendres soins, ses deruières émotions ont été celles de la reconnoissance et de l'amitié.

Daus les premiers mois de 1787 , ou s'aperçut que la santé de M. Ponlletier se dérangeoit. Il éprouva ce qui arrive sur-tont anx personnes foiblentent constitnées : les forces de tous les organes diminuant en mêne proportion, le dépérissenent se finit d'une manière insensible, et la nort survient sins qu'ancune affection sare ait paru la précéder. Ce fut ainsi que M. Poulletier succomba, an nois de mars de cette année. Ses médecins, qui étoient ses anis et ses confrères, reconnurent de bonne heure que les suites de sa maladie seroient funestes, et ils nee firent point pour le gnérir des efforts qui auroient été sans succès. Celse a établi pour principe que dans ces sortes de cas on doit s'abstenir des remèdes, pour ne pas les diffamer. Il seroit plus humain et plus vrai de dire qu'il faut cesser alors d'en faire usage, pour ne pas angmenter la souffrance des malheureux qui sont condamnés à ınourir.

La nonvelle de la perte de M. Poulletier a répandu la consternation dans les campagnes où il avoit des possessions. Il y aroit établi des hospices où il traitoit les T. 2. 
habitans lorsqu'ils étoient malades : les autres avoient aussi part à ses bienfaits. Tous l'aimoient et tous l'ont regretté.

M. Poulletier doit être proposé comme un modèle aux amateurs des sciences et des lettres, qu'il cultiva pour elles-mêmes. En s'associant à leurs travaux, il ne chercha point ì faire un vain bruit; il n'exigea rien, mais il obtint de nous tout ce qui pouvoit le flatter, égards, déférence, estime, amitié. Son nom sera inscrit parmi ceux des savans qui ont été les premiers et les principaux appuis de notre Société. 


\section{SCHÉELE.}

$\mathbf{L}_{\Lambda}$ vie de Mr. Schéele offrie lexemple d'un sarant aัน ณ modeste qui, dédaignant tout éclat, eut le courange de virre obscur; dont le zèle n'ent pas besoin d'ètre excité par la lonange, et qui, connu des gins de l'art, mais presque ignoré de son siecle, aroit rendu son 11011 immortel lorsqu'il n'avoit pas encore de célíbrité. Travaillant dans le silence, il ne désiroit et ne cherchoit que l'instruction. Des déconsertes inportintes l'avoient enfin tralii, ot il allnit jonir dn fruit de ses veilles lorsqu'il nous fint enlevé ponr tonjours. Le bruit de sa perte se répandit alors cu inème temps que celui de sa renomnée; on apprit à le regretter en quelque sorte avant de le connoitre, et le public ne sait pas encure combien sa personne mérita d'estime et tont ce que les sciences doivent à son inépuisable fécondité.

Charles-Guirtaume Schéele, membre de l:Académie des sciences de Stockholm (1), de la Société des naturalistes de Berlin (2), de l'Acadénie des sciences de Sardaigne (3), et associé étranger de la Société royale de médecine (4), naquit le 9 décembre ${ }_{1742}$ à Stralsund, capitale de la Pomérauie suédoise,
(1) En 1775 .
(2) En 1778 .
(3) En 1783.
(4) En 1785. 


\section{2o ELOGES HISTORIQUES.}

de Chrétien Schéele (1) et de Marguerite Éléonore Vamecross.

M. Schéele fut envoyé au collége public; mais il y prolita si peu que ses parens l'en retirèrent pour lui faire apprendre un métier. M. Bauch, apothicaire à Gothebourg (2), et qui étoit l'ancien ami de sa famille, offrit de s'en cliarger, 'et de lui apprendre la pharmacie. Le jeune Schéele avoit alors quatorze ans: son apprentissage dura six années, après lesquelles il demenra pendant deux ans encore chez M. Bauch, en qualité de garçon. De Gothebourg, il passa à Malmo, ville fortifiée de la Scanie, où il fut employé pendant cinq années dans le laboratoire de M. Keustroëm, apothicaire.

Jusqu'à cette époque on n'avoit remarqué en lui que de l'untelligence et du zèle; il avoit ln tous les livres de chimie qu'il avoit pu se procurer : le Traité de Neuman (3) avoit sur - tout fixé son attention; mais al n'avoit ténoigné ni enthousiasme, ni surprise. Calme et tranquille, il suivoit avec résiguation le mouvement de sa destinée.

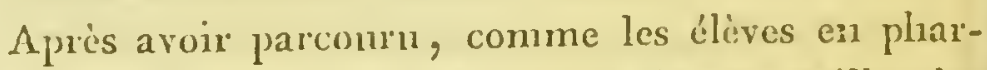
macie le font ordinairennent, les différentes villes des

(1) Son père, qui étoit marchand à Siralsund, aroit onze enfans, dont M. Sclicele: ćtoit le septicune.

(2) Ine frìre ainé de M. Schécle (Tean-Martin) avoit demenró clum ce méme apothicare, et il étoit mort pendant son apprentịss.tge.

(3) Le Conry de chimie de Neunau, ea ullemand. 
PHYSIC. ET CHIM. - SCHÉELE. 2r provinces, il résoulut d'aller à Stockholm et ensulte à Upsal.

Il arriva en ${ }_{17} 6$ gà Stockholm (1). Plusicurs membres de l'Académie des sciences de cette ville lui ouvrirent leurs bibliothèques, et l'engagèrent à faire diver'ses expérieuces dont il leur avoit communiqué le plan. Il se rendit à leurs conseits : mais le pharmacien chez lequel il demenroit fut effrayé de ses préparatifs; il craignit que les travaux de son laboratoire ue se fissent pendant ce temps avec noins d'activitó; M. Schéele le rassura par la manière dont il le servit.

Dans l'année snivante, it mit lit dernière main it une de ses plus belles productions, à son Mémnire sur le spath-fluor (3); il l'offrit à l'Académie des sciences de Stockholın (3), et il partit aussitût après pour Upsal (4).

Dans cette ville, mème amour dhu travail ct mêne goût pour la retraite; mais M. Locke, maitre en plrarmacie, chez lequel il fut reȩu comme garçon, s'aperçut bientôt de l'étendue de ses connoissances et sur-tont de la grande habileté avec laquelle il dirigenit ses essais.

(1) Il y demeura trois annèes chez MI. Scharenberg, apothicaire a l'enseigne du corbeau, place du Grand-Miarché.

(a) Ce travail fut anroncé avec éloges dans les journaux alle. mands de 1771 .

(3) Dès $177^{\circ}$, M. Retzius aroit fait la mention la plus honorable de M. Schéele dans son Mémoire sur le tartre. (Académie des scicuces de Stockluolm).

MIM. Boeck, Bergius et Schultzen avoient aussi confu la plus hante opinion des taleus de ce chimiste.

(f) En 1772 . 
La ville d'Upsal, après avoir été, par les travaux de Linné, le chef-lieu de l'enseignement pour l'histoire naturellí, étoit devenue, par ceux de Bergman, la prennière de tontes les écoles de chimie. Un entlrousiasme général dirigeoit tons les esprits vers l'étude de cette science, et il étoit impossible que M. Schéele y demeurât plus long-temps ignoré. Vons devriez vous présenter à M. Bergman, lui disoit-on sans cesse. Mais M. Schécle craignoit cette entrevue au moins antant qu'il la désiroit, et il n'osoit s'y déterminer. Il redontoit le coup d'oil d'un grand maître, qui devoit d'un seul regard, justificr ou anéantir scs espérances. C'étoit cependant ce jugement dont il aroit besoin, et qu'il étoit venu chercher à Upsal. Pendant qu'il délibère et que pour la première fois peut-être l'inquiétude de l'amour-propre lui fait éprouver quelque tourment, Bergman apprend son embarras; il court à lui : quelle surprise! Schéelc, les yeux baissés et dans la contenance d'un homme qui demanderoit une grace, lni montre, quoi? non quelques sels surajoutés à la liste de cenx que l'ou connoìt déja, mais des terres, des acides, des régules nonveaux; mais les principes d'un grand nombre d'affnités complexes, mais les élémens d'mue nouvelle théorie de l'air et dı feu; il tremble, et ne sait pas encore s'il ne s'est point égaré. Bergman, muct d'étonnement, ne comprend pas comment tant de déconvertes penvent être l'onvrage d'un jenne homme incomm. Quclle scine fut jamais plus touchinte ! Après quelques nomens de silence, Bergnuan saisit Sclicele arec transport. Ce ne sont pas des applandissenens qu'il 
PHYSIC. ET CHIM. - SCHÉELE. 23 lui donne, ce sont des respects qu'il lni rend; c'est le génie qui apprend an génie à s'estimer ce qu'il vaut, qui lui révèle le secret de sa destinée ; c'est $n$ élève obscur cun'il place an rang éclatant des grands hommes. Combien est puissante la passion de la gloire qui reçoit et donne de semblables récompenses!

Dans le nitêne temųs, l'Académie des sciences de Stockholu fut telleurent satisfaite dn ménotre que M. Schéele lni avoit adressé, quelle le nomuna son associé ordinaire (1), et cette distinction fut accordée, ce dont il n'y avoit jamais eu d'exemple, à un éléve en pharmacie!

Ces diverses circonstances étant devenues pour lui l'occasion d'nne grande perte de temps, il résolut de se retirer daus un lieu plus trancuille. On hioftrit la direction d'une pharmacie, dont le propiétaire (2) venoit de mourir ì Kocping (3), petite ville de Suède, et qui appartenoit à mue venve que l'on croyoit riche et dout on lni faisoit cspérer la main. Il partit (4); mais

(1) En $177^{5}$. Il coununuiqua cette annèc il l'Académie ses Remarques sur le sel du benjoin et sur l'acide arsenical. Mr. Bergman, président de celte compagnie en 1777 , lui obtint, à cette époque, une pension annuelle de $600 \mathrm{lir}$, destinée a payer au moins en partie les frais de ses travaux.

(2) MI. Polıl, apothicaire.

(3) Petite ville de Suède, bàtie sur le lac Malare.

(4) M. Bergman lui fit plusieurs propositions très-arantageuses pour le retenir à Upsal; le gouvernement Ini offrit la direction de diflérentes manufactures. Le roi de Prusse lui témoigna le désir de l'attacher à son académie. MI. Schéele refusa tout, pour aller à Koeping. Les magistrats de cette rille le nommèrent apothicaire 
il trouva la succession du maitre en pharmacie de Koeping dans le plus mauvais état; il n'en fut point rebuté. Nous l'avons vu grand et modeste. Il va se montrer sensible et généreux. Après plusieurs années de travail, il paya les dettes de la veuve (1): heureux, disoit-il, de pouvoir lui donner ce qu'elle-même lui avoit offert, et il l'épousa le 18 mai 1786 ! Mais le jour même de son mariage, il fut attaqué d'une fièrre aiguë dont il périt (2): condamné sans donte à ne jamais jouir du repos, ni du bonheur dont il étoit si près et qu'il méritoit si bien.

La vie des grands hommes se divise natnrellement en deux parts : l'une appartient aux besoins, aux convenances, aux distractions de la société; l'autre est celle du travail, et trop souvent c'est aux dépens de la seconde que la première s'agrandit. L'éloge de M. Schéele ne présentera point ce contraste.

Stérile en événemens, c'est en découvertes que sa carrière fut féconde. On apprend à son école ce que peut le talent sans dignilés, sans protecteur et sans appui. On l'apprend sur-tout en comparant la conute durée de sa vie avec le riche tableau de ses productions, et les obstacles qu'il surnonta avec le peu de

du bajlliage; le Collége royale de mélecine, non seulencnt lui délivra ses lettres gratis, miais encore le dispensa du serment. Ses lettres d'apothicaire sont datées de $\mathbf{1 7 7 7}$.

(1) Il fit construire une des plus belles maisons de la ville sus la place du marché, ò̀ il demeurois.

(9) Il mowrut le as mai 1786 , Agé de 4 ans. 
PHYSIC. ET CHIM. - SCHÉELE. 25 ressources qu'il ent pour obtenir d'anssi nombrenx succès.

Pour interroger la nature avec profit par la roie de l'expérience, on a besoin des lumières de l'esprit, des seconrs de la fortnne et d'un bon "mploi du temps.

M. Schréele ent sans doute plus que de l'esprit ; mais il manquna de cette premièrééducation qui on riggle la marche et qui en laâte la maturité. Ses travaux journaliers l'ayant éloigné de tont suseignement, ses pro. grès durent être difficiles, parce qu'il ne put étudier

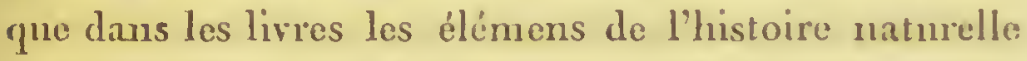
et de la physique expérinentale, si nécessaires an conplément de son instruction. M. Schéele ne reçnt des leçons de personne; il fut en quelque sorte l'éléve de sa propre pensée : forcé à tout acquérir, il dut tont à son industrie; aussi sa méthorle est-elle quelquefois cn défaut: nrais s'il paroit obscur, $11 n$ trait de hnnière dissipe aussitôt le muage dont on le croit environné. Si la chaine de son raisonnement semble se rompre, on la voit se renoner d'elle-mè̀ne ; nn instinct irrésistible le porte vers ce qui est nenf et piqunnt. Tontes les routes le conduisent à la vérité : c'est lorsqu'elle va lui échapper qu'il s'en saisit; non senlement il la tronve, muis il l'observe avec une attention profonde; et ses regards pénétrans ne laissent rien à découprir à cenx qui la verront après lui.

Quant à la fortune il en ent peu, mais assez. Un revenu très-modique lui suffit pour atteindre au faitte de la gloire: de six cents livres qu'il gagnoit chaque ammée, il en employoit cinq cents à ses recherches, et 
ce fut avec ce foible secours qu'il alluma tant de fois lc feu de ses fourneanx et qu'il opéra tanl de prodiges. Comme, à l'aide d'un grand savoir et d'un coup d'neil sûr, il ne tentoit qu'un petit nombre d'essais pour arriver à chaque résultat, il procédoit à chaque essai de la manière la plus simple, qui est presque toujours aussi la moins dispendicuse : de sorte que l'esprit d'ordre et cclui d'économic se confondoient et $n$ 'en formoient qu'un seul en lui. L'expérience qu'il préféroit pouvoit tonjours décider plusicurs questions et servir à plusieurs usages. Son travail ne fut jamais sans salaire, parce qu'il n'opéra jamais sans dessein. Il cût peutêtre moins fait avec plus de fortune, parce qu'en prodiguant les dépenses il auroit plus attendu du hasard et moins obtenu de son talent.

Pour son temps, il n'étoit point à lni : il appartenoit au maître chez lequel il demcuroit, et M. Sclicele étoit incapable de manquer à ses engagemens. Mais son génie n'étoit à personne, et son activité Je menoit à tout. A côté de l'appareil nécessaire pour l'opération pharmacentique qu'il dirigeoit, il en plaroit nn antre qu'il conduisoit en même temps et qui servoit à ses recherches. Quelquefois le même fén, dirigéavec intelligence, les animoit tous deux. D'une part, fidèle à son devoir, il exéculoit des procédés grossicrs et pour ainsi dire mécaniques; de l'autre, entrâné par son penchant, il analysoit les corps les plus réfractaires, et il s'élevoit aux plus luarles conceptious : ici, seulement imitaleur ou arlisan; là, graud obscrvateur, inventenr mence, et par-lont exact et rignurenx, il 
PHYSIC. ET CHIM. - SCHÉELE. 27 donnoit le même temps et le même soin à la potiou qu'il préparoit pour un malade et à la découverte qui devoit l'inmortaliser : mélange sublime de bonhenr et d'infortune, de grandenr et de sinplicité, de savoir et de modestie! Qui pourroit dire s'il falloit plaindre ou envier son sort?

Les leures de la nuit ćtoient les senles dont il pît disposer, et il savoit les employer utilentent. Janais cependant il ne paroissoit empressé; mais aussi janais il n'étoit oisif. Silencieux sans tristesse, et ne pouvant prendre conseil que de lui-mème, il méditoit longtemps avant que d'agir. Jannais on ne le surprit livéé daus le même temps at $u n$ grand nombre de travanx. M. Schéele, tont entier à la solution d'un probleme, ne suivoit qu'mu ordre de recherches correspondant toujours il nu certain ordre d'idées. Persome ne fit moins de cas que lui du luxe des instrumens et des machines, et ne sut mienx s'en passer : physicien vraiment habile, il s'accommodoit des moyens qui étoient à sa portée, et il ne dut qu'ii lni senl tout le succès de ses travanx.

C'est une triche pénible que de rendre compte des onvrages de ce' sarant. Épars dans les recueils de l'Académie des sciences de Stockholm, et dans les journaux allemands de M. Crell (1), ses 'différens mémoires n'out aucune liaison entre eux : il n'appartenoit qu'à l'autenr de les rassembler en un corps de ductrine; et

(1) Voyez anssi le Journal de physique, ou une partic de ces travaux a étẻ annoncée. 
cependant il a fallu me substituer un moment à lui. pour en rédiger le tableau. Une autre difficulté s'est offerte à moi dans ce travail. La chimie, telle que $M$. Schéele l'a traitée, est en quelque sorte une chimie transcendante, et j'aurois commis une grande faute si j'eusse osé la soumettre à ma seule censure, et m'en rapporter à mon senl jugement. MM. Lavoisier, Berthollet et de Fourcroy ont guidé mes pas. Qu'il me soit permis de m'appıyer de leurs conseils en m'lonorant de lenr amitié.

Lorsque j'ai essayé de diviser en plusieurs classes les nombreuses productions de M. Scliéele, j’ai vu qu'il avoit porté successivement son attention sur les acides des trois règnes, sur plısieurs régules, sur la décomposition des sels neutres, sur la préparation de certains médicamens, sur quelques procédés utiles aux arts ; et je me suis aperçı qu'il étoit possible de réduire à ces différens clief's toutes les découvertes de ce climiste.

Daus le cercle éternel de mouvement dont Becclict a tracé l'inıage, dans ce combat perpétuel des substances qui s'attirent et se repoussent, c'est à l'action réciproque des fluides et des solides que doivent être rapportés les mouvemens intestins des corps, et dans cette action les acides ont nne influence dout on ne counoît pas cucore toute l'étendue. Newton l'avoit pressenti. L'acide, a-t-il dit, est ce qui attire fortenent, et qui est fortencul altiré. Mais l'art des chimistes s'étant borné long-temps ì l'extraction des acides que fournissent le vilviol, la situe, le sel marin et quelques vígétaux, on 


\section{PHYSIC. ET CHIM. - SCHËELE.}

n'avoit point compris le sens de cette grande pensée. Le chanp des connoissances s'est enfin accru. L'on a tiré nn acide particulier de la craie, et ce nouvean fait a changé la face de la chimie. Il a déroilé les canses de l'effervescence, de la causticité, dı nuéphitisme. Il a montré les substances alkalines et calcaires en plusienrs ćtats, et nons arons appris à composer les canx nérales gazenses. En suivant la même ronte, on s'est élevé à des déconvertes inattendues, et l'on est entré pour ainsi dire dins le pays des merveilles : des molécules incoërcibles et qui échappent à l'wil ont été dégagées et analysées; on a trouvé dans l'air nu fluide plus respirable que l'air lui-n̂ĉne, et 111 antre flnide qui éteint la flimme dont le premier est l'aliment. Cos deux êtres opposés dans leurs effets, réunis dans leur composition, sont l'un, le principe des acides, l'antre, celui des alkatis. L'océan on nons sommes plongés donne et reçoit des torrens de matière élémentaire; l'ean résulte elle - mène de la combinaison de deux fluides aériformes; et les rastes bassins de la mer où se préparent la soude, l'acide muriatique, la chanx et la nagnésie; où vivent et menrent taut d'arimaux et de plantes; oì se choqnent et se brisent des flots sans nombre : ces bassins immenses ne sont remplis que de deux gaz condensés, auxquels se joignent accidentellement des substances étrangères à l'cau qui les dissout. Nous royons ce fluide décomposé dans la putréfaction dont il est l'agent, et retenu dans les corps marins dont il fait partie. Ailleurs, la base de l'acide crayeux, et le gaz inflammable : absorbés par les 
plantes, y composent le clarbon et les huiles, tandis que l'air vital est versé dans l'atmosplière: la moffette se fixe dans les animaux, et la base de l'air se combine avec les substances inflammables pour former les acides; elle produit par ses combinaisons diverses la dissolution, la calcination et la réduction des différens corps; elle masque l'éclat des régules; elle augmente le poids des chaux métalliques; elle détermine enfin, par ses affinités nombreuses, celles de toutes les substances salines dont il a fallu recomposer le tablean.

Enrichie de tant de découvertes, élevée pour ainsi dire au-dessus d'elle-même, la chimie, comme toutes les sciences très-avancées, ne peut maintenant devoir ses progrès qu'à des liommes d'un grand talent : on en jugera par les travaux de M. Schéele.

La nature du spath vitreux, de la molybdène, de la pierre pesante et de l'arsenic, n'étoit point connue: M. Schéele en a fait l'analyse, et il y a découvert un acide particulier dont personne n'aroit soupconné l'existence dans des corps aussi compacts.

C'est par l'intermède de l'acide vitriolique qu'il a dégagé l'acide dn spatlı vitreux de sa base, qui est calcaire. Ce nonvel acide, reconmu maintenant par tous les chimistes, a la propriété de dissoudre la terre siliceuse, même étant dans l'état de gaz, saus qu'alor's, ce qui est très-ćtonuant, les molécules terreuses soient visibles à l'neil. Son odeur est analogue at celle de l'acide marin: il n'agit point sur l'or, mène avec l'addition de ce demier acide; il attaque le fer avec un prompt 
dégagement de gaz inflammable, et la plupart de ses dissolutions sont gélatineuses.

L'auteur très-recommandable d'un écrit qqui a parı sons le noun de Bonlanger objecta à M. Schúele que l'acide spathique n'étoit que de l'acide marin, et M. Monnet prétendit an contraire que cet acide résultioit de lí combinaison de l'acide vitriolique devemu volatil avec le spath vitrenx lui-même. NI. Schécle répondit a l'un que ce spatly contenoil en effet un pen d'acide marin gu'il étoit possible d'en séparer entiưrement; et à l'autre, que tont l'acide vitriolique mis en usage dans ce procédé se trouroit mui à lit chinux sous la forme de sélénite, et que l'on ponvoit se passer de cet acide pour dégager l'acile spathique. C'est la senle fois peut-être que l'on se soit éleré contre les expériences de ce chimiste, qui publioit alors son prenier onvage. Sa réplique, qui parut en 1780 (1), fut si vigonrense et si convaincante qu'ou n'osa plus l'arrêter daus le areste de sa conrse (2).

Avant M. Scluéele, on ne connoissoit point lil différence de la plombagine d'avec la molybdene. En calcinant cette dernière substance, il la vit se sublimer en cristanx aiguillés et il la changea en un acide, qui, joint à l'acide inarin, précipite l'argent et le mer-

(1) Académle des sciences de Slockholm.

(a) Depuis que cet éloge a été lu, uu auteur célèbre a publié une réponse très-ingénieuse; mais les chimistes que j'ai consultís pensent que la doctrine de MI. Sclieje n'en jouit pas moins de toute
sa force. 


\section{2}

\section{ÉLOGES HISTORIQUES.}

cure de leur dissolution dans l'acide nitreux; qui, sons forme concrète, se dissout abondamment dans l'acide vitriolique, s'épaissit en se refroidissant, et prend une couleur bleue.

Les naturalistes regardoient la pierre pesante comme une chaux d'étain. M. Schéele a prouvé qu'elle étoit: composée de terre calcaire et d'un acide particulier, qu'il a dégagé par l'action successive des alkalis et de: l'acide nitreux, et il a régénéré la pierre pesante en combinant cet acide avec la chanx.

En écrivant les éloges de MM. Macquer et Bergman, j'ai parlé de l'arsenic et de son acide; mais rien ne peut me dispenser de rappeler ici que la découverte de cet acide appartient ì M. Schéele : fécond en moyens et en ressonrces, presque toujours il indique phnsienrs procédés pour obtenir le même résultat; ici l'acide: nitreux, et l'acide marin déphlogistiqué, lui servent: également pour la préparation de l'acide arsenical qui forme des sels insolubles avec la plupart des substances terreuses et calcaires. Une circonstance remarquable, et qui n'a point échappé à M. Schéele, c'est qu'en sublimant le sel ammoniacal d'arsenic, nne partie de celte combinaison reparoìl sons l'aspect d'arsenic blanc; tandis qu'il se déreloppe 111 ga\% qui n’'est point de l'acide crayeux, comme on l'avoit dit, mais de la inoffette, due it la décomposition de l'alkali volatil, ainsi que M. Berthollet l'a prouvé.

La manganese est nue substance minérale très-composéc. M. Schéele y a découvert de la chaux de fer, de la terre silicense insoluble, de la terre calcaire, et 
PHYSIC. ET CHIM. - SCHÉELE. 33 une petite quantité d'une terre alors inconmuc, que M. Bergman a nomméc terre pesante, ct dont M. Schécle a déterminé les principales propriétés. On obtient la minnganèse pure en la dissolvant dans l'acide vitriolique, et en lil précipitant par l'alkali fixe. La phupart des acides l'attaquent, sur-tont lorsqu'elle n'est qu'ì demicalcinćc; mais les phénomènes qu'elle présente avec l'acide marin sont tout-à-fait extraordinaires, et M. Schéele ent besoin de répéter plusienrs fois celte partie de ses recherches pour accorder sa confiance ì ses propres essais. La manganése distilléc arec l'acide marin le rend propre at dissondre tons les métanx, l'or lui-mime, saus effervescence; il clanger les conlenrs des vígétanx, en les jannissant; ì blanchir lo papier blen du tournesol, et à épaissir les luniles et les graisses.

En offrant cette esçnisse des mémoircs oì MI. Schécle a traité les questions les plus abstraites et les plus difficiles de la minéralogie, je dois avertir que je n'ai pu faire mention que d'mue partie des déconvertes quils conticnnent. La climie tont entière y est appliquée à chaque sujet; chaque sujet y cst appliqué réciproqucment it toute la climie, et les faits $y$ sont réunis en si grand nombre, que l'œil ne sait où sarrèter.

A quoi tient donc cette fécondité d'esprit? Y a-t-il un petit nombre d'hommes auxquels appartienne l'art de surprendre les secrets de la nature? Est-ce à leur pénétration ou à leur destinée qu'est reserré cet inestimable avantage? Je réponds que c'est sur-tout à l'opiniâtreté dans lo travail, sans laquelle il n'y a point T. 2 . 
de durée dans le succès; je réponds qu'il en est des richesses de l'expérience et de la pensée, comme de celles que la terre cache en son sein; que les unes et les autres ne se trouvent qu'à de grandes profondeurs; qu'il faut creuser long-temps avant d'arriver à ces veines heureuses qui sont le salaire de la peine et de l'industrie; qu'à la surface sont semés avec profusion ces faux-brillans dont la paresse se contente et dont se pare le mauvais gout : je réponds qu'il ne suffit pas d'avoir découvert à grands frais des matériaux précicux; qu'il faut encore les préparer, les mettro en œuvre à l'aide de la méditation et du temps. Voilà ce que fit M. Schéele, et ce que ne pentvent se dispenser de faire tous ceux qui voudront s'immortaliser après lui.

Entre les résultats des recherches de ce chimiste et sa théorie, on remarque quelquefois une incohércuce qui doit être regardée comme le garant de ses assertions. Elle prouve qu'il n'a pris aucune peine pour tourmenter les faits et pour les nettre d'accord entre eux. C'est ainsi qu'en réduisant tout aux affinités du plilogistique, il a consigné dans ses écrits des détails d'où naissent les argumens les plus forts contre ce systène. La plupart de ses nombrenses expériences sur les spaths, sur les bases des métanx et sur la plombagine, sont inexplicables dins toute autre théorie que dans celle des gaz, qu'elles confirment en s'y rapportant; et M. Schicele est peut-être cchir de tous les chimistes qui, sans le saroir, a fonmi le plus de faits it l'appui de cette doctrime.

On croirvit, an premice coup d'ecil, que les acides 
PHYSIC. ET CHIM. - SCHÉELE. 35 végétaux (1) seroient plus faciles à dégager que ceux dı règne ininéral, puisqu'ils appartiennent à des matières moins compactes; mais ils sont nuĉlés arec tant d'antres substances, qu'il est difficile de les obtenir dans un état de pureté; opération sans laquelle on ne pent cependant parvenir à les connoître. M. Schéele imagina d'ajouter de lin chanx on de la craie an fluide (2) qui les tenoit en dissolntion; il les sépará de ces bases par. Yinternéde d'un autre acide, et il les fit cristalliser : c'est ainsi qu'il a obtenu les acides du benjoin, du citron (i) et des pommes. Il a découvert que certains sucs végétanx contenoient denx espèces d'acides; dans le suc de groseille, par exemple, sont réunis l'acide des pommes et celni du citron. Un procédé très-ingénienx y a condnit M. Schéele. De l'esprit de viu versé sur le suc, réduit à consistance d'extrait, en a coagulé le mucilage et la gonme; après l'évaporation de l'esprit de vin, le. résidn, délayé darss l'ean, a été saturé avec de la craie: d'oǹ il est résulté que l'acide du citron, formiunt avec cette base un sel presque insolnble, s'est précipité, tandis que l'autre sel est resté suspendu dans la liqueur.

Après avoir reconun plusieurs acides dans le mème fruit, M. Schéele a rédnit à une seule espéce les acidés de plusieurs régétaux. Il a fait roir que celui dı sucre étoit le même que celui de l'oseille. Il a recomposé ce dernier en versant pen à peu une liqueur

(1) Sur l'acide des fruits: Acarlémie de Stockbolm, 1785.

(2) Journal de Chimie, par irI. Crell.

(3) Acadëmie de Stockholın, 1783. 
alkaline sur me dissolntion d'acide saccharin : de sorte que celui-ci, que l'on croyoit n'être que le produit de l'art, se trouve abondainment dans la nature.

A peu près dans le même temps, MIM. de Lassone père, et Cornette, ont fait sur les acides végétaux un travail qu'ils ont communiqué à l'Académie des sciences, et dans lequel ils annoncent que toutes ces combinaisons salines sont analognes à la crême de 1artre, et M. Crell a cliangé la plinpart de ces acides et l'esprit de vin lui-même en vinaigre; découvertes qui conduiront sans doute à fäire quelques cliangegemens dans la nomenclature de ces substances: car, si les mots y étoient plus nombreux que les idées, il fandroit bien les rédnire ì leur juste valeur pour éviter l'inconvénient de parler sans rien dire, ou de dire le contraire de ce qu'on derroit exprimer.

La chimie moderne a démontré dans le règne animal l'existence de plusienrs acides qui lui sont propres. La mature de cenx du petit-lait et du sucre de lait a été détermincée par M. Schéele.

La découverte d'un acide daus la pierre de la ressie est eucore le fruit de ses travanx. On a cru long-temps et la plupart croient encore que le calcul est de nature calcaire. M. Sclréclea pronvé qu'il cstan contraire formé d'mu acide particnlier, concret, et d'nue petitr quantité desnbstance gélatinense. Le sédinent briqueté des pierrenx est le nême acide sous nue antre apparence. Tontes les pierres de la vessie, quelles que soient: leur consistance et lenr forme extéricure, se réduiscut anx mentues principos. Non seulenenob l'ean do chanx et les alkalis 
PHYSIC. ET CHIN. - SCHEELE. 37

ranstiques les attaquent; mais l'ean elle-mène en grande masse ct avec le secours de la chrileur les dissont entierenent.

Ces décourertes ne sont pas les senles que lon doire à M. Schéele sur celte partic dh rígne animal. Il a tronvé le sel phosphoriąne calcaire et l'acide phosphorique à nu di me l'urine: il a observé que ce fluide contenoit moins d'acide dans l'état de sarnté que dins celui de maladie; et M. Biertholet, yui a resndu ces expéricnces plus completes, en at fint l'application it la connoissince du rorps lumain.

Arrêtons-nons un monent ici, at demandons ce qu'il fantroit penser d'un mélecin qui, n'ityant ancune notion sur l'analyse de l'uriue, prendroit ponr du lait des substances silines blanchatres qui se dissolvent in l'aile de la chaleur et se précipitent par le froid; qui traitant souvent des pleurésies dues à la suppression de la suenr, ne vonkloit point saroir que l'acide phosphoriqune de ce fluide, répercuté, produit la plupart des accidcus fìcheux dont on se plaint alors; qui conseilleroit ì ses malades des antilaitenx pour combattre nu vice imaginaire, on qui emploieroit des compositions propres a fondre la pierre qu'il croiroit calcaire, tandis qu'elle seroit éminemment acide? Ces méprises et tant d'autres que je pourrois accumuler ici sont celles de médecins qui, calomniant les scicnces exactes, refusent leur attention à ce qu'il est de leur devoir et unĉme de leur intérêt d'apprendre. Elles exciteroient le rire, si clles n'aroient aucune suite fàcheuse pour I'humanité. 
C'est ici le lien de le dirc, notre science se compose de toutes les autres sciences, qui l'éclairent ct qu'elle éclairc à son tour; et celui-là seul est digne de la confiance publique qui recueille tout ce qu'il peut trouver d'instruction et de lumières pour rendre moins difficile et moins obscure la route par laquelle il marche vers la vérité.

Aux mémoires que M. Schécle a publiés sur les acides des trois règnes, succedent des travaux noll moins étendus sur la décomposition du vitriol de soude, et sur celle des sels neutres par la chaux vive et par le fer, sur le quartz et sur l'argile, dans laquelle il n'a point trouvé d'acide vitriolique; sur la composition du gaz méphitique, et sur le bleu de Prusse.

Les recherches de M. Schéele sur cette dernière substance auroient suffi pour lui mériter la réputation la plus distinguéc.

Après s'êtrc assuré que le principe colorant du bleu de Prusse, lorsqu'il étoit combiné avec un alkali sans l'intermède du fer, s'échappoit sous la forme de gaz; que c'étoit l'air fixe de l'atmosplière qui le dégageoit ainsi, et que tous les acides jouissoient de celte propriété: il chercha un moyen de séparer ce principe du blen de Prusse et de l'obtenir sans aucurı ruélange, et il y parvint par un procédé des plus couplipués, qu'il a exposć avec une grande précision, et dout l'expérience a démontré l'exactilude. Ici, des réactions mombreuses, des affinités successives sont nuises en jen: M. Sclićele nous dévoile tout-à-coup une des plus belles opérations de la chinie noderne, sans dire 


\section{PHYSIC. ET CHIM. - SCHÉELE. 39}

quel fil l'a dirigé, quelle théorie l'a couduit, et il nous laisse dans l'étommennent, nou de ce qu'il s'est éleré à une telle hantenr, mais de ce qu'en franchissant 111 anssi grand espace on ne voit aucune trace de ses efforts, ancun vestige de son passage : c'est le génie de l'invention qui se jone des obstacles, et qui ne daigne pas neême se souvenir des difficultés qu'il a vaincues.

La chinuic des arts doit à M. Schéele la décourerte d'une nouvelle couleur verte qui peut être enployée à l'eau et à l'luile, et qui n'avoit pas éprouvé le plus léger changenent aprís nu intervalle de trois amuées.

Parui les nombreux services que M. Schécle a reudus à la pluamacie, je citerai les suivans. Il a indiqué nu moyen facile ponr conserver loug-temps le vinaigre sans qu'il se corrompe. Il a séparté des fumles exprimées et des graisses (1) un principe doux et sucré (2). Il a retivé de la racine de rhubarbe (3), de plusieurs autres racines officinales et de quelyues écorces nu sel insoluble, formé de l'acile oxalique et de la claaux. Il a fait voir que la conleur noire de la pierre infernale étoit due an cuive, dont l'argent fin u'est pas tout-il-fait dépourvin. Il a rendu plus simple et moins dispendieuse

(1) Acadénie de Stockholm, 1783.

(2) Pour l'obtenir, il faut dissoudre une partie de litharge pulvérisée dans deux parties d'huile ou de graisse, en y ajoutant un peu d'eau, et en tenant ce mélange en èbullition jusqu'à ce qu'il ait pris la consistance d'onguent. L'eau que l'on sépare en décantant contient ce principe.

(3) Académie de Stockholın, 178$\}$ et 1785. 
la préparation de la poudre d'algaroth, dont M. de Lassone s'est servi avec succès dans la composition du tartre stibié. Le procédé que M. Schéele a conseillé pour obtenir le mercure doux étoit connu depuis longtemps en France, comme M. de Fourcroy l'a reinarqué; mais son mémoire sur l'éther contient un grand nombre d'observations nouvelles. Jamais l'action des acides et des sels métalliques sur les liqueurs spiritueuses I'avoit été soumise à tant d'épreuves. Il nous suffira d'ajouter', comme un résultat général de ces belles expérieuces, qu'une condition nécessaire pour que les acides changent l'esprit de vin en étlıer, est qu'ils puissent agir sur ce fluide en se dépouillant d'une partie de l'air vital qu'ils coutiennent: ce qui explique pourquoi tons les acides végétaux n'ont pas cette propriété.

Jusçu'ici M. Schéele s'est montré, par le nombre et l'originalité de ses découvertes, le rival de Beccher et de Stahl. Nous allons le voir se placer à côté de Boërrhaave, daus son Trailé de l'air el du fén, celle de toules ses produclions qui a donné la plus grande idée de son talent. En Suède, Bergman y ajonta une savante préface, et voulut en être l'éditcur. En France, M. le baron de Dietrick le traduisit à la sollicitation de feu M. Turgot, et tous les physiciens le lurent avec avidité. En Angleterre, M. Kirwan se chargea de le publier; il y joignit des notes très- ćtundues, ct par-Lont MM. Bergman, Priestley, Crawford ct Kirwan, en parlant de M. Scliéele, lni prodignent Jes nons de chiniste du prenier ordre, de girand maitre, de génic sublime : heurcux, lorsque daus ce concert 
PHYSIC. ET CHIM. - SCHEELE. 41 de louanges je dois nèler ma voix à la lenr, d'avour de pareils garans de mon adniration et de la manière dont je l'ai exprimée dans cet éloge!

Le feu est pour les chinistes un instrument de tous les instans. M. Schéele, qui aroit le phiss grand intérèt à le connoitre, s'aperçnt bientût quue l'air, s'il n'entroit pas dans sa composition, servoit an nnoins à l'entretenir, et qu'il falloit s'occuper en mène temps do l'eximen de ces denx flnides.

Anx yeux de Bö̈rrhaave, l'air proprement dit et la matière de la chalenr avoient toujonrs été des ètres simples. M. Schérle alla plus loin; il comnut quelques-mus de lenrs élemens. Ayant observé que l'air atmosphérique, mis en contact arec un mélangé do sonfre et de limaille de fer diminnoit constamment de volnue par l'absorption d'mue partic de sia masse, il déconvrit dans l'atmosphière nu fluide particnlier dont il détermina la natnre, et qüil appela air dn feu, parce qu'il sert en effet ì l'alinuenter (1). P'resque daus le mème temps M. Priestley finisoit it Londres la déconverte dn nène gaz, sons le nom d'air déphlogistiqué. MI. Schécle mit le complément à ses recherches, en prourant qun'il entroit ì pen près neuf trente-troisièmes de ce fluide dans l'air atmosplı́rique.

Cette déconverte de deux grands hommes répandue dans le monde littéraire y trouva beauconp de détracteurs. On s'étomna qu'il y eût unı mortel assez témé-

(1) Il a donné le nom d'air vicié à l'autre partie constituante de l'atmosphère. 
raire pour oser dire qu'il avoit décomposé des élémens qu'Aristote avoil déclarés inaltérables : on nia, puis on douta, puis il fallut croire; marche contraire a celle que l'on tient pour le prestige et pour l'erreur. On commence alors par croire, puis on doute, et enfin la raison nie ce que l'enthousiasme avoit admis avec transport.

Que le principe du fen se dégage de l'air qui lui doit son ressort, c'est ce dont il 11'est pas maintenant permis de donter; mais la chalcur elle-mêne s'est offerte à M. Schéele (1) sous divers aspects. Tantôt ardente et sombre, elle tend à s'élever daus l'atmosphère, où clle produit des mouremens vacillatoires autour $\mathrm{d} u$ corps qu'elle a pénétré; elle se combiue avec l'air qui Ia touche; tlle se transmet facilement d'un corps dans un autre, et elle ne se réfléchit point par les miroirs. Tantôt active et rayonnante, elle se répand à de grandes distances, en suivant des lignes droites: dans cet état elle ne se combine point avec l'air; les miroirs inétalliques la réfléchissent avec chalenr dans le foyer, et sans s'échauffer enx-ınêmes; les niroirs de verre la réfléchissent, mais leur foyer n’est pas brîlant. Placé entre la flamme et le miroir de métal, le verre plan le plus mince ôte à son foyer la propriété de communiquer la chaleur, et tous ces effets sont bean-

(1) Suivant ce climiste, l'air vital est un des demers du feu. Cette proposition n'est pas exacte. Il ue faut pas dire que ce fluide entre lui-mene dans la composition du feu, unais seulenent que le principe du feu se dégage de l'air lorsque colui-ci est fixé par quelque substance qui a plus d'atfinité nrec lui qu'il n'en a arec le feu. 
PHYSIC. ET CHIH. - SCHÉELE. 43 coup plus marqués lorsque le charhou est ardentclair, qu'au moment où la flanme brille de tout son éclat. Ce n'est done pas à la lumière proprement dite qüll faut attribner ces pluénomènes, mais ì la matière de la clialenr, prete it se changer en lumière, comme il a vu celle-ci se convertir en chaleur rayomnante, que par d'antres modifications il savoit rendre ardente ou sombre. Quel honme que celui près duquel l'air, la chaleur, lis flanme, l'étincelle et la linnière n'out pu se soustraire à l'analyse! Qui pourroit lui disputer ce bean nom de plitlosophe dn feu, créé pour quelques chimistes et que nunl ne mérita comme lui.

A côté de ces belles déconvertes sur le fent, se trouve, osons le dire, une théorie sans fondement et sans appui. Suivaut M. Schéele, l'air se combinoit pendant la combustion avec le plulogistique, et il passoit sons formo de clalenr an travers des vaisseanx. M. de Lavoisier a détruit celte explication adoptée par Bergunan, en prouvant que le poids des vaisseaux fermés, dans lesquels on fait des combustions étoit le mème arant et après cette expérience, et que celni dn corps brùlé angmentoit toujours en proportion de ce que l'air des vaisseaux avoit perdu.

C'est un spectacle bien digne de l'attention des philosophes, que de voir deux homınes de l'ordre de MM. Bergman et Schéele, partant ici d'un faux principe, employer tontes les ressonrces de la physique et de la chimie, suirre nn long enchânement de conséquences bien dédnites et de faits presque tous nouveaux pour arriver à l'crreur. 
Cette association intime de MM. Bergman et Schéele qui s'est éteudue jusqu'aux fautes qu'ils ont commises, cette nuion de pensées et de travaux ne les ont pas mis à couvert des traits de l'envie: on a reprochée ì l'un de s'être emparé des découvertes de l'autre. Quela calommie écoute, si cependant elle sait écouter, M. Schéele luimême amonçant dans le journal allemand de M. Crell la mort de son illustre compatriote. " La chimie, ditil (1), a perdu tout ce qu'elle peut perdre dans un seul homme. Il n'est plus ce professeur, le premier de tous ceux que l'on a connus jusqu'à ce jour, et dont la bonté faisoit disparoître entre nous tout intervalle de connoissances et d'âge. Que ne puis-je lui élever un monument durable! Son souvenir au moins me sera tonjours présent, et j'écrirai l'histoire de sa vie, car je veux que l'on sache qu'il fut mon ani ». Il ne l'a point écrite cette histoire; c'est moi qui l'ai tracée, et luimême il n'est plus. Leurs uonıs, réunis à jamais, recevront les mềnes lonmages; et s'ils ont mérité quelques reproches, ils les partageront encore : c'est le triomple de l'annitié.

Nos regrets s'accroitront si nous comparons leurs diverses qualités entre elles. L'un, formé par l'étude des sciences exactes, ct sévère dans le choix des preures, appliqua le calcul aux détails et traita les grands sujets avec antant de méthode que d'élération; l'antre, abandouné anx seules impulsions de la nature, cutraîna par la conviction des faits qu'il accumula sans désordre,

(3) Annales chimiques de M. Crell. 
PHYSIC. ET CHIM. - SCHËELE. 45 et qu'il rapprocha sans les enchaîner. Le premier vous condunt à la vérité par la voic de la démonstration, et vous la déconvrez arec lui; arec le second, c'est ello qui se montre ì vous et qui semble rous chercher. MI. Bergman, vivant an sein d’nne acadénie célébre, entouré de disciples et tonjours en coumerce arec les savans, avoit accquis cette étendne de connoissances et celte sûreté de goùt que donnent nue société choisie et des relations nombrenses; MI. Schéele travaillant seul, donumé par la vigneur, j'ai prescue dit par la rudesse de son talent, n'aroit point appris à se défier de ses propres forces, quil le portèrent sourent an-delà du but: M. Bergnanétoit pent-ètre plus loin de l'errenr, et $M$. Schéele plus près des vérités nonvelles. 1)ivisés, ils anroient en chacm quelque sonlait à former; rénnis, ils possédoient tont : génice, sitroir, néthode, élígance et clarté. Que n’en ont-ils joui phus long-temps!

MM. Bergman et Schécle, car nous ne pourons plus les séparer; étoient devenus nu objet de curiosité ponr les étrangers. M. le président de Virly, amaten éclairés des sciences et desarts, fit $\operatorname{cn}_{1} 782$, avee NI. Elhyyart (1), Espagnol, le royage de Suède, dans le dessein de les voir et de les entendre. La manière dont M. Schéc le les reçut achevera de faire connoître son caractère. Arrivés à Koeping, ils se présentent clez ce sarant arec une lettre

(1) Frìre de celui que le goureruement d'Espagne a envoré eu Hongrie pour approndre la mithode de traiter les nines dor, déconverle par M. Born. Il est actucllement directeur des mine d'Espague dans l'Amcixique méridionale. 
de M. Bergman, la meilleure recommandation qu'il fût possible d'avoir auprès de lui. Ils trouvent un jeune homme en tablier, auquel ils le demandent. Ce jeune homme est M. Schéele lui-même. Il ouvre la lettre de son ami, la lit, et les accueille avec joie; il les fait asseoir, il converse avec eux, et il continue son travail sans leur demander excuse pour une chose qui n'en a pas besoin. Il leur parle indifféremment des déconvertes des autres et des siennes propres, sans montrer ni vanité ni modestie; il leur expose sans réserve tontes les expériences dont il s'occupe; sonvent il s'interrompt ponr les entretenir de M. Bergman. “C'est l'honneur de la Suède », leur dit-il, sans avoir l'air de soupçonner que l'on puisse en dire autant de lui. Chaque jour les voyagenrs l'invitent à dîner avec eux, et chaque jonr il accepte sans remercier et sans permettre qu'on le remercie; mais le repas fini, il se hâte de retourner à sa nıaison, oì ils le suivent. Son temps étoit ce qu'il ne cédoit à personne. Ils le quittent enfin avec regret, et bien convaincus que tons ceux qui aiment vraiment l'étnde donbleroient lenr existence, si, comme M. Schéele, ils osoient secouer le joug du cérénuoiial et de l'importunité.

Une antre singnlarité dans l'histoire eles travanx de M. Schéele est, que nons devons di une femme la connoissance de ses nombrenx ménoires. Enconragée par M. de Morvean, l'mn des savans les phus distingnés de ce siecle, madame Jicardet, éponse d'mn magistrat de Dijon, résolut d'apprendre les langnes alleniande et suédoise minquenonest ponr transmettre dans la nôtre 


\section{PHYSIC. ET CIIM. - SCHÉELE. 47}

Ies découvertes du chimiste de Koeping; et son culreprise ent le plus grand succès. Cet acte de dévonement et de conrage suppose dans le traducteur de M. Schéele, son le bel espril qu'on lone trop, mais le bon esprit qu'on ne lone poiut assez, et qui se inoutreroit saus donte plus souvent s'il étoit apprécié ce qu'il vant.

Si quelqu'un demande encore à fuoi servent les éloges: ils scrvent, dirons-nous, ’े faire connoître de grands noms qui seroient denenrés dans l'oubli, it désigner les véritables sources de liustruction et du saroir. Peut-être aussi que le spectacle diune assenublée noumbreuse attentive ì la lecture d'un éloge a quelque chose de consolant pour l'humanité. Ces lectures sont, dit-on, vouces at lindulgence. Tonucquoi ne laisseroit-0n pas entrevoir anx hommes qu'il suffit d'aroir rendu des services réels anx sciences, aux lettres, à la patrie, ponr oblcuir, s'ils en ont besoin 111 jour, quelques grices deraut clles? Vit-on jaınais la satire, lil critique même se renfermer daus de justes bornes? De quel droit condanneroit-on la lonange seule it n'en point sortir? Les parégyristes au reste ne seroient jannais exposés à de tels reproclies s'ils aroient toujours à lower des hommes comme MI. Schéele, dont la vic frugale et pure fut cousacrée tout entic̀re à la recherche de la vérité el à la pratique de la rertı. 


\section{SPIELMANN.}

Jaceues Remmolo Stimiarann, docteur en médecine et professeur de chimie dans l'Université de Strasbourg, correspondant de l'Académie royale des sciences, niembre de celles de Nancy, de Berlin, de Pétersbourg, de Stockholm, de Turin, de Hall, de Hesse-Hambourg, associé régnicole de la Sociéíé royale de médecine, naquit à Strasbourg en avril 1722 , de Jean-Jacques Spielnuanu, maître en pharmacie, et de MarieElisabeth Frédéric.

Après avoir fait ses études, il clooisit la professiou dans laquelle ses parens avoient acquis de la considération et de la fortune. Dès le quatorzième siècle, la famille des Spielınaun éloit comptée parmi les patriciennes; mais elle n'a jamais fait d'efforts pour sortir de la classe de la bourgeoisie, et la maison que NT. Spielmann le père occupoit, et oì il désiroit de voir son fils établi, hii avoit été transunise par ses ancètres. Daus les villes où le luxe est peru répandu, on tronve encore nu pelit nombre de ces familles qui ne cherchant point it s'élever au-dessus de leur état, bornent leur aubition à voir lent probité passer en lićritage à leurs cufaus. Le toit qu'ils tienuent de lenrs pères et oì sont dressés leurs atcliers est simple conme 
PHYSIC. ET CHIM. - SPIEIMANX. 49 enx, et ancien comme leur race; et leur généalogic, saus taclie comme saus illustration, est écrite dans le souvenir d'mu peuple nombreux qui les honore.

Ce spectacle, maintenant très-rare dans nos grandes villes, est encore assez commun dans quelques-nues de celles de la Suisse et de l'Allemagne. M. Spielmann se sommit avec empressement à ur usage reçu dans sa fimille. Il étudia en plarmacic, d'aloord il Strasbourg, ensuite à Nurenberg, oi cet art s'exerce arec une grande cellébrité.

La pharmacie n'occupoit point tous lés momens de: M. Spichnan; il cultiroit en mène trulps et aree: wne grande ardene tous les genres de litterature; et déja la médecine finsoit partue de ses tratranx. ije Nuremberg il passa à Leipsick, oì TValtlier, Hebenstreit, Ludwig et Craner enscignoient les diverses parties de laut de gnérir. WVolte Hofluan le retinent quelque temps it Hall; mais cétoit ì Berlin qu'il deroit finire le plus long séjonr. Cette capitale, qui rénuit depuis si loug-temps des héros et des sarans, ou tous les genres de gloire sont rassẹnblés, oì le bruit des armes prises tant de fois ne troubla jannis la paix des arts, si sonvent recréés par la présence de la victoire; cette ville étoit alors, comme anjourd 'lui, célebre par les grands maitres qui composoient son Académie. Sprocgel y professoit la médecine; Pott et Margraf, la climie; Ludolf, la botanique; Budreus, Cassebolun et Lisberhumk, l'anatonie; Fritsch, l'histoire naturelle des animanx; ct parmi ces grands noms, ccux de Frédéric T. 2. 
et de Henri, plus grands encore, fixoient déja les regards étonnés des voyageurs, comme ils arrêteront ceux de la postérité.

M. Spielmarm ne quitta qu'à regret me école où il avoit trouvé tant de lunières. Le fanneux Henkel lui permit l'entrée de son laboratoire à Freiberg; il suivit à Paris les leçons des Jussieu; Reaumur et Geoffroy l'admirent dans leır intimité; et il revint. is Strasbourg, riche des connoissances des peuples les plus éclairés de l'Europe, et excité par cette énulation qui devoit illustrer sa carrière.

Peu de temps après son retour il fut reçu maître en pharmacie, et successivement docteur et professenr surnumćraire en médecinc. Sept années s'ćcoulèrent avant qu'il y eût me chaire vacante dont il pût être titulaire, et pendant cet intervalle il se livra tont entier à l'étude de la climie, de la matic̀re médicale et de l'histoire naturelle, qu'il démontroit aux élèves. Ces leçons particulières acquirent nue grande célébrité : les jemnes médecins venoient de tontes les parties de l'Allenagne pour les entendre, et l'Université de Strasbourg en receroit nn nonvel éclat. Empressée de lui en ténoigner sa reconnoissance, elle ne craignit point de s'exposer an reproche d'avoir fait un clioix bizarre en le nommant en 1756 à la place de professenr de poésie, qui vaqua cette amnće. On ne pent, saus être surpris, roir mu chiniste cliargé d'un département anssi différeut du sien; nitis on sera peut-ĉtre plus surpris encore cu apprenant quili il 
PHYSIC. ET CHIM. - SPIELMANN. 51 rempli les fonctions de cette chaire pendiunt trois anmées, ì la grande satisfaction de ses auditeurs. Il avoit recucilli les plus be:ux passages des poëtes grecs et latins, dont la lecture lui ćtoit fannilière, et il y puisoit les règles du gont; il se plaisoit ì nuontrer combien Homere et Virgile étoient versés dans la comnoissance de la nature, dont l'étnde est pent-ètre nn pen trop négligée par les littrirateurs modernes; et il ue cessoit d'inviter ceux qu'un attrait irrésistible entraìnoit vers ce genre de tatent, ì n’écrire quaprès avoir bien observé l'homme et ses rapports, et avoir épronvé cn enx-mêmes cette explosion d'une ane active, sans laquelle le discours est tonjours incapable l'attacher et d'émonvoir.

Les six lives de Lncrèce sur la rature des clioses étoient cenx qu'il expliquoit et qu'il commentoit de préférence. Ce poëme, qui peint ètre consideré comme un traité de physique, oì l'anteur expose et discute dans de beanx vers les opinions des philosophes sur les élemens des corps, sur la lumière, sur les sens et mème sur les malitlies, fonrnissoit à M. Spielmann l'occasion de tracer la marche et les progrès des sciences. On apprenoit pent-ètre dans ses leçons moins de poésie que d'histoire matnrelle; mais il avoit trouré le moyen d'intéresser le public et de plaire en instruisant; ce qui doit être le but de tous ceux qui ont ì parler anx hommes.

En ${ }_{1759}$, M. Spielnamn abandonna nne carrière yui lui étoit étrangère. Nommé professeur ordiaaire 
de chimie, it rentra avec joie dans son laboratoire pour n'en plus sortir; car s'il est vrai que chaque: chose ait besoin d'être à sa place, c'est à l'homme sur-tout qu'il est le moins permis de s'en écarter. M. Spielmann a exercé pendant vingt-quatre ans avec la plus grande distinction les fonctions de cette dernière chaire.

Il n'est point étonnant que la chimie ait excité dis sou origine un enthousiasme universel. Ses recherches sont peut-être les plus piquantes de toutes celles qui s'offrent à la curiosité. La pliysique expérimentale présente un appareil imposant; ses machines tracent les lois du mouvement et dévoilent le mécanisme des cieux; mais toutes ses opérations se passent à l'extérieur des corps : elle ne sait que les diviser; elle no les décompose point. L'histoire naturelle embrassęles trois règnes : lrabile à comparer et ì décrire, il n'est rien qu'elle n'observe, qu'elle ne classe: mais elle ne porte point son examen jusqu'à la structure intime do ces substances. Le climiste, plus difficile à satisfaire, pénètre leur tissu. La dureté, la transparence, la mobilité, ne résistent point à ses moyens. Des fluides légers, incoërcibles, sont dégagés, analysés et cliangés en des masses pesantes; il sćpare ct rémil i son gréles élcmens; il semble créer de nouveaux êtres. Tant de cliangemens inattendus, tant de formes données à la matière, des essais d'oir maissent des espérances si vastes et des chimeres si sédnisantes, peuvont-ils ne pas enflammer l'imagination de cenx entro les mains dosquels 
PHYSIC. ET CHIM. - SPIELMANI. 53 s'opèrent ces sortes de prodiges? M. Spiehmann étoit vraiment digne de cultiver cette science. Quoique d'us caractère froid et tranquille il s'aninnoit dans son laboratoire; il étoit sonvent assez henrenx ponr y ressentir quelques-nxies de ces inspirations qui donnent des vues nonvelles et présagent des succès. Il se renfermoit alors, et ne songeoit aux besoins de la vie qu'après aroir satisfait à cenx que l'auour du travail rendoit les plus pressans.

Les recueils des thìses soutenues dans les nuiversités sont les dépùts oì la plupart des savans étrangers consignent leurs recherches. Celles de M. Spielinann se tronvent parmi les Dissertations médicales de Stratsbourg, publices à Nurmberg eu quatre volumes, dont elles forment la plus grande partic. Ces mémoires, qui sont très-numbrenx, peurent ètre divisés cn quatre ordres; plusienrs sont relatifs ì la chinie et forment la première classe. L’analyse et les propriétés des eaux minérales de Niederbrun et de quelques antres sonrces sont exposées dans deux dissertations qui composent le second ordre; daus le troisiène on pent rauger ses recherches sur l'acacia des bontiques et sur les différentes espéces de cardamome, plante cultivée par les anciens, et si mal décrite dans leurs ouvrages, qu'il. est difficile d'en déterminer le genre par ce qu'ils en ont dit. Eufun deux mémoires sur des sujets relatifs à l'hygiène penrent être rapportés ì la quatrième classe. Dans l'un, il a f'ait connoître à ses concitoyens tous. les végétanx malfaisans ou vénéneux de l'Alsace; l'autre 
contient l'aralyse la plns exacte peut-être qui ait été faite des différentes espèces de lait considérées sous tons leurs rapports, dans des tables très-détaillées. Le but de cet onvrage est de prouver que le lait maternel est le senl aliment que l'on doive offrir anx nouveaunés; précepte que la nature a entouré de jonissances, et dont il est honteux qu'il faille rappeler le souvenir aux liommes.

Au mérite des expériences faites arec ordre ct exposées arec clarté, les dissertations de M. Spiclmann joignent celni de l'exactitude et de l'étendue des recherches historiques. On voit en les lisant qu'il les a rédigées avec tont le soin dont il étoit capable; aussi n'a-t-il point épronvé le sort des écrivains qui, traitant légèrement le public, ne doivent pas être surpris d'en être traités de même.

Les chimistes font le plus grand cas de son Mémoire sur la nature du principe salin; grande et belle question, parce yn'clle ne tient pas à un ordre de faits isolés, mais à tous les êtres en génćral. Les acides des trois régnes y sont exaninés successivement. Après avoir indiqué les quantités respectives de terre et d'ean qui les composent, il en conclut que l'acide vitriolique est le principe salin le plus pun' que l'acide nitrenx contient plus d'ean; que cet élement est plus abondant encore dans l'acide marin; que dans ces deux dernicrs la combinaison du principe salin proprement dit est altéréce, et que les acides végétaux doivent ì une cerlaine quantité d'huile inhérente des propriétés savonuenses 
PHYSIC. ET CHIM. - SPIELMANN. 55

qui sont utiles daus le traitement de plusienrs maladies.

Ailleurs il recherche quels sont les effets des différentes préparations mercurielles sur les lumenrs animales et principalement sur le sang, et il donne la préférence an mercure employé sous forme saline, parce qu'il est plus soluble et qu'il est plus facile d'en estimer les doses.

Ce qu'il a écrit sur la nature de la bile, déterminée par des expériences exactes, sur l'argile, sur le principe de la cansticití, sur l'acide innaginé par Meyer, dont il lone les travaux en rejetant son système, et sur les gaz dont il a publié l'histoire jusqu'en $177^{6}$, amnonce un savant également consonuné daus la pratique et dans l'étude de la chinive. Il a reliré de l'ur'une, par l'analyse, de l'ean, de l'huile, du sel ınariu, du sel fébrifuge de Sylvius, du sel admirable de Glanber, un sel ammoniacal fixe, de l'alkali volatil, de l'acide phosphoriqune, de la sélénite et des terres ritrifiable, calcaire et aluminense, dont il a fait connoître les proportions et les sources. Il regardoit le tartre comine un acide anquel se sont jointes, dans le trasail de la végétation, quelques portions cle terre calcaire et d'huile.

On saroit depuis Stahl que tous les fluides dans lesquels l'huile, l'acide et la terre étoient réunis de manière à produire une sareur douce ou sucrée, pou. voient fournir des esprits ardens. Quoique le lait possède éminemment ces qualités, les chimistes étoient bien loin de présumer qu'il fût susceptible de la 
fermentation vineuse : M. Spielmann lui-même en aroit long-temps douté; mais M. Oseret's-Kowsky lui ayant assuré en $177^{8}$ qu'llavoit vu les Tartares préparer, avecle lait de jument et sans aucune addition quelcon(que, une boisson spiritueuse, il donna le plan des expéricnces qui furent tentées à Strashourg pour vé:ifier ces assertions, et il obtint le même résultat avec le lait devache: il ne faut que l'agiter long-tenıs dans un tonneau sans qu'il ait précédemment épronvé la plus légère altération. L'effet du mouvemest est de s'opposer à la séparation des parties constituantes de ce fluide si légèrement umies entre elles, qui, rekenues dans leur. contact, fermentent ensemble et peuvent alors fournir les principes nécessaires an produit que l'on attend. M. Spielmann s'est assurć que le seconrs des farincux est inutile au succès de cette opération, dans laquelle les Tartares ont été nos maîtres. Ainsi le lait, cet aliment de l'embryon et de l'enfant, peut se changer cn une boisson vineuse pour l'adulte, en un acide pour étanclier la soif; il abreuve le malade d'une sérosité bienfaisante; il contient une luile abondante et donce; il foumit un sel analogue au sucre: lui senl pourroit suffre ì tons les îges et à toutes les conditions de la vie. Que de propriétés, que de vertus, que de substances cachées dans wn senl être! Disons avec Pascal: Combien l'homme est ingénienx et grand, puisqu'il sait dénèler et créer en quelyue sorte ces objets de son achniration el de ses hesoins!

'lous ces ouvrages, tous ces travaux éloient dirigús 


\section{PIIYSIC. ET CIIIM. - SPIELMANN. 57}

vers l'instruction; et c'est principalenent comue professeur que nous devons cólćbrer la ménuoire de MI. Spielmann. Deux excès doivent être évités dans ce genre, et cette extrêne lógèreté yni ne laisse point de questions indécises, et cette cxcessive réserve qui n'ose rien affrmer. Celui qui énsrigue doit se considérer comme un guide; si sa marche n'est point assuré, il ne pent inspirer de confiance à ses disciples. M. Spichann avoit bien saisi ce juste milien. Son nsage étoit de réduire il des propositions générales les résultats de ses réflexions et de ses cxpéricnes: s'il lontoit il en exposoit clairenent les motifs; sur-tont, il connoissoit le degré d'attention dont ses auditeurs étoicnt susceptibles, et il ne l'cxcédoit jamais. Ne pourroit-ou pas dire qu'il en est de l'instruction connue des alimens, qui doivent être préparés arec choix ct toujonrs proportionnés à la force des organes, que l'on affoiblit égalenent et larsqu'on les épuisc et lorsqu'on les surchirge?

Il n'appartient qu'aux grands maîtres de tracer les éléncus des sciences qu'ils cultivent. Les Institnts de chimie rédigés par MI. Spichnann justifient les éloges que mons arons donnés à la méthode de l'anteur. Il a suivi l'ordre des grandes općrations chimiques et nou celıi des règues. Déjar Geber et Vogel avoient adopté cette marchc. Elle ticnt de plıs près et mène plus dircctement ì la pratique; et tous cenx que leur état cngage it s'y livrer liront avec fruit cet ouvrage écrit par une main que le travail a formée. Ils y rema- 
queront sur-tout, ce qui ne se trouve point ailleurs, un exposé des progrès de la climie, et des procédés des anciens comparés avec ceux des nodernes. Ces Instituts out été traduits daus presque toutes les langues de l'Europe; et ils servent encore anjourd'hui de livre classique dans plusieurs miversités: mais il ne faut point confondre avec les autres éditions celle que M. Cadet de Vaux a publiée à Paris en 1770. Revu par l'auteur lui-niếme, cet ouvrage est compté duns le petit nombre de ceux qui sont sortis des mains du traducteur plus parfaits qu'ils n'étoient auparavant.

La matiére médicale, plus composée encore que la climie, résulte d'mn concours de connoissances qu'il est très-difficile de réunir. Le Traité de M. Spielmann sur ce sujet, dont les grandes classes de médicamens forment les principales dirisions, est digne de la réputation de ce professeur : il est écrit avec précision et il ne mérite point le reproche que l'on peut faire ì tant d'autres. A en juger par lenr étendne, on croiroit que nos ressources en médecine seroient immenses : il semble que les anteurs de ces volnmineuses productions aient vouln imiter ces ruses de guerre dans lesquelles on ajoute des armes simulécs aux véritables pour tromper et iuspirer plis de confiance par nu appareil imposant.

M. Spielnnam a déterminé dans mu antre onvrage les doses des divers onédicanens. Enfin, dans sa Pharmacopuée générale, ì des procédés clininiques qui sont très-exacts, et à une histoire compléte des drogues, il a joint tontes les formules des plus célèbres méde- 
PHYSIC. ET CIIIM. - SPIELMANN. 59 cins commus, et sous tous ces rapports pen d'hommes out travaillé dams ce siecle aussi utilement et avec autant de zèle pour l'avancement de notre art.

La vigilance de M. Spielınann s'est étendne jusqu'an jardin de botanique de Strasbonrg. Lorsfue ce terrain lui fint confié, il $n^{9} \mathrm{y}$ avoit ni serres, ni écolo: ancuns fonds n'étoient destiués à sou entretion. M. Spielmanm eu sollicita et en obtint; et ce jardiı, qüil distribua suivant nn nonvean plan, est maintenaut un des mienx tenus et des plus riches que l'on commoisse. M. Gérard, préteur de Strasbourg, l'a enubelli en y déposant nue collection des plantes les plus curienses de l'Amérique septentrionale, qu'il a rapportées lui-nème descruvirons de Philadelplice. Soignés avec nue sorte de respect par M. Spielmann, acclimatés sons 11 cicl ani du lenr et propice à leur culture, ces végétaux y rappelleront long-temps ce que peuvent l'alliance et les armes dıs monarque frangais.

La Socićté royale nomma M. Spielmann son associé régnicole eu i777, et depuis cette épocpue il nous a fait parvenir, cliaque amuéc, le résultat de ses travaux.

Si lon en croit le témoignage des fils de M. Spielmann et celıi de M. Lorenz, rectemr de l'Université de Strasbonrg, antenr d'ın éloge de ce médecin célèbre, nulle rivalité, nulle jalonsie, ml chagrin, ne mêla son amertume à ses succès. Lirré à des traraux qui faisoient ses délices, comblé d'hommenrs au sein même de sa patrie, entmuré de disciples qui l'admiroient, d'une famille nombrense qui le cliérissoit, marié denx 


\section{ro ÉLOG. HIST. PHYS., etc. - SPIELMANX.}

fois sans avoir eu sujet de s'en repentir, jamais on no: courut avec plus de bonlieur tous les hazards de la vie.

En septembre 1783, il fut attaqué d'une maladie peu douloureuse, et la mort la plus douce termina sa carrière.

Telle est l'histoire simple, mais rare, d'un citoyen qui vécut heureux et tranquille, quoiqu'il fût illustre: par son savoir et recommandable par sa vertu. 


\section{ÉLOGES HISTORIQUES.}

TROISIEME SECTION.

\section{ÉLOGES}

DE WATELET ET DE VERGENNES;

E T

MÉLANGES DE LITTÉRATURE.

\section{AVERTISSEMENT.}

LA Société royale de médecine, que Vicq-d'Azyr avoit formée et qui fut constamment animée de l'esprit de son fondateur, considéra la médecine daus le point de vue le plus raste et dans ses rapports avec toutes les sciences physiques et morales, auxquelles elle peut offrir ou deinander un tribut de connoissances et de lumières.

Cette illustre Société, qui fut pendant longtemps obligée de combattre les ennemis les plus dangereux, ceux de la raison et de tout changement utile, se trouva dans la nécessité de chercher souvent un appui dans le crédit de 
quclques amis puissans, et d'inscrire sur la liste de ses inembres les noms de plusicurs hommes que leur profession et leurs ćtudes habituelles rendoient entièrement étrangers à la médecine. Tels furent principalement WATELET et DE VERGENNES, qui s'intéressèrent à l'établissemerit de la Société royale, et que les membres de cette illustre académie placèrent par reconnoissance sur la liste de leurs associés libres.

Nous avons cru devoir ranger sous un titre: particulier les éloges de ces deux bienfaiteurs de la Société de médecine, et nous avons rapporté au même titre quelques mélanges littérairesi de Vicq-d'Azyr, qu'il nous eût été impossible de: placer dans une autre section.

Ces articles, entièrennent relatifs à la philosophie et à la littérature, prouvent d'aillcurs avec: quelle supériorité l'esprit flexible de Vicq-d'Azyr: savoit s'appliquer aux objets les plus éloignés du genre de ses études liabituelles.

Ces articles sont, $10^{\circ}$ une Notice historique sur les académies; $20^{\circ}$ des Réflexions gćnérales sur les sciences, en réponse an Discours de Rousseau; $3.0^{\circ}$ un Discours lu il l'ouverture de la sćince du 26 octobre 1784 , à laquelle le prince Henri de Prusse assista. 


\section{ÉLOGES HISTORIQUES.}

\section{WATELET.}

Cum mar le nom de M. Watelet, qui a consacré sa vie entière à la poésie ct anx arts, s'est-il tronvé inscrit sur notre liste? Je me hâte de répondre à nue question que le public a sans donte le droit de nons faire.

Lorsqu'en $177^{6}$ feu M. Tnrgot et M. de Malesherbes obtinrent la sanction royale an plan de notre institntion, M. VVatelet contribua beanconp à ce succis par son crédit et par ses conseils; et des circonstances parrticulieres lni conficrent en partie l'examen de nos premiers règlemens. Ce furent donc la reconnoissance et l'amitié qui le placèrent parmi nous; c'est d'elles aussi que sa mémoire attend le tribut de nos regrets, et c'est cu leur nom que je sollicite l'iululgence de l'auditoire. Chargé, pour obéir à nos lois, de lire dans cette séance l'éloge de M. Watelct, et ne ponvant le loner que par ses anvres, je demande la permission de parlẹr ici des belles lettres et des beaux arts.

CLAUDE-HENI WATELET, recerenr général deś finances, l'un des quarante de l'Académie française, des acadénies de Berlin, della Crusca, de Cortone, dé l'Institut de Bologne, lionoraire des Académies royales de peinture et d'architecture, associé libre de la Sociét 
royale de médecine, naquit ì Paris le 28 aotit 1713 , de Henri Watelet, receveur général des finances de l'Orléanois, et de Margnerite de Beaufort, fille de M. de Beaufort, fermier général.

Il fit ses liumanités au collége d'Harcourt.

On remarqua de bonne heure en lui un goût très-rif pour le dessin et pour la musique, et ses parens ne mirent aucun obstacle à ces dispositions.

Il n'est point en effet d'étude qui convienne mieux à la mobilité de l'enfance et à l'activité de la jcunesse que l'étude des arts. Considérez jusqu'à quel point tous les organes sont alors impatiens de jouir : il n'est rien que l'enfant ne voie, qu'il ne touche, qu'il n'cntende, qu'il ne répète, qu'il n’imite. Voulez-rous accélérer le développement de ses facultés? appelez ì votre secours les beaux arts, si nual-à-propos exclus des colléges, et qu'ils soient admis parmi ses jeux : que son oreille soit fiappée de l'harmonic des sons, et vous le verrez régler ses mouvemens sur leurs mesures. Dessinez en sa présence les objets qui l'auront le plıs intéressé, et vous arrachant le crayon, il vous forcera de lui apprendre at s'en servir. Onvrez-lui ces ateliers dans lesquels l'argile prend sons la main de l'artisie des formes divines ou humaines, et l'enfant qui roudra la paitrir acepuerra des idées exactes des granden's et des contonrs; il se plaît à représenter par des constructions bizarres des temples et des autels. Du'il joue avec des colonues de tous les ordres, "griil les combinc de mille manières; et sa curiosité vous interrograria bientố sur lemrs 
altributs et sur leurs rapports. Ainsi vons n’aurez parlé qu'à ses sens et vous l'aurez instruit; sans l'attrister vous anrez obtenu son attention et fixéson inronstance; en $n$ mot, il sera subjugné, mais il n'aura point cessé d'ĉtre libre, parce que rons hii aurez nontré la nature avec tous ses charmes, et qu'il se sera lıi-mème sommis à l'observation de ses lois.

Presque tous les détails de ce tablean penrent s'appliquer at l'culance et at la jemesse de M. Watelet. Siz santé, foible et chancelante, avoit besoin des ménagemens d'une éducation facile, de l'exercice modéré que dome la pratique des arts, et sur-tont de ces émotions donces qui développent dans les organes la sensibilité, le monvement et l'énergie.

On jugea qu'un voyage contribueroit is le fortifier; et son pere, quil'aimoit tendrenent, le fit partir pour lAllenugne, qu'il parconrut accompagné de M. Leroi de Simint-Agnan, médecin, et lonnue ainuble antant qu'éclairé.

A Vieme il fut ténoin des fêtes qui enrent lieu à l'occasion dn mariage de la fene inpératrice reine Marie-Thérèse : il passa en Italie par le Tyrol; à Naples il fut attaqué de la petite-vérole; à Irome, il fut plus lieureux; sa sinté y derint meilleure et il y acqunit un ani.

M. Pierres, actuellement premier peintre du roi, Y résidoit alors. Ils se lièrent intimement ensemble. Mème respect pour l'antique, même pureté de goût, mùne anour du vrai, les ont toujours caractérisés l'un T. 2 . 
et l'autre. Devenu en quelque sorte un des élères de l'É-. cole françoise à liome, M. Watelet s'associa à leurss travaux. Il visita avec eux les monumens répandus, dans cette capitale des arts, où il prolongea son séjour..

Pour savoir jusqu'à quel point ce spectacle devoits l'intéresser, que l'on jette un regard sur lo tablean de. sa vie. On le verra recueillant dans les ouvrages de? Miclicl-Ange et de Raphaël les principes des proportions et de l'ensemble ; on le verra, joignant le talent de la poésic à celui des arts, peindre en rers français, d'après; le Tasse, la prudence consommée de Godefroi, la bra-. voure souvent indocile de Renaud, l'amour furicux: dans Armide, passionné, mais doux et tendre dans Her-. minie; on le verra parmi les fécrics de l'Arioste es-. sayer de transmettre dans notre langage la gaieté, la richesse et la variété de ces tableaux. Il crayon-. nera les exploits du terrible Roland, les aventures $d u$ sensible Roger; pénétrant arec lui dans le palais de l'enchanteresse Alcine, il nous la montrera si touchante, que nous n'apercevrons en elle d'autre ponvoir que celui de ses yeux, d'antre magie que celle de sa beauté : et si l'on se rappelle qu'âgé de dix-ncuf ans il habitoit la patrie des grands hommes qui ont douné ces chefs-d'œuvres au moade; que ce fut alors qu'il traça d'une main libre et hardie le plan inquel il a soumis toute sa carriòre, qu'il se voua pour toujours à l'étude des lettres et des arts : on jugera sans peine de l'énergie de son zíle et dia bonheur de ses premieres anuées. 
Mais il fallut quitter ces clinats où les jours conloient si promptement pour lni : il reviut en France, oil la reuommée avoit publié ses succès. Sa tète étoit pleine d'images; les illusions de la Fable, embellies par le pincean des grands artistes, s'offroient en foule à sa ménnoire; en 111 not, il ćtuit devenn poëte ì l'Ĺcole de Rome, prarni les peintres; it Paris il se distingua comme peintre et comme poüte, et il cut des succés daus ces denx geures.

Bientôt les sociétés les plıss brillantes le recherchèreut. A une amabilité naturelle, il en joignoit nue , acquise, qui plaisoit pent-être davantage ; il fitisoit avec facilité des chansons, des fables, des drames, des opéras; il raisomoit sur les divers genres de poésie, de peinture, de musique, sur les antiquitús; il sembloit avoir plusieurs formes, comme il aroit plusienrs taleus; et on le fètoit dans des cercles dont les gonts étoicnt opposés : chez Mesdanies de Tencin, de Ponı padonr, et Geoffrin, chez MM. de Maurepas, de Caylus et d'Argenson.

Il étoit sans doute à craindre quue ce succès rapide, récompense dangerense d'nn talent naissant, ne nuisit A sa maturité. Peut-être aussi pourroit-on dire que M. Watelet ne se défía pas toujours assez de ce penchant qui entraine l'homme de lettres vers le torrent du monde, oì il est applandi. Là mancquent denx grands moyens sans lesquels nul n'atteint à la perfectiou : la néditation et le temps ; mais s'il fut quelquefois séduit, il ne se laissa jamais arengler. Il distingna tonjours, 
parmi ses écrits ceux qu'il destinoit an public, d'avec cenx qu'il accordoit aux diverses circonstances de la société ; et si cette dernière part a été la plus forte, pourquoi le blîmerions-j̣ous d'avoir sacrifié sa gloire à son bonleur, et l'amour-propre à l'amitié?

Celle de ses occupations qu'il préféroit et à laquelle il revint toujours, fut l'étude des arts.

S'il en est un dont les principes méritent d'être recueillis et ornéspar la main des poëtes, n'est-ce pas l'art de peindre? Déja Dufresnoy (1) et Marsy (2) en avoient tracé les élémens dans des vers latins, aussi bons peutêtre qu'il soit possible d'en faire à présent; mais la langue française, qui compte maintenant plus d'un succès dans ce genre (3), ne s'y étoit point encore essayée lorsque M. Watelet résolut de s'y livrer; il ne se dissimula point les difficultés de son entreprise. Composer un poëme sur la peinture n'est-ce pas en effet s'astreindre it montrer ses rapports avec tous les arts, avec tous les événemens, avec toutes les passions? n'est-ce pas embrasser la nature entière, les dieux et leur puissance, le ciel et ses merveilles, la terre avec tous ses sites et ses

(1) Pictura, carmen; auclore Frnncisco Maria Mansr.

(2) De arte graphica liber; auctore C. A. Dufresnox.

(3) Voycz. La Peinture, poëme en trois clants, par M. Learitne; in-4.0, à Paris, clicz Lejay, librairc, ruc Saint-Jacques, au-dessus des Mathurins, an graul Corncille, $176 y$.

Ou trouve dims ce poëme, ecrit avec enthousiasme, un grand nombre de tableaux ćlégamucnt et fursement dessinés. 
tábleaux, ses plaines et leurs moissons, ses montagnes et leurs volcaus, ses forêts et leurs ombrages; ses mers, leur calıne et leurs tempètes; le teunps et ses époques, l'histoire et ses leçons, la Fable et ses mensonges, l'homme lni-même, entin, avec sa graudenr et sa misère? Tontes ces images se présentent en foule an poüte étonné, que l'ascendant de son génie pent seul élever à la hatiteur d'mu aussi grand sujet.

Averti par cette pensće, M. Watelet comunt ses forces; et déterminant la marche et les limites de son projet, il sut les mesurer avec celles de son talent.

Le dessiu , la couleur et l'invention forment la division de son poëne (1): il dit dans ses vers quelles sont les proportions des différentes partics du corps, comment on en exprime les attitudes et les contours ; conment doivent être dirigées les ligues de la perspective, de quelle substance l'artiste doit se servir pour colorer ses pinceanx : et ces détails ont tous reçu les formes de la poésie ; et lorsqu'il traite de l'ćlégarice et du goût,

(1) L'Art de peindre, poëme, avec des réflexions sur les différentes parties de la peinure; par MI. Watelet, associc libre de l'Académie royale de peinture el de sculpture: nourelle édition, angmentée de deux poëmes sur l'Art de peindre, de II. C. A. Dufresuoy et de M. l'abbé de MIarsy. A Amsterdam, aux dépens de la compagnie, 1761 .

Ce poëme avoil élé publié précédemment in-f.o grand papier, Paris, ${ }_{1760}$. Il y a anssi une édition in-8.9 de la mème année.

Ce poëme a essuyé plusieurs critiques : voyez, entrautres:, la leltre is $I * * *$, contenant quelques observations sur le poëme de L'Art de peindre. 
il ne manque jamais de donner ì la fois le précepte et l'exemple.

Que l'on ne croie pas cependant que tout le mérite de ce poëme didactique se borne à l'enseignement et à l'exposition. Qu'on jette les yeux sur la belle descrip-tion des couleurs du prisme; qu'on lise les adieux d'An-. dromagne et d'Hector, et le tableau dn vainqueur de: Porus, et les attribıts des héros d'Homère : et l'on ne. poulra refuser à $M$. Watelet le double laurier qu'il a. mérité comme peintre, et comme poëte en chantant les beaux arts.

Les réflexions qu'il a publiées à la suite de ce poëme ont réuni tous les suffrages; leur distribution est rraiment pittoresque. En tête de chaque article est le portrait du peintre le plus célèbre dans le genve qui en est le sujet; de sorte que ce n'est pas l'auteur, mais le peintre lui-même qui parle et qui enseigne. On ne lit point un livre; on assiste aux leçons des grands artisles, et on s'iustruit à leur école.

Avec eux, on reclierclie, dans l'examen des statues antiques, comment de la réunion des parlies proportionnées d'un corps naît sou enseuble; on compare le jeune Faune avec l'Antinoüs, celni-ci avec le Gladiateur, et l'Hercule avec le Laocoon ( 1 ); et parcourant

(1) Les artistes qui veulent donnor une idéc complèe de la douleur doivent, s'ils suirent les conseils de M. Waletet, avoir sans cesse sous les yeux le Laoconn: on voit les affections déchirantrs s'érendre jusqu'aux extrónités, ì raison du grand nombre d'arliculations et de cordes qui s'y tronvent daus un ficlit espace. 
ainsi dans ces chefs-d'œurves des arts le cercle des divers îges et des différentes conditions de la vie, on y découvre ces rìgles précises, ces dimensions cxactes d'où résulte la heatuté des formes, dont elles sont la mesure, et qu'une étude profonde a retrourée et fiat revivre parmi nous. Des proportions (1) et de l'ensemble naissent l'équilibre et le monvenent; ct c'est Léonard de Vinci que M. Vatelet interroge sur cette partie de son art. C'est par son organe qu'il expose comment les efforts et l'appui, mal combinés entre enx, doment de la gêne il la fignre et de la fitigne au spectittent. Vous aimez ì voir Hercule tenant le géant. Anthée suspendu daus ses bras nervenx et prèt it l'úlonffer sur son sein : e'est que les lois de l'équilitre, complétement observées daus ce groupe, vous rendaunt. en quelque sorte témoins de l'action, vous applan-

En effet, claque doigt éproure une porliou de la douleur qui agit sur lous les muscles; il semble que les affeclions, portées jusqu'aux extrémilés, redoubleut de violence, jarce qu'elles ne peuren I s'étendre plus loin.

(1) Il paroil maturel de croire, lit MI. Watelet, qu'un objet, par exemple, une figure d'houme ou de femme, représentie dans sa grandeur et dans les proportions naturelles, a quelque arantage relativement à l'illusion dans la conformite des dimensions.

Il est une infinité de circonstances où cet arantage est sensible. Ainsi la représentatiou de la serrante de Rembrant, dont ce peintre exposa le portrait à sa feuère, u'auroit pu tromper les passans si l'initation avoit été plus grande ou plus petite de proportion que la nature.

Mais il faut olserver que plus on s'appuieroit sur cette base, moins l'illusion appartiendroit au libèral de l'art. 
dissez à la défaite du monstre impie vaincu par le demi-dieu.

Qui peut mieux que le Titien donner des lecons sur l'harmonic des couleurs? Qui dira nienx que lui comment les ráyous, dirigés du centre luminenx vers les divers joints de l'objet, y portent le jour et sout terminés par les ombres; quelles sont les lois de leur incidence et de leurs reflets; quelles sont celles de la dégradation des couleurs et de leurs sympatlies; jusqu'à quel point les organes de l'artiste influent sur le ton de ses tableaux, et sur-tout avec quel soin on doit éviter le faux-brillant qui, dans la peinture comme dans la poésic et dans toutes les productions de l'esprit, diminue l'effet au lien de l'angmenter.

De ces nuances bien senties résultent la grace (1) et la beauté, dégagées de toutes les fantaisies de la node et de la contrainte des manières, telles enfin qu'ou les voit quelquefois sortir des mainsde la nature, on telles qu'on les a vu naître'sons les pinceaux du Corrège et de l'Albane.

Ne faut-il pas encore que l'expression anine et varie les tableaux? Ici le Dominiguain et le Brun se rénnissent

(1) La grace, dit M. Watelet, nait du juste accord des sentinens de l'auc avec l'action du corps: le peintre, pour la représcuter, dojt douc apprendre i hieu connoitre, par l'observation et par la miditation, cette marche corrélative des affections et des mouvemens; marche quelquelois parfititement correspondaute, mais Imp sourent iurgale, scilt que l'expression éprouve de la gene, ou yue le sentiusent suil contritiut. 
ponr dévoiler les secrets de l'ame affectée par les passions, et pour apprendre l'art d'en saisir extérieurement les caractères; mais où trouver des snjets propres à ce genre d'initation? Seroit-cedans les villes, où les gestes et la physiononie obéissent is la convention dès l'enfance? Seroit-ce près des villes, on tont ce qui les envirome, les chanps, les animanx, et les arbres enx-mèmes, portent le sceau de la contrainte et do l'unilormité sociale? Seroit-ce loin des villes, on les organes, fitigués et grossiers, ue reçoirent qu'nu petit nombre d'impressions qu'ils savent anssi dissimuler? Parmi tant de causes propres à masifucer la nature, le senl modede des arts, qui retrouvera la trace des émotions du cœur lnmain, si ce n'est l'olsc "vation gnilée par l'cuseignement des grands maitres unns les acarlénies, oi l'on garde mu souvenir profond de ce que l'honme fut autrefois, et de ce qu"il a perdn, dans les grandes associations, de force, de franclise et de simplicité?

Est-il donc une étude plus grancle et plus belle que celle de l'art de peindre ainsi considéré? Connre il s'unit à la philosoplie par le tableau des sensations; à la morale, par celui des vertus et des vices; à l'histoire naturelle, par celni des attitudes et cles gestes ; a la science de l'équilibre, par les lois de la pondération des figures; à l'optique, par les illusions de la perspective; à l'anatomie, par le dessin des masses et des articulations; enfin, à la chimie, par la fabrication et Ic mélange des coulenrs!

En lisant cet ourrage, on est étomné du graud 
nombre de pensées et de vues resserrées par l'auteur dans aussi peu d'espace. Ces réflexions ne sont en effet: que le sommaire d'un grand traité auquel M. Watelet a consacré sa vie, qu'il a enfin rédigé sous la forme de dictionnaire, et dont le public jouira bientôt. Tout re qui concerne l'art de peindre y est discuté sans longuenr et sans ennui ; le précepte ne s'y montre jamais. isolé ; on voit toujours d'où il naît et ce qu'il doit produire. L'enthousiasme et le goût (1) sont assujétis à quelques règles; elles y sont tracées. Nul n'y puisera sans doute ni cette vive émotion d'où l'ame tire sa vigueur, ni ce tact exquis d'un sens intime qui la dirige dans ses jugemens; mais ceux qui en sont pourvus y trouveront des conseils dont ils sauront profiter.

(1) Il faut distinguer, suivant M. Watelct, lc goût qui jouit, du goût qui opc̀re : non qu'ils soient essentiellemeut diffërcns, mais parce que l'un agit avec promptitnde, et l'autre avec réflexion. Du reste, tous deux ont égaleınent pour basc ce scutiment délicat qui se décille d'après les convenances ou d'après les conreutions. Lo gont, appuyé sur les convenances, a plus de perfection et de stabilité. En effet, les convenances naissent de la nature mème des hommes, c'est-d-dire de ce qu'ils sont essenticllement et de ce qu'ils doivent être lę uns à l'égard des autres dans l'ordre géuéral. Le goùt, appuyé sur les couveutions, est plus restreint, parce que Ies conventions n'embrassent ni les choses ni les hommes on général, et ne s'établissent le plus ordinairement que parmi un certain nombre d'liommes. Anssi les conventions differeut entre elles dans les diffërens climats, dans les tempss dirers, dans les aociétés, et jusque daus les plus petites portions des sociétés.

C'est par ces raisons que !r gont qui nait des conventions peut ctre établi sur tant de bases qu'on doit le regarder comne arbiIraire. 
L'art de peindre reconnoîl denx origines, l'une naturelle, l'antre historique. Ce bel art exerce son domaine sur deux moudes, dont l'un est réel et l'autre imaginaire; il représente denx espèces de heautés, dont l'une est vraie et l'antre senlement idéale. Tantòt il montre la vérité dans tout son jour, tantôt il la cache sous le voile des symboles. S'agit-il de ses geures? Ils sont assez variés pour sulfire il tout ce que l'esprit pent concevoir d'images et de tableaux. S'agit-il de ses procédés et de ses effets? Les uns sont anssi minutienx que les autres sont sublimes. S'agit-il enfin de la poétique de cet art? Elle se compose de tont ce que l'inngination a de moyens et d'énergie. On lit dans le: Dictionnaire do M. Watelet (1) un grand nombre d'articles, on plutôt de traités sur ces différentes matieres.

S'il falloit indiquer quelque rapprochement entre nos travanx et les siens, nous le trouverious dans les mots Anatome et figune qu'il a rédigés, soit pour l'uncienne édition de l'Encyclopédie, soit pour le Dictionnaire qui fera partie de la nonvelle; et nons pronverions que plusicurs de nos commoissances ne lui étoient point étrangères, en faisant roir combien ce qu'il a dit du squnelette et des muscles est exact et précis.

(3) Dictionnairc de peinture, destiné à faire partie de l'Encyclopédie métlrodique. On troure en tête des wotions préliminaires sur la peinture, et un tableau des principales parties qui constituont cet art. J'ai entre les mains les premières feuilles de ce dictionnnaire jusqu'au mot Costour; en tout 126 pages in- $4 .^{\circ} \mathrm{en}$ deux colounes. 
Veut-on maintenant avoir nne juste idéc de ce que fut M. VVatelet, ì qui tant de rapports étoicnt conuus? Qne l'on se représente un liomme également versé dans toutes les parties des sciences et des lettres qui intéressent les beaux arts; se servant avec le mênue succès de la plume, du burin et du pincean; placé pour ainsi dire entre les poëtes, les philosophes et les artistes, et rendant communes à tous les richesses propres à chacun d'eux; souvent consnlté, parce qu'il joignoit à l'affabilité une vue qui s'étendoit au loin, et m tact qui s'appliquoit à tout; consultant plus souvent encore, parce nul ne rechercha de meilleure foi l'instruction et les lumières; applandissant avec transport au talent; habile à consoler et à faire renaître le courage dans les revers; accueillant les élèves, sur-tout lorsqu'ils avoient plus besoin de ses secours que de ses avis; les recevant dans sa maison, les traitant en père on en ani, et janais en protecteur; en un mot, aimant les arts saus faste et les artistes pour eux-mèmes, et formant des voux qui étoient tout entiers pour leurs progrès et pour leur gloire : tel fut M. Watelet aux yeux de ses contemporains, et tel il doit paroître à ceux de la postérité.

Jusqu'ici je l'ai présenté comme liveé seulement à l'art de peindre: il a traité, daus un autre ouvrage (1), de l'origine el de la destimation des heaux arts, consi-

(1) De l'origine et de la destination des arls liberaux, in-3.", 1771). Ia premiche partic est depuis ce remps prère a paroitre; je ue sais pourquoi elle n'a pas encore été renduc publique. 
dérés en général et sous leurs différeus rapports. J'ajouterai mème qu'il n’a montré mulle part autant de profondenr. Cet écrit, dont la première partie est impriunée, n’étant point conntı, j’ai cru (pue l'on nne santroit gré d'en problier une esquisse (1).

Interoge-t-on la nature? dit MI. Tiattelet: on est sur la route des sciences. Cherchic-t-on il l'inuter? on est sur celle des arts. Ceux-ci fixent-ils rotre attention, et denandez-vous quelle est lentr origine? Semblables

(1) TABIEA U des principales parties qui constituent l'art de la peinture.

Il faut considérer dans l'at de la peinture,

\section{SON ORIGINE}

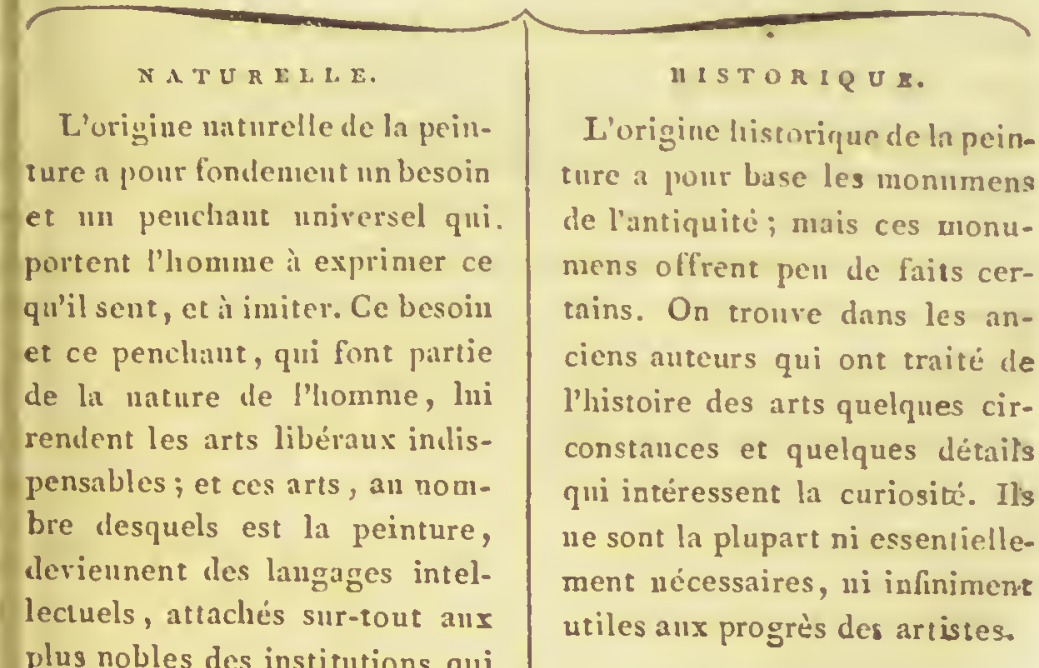
s'établissent dans les sociétés; je reux dire les systèmes de religion, d'héroïsme et de patriotisine. 
anx races illustres, leur génération se confond avec celle des hommes. Leur principe commun est l'imitation. Avant M. Watelet, l'abbé le Batteux l'avoit dit, et il avoit trouvé le germe de cette idée dans Aristote. Que l'on observe l'homme dans tous les temps de sa vie, et on le verra pressé par le désir d'exprimer ce qu'il

Suite du tableau sur l'art de la peinture.

SON USAGE,

\begin{abstract}
UTILE
Aux sciences et institutions en général par la représentation des objets dont elles s'occupent, et des moyens
\end{abstract} qu'elle's emploient ;

A I'histoire, par la représ entation des faits, par lá conservation tidèle des objets, des monumens, des ressem. blances, ct des usages en purticulier;

A la morale, par la représentation des actions Innalules; et esufin,

Ans. inst itutions, parce que 1 a peinture les rend sensibles, en methant sous les yeux les faits qui a ppartiennent it ces institutions, et less allégoris: qui leats sont pro. pres.
UTILE ET AGRÉAELE

Aux arts libéraux, par les rapports que la peinture qui en fait partie a arec eux.

Aux arts mécaniques, en facilitant l'intelligence, l'exécution et l'initation de tout ce qu'invente l'industrie hunaine; car l'art de la peinture est à cet égard une langne universelle.
AGREABLE,

Comme objet de délassement et de plaisir, soit par la satis. faction particulic̀re que la peinture fait éprouver dans les imitations qu'elle produit ;

Soit à titre de monumens et d'oirrages patriotiques;

Soit encere it titre de proprićté et de jonjssance personnelle. 
sent, et d'imiter ce qu’il voit. Qu'on le suive arec le seconrs de l'histoire dans l'étude progressive des arts, et l'on apercevra (p'en imitant il a mis en usage des moyeus de divers ordres; que ses représentations out d'abord été simples, ct qu'elles sout eusuite devenues complexes; c'est-à-dire qu'apries avoir reudn les formes par des formes plus habiles i tromper, il a enlin représenté les relicfs par des trinits et par des coulenu's.

Suilc du tablcan sur l'art de la peinture.

SA PERFECTIBILI'T

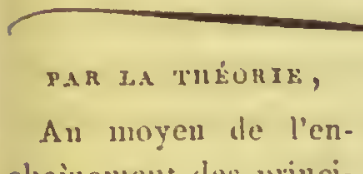
chainement des principes neicessuires ì l'art;

Par les secours qu'elle tire des parties de différentes sciences, telles que l'anatomic, qui ılémontre an peintre l'osrcologie et la uyologie;

Par les mathematiques, qui seules peureut domer des lois pricises de la perspecive et de Ia pondiration;

Par l'histoire et la fable, oil se trouvent cousigués les faits intéressins et le costume des peuples, ainsi que les allegurories.

par La PRATIOUE,

Au moven des olservatious sur les formes des corps ;

Leurs conleurs;

Le's elfers de la lumice ;

Les effets des passions ;

Les mouremens apparens des corps animés ;

Les accidens de tonte esprece auxquels la nature visible est sujettc.

\section{Qui compreud :}

l'exercice habituel de l'art, d'oì résultent la liberti et la facilite d'operer;

Le cloix des uneil. leurs moyens et de tous les secours que peut employer l'art ;

Ise perfectionnement des ustersiles et des maticres, de la préparation le ces matidres, et la par. laite connoissance de l'emploi qu'on peut et qu'on doit eu faire. 
Recherche-t-on quelles sont les liaisons des beaux arts avec nos besoins? $M$. Watelet répond qu'ils doivent êtro considérés comme autant de langages (1). Le plus simple

(1) TA B E A U des six arts ou langages libéraux, arec la différence qui distingue trois d'entre eux des trois autres, d'après M. Watelet.

Arts ou langages dont les productions sont transitoires ou instantanées.

Art de la Pantomime... Langage d'action.

Art de la Parole ..... Langage des sons articulés. Art de la Musique...... Langage des sons modulés.

Arts ou langages dont les productions sont fixes et durables. Art de la Sculpture.... $\begin{aligned} & \text { Langage par l'imitation des for- } \\ & \text { mes de tous les objers visibles } \\ & \text { et paljables. }\end{aligned}$ Art de l'Architecture.... $\begin{aligned} & \text { Langage par le mnyen drs dispo- } \\ & \text { sitions ingénieuses et significa- } \\ & \text { tives dont les constructions sont } \\ & \text { susceptibles. }\end{aligned}$ Art de la Peiuture..... $\begin{aligned} & \text { Langage par le moyen des con- } \\ & \text { leurs, disposées et appliquées } \\ & \text { avec intelligence et intention } \\ & \text { sur des strfaces unies. }\end{aligned}$

La différence ci-dessus indiquée consiste, d'une part, dans l'instantanéité d'existence

De la Pantomine,

De la Parole,

Et de la Musique.

De l'autre part, daus la fixité ct la duréc

De la Sculpture,

Dr l'A relitecture,

Iit de la Pointure. 
et le plus ancien est le langage d'action ou la pantomime. Celui des sons articulés ou la parole lui a succédé. Celıi des sons modulés, plus tardif, dut ì la joie ses premiers accens; et ces trois moyens d'expressions, images de la pensée, sont anssi prompts et aussi peu durables qu'elle. Ils ont cessé, et leur trace n'est déja plıs. La peinture, la sculpture et l'architecture constituent trois autres langages dont les produits, au contraire, sont permanens, et penvent en quelque sorte parlec d plu-ieurs siècles.

Tous ces moyeus d'expressions ont donc un principe d'existence bien déterminé dans l'exercice des facultés intellectuelles. Essayons de montrer connent ils sont parvenus, dans les grandes sociétés, an plus haut point de perfection et de gloire. Ne cherchons cet exenple ni dans les climats oì l'exots dn froid ralentit le fen de la vie, ni dans les pays brâlés par une clialeur ardente, oil l'inaction est un besoin. Fnyons encore les lieux habités par des esclaves, et disons: S'il a existé une nation brave et polie, qui, sous une température douce et mòdérée, ait possédé une langue liarmonieuse et riche; qui, reconnoissant autant de pnissances dans le ciel qu'il y a de vertus et de passious dans le cœur humain, leur ait rendu un culte aussi magnifique dans sa poinpe, qu'ingénileux et délicat dans ses allégories; qui ait placé la victoire et la liberté suv des autels; qui passionnée pour les actions d'éclat les ait récompensées par des apothéoses; qui se soit honorée elle-même en se croyant en partie composée de T. 2. 
demi-dieux : si cette nation a existé, ça été sans douto au milien d'elle qu'ont fleuri les beaux arts. Qui no retrouve pas l'ancienne Grèce dans cette esquisse? Lì s'établirent trois cultes très-distincts, quoique liés ensemble de la manière la plus étroite : le culte des dieux, le culte des grands hommes et celui de la patrie. Là furent célébrés des fêtes et des triomphes; là furent élevés des statues et des temples; là enfin le ciseau des arts, exercé par tant de glorieux travaux, s'immortalisa dans ces monumens consacrés au génie des héros et des peuples avec lesquels il devoit partager un jour l'admiration de l'univers (1).

Dans la suite de ces mémoires, que l'on quitte à regret; l'auteur offre comme très-probable ume conjecture ingéxieuse. Il présume que le dessin, dont les élémens sont des lignes droites et courbes de toute

(1) J'ajouterai au tableau de cet ourrage un résultat qui suffiroit pour en faire sentir toute l'importance, e'est qu'en considerant les trois institutions on eultes portés si lnin dans l'ancienne Grèce comme la eause principale de l'avaneement des beaux arts, soit que l'on parcoure l'histoire, soit qu'on jette un coup d'ouil sur l'état actuel de l'Europe; on tronve par-tout une liaison si iutime entre leurs progres et ces grands moliles de l'esprit des nations, qu'on peur toujours juger des uns par les autres, vu la juste proportion qu'ils couservent entre enx.

Il semble, a dit un plitosoplse molerne, que l'amour-propre des princes soit encore plus intéressé à protéger les benux arts que les sciences mèures : car lorsqu'eu parle de celles-ci, on dis le siècle d'Aristote, de Newton; et lorsqu'on parle dis arts, on dit le siécle d'Aleximdre, de Líon $\mathrm{X}$, des Médicis, et de Lonis XIV. 
espèce, peut n'avoir été dans son principe qu'ıne imitation de la pantomine, par laquelle sont tracées des lignes semblables dans le vague de l'air. Il expose par' quelles nuances ces signes durables des gestes ont pu conduire à ceux des idées; enfin, connuent, en les fixant par des caractères, l'homme est parvenu ì joindre le passé au présent, et, soutemu sur celte base, à s'élancer vers l'avr nir.

A près a voir fait une étude anssi longne et aussị réféclie des arts, il étoit naturel que MI. VVatelet désirit de revoir l'Italie. Des personnes de sa société intine et qui avoient les mêmes goùts l'accompagnèrent. Il nuit sur-tont un grand soin à comparer ses sensations avec celles de sa jeunesse, et il jugea mieux parce qu'il fint moins séduit.

M. VWatelet reçut dans toutes les capitales où il séjourna des témoignages de la considération publique. Le roi de Sardaigne et le pape Rezzonico l'accueillirent d'une manière distinguée. Il rentra arec joie dans l'Ecole française à Rome: il s'y étoit assis parmi les élèves, il y fut fêté comme nun des naitres de l'art. Il devint l'ani du cardinal Albani, l'un des plus grauds littératerr's et des plus aimables hommes de l'Italie; il se lia arec les PP. Lesueur et Jacquier, que leur attachement réciproque avoit rendus célèbres, et dont les cœur's sensibles ne s'approclıoient pas sans émotion; et il revint à Paris avec des connoissances et des affections nouvelles.

Quelques années aupararant, M. Watelet aroit parcouru la Hollande et les Pays-Bas autrichiens dans le 
dessin de comnoître les tableaux sortis de l'école de Hubert et de van Dick.

Ses délassemens, parmi tant de travaux consacrés aux arts, étoient la traduction en vers français de la Jérusalem délivrée et de Roland le furieux, et la composition de quelques autres ouvrages en vers, tels que des comédies et des fables.

Pour mieux entendre les chefs-d'curres du Tasse et de l'Arioste, et pour ne laisser échapper aucune de leurs beautés, M. Watelet avoit commencé par en faire une version en prose, dont il traduisit une partie en vers. Mais ces premiers essais ne satisfirent ni M. Watelet, ni ceux de ses amis auxquels il s'en rapporta. On sait a vec quelle abondance les fictions les plus ingénieuses sont répandues dans cesdeux poëmes; avec quelle profusion, mais arec quel art les ornemens do toute espèce y sont distribués ; on sait aussi jusqu'à quel point la langue du Tasse est féconde dans ses nuances, et sur-tout combien les poëtes italiens du scizième siècle étoient hardis dans leurs inversions. Ces difficultés nombreuses cachées au lecteur par l'agrément de la composition, se montrèrent tolyt-à-coup à $M$. Watelet lorsqu'il fillut traduire en poëte. Il vit qu'il devenoit diffus lorsqu'il rouloit être exact; que les formes des images étoient si délicates et si légères, que le moindro changement en altéroit la grâce, et qu'en tonchant alors an coloris il en détruisoit la fraichenr; et il résolut alors de publier, non nne traduction, mais seulenent une inuitation de ces deux épopées. Lorsque 
res onvrages paroîtront (1), l'auteur, qui n'est plus, sera jugé sans doute avec impartialité. On y trouvera plusicurs morceaux dignes de sa réputation et de ses modèles, et l'on répétera ce que M. de Marmontel a dit (2) en citant la traduction d'm épisode du Danto par M. Watelet, que ce nul homme de lettre ne fut plus » exercé dans l'étude des poëtes italiens, n'en sentit 》 mieux les beautés et ne sut mieux les reudre. 》

Il faut le louer sur-tont d'avoir bien connu ce qu'il devoit au public, à ses amis et à lui-mêtnc. De toutes les pièces qu'il avoit écrites ponr différens théàtres, altcune n'avoit encore été imprimée en 1784 . Ce fut alors que, jugeant daus le silence de la solitude ces onvrages de sa jemnesse, quelques-uns tronvèrent gràco devaut lui; il les réunit daus un volume (3), et l'accucil qu'ils reçurent dı public justifia son choix.

On y remarque sur-tont mue comédie intitulće les

(1) Imitation du poëme de l'Arioste, en vers franģais. J'ai entre les mains tes quatre premiers cliants imprimés et le commencement du einquicme : en rout 112 pages.

(a) Poëtique française, 3 rol. in $-80^{\circ}$, pag. 4 f.

C'est le tableau du comte Ugolin dérorant dans les enfers Ia tête de l'archerèque Roger.

M. de la Harpe, tome VI de ses aurses, in-8. ${ }^{\circ} 177^{8}$, pag. 36z, parle aussi avec éloge de la traduction du méme morceau du Dante par M. Watelet.

Le témoignage de ces delux grands littérateurs est si honorable a la memoire de M. Watelet, que j'aurois cru manquer à mon devoir en oubliant d'en faire neution ici.

(3) Recueil de quelques ourrages de MI. Wateler, de l'Académie 
Veuves, dans laquelle M. Watelet a mis en action le conte de la Matrone d'Éphèse (1); plusieurs drames, tels que les Statuaires d'Athènes, Phaon, et Délie, où l'on trouve des tableaux pleins de grâce et de finesse, présentés ailleurs sous d'autres formes; et la charmante comédie de Zénéide ( 2 ), dont la fable est simple, ingénieuse et très-morale. Au reste, ces pièces, dont (3) la plupart n'ont point été jouées, sont dignes au moins d'être lues: différentes en cela de plusieurs aux-

française et de cclle de pcinturc : à Paris, chez Prault, imprimeur du roi, quai des Augustins, in -8. ${ }^{\circ},{ }_{1784}$

Les pièces contenues dans cc recueil sont :

Silvie, roman imité de l'Axirte du Tasse.

Zí⿴囗十́IDE.

Les Statualres D'Athèyes.

Les Veuves, ou la Matrone d'Ephèse.

MrLox, intermède pastoral.

Deucalion et Prorna, općra.

Déle.

Phan.

(1) Avcc cette différence qu'il a substitué un corsaire au soldat, ct que le mari, qui n'est pas mort, mais qui a feint de l'étre pour éprouver Astéric, terminc la pièce par unc moralité sur le bonheur, que l'on détruit souvent en l'examiuant de trop près.

(a) Un liomme de Icttres à qui M. Watclet aroit confié le manns. crit de cette comédic, l'a misc cu vers, et le public la voit tonjours avec plaisir.

(3) Milon, drame lyrique ; ct Dẹcucalion et Pyrrha, sujets riclics de tous Ins contragtes que peuvent prodnire la furcur des hommes et la colire des dicux, nnt les mêmes beautés et les mênes défauts; nu y irnuve des vers laciles et des tableanx bien dessinés, mais dans lesquels on désireroit plus de clialenr, plus de couleur ct 
quelles on a accordé la première distinction, sans qu'elles aient encore obtenu la seconde.

M. Vatelet fut reçu en 176 . membre de l'Acadénie fiançaise (1), où il succéda à M. de Mirabeau. La carrière des lettres fut pour lui sans orage. Comme il étoit démué de toute prétention, il n'y chercha point

d'énergie. Les drames intitulés les Statuaires d'Athènes, et Dílie, ont quelques rapports daus leur principale situation. Dans le prenier, deux éleves de Plyydias oftreut aux Athéniens rẻunis dans le temple de Vénus pour aljuger le prix de sculpture, l'un, une jeune fille sous la forme de cette déesse; l'autre, un jeune lomue, son amant, sous celle d'Adouis. 'Tuus les jeux sont trompes, mais la tendresse paternelle ne saurnit l'dere; les entrailles des deux pères sont émues, et le mystếe est découvert.

Dins le secoul, Anacrén cioil rendre lomuage an portrait de Délie, et c'est à Délie elle-udine que s'ulressent ses vaux; elle les reģoit et le couronue.

Des auteurs trds - estimables ont employe arec succes sur nos thédres des moyens du mème genre.

(1) Discours prouoncés dans l'Acalémie franģaise le lundi 19 janvier 1761 , i la réception de 11 . Watelet. A Paris, au Palais, chez la veuve Brunet, imprimeur de l'Acadèmie frangaise.

M. Watelet y succéda i MI. de Miraheau, connu par sa traduction du Tasse et de l'Arioste, lont M. Watelet s'est aussi nccupé. La réponse à M. Watelet fut faite par MI. le comte de Buffon. Ce grand homme avoit bien juge l'académicien qui est le sujet de nos regrets; il s'exprime ì son égard de la manière suivante. "Vous veuez, dit-il, d'enrichir les arts et notre langue d'un ourrage qui suppose avec la perfection du goù tant de connoissances différentes, que vous seul pent-être en possédez les rapports et l'ensemble; vous seul avez osé tenter de représenter par des vers harmonieux les effets des couleurs; rous arez essayé de faire pour la peinture ce qu'Horace fit pour la poésie, un monument plus durable que le bronze. Rien ne garantira des outrages du temps 
d'adınirateurs et il y trouva des amis. Que l'on me permette, sa cendre n'y scra point insensible, de rassembler ici leurs noms autour du sien. Tels furent, parmi ceux qui comme lui ne sont déja plus, MM. de Foncemagne, de Château-Brun, le comte de Caylus, l'abbé de Condillac, Turgot, d'Alembert, Thomas, l'abbé Copette, auxquels il a donné tant de regrets; et parmi ceux qui lui survivent, MM. le duc de Nivernois, le comte d'Angivillier, de Saint-Lambert, Pierres, le duc de la Rochefoucauld, le malquis de Condorcet, de Keralio, Daubenton, Marduyt, Dusaulx, qui l'ont tant regretté. J'oserai ajouter mon nom à une liste aussi honorable; en l'oubliant, j'offenserois à la fois l'amour-propre et l'amitié.

Plusieurs de ceux que j'ai nornmés ont reçu de $\mathrm{M}$. WVatelet une marque particulière d'affection. Il a lui-même dessiné et gravé leurs portraits. Cette manière de s'occuper de ses amis en se pénétrant de leur image, a quelque chose de tendre qu'il n'appartient qu'aux ames délicates et pures d'inspirer ou de ressentir.

ces tahleaux précieux des Raphaël, des Titien, des Corrège; nos arrière-neveux regretteront ces cliefs-d'ocurres comnie nous regrettons nous-mémes ceux des Zeuxis et des Appelle. Si vos legrons savantes sont d'un si grand prix pour nos jeunes artistes, que ne vous devront pas, dans les siècles fururs, l'art lui-mente es ceux qui le culriveront! Au feu de vos lumiéres, ils pourront réchauffer leur génie, ils retrouverout an moins dans la fécondiré de vos principes et dans la sagesse de vos próceples une partic des secours qu'ils anroient tirés de ces modeles sublimes qui ue subsistcront plus que par la scroumćc, s 
N'est-ce pas ici le lieu de parler de l'Essai sur les Jardins (1), ouvrage que dictèrent à $M$. Watelet les plus agréables souvenirs? A des vues très-philosopliques sur les progrès des arts, l'auteur a joint dans cet écrit des préceptes ingénicux sur la décoration des jardins de toute espèce; mais ce que l'on y renarque avec le plus d'intérêt, c'est le tablean de sa vic daus l'asile champêtre où il devoit à ses amis le bonhenr et l'hospitalité; asile devenu fineux par les beautés de son site et do ses dispositions, et oǹ lat nature fut toujours respectée; asile visité par les grands, habité par les Muses, célébré par le chautre ainuable des Jardins (2), et qui fint la retraite d'un sage. Le cours et la limpidité des eaux, la fraîcheur et le sileuce des grottes, des fleurs éparses sur des terrains incultes, et l'aspect de quelques ruines

(1) Essai sur les jarlins, par M. Watelet, de l'A cadémie franraise, et honoraire de l'Aculimie rnyale de peinture el de sculpture, etc. Fortunatus et ille, deos qui novit agrestes. Georg., lib. 11. A Paris, chez Pranlt, imprineur dn roi, quai des Angnstins, 1774.

(2) Tel est, cher Walelet, mon cour me le rappelle, Tel est le simple asile où, suspendant soul conrs, Pure comme les manrs, libre comne tes jours, En caulux ombragés la Seine se partage,

Et visite en secret la retraile d'un sage.

Ton art la seconda; non cel art imposteur, Des lieux qu'il croit orner hardi profanateur. Digne de voir, d'aimer, de sentir la aature, Tu traitas sa beauté comme une vierge pure, Qui rougit d'ètre nue et craint les ornemens. (Les JARDiss, poënc, par MI. l'abbé Delille, chant III.) 
accompannées d'inscriptions en vers harmonieux et doux, y rappeloient ce que valent dans le sein de l'amitié la liberté, le repos et le temps.

Se pouroit-il que les jours de M. Vatelet continuassent jusqu'à leur terme d'être heureux et sereins? Un événement imprévu troubla cecalme eu le privant d'une grande partie de sa fortuue. Le bon usage qu'il en avoit su faire rendit ses regrets légitimes et touchans. Les jennes artistes dont il prévenoit les besoins, et les malleureux qu'il sollageoit, y perdirent au reste moins que lui. Ce fut sur la part qu'il s'étoit réservée qu'il fit le plus de retranchemens. L'estime publique ne l'abandonna point dans ce revers; des amis puissans lui donnèrent des preuves de leur zèle : un entre autres, que ses bienfaits désigneront assez, lni prodigua toutes les consolations d'une ame affectueuse et tendre, auxquelles il joignit des secours qu'il est rare que les hommes de son rang donnent à ceux de l'état de M. Watelet.

C'est sur-tout dans les tempéramens foibles et sensibles que le chagrin appelle la souffrance, à laquelle succèdent la langneur et le dépérissement. M. Watelet s'aperçnt pendant ses demières années que le travail des lettres le fatiguoit beaucoup; il y substitua celui des arts. Tantôt il dessinoit, tantôt il gravoit à la milxière de Rembrant, dont il se flattoit d'avoir déconvert le procédé, dont an moins il savoit rendre quelques effets. S'étant affoibli davantage, il se contenta de modeler en cire; plus foible encore, il parcouroit ses 
porte-feuilles (1), il conversoit avec de jemnes artistes dont le feu le ranimoit; et proportionmant toujour's ces nuances de plaisir à l'état de ses forces, il ne cessa d'en goûter les chames qu'au moment oir ses sens refusèrent de lui en transmettre les impressions. Il s'éteignit ainsi d'une nınicre insensible au milieu de ses joursances, et il expira sans doulent, en croyant s'endormir, le 12 janvier 1786 ( 2 ).

Sa mort fut donc anssi douce que sa rie avoit élé tranquille (3). Tous ceux qui l'ont comnu savent que sa

(1) Voyez le catalogne des tableaux, dessins montés et en fenilles, pastels, émail du célebre Petiot; bustes, figures et gaines de marbre, tables de porphyre, instrumens de plyyrique et de gíomeitrie, rstaupes d'aprds les plus grands maitres, dilteirens nuvres de Reubrant, Hubens, Labelle, Hollar, Callot, ert.; planclies graves par llembrant, M. Watelet et auties.

Le tout provenant du cabinet de feu MI. Watelet; par A. J. Paillet, in $-80^{\circ} 17^{86 .}$

(a) Voyez, dans le Journal de Paris du 28 janvier 1786 , un article très-bien fait sur la vic et les ouvrages de MI. Watelet.

(3) On a trouvé parmi les papiers de feu $\mathrm{MI}$. Watelet les mauscrits suivans :

1. La traduction on imitation en rers français des poëmes du Tasse et de l'Arioste. Ces manuscrits sont en bou état.

2. ${ }^{\circ}$ Un recueil de cinquante fables, avec une épitre lédicatoire à M. L. C., un prologue et un épilogue. Ce manuscrit est en bon état.

3. Q Un carton contenant des vers relatifs a Moulin Joli. C'est de ce recueil que $M$. Watelet a extrait les inscriptions en vers publiées dans son Essai sur les jardins.

$4_{0}^{\circ} \mathrm{U}_{11}$ rolnme contenant des rers, intitule Bouquet, etc., \ Madaıne....

5. Imitation libre de. la première èlégie de Tibulle. 
modération étoit grande; mais on ne sait pas assez que cette modération fut moins un présent de la nature, dont il recut une ame très-active, que l'ouvrage d'une raison sévère qui en avoit de bonneheure réprimé

6. Plan d'un poëme sur les différentes parties du jour.

$70^{\circ}$ Fragment de la traduction d'un poëme italien intitulé : Grenade conquise.

$8^{\circ}$. Un grand nombre d'articles destinés à former le Dictionnaira de peinture pour l'Encyclopédie méthodique.

9. Plan d'un Traité de la peinture, à l'usage des poëtes; ct De Ja poësic, à l'usage des peintres; a vec un supplément sur les divers costuines.

10.9 Plan d'un essai sur le sentiment de la nature.

1..$^{\circ}$ Quelques matériaux pour un traité des monumens.

12. Plan d'un ouvrage dans le genre du Spectateur.

13. Plan de conversations sur divers sujets morsux.

14. Traduction des Méditations sur le bonheur; ouvrage italien du comte Verri : Meditazioni sulla felicita. Si l'on est curicux de voir cette question traitée sous différens rapports, on comparera cet ouvrage avec les Réflexions de Fontenelle sur le même sujet, et avec l'Essai sur le bonleur, par Fergusson. (Histoire de la société civile.) On en trouve dans le Mercure de France, juin 1774, page 190, une traduction dont l'auteur est une femine aussi respectable par ses rares vertus qu'elle est recommandable par l'étendue de son savoir. Sa modestie me feroit un crime de la noinmer.

15. M. Watelet avoit formé le projet de répandre l'instruction parmi le peuple des villes et des campagnes : il aroit comulencé 12 rédaction de divers écrits intitulés Feuilles morales, Feuilles citadines, Feuilles paysanues on campaguardes.

16. Notes sur plusieurs voyages en Allemagne, en Hollande, en Italic et sur l'ile de Caprée.

Plusicurs de ces manuscrits nnt été remis à M. Dusaulx,

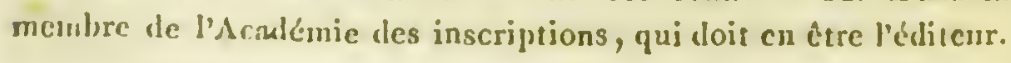


les mouvemens. Cette surveillance s'appliqua successivement à toutes ses passions, dont il redoutoit les transports, et auxquelles il sembloit qu'il craignît de s'abandonner. Il s'étoit interdit tout projet de fortune, d'annition et de gloire; aussi ne chercha-t-il daus l'étude que des plaisirs et nou des succès. Son amour-propre n'offensa jamais celui desautres; il ne troubla l'amitié par ancun sentiment inquiet. On aimoit ì s'eutretenir avec lui, parce qu'il savoit écouter, et sur-tout parce qu'en répandant un grand intérêt il ne songeoit point à s'emparer des suffrages. Ses observations ne déplaisoient point, parce qu'il étoit indulgent et juste; tonjours calme, jamais indifférent, quoiqu'il eût l'air de s'oublier lui-même, sou plus grand bonhenr étoit de croire que ses anis ne l'oublieroient jamais; et ce caractère n'étoit point un masque dont il se courrìt. M. Watelet étoit le unème clans tous les lienx et ponr tous les hommes. Plus on le voyoit, plus on sentoit le prix de cette longue habitude de se vaincre, qui nuèue infailliblement à la vertu; de cette constance dans les goûts, de cette simplicité daus les unœurs qu'expriment si bien les vers suivans, où il s'est peint lui-ınême, et par lesquels je terminerai cet éloge :

Consacrer dans l'obscurité

Ses loisirs à l'étude, d̀ l'amitié sa rie :

Voila les jours dignes d'envie.

Être clıéri vaut mieux qu'ètre ranıé (1).

(1) Essai sur les jardins, page $15 \mathrm{r}$. 


\section{VERGENNES.}

Cimaries Gravier de Vergennins, ministre et secrétaire d'état au département des affaires étrangères, commandeur des ordres du roi, chef du conseil royal des finances, conseiller d'état d'épée, associé libre de la Société royale de médecine, naquit le 28 décembre 1719, à Dijon, de Charles Gravier de Vergennes, maittre des comptes de Bourgogne, et de Charlotte Chevignard de Charodon, fille de Jean Chevignard, premier président du bureau des finances de la même ville.

La famille de Vergennes est divisée en plusieurs branches établies dans le Berri, dans le Poitou, dans l'Agénois et dans le Charollois : celle-ci, dont M. de Vergennes est issu, fut loug-temps agitée par les guerres de religion, fléan dónt le souvenir effraie encore les descendans de coux qu'il a frappés, et qu'une loi de clémence et de justice a enfun éloigné pour toujours des habitans de ces climats.

Lorsque la Société royale de nédecine fut établie, elle dut, conformément aux vues de son institution, se ménager des correspondances nunltipliées avee les divers colléges et acadénies et avec les nuédecins les plus célihres des pays étrangers. La confiance dont M. de Vergennes jonissoit dans tontes les conrs nous 


\section{VERGENNES.}

fournit de grandes facilités pour exécuter ce projet; et ses services furent ses titres auprès de nous.

Jusqu'ici la reconnoissance a tout fait, et celui qui en est l'organe rempliroit un ministère facile et doux, s'il pouvoit se borner à ces premiers épanchemens de son cœinr.

Mais les devoirs d'une grande place ont fixé sur M. de Vergennes les regards des nations; ses conscils out influé, je ne dirai pas sur le sort de l'Enrope, jo dirai sur celui des deux moudes. C'est par eux que s'est allumé, que s'est éteint le flambean de lil gulerre; que des penples puissans out réglé les intérêts de leur commerce et de leur gloire : les détails de sa vie sont liés aux érénemens de deux règnes, et il finıt que co tablean soil trácé dans mon disconrs.

Le ministre anquel cet éloge est consacré montra-t-il autant de lnmières et d'énergie dans ses plans qu'il nuit de prudence dans sa conduite, de convenance et d'accord dans ses moyens? Il ne n1'appartient point, il ı'appartient peut-ètre à personne, d'agiter aujonrd'hui (1) cette question. M. de Vergemnes n'est plis; mais ses projets subsistent : le voile de la politique les couvre; l'adnlation et l'envie le poursuivent encore dans la tombe; et dans ce jonr que riens-je offrir? si ce n'est le dernier tribut de l'humanité; tribut de louanges que les morts illustres reçoirent de lenrs panégyristes, en attendant que lenr jugement soit prononcé dans l'histoire.

(1) 12 férrier 1798 . 


\section{ELOGES HISTORIQUES.}

M. de Vergennes fut porté vers la carrière diplomatique par l'exemple du comte de Cliavigny, son oncle maternel. Il avoit ì peine vingt-un ans lorsqu'il accompagna cet oncle dans son ambassade à Lisbonne (1).

Un petit état dont le sol est fertile, dont l'Océan baigne les rivages, dont la position, les bornes et les besoins semblent appeler la constitution républicaine, cet état obéit, depuis le règne du premier des Alphonses (2), à un pouroir absolu. Ce fut là que M. de Vergennes fit ses premières études dans l'art de gouverner les liommes.

Depuis long-temps le Portugal étoit en paix; les Anglais bombardoient Carthagène; ils aroient attaqué la Floride (3); la France s'étoit jointe à l'Espagne pour les repousser, et la cour de Lisbonne se contentoit de former des vœıx pour le succès de celle de Londres.

Bientôt on vit changer la scène; l'empereur Clıarles VI mourut: l'Allemagne, la France, l'Espagne et l'Italie s'armèrent, soit pour décliirer ses états, soit

(1) Ce fut eu janvier 17 \{0 que M. de Chavigny emmena M. de Vergennes avec lui dans son ambassade de Lisbonne : il y demeura jusqu'au mois de mai ${ }^{2} 743$, époque à laquelle M. le Chariginy fut nummé ambassadeur près de l'empereur Charles VII, qui sourut en janvier 1745 .

En 1746 il retourma i Lisbonne, où il resta jusqu'en 17 \$6.

(2) Abrégé chronologique de l'histoire d'Espngue et de Portugal; Paris, 1765 ; som. I, pag. 24 1 et suiv.

(3) Ibid., tom. II, pag. 648,49 ct 50 . 


\section{VERGENNES.}

pour lui nommer un successenr. Louis XV joignit ses furces ì celles des rois de Pologne et de Prusse, et avec leur appui l'électen' de Bavière fut élu. II importoit à la France d'avoir un ministre liabile pres du nouvel eniperenr: le comte de Chavigiry ent ordie de s'y rendre, et $M$. de Tergemes l'y snivit.

Ce ri'est pas senlement it lit conr des rois puissans, c'est sur-tont prés des rois mallienrenx queles ambissadeurs tronvent de grandes instructions it recueillir. Charles V1I, prócipité da faite de la graudeur, dont it u'il joui qu'un monent, chassécle ses états, et portant de ville en ville avec son infortune le vain titre dont il étuit revêtu; deux ligntes formées, l'une ì WVorms, l'autre ì Francfort; me multitude d'écrirans anx gagers des électenrs, finsant valoir lenrs prétentions opposées; et, parnir ces troubles, l'héritieve dn dernier des princes de la maison d'Autriche, Marie-T'hérèse, que l'on avoit mal-à-propos jugée sans ressources lorsquielle avoit celle de sa grande ane et de sun conrage, conmençant par triomplier du plus redontable de ses emenis, du malhenr, dont elle ne se laissa point abattre; fière de cette première victoire, parlaut au nom de son fils, de sa fille, de l'enfint qu'elle porte en son sein; émue par tant d'affections, éloquente par tant de motifs, et prononçant an milieu des Palatins, transportés d'admiration et d'amonr, le famenx serment d'André II : quel spectacle! et qui ne roit pas que le succès ne pouvoit ètre douteux entre des a rmées étrangères à cette querelle, et des citoyens qui rengeoient lirijure de leurs rois, en combattant pour la patrie? 
Les forces des alliés contre la maison d'Autriche s'affoiblirent en effet; la guerre fut portée du Daunbo au Rhin, et la France trembla pour elle-même: Alors Charles VII abandonné succombe; il meurt, et une pompe imposante l'environne; son cortége se grossit de ses ennemis en deuil : lorsqu'il n'est plus, tous se rangent sous ses drapeaux, et c'est seulement à ses funérailles que Charles-Albert est empereur. Le comte de Chavigny et $\mathbf{M}$. de Vergennes témoins, et, pour ainsi dire, compagnons de ses désastres, n'aroient cessé, pendant ce que l'on appelle son règne, qui ne fut qu'un tissu de misères, de lui prodiguer des consolations de toute espèce ; ils lui rendirent les derniers devoirs, et ils sortirent de Munich le cœur déchiré par le tableau de ces grandes injustices que les nations commettent saus frein, comme sans remords et sans pudellr.

Ils retounnèrent, suivant lenr destination, à Lisbonne. Les Anglais continuoient d'attaquer en Amérique les possessions de l'Espagne, et le roi de Portugal avoit résolu de faire payer chèrement solı inaction : il réclamoit, conformément an traitó d'Utrecht, le libre usage de la colonie dı SaintSacrement (1), à laquelle l'Espague avoit opposé le fort de Montevideo (2), pour empècher, en lis blo-

(1) Ia colonic du Saint-Sacrenent avoit été fondée en 168o sur les bords de la rividre de la Platio.

(2) Abrégé chrounologique de l'histoire d'Espague et ile Portugant, pors. 11, jag. 656. 
quant, le commerce interlope dont elle étoit le foyer. A force d'écrire sur cette afficire, on l'aroit cmbrouillée, ct la cour de France, choisie pour médiatrice, n'osoit prononcer sur un différent dont les circonstances ne lui étoient pas assez commes. M. de Vergennes la tira de son incertitude par 111 mémoire (1) de quelques pages, où la question ćtoit rancurée ì ses premiers élénens. Le marq̨uis d'Argenson, alors ninistre des aflaires étrangères, conçut beancoup d'estime ponr l'auterr de cet écrit, oì il apprit qu'il s'agissoit, conme il arrive si sonvent, de ce dont on ne parloit point, et qu'il ne s'ingissoit pas de ce dont on partuit (2).

Ce fut en 1749 que le conte de Clatrigny reviut de Lisbome. "Le jente négociateur que j’ai formé, " dit-il au roi, n'it plus besoin de mes secours, et » j'anrois besoin des siens pour continuer il servir 》) votre inijesté : il est temps que je finisse et qu'il 》 commence ». M. de Vergelures firt anssitut nommó ministre résident près de l'élerteur de Trèves.

Les ambassadenrs ordinaires our résidens sont d'uno institution très-moderue; ce qui montre, dit Grotius (3), qu'ils sont pen nécessaires. M. de Vergennes, dans les papiers duquel on a trouvé des réflexions

(1) Ce mémoire est daté du 30 mars $17 f 6$.

(a) De noureaux mẻmoires enroyes a 1 . de Puisieux, successeus du marquis d'Argenson dans le deipartement des allaires étrangères, sur le traité de commerce que l'on desiroit alors de conclure avec le Portugal, achevèrent de faire connoitre les talens du chevalier de Vergennes.

(3) I_c Droit de la guerre et de la paix, par H. Grotius, nourel!e trad. par J. Barbeyrac, in $-\left\{0^{\circ}, 1729\right.$, lir. II, ch. srir, p. 17. 
sur ce sujet, étoit d'un avis opposé à celui de Grotius. Il pensoit, comme les publicistes de l'Allemagne, avec lespuels il avoit plısieurs fois traité cette question inportante, que les anciens étoient à cet égard surpassés par les modernes, et que c'étoit le régime des nations" qui seul avoit long-temps repoussé cet établissement ntile. Quelles fonctions, en effet, de tels ministres auroient-ils puremplir près de ces peuples conquérans qui traitoient de rebelles tous cenx qu'ils n'avoient point asservis? Qu'auroient-ils fuit lorsque Mahomet propageoit par le fer sa religion guerrière? Quels services auroient-ils pu rendre lorsque sept tyrans opprimoient l'Angleterre, et que des corsaires danois faisoient trembler ces sept tyraus? lorsque les conronnes s'accumuloient sur la tète de Cliarlemagne, avide de gloire et de combats? lorsque les homunes du Nord fondoient sur les nations plutôt pour les dépouiller que pour les vaincre? lorsque tous les états de l'Europe s'épuisoient pour faire en Asie de climériques conquêtes, ou lorsque l'esprit de clievalerie peuploit le monde de braves tonjours prêts à s'attaquer, et qui ne négocioient jamais?

$\Lambda$ près tant de secousses, les nations, plus calınes, se sout reposées sur lenrs bases : plus éclairées, elles ont réfléchi sur leurs prétentions; les foibles out trouvé des protecteurs: les gnerres ne sont plus ni les entreprises d'un penple andacienx sur la proprićté de tous les peuples, ui des fléaux prorluits par lirruption des harbares; elles résultent dn choc des intérêts : le sort des anmes, an délant de tribmal, juge les querelles 


\section{VERGENTES.}

des rois; affoiblies on fortifiées, les puissances se cunbinent d'une manière nouvelle, et le repos succids aux combats. C'étoit à ce seul systènc que les ministres résidens pouvoient appartenir; et c'est sur la perlicition qu'il recerra de li main du temps qu'est fondíe l'espérance de voir 1 jonr les guerres devenir plus rares, et les hommes pent-être moins mallienremx lorsqu'ils seront plus tranquilles.

La paix d'Aix-la-Chapelle aroit terminé la guerre saus avoir mis fru ì l'animosité qui subsistoit depuis tant d'années entre les cours de Vienne et de Versailles. L'archiduc Joseph étoit ì peine sorti du hercean lorsque l'impératrice-reine manifesta le projet de le firire élire roi des Romains. L'Angleterre sontenoit ces prétentions; et Lonis XV, d'accord aree le roi de l'russe, sans avoir résolu d'y unettre nne opposition constante, avoit quelques raisons pontr refuser alors d'y consentir. Fatignés de la gucre, ils craignoient de la ralluner, et tont le soin de cette affare fut remis anx neggociateurs. Il ne manquoit à la conr de Vienne que la voix de l'électeur de Trèves, qui étoit prèt à la donner lorsque M. de Vergenues arriva. Bientùt ce prince rompit, par son indécision, les mesures appuyées sur l'espoir de sou suffirage.

L'Angleterre, intéresséc à perpétuer la couronne impériale dans une maison qui devoit tant à ses armes, fit de nonveanx efforts pour la servir. Le duc de Newcastle proposa à Georges II (1) d'assembler à

(1) Georges II rint is Hanorre en ${ }_{17} 53$. 
Hanovre les ministres de tous les électeurs. M. de Vergennes, nonmé plénipotentiaire à ce congrès (1), s'y conduisit avec tant d'adresse, qu'il sut le rendre inutile aux vues pour lesquelles on l'avoit formé. Il fit intervenir plusieurs de ces questions embarrassées d'où naissent des discussions interminables : on parla beaucoup; on n'arrêta rien; et le roi d'Angleterre, ennuyé de ces débats, quitta brusquemeut Hanovre. Dans cette gnerre politique, non seulement M. de Vergennes demeura maître du champ de bataille, mais encore il reçut les félicitations du roi de Prusse et celles du duc de Newcastle lui-même, qui fut assez généreux pour en écrire à $M$. de Saint-Contest : « Tant » de capacité; dit-il, doit mériter à M. de Vergennes "la bienveillance du roi. »

Georges II eut un moment le projet d'assembler de nonveau ce congrès à Londres. Le roi de Prusse, craignant alors que M. de Vreden (2), abandonné à lui-même, ne fût subjugné par lo ministre anglais : "Le duc de Newcastle, écrivit-il à milord Maréchal, » se flatte d'avoir bon marché de M. de Wreden à "Londres; il n'y seroit plus, ajoutoit-il, sons l'in") fluence d'un ministre aussi vigilant et aussi ferme " qu'à Hanovre \#. Ce n'est pas seulement à la mémoire de $M$. de Vergennes qu'il importe de recueillir ces paroles. Le panégyriste s'appuie sur de tels témoi-

(1) Il est connu sous le nom de Congrds de Manoure.

(a) Ministre de l'ćlecteur palatin. 


\section{VERGENNES.}

gnages; et un éloge avoué par Frédéric a des droits à la confiance de la postérité.

Mais le duc de Newcastle s'étoit vanté (1) qu'il feroit un roi des homains: il essaya de gagner l'électeur palatin; ct déja le ministre et le prince lui-mêtne s'étoient rendus à une négociation secrète lorsque M. de Vergennes en déconvrit la trame. L'aillance projetée (2) n'eut point lieu, et M. de VVreden reçut ordre de justifier sa conduite près la cour de Versailles.

Cette continuité de succès étnit un beau début dans la carrière; car repousser la ruse, c'est prudence et sagacité; persévérer unalgré de grands obstacles, c'est constance; rompre des résolutious déja prises c’est habileté; mais forcer à eu prendre de contraires, c'est le chef-d'œurre de l'art et le comble du talent.

M. de Vergennes devoit résider près de l'électeur palatin; mais le marquis de Tilly demenra plénipotentiaire de la cour de France à Manheim, et M. de Vergennes fut réservé pour de plus grandes choses.

M. Dessaleurs, ambassadeur de France à la Porte, mourut subitement en 1754 , et M. de Vergennes lui succéda. Osman venoit de monter surr le trône ottoman (3) vacant par la mort de Mahamout(4). Ce prince,

(1) Dans une des séances du parlement d'Angleterre.

(2) Ce traité de la cour de Vienne arec l'èlecteur palatin fut sur le point d'être signé en 1753 .

(3) Mémoires de Ml. le baron de Tott, prem. part., p. 7f et 75 .

(4) Joumal historique, ou Fastes du règne de Louis XV, surnammé le bien-ainé, in-8. ${ }^{\circ}$, II. ${ }^{\circ}$ partie, pag. 97. Paris, ${ }^{1} 766$. 
sorti des prisons du sérail pour régnel sur un grand empire, peu éclajué sur ses intérêts et sur ceux de ses alliés, punvoit se laisser prévenir par l'Angleterre. M. de Vergennes ent oldre de partir sans délai ( 1 ). Des vents contraires ayant retardé son entrée daus le détroit des Dardanelles, il ne mouilla que le vingt-unième jour de mars 1755 dans le port de Constantinople. Transporté des rives de la Moselle et du Rhin au Bospliore de Thrace, il y tronva d'autres mœurs et d'antres lois : là, tout souvenir de ce qui fut grand est effacé. Dans les murs de l'ancienne Bysance (2) repose un sultan; plus loin règne un visir; et les ruines seules disent an voyageur quels furent autrefois les habitans de ces climats.

Les mémoires de M. le baron de Tott, qui accompagna M. de Vergennes dans ce voyage, contiennent des détails curieux sur lenr arrivée et sır le cérémoujal de Ieur réception. Il faut y lire quel fut l'étonuement des seigneurs turcs (3) lorsqu'ils vireut les ambassarleurs danser dans une fête à laquelle M. de Vergenues les aroit invités; il faut y lire comment, lorsyu'il se rendit pour la première fois à l'andience dn visir,

(1) M. de Vergeunes partil pour Constantinople au commencement de l'année 1755 , ì la hàte, sur un bâtiusent marchand; il n'avoit d'autre qualiti que celle de ministre plenipotentiaire, qui ue: comporte ancune: spèce de cérémnnial : cependant on lui rendit les houncurs en usage pour les ambassauleurs.

(2) Ce sont les murs do: l'ancicnue bysance qui serrent aujourd'hni d'enceinuc au scirail du nrand-scignent.

(3) Mlimoires de $\mathrm{M}$. Ie biron de Tolt, 1." partic, pag. 3. If et 15 . 
le grand-seigneur, déguisé en homme de loi (1), suivit par-tout le cortége pour jour de ce spectaçle an milieu dı peuple, que la présence de sa hantesse glacoit d'effroi.

M. de Vergennes passa quatorze amićes à Constantinople, où il vit de grandes révolntions se succéder. La tête du visir Sélicktar (2) tomba sons la lıachı dn bonreau; peu s'en fallnt qu'elle ne tombit sons le sabre d'Osman lui-nè̀ne: la ville de Constantinople fint dévastée par des incendies; la cherté dı pain (3) excita le mécontentenent du penple, indigné des excès d'un monopole armé : pàle de frin et de colìre, nne fenme fit trembler le plus absolu des sultans. La peste snivit la disetre et la révolte, fléanx tonjours prèts à naitre l'un de l'antre en ce pays (f). Osmran nuonut an retonr de la mosquée (5), où, malgré sa maladie, le préjugé, plus fort que le despote, l'avoit conıluit. Mustapha, fils ainé d'Aclunet, ceignit le salore (6) impérial, et anssitòt il numltiplia des vexalions dont des lois somptuaires (7) furent le prétexle. Cependant la caravane de la Mecque fut taillée en pièces; le

(1) MÍmoires de M. le baron de Tott, I. ${ }^{\mathrm{re}}$ part., pag. 26 et 27.

(2) Aranı que d'èıre visir, il aroil èté sélickıır-pacha. (IIém. de MI. le birron de Tott, I. ${ }^{\text {re }}$ parr., pag. 29.)

(3) Ibid., pag. 37 el 38.

(4) A Constantinople on cile presque tonjours pour époque celle d'une pesle, d'une famine, d'une rébellion ou d'un incendie.

(5) Mlémoires de II. le baron de Turt, I. ${ }^{\mathrm{re}}$ part., p. 125 el 126.

(6) Ibid., p. 230.

(7) Ibid., p. 1 \{̧. 
vaisseau amiral, qui portoit l'inviucible pavillon du prophète (1), fut pris et conduit à Malte, et la consternation devint universelle. Comme celui qui peut tout doit aussi répondre de tout, on murmura contre le diran. M. de V'ergennes employa le crédit du roi pour faire acheter à Malte le vaisseau si désiré de Mustapha, et qui lui fut bientôt rendu; tous bénirent le ministre de France. Ce peuple aveugle lui sut plus de gré de ce léger bienfait, que s'il lui en̂t épargné des guerres sanglantes, ou que s'il lui eút onvert les yeux sur une religion insensée, qui rend les hommes féroces en ne cessant d'exciter leur courage, sans leur permettre de cultiver leur raison.

Une senle fois $M$. de Vergennes vit la Porte occupée d'un projet utile et grand. Il s'agissoit de couper l'Asie mineure par un canal navigable (2); M. de Vergennes engagea $M$. de Tott et tous les Français qui avoient des connoissances en ce genre à seconder les efforts des Turcs, qui, faute d'instruction, demeurèrent sans succès.

Pendant tout le reste de l'ambassade la nation languit dans cet état d'ignorance (3) et d'abandon qui

(1) Mémoires de M. le baron de Tot:, I. ${ }^{\text {re }}$ part. pag. 1/2, 145 et 1 . 6 .

(2) Il falloit, pour remplir ces vucs, réunir le fleure Zacaric à la ville d'Isuic, qui est l'ancienne Nicere, on se scrvant d'un lac situe à moitit clicuin, dont les canx auroient servi à la dépense des écluses, et qui cst rentpli par plusicars rividres. On trourc un projet semblable dans Pline.

(3) Il n'y a que pru d'années que l'on a ru des vaisscaur 
dure depuis si long-temps : toujours faisant ce qu'ello a déja fait; oubliant le passé, que u'ose recueillir l'histoire; ne pouvant jonir dn présent, dont le despote est le maître; ui disposer de l'avenir, qui appartient an destin.

Toutefois ne plaignons pas le ministre dont nous écrivons l'éloge. Destiné à gouverner un grand état, sous les ordres d'mu souverain qui se plait ì communiquer avec ses peuples, ses yeux n'auront point été frappés en vain des abus dı despotisme; c’est an moins ce qu'exigerout de lui cenx qui anront à en parler dans l'histoire.

M. de Vergemes n'étoit que plénipotentiaire de la cour de France lorsqu'il fut envoyé à Constantinople : il y reçut, pen de tems après son arrivée, le titro d'ambassadenr; ct l'on s'y sonvient encore que le sultan ronlut bien, lorsqu'il l'adnit à son andience, déroger à l'nsage en lni adressant directement sa réponse (1), qu'en parcil cas le visir est toujonrs chargé de transmettre.

Alors la guerre embrasoit l'Europe. Des côtes de la Grande-Bretagne jusqu'it celles du Canada, les corsaires anglais infestoient les mers. Cependant l'Archi-

russes derant Constantinople. Jusque - là les Turcs aroient pensé qu'il n'y aroit point de comnumication entre la Battique et l'Ar. chipel. La navigation des raisseaux danois et sućdois ne les aroit point désabusés; ct le diran persistoit dans cette erreur lorsqu'à l'époque de l'invasion de la Morée l'on aperçut dans le dérroit des Dardanelles douze raisseaux de ligne russes.

(1) Mémoires de II. le baron de Totr, I. pre part, pag. 29. 
pel jonissoit d'une paix profonde, et les raisseanx fiancais trouvoient dans les ports dn grand-seignenr une sûreté qui leur étoit refusée dans cenx des pareus et des alliés dı roi.

Le traité de 1756 , par lequel les maisons de Bourbon et d'Antriche contractèrent une alliance solennelle, et l'accession de la Russie à ce traité, avoient étonné toutes les cours : celles d'Angleterre et de Prusse r'eurent pas de peine à rendre cette alliance suspecte ¿ la Porte. M. de Vergennes détruisit ces impressions, et la neutralité de la Turquie ne se démentit point pendaut toute cette guerre, malgré les pressantes sollicitations qu'elle reçut pour agir contre les deux impératrices.

Ja paix de 1767 avoit à peine mis fin à ces trouthes qu'il s'en éleva de nouveaux. La Pologne perdit Auguste III, son sourerain. La cour de Vienne se déclara pour la maison de Saxe; mais l'impératrice de Riıssie, secondée par le roi de Prusse, fit élire le conıle Ponialouski, dont la reconnoissance ne put se refiser à des sacrifices, qui armic̀rent contre ce prince une partic de la nation. Les catholiques et les grecs, divisés (1), recherclièent, les nus, la proteclion de la diète, les antres, celle de la llussie, qui, sous prétexte de suivre 111 zile religieux, fit cutrer de nouvelles trompes en Pologne. Déchiré par ses propres mains, opprimć et presque euvalii par les liusses, cétoit,

(1) IJistoirc dr Mussic, par M. Léréque, tome V, pag. 116 तi 117 . Paris, 1782. 
sous le nom de Stanislas Auguste, à Catherine que cet état obéissoit. Les puissances du Nord formoient une ligne redontable contre celles dn Midi, et l'Europe étoit menacée d'une guerre générale. Le duc de Choisenl, habile it trouver daus ces sortes d'occasions des expédiens qui auroient échâppé à bien d'autres, proposa, pour détoumer l'orage, de faire intervenir les'Turcs an milieu de ces tronbles, et $\mathbf{M}$. de Vergennes ent ordre de mettre tont en cenve pour les sonlever. Il leur rappela que la Porte étoit intéressée d̀ enpècher le démembrement de la Pologne, dont elle avoit garanti l'intégrité à la république; il représenta que les Russes avoient poursuivi jusque sur les terres de sa hautesse des confédérés polonois qui s'y étoient réfingiés (2). La prise de Balta sur les frontières de la Crimée lui fournit un argument anquel la Porte, jusqu'alors indécise, ne put résister. La rupture fit éclatante. Le ministre de Russie fut, suivant l'usage, renfermé au cliatenu des Sept-Tours ( 2 ). Krin-Guéray fiut replacé sur le trône des Tartares, et MI. de Vergennes vit domer des ordres, soit pour rassembler ces nonubrenses armées qui ont été dispersées on détruites sur les bords du Pruth et près du Largo (3), soit pour équiper ces flottes (4) que le feu des Russes a consumées dans l'Archipel. Mais il aroit fallu du

(1) Histoire de Russie, par M. Lévèque, lone $V, p .119$.

(2) Iémoires de MI. le baron de Tolt, II.e part., p. 1;0 el 171.

(3) Histoire de Russie, par MI. Lérèque, tom. I; p. 123.

(i) Ibid., tum. $T$, pag. 120, 128 et 1 "̈o. 
temps pour déterminer la Porte à cette guerre; peutêtre aussi M. de Vergennes n'usa-t-il pas de toute la diligence possible dans l'exécution d'un projet dont sa correspondance montre assez qu'il n'approuvoit pas les dispositions. La cour de France l'accusa de lenteur et le rappela (1). « Voilà le pendaurt de la journée d'As» teinbeck », dit le duc de Choisenl lorsqu'il apprit qu'arant le départ de $M$. de Vergennes les Turcs avoient résolu d'armer.

Le résultat de cette négociation étoit d'autant plus remarquable, qu'elle n'avoit rien coûté à la France. M. de Vergenmes laissa ses juges convaincus de l'intégrité de sa conduite, et il partit pour la Bourgogne.

'Tranquille en sa retraite tandis que des bords du Danube jusqu'au mont Caucase l'esclavage et la mort frappoient des milliers de victimes, il goùtoit le bonheur de revoir l'habitation de ses pères; il y retrouvoit, tels qu'ils sont dans la nature, le repos du soir et l'activité du matin; et les souvenir's de tant d'orages

(1) Il revint de Constantinople à Paris vers la fin de 1769.

Parmi les témoignages d'attachement et d'estime que Mr. de Vergennes reçut pendant son séjonr it Constantinople, je n'oublierai point ceux de la nation française, dont il avoit protégé le commerce. Elle clargea ses députés de lui offrir une épée d'or où sont gravés les principanx événemens de son ambassade, cul le suppliant de ne pas refuser ( je conserve ici leurs expressions) ce tribut de reconnoissunce et d'annour. (Extrait d'une lettre écrite le 16 janvier 1769 .)

Les négocians frunģais résidant à Constantinople avoient arrẻté, par une clélibération, que, pour tímoigner leur recomnoissance d M. de Vergennes, son portrait scroit placé dans la clambre du commerce : ce qui a été cxćcuté. 
étoient adoucis par les tableaux de la vie champêtie, dont il regretta toujours de n'aroir pas joui plus long-temps. Bientot il fallut rentrer dans lit carrière; le roi le nomma son ambassadeur en Suède (1).

Des états d'Allemagne oì ume assembléc famense prononce sur les questions qui peuvent intéresser l'Empire, où rarement on fait la grerre sans qu'on se soit efforcé, dans de savans némoires, d'en justifier tous les motifs, M. de Vergenues avoit passé chez les Turcs, où l'on n'écrit point, oǹ l'on ne sait quı'obéur'; et il alloit être, daus le Nord, le témoin et le coopérateur d'une révolution dont le succès u'a peut-être point d'exemple dans l'histoire. Les Suédois sont, de tons les peuples septentrionaux, cenx qui ont versé le plus de sang pour le maintien de leur liberté, et ani out consacré le plus de veilles an progrès de leur raison. Depuis le règne de Magnus Sméek (2) jusqu'à celui de Cluristien II (3), leur histoire n'offire qu'une suite de combats entre la nation et ses tyrans (4). Gustave Vasa (5) transmit la couromne dे sa fimille; Charles XII epuisa le royamme, dont il fit le malheur et la gloire; et

(1) En 1771 M. le duc de la Vrillière étant par interim chargé du département des affaires étrangères, 11. de Vergennes ful noınmé amljassadeur en Suède.

(2) En 13330 .

(3) En 1520.

(4) Histoire des rérolutions de Suède, Paris, ${ }^{1222}$, par l'abbé de Vertot, tom. I.er, pag. ig et 20; et Abrégé chronologique de l'Histoire de Suède, pag. 306 et 307 : à la suite du second volume de l'Histoire des rérolutions.

(5) En 1523. 
comme il ne laissa point d'héritiers directs, le penple reconva le droit d'élire ses sonverains; unais il en abusa trop, pour le conserver long-temps (1). Les priviléges du trône furent usurpés par le sénat. Alplionse Frédéric étoit trop foible pour les réclamer; il mourut (2) tandis que le prince royal étoit en France, on il trouvoit des secours et des conseils. La réserve du nonvean roi enlardit les opposans; ses anois furent exchus du sénat; l'ou n'admit au conseil que les partisans des conrs de Londres et de Pétersbonrg: le ministre de France dissimula, parce qu'il n'étoit pas temps d'éclater; les nobles, dont le parti succomboit, s'attachèrent à celui de la cour, qui laissa les troubles s'accroître, leur excès pouvant seul eu amener la réforme. Les princes Charles et Frédéric parcouroient les provinces (3), où ils disposoient favorablement les esprits; une révolte feinte leur foumit le prétexte de rassembler une armée: l'on s'aperçnt qu'en se croyant libre on n'embrassoit qu'un fantôme; tont étoit prèt, ct le jour fut marqué (4). M. de Vergennes tonchoit ‘u moment où l'ou devoit enfin cesser d'insulter it son pouvoir. Alors un secret impénétrable enveloppe

(1) Deux factions divisoient la Suide. La première, soudoyic par la Hussic et l'Angleserre, avoit pris le nou de lionnets; lat secoude, fuvorisée par la France, et composće de l'élise de la noblesse, étoit connue sous le nom de Chapeaux.

(2) Jin févier 1771.

(3) Sur-tont celles de Scauie et d'Ostrugothic.

(1) Ce fut au mois de unai $177^{2}$ que le plan de la rérolutiun fiut trac: $c$. 
toutes les mesures. Gustave harangue ses gardes, dont la fidélité lui répond de celle de ses soldats. Le palais est entonré; des canons que l'on n'a point chargés menacent l'assemblée des états; les sénateurs sont retemus dans la chambre dı conseil; Rudbeck, général des opposans, est mis anx arrèts; toute conmunication de lis ville avec l'extérieur est inter rompue; on répand que des troupes rappelées de la Finlande sont anx portes de Stockholm; les factienx tremblent, le peuple espère, le roi s'ivance. Il guittera le sceptre si le vœu public ne répond point à son zèle : tons le smpplient de ne pas les abandonner; il reproche aux états lenrs divisions et lenr vénalité, leurs injustices; et la multitude s'indigne arec lui : je ne venx itte, ajonte-t-il ane le chef d'nn penple lihe : on applandit avec transport; il lit les articles d’une législation nonvelle; on les accpte; il pronorce mis serment solenurl, il est interrompu pas des acclamations; il onve un livre saint, et il rend graices an ciel, en lui adressant une liymne que, toutes les roix répétent et qui retentit dans tous les cœurs. Pas nue gontte de sang n'a souillé son triomphe; il rentre sans qn'ancun des nembres de la nombreuse famille qui se presse smi ses pas ait des plenrs it verser, et tous les citoyens sont derenus ses sıjets sans aroir perdu leur énergie, parce cy'en se dommant enx-mèmes ils n'ont cédé qưà l'ascendant dı courage, de l'éloquence et de la raison (1).

(1) An History of llie late revolution in Sweden : containing an accoum of the transactions of the three last Diets in that T. 2. 
Qnelle part M. de Vergennes cut-il à l'exécution de cette entreprise ( 1 )? Je ne sais : mais l'auroit-on rappelé de la Bonrgogne, oit sa santé, chancelante encore, avoit besoin d'un plus long repos, si l'on n'avoit attendu de lini des services? Se pourroit-il que le mimistre de France n'eût point influć sur un projet dont le résnltat devoit être d'affranchir l'allié de cette cour des obstacles que lui opposoient sans cesse l'Angleterre et la Russie? Et si, comme quelques-mns l'ont

Country; preceded by a short abstract of the swedish history, so far as was necessary to lay open the true causes of that re. narkable event; by Charles Francis Sheridan, esq; of Lincoln'sinn, and secretary to the british envoy in Sweden, at the tine of the late revolution. The second edition. London, 1783.

En tête de ce volume se tronve une introduction où l'auteur traite d'une manière très-philosophique des divers gouvernemens, de la manière dont ils se perfectioment et dont ils diggénèrent. C'est principalement dans la cinquième section de cet ouvrage que j'ai trouvé l'histoire de cette rérolution.

Section V: "Containing an account of the revolution, and of the Siep which immediately led to it ", pag. 247 .

On lit aussi dans tes Aunales belgiques une notice de la dernière rérolution de Suède.

(x) Je rapporte ici le senl passagge oir IJ. Sheridan paile de M. de Vergennes.

"Sthortly after the king's arrival at Stockluolm, the court of Fraare, which lad lutely only ministers of the second order in Sivrden, now sent an ambassidor thither, whicls was a sulficient proot of the inportance of the commission with which he was charged.

"2I. de Vergennes who just before had been nmluassador at Constantinople, a worty and respectable nan. He is now minister

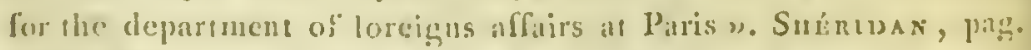
4ho at 261. 
dit, ce succès lui fint tout-à-fait étranger, ponrquoi Lonis et Gustave récompensèrent-ils son zèle, l'un par un brevet de conseillel d'état d'épée, l'autre par un présent (1), accompagıé d'me lettre où la jonrnée du dix-nenf (2) est citée avec honnenr?

Au reste, dins cette circonstance, l'anonr-propre de M. de Vergennes ne tralnit point son secret; il demenra jusqu'en 1774 en Sucide, d'où, fittigné par diverses indispositions (3), il sollicitoit son rappel, lorsqu'il apprit sa nomination d la place de muinistre des affaires étrangères (4).

Ontre le monvenent général qui entraine les corps politiques vers la perfection pour les précipiter ensuito vers la décadence, leur durće se conpose d'un certain

(1) Le roi de Sucde fit préseut ì M. de Vergenues d'un diımaut inouté en bague, sut laquelle est inscrite l'époque de la rivolution. Pen de temps après le roi lui douna son portrail en buste.

On sait que M. de Vergenues fournit, au nom de la France, des secours qqui lutiteut la révolution.

Différentes lettres prourent qu'il a rendu des services au parti du roi; mais les expressions de ces lettres sout générales, et u’apprement rieu de précis à ce sujet.

(2) Ce fut le 19 aodt $177^{2}$ que se fit la rérolution.

(3) Alors la santé de M. de Vergennes s'affoillissoil : il demandoit son rappel, et il boruoit tons ses désirs à obtenir un jour l'ambassade de Suisse, qu'il regardoit comme devant ètre le terme de ses traraux.

(f) Il fut nonuné ministre des affaires étrangères le 12 juin 177.

Ce dhoix, qu'il n'avoit ni sollicité, ni préru, ne l'étonna pas moins que cсих qui en apprireut en mème temps la noureile. 
nombre de périodes, pendant lesquelles, suivant la destinće de leurs chefs, ils renaissent, se fortifient avec eux, et vicillissent pour rajeunir encore. Ainsi la France venoit d'être régénéréc. Les vues ambitieuses de Louis XIV avoient si profondément blessé les nations, que, malgré ses levers, et la guerre malheureuse qui termina le règne de son successeur, ce ressentiment n'étoit point éteint; il n'avoit fait que s'affoiblir. Tous les regards, fixés avec inquiétude sur l'héritier de tant de rois 'or'squ'il prit en 1774 les rènes du gouvernement, sembloient demander s'il seroit juste, modéré, pacificateur : il l'étoit; ct M. de Vergennes fut chargé de l'annoncer ì tous les peuples. Un parfait accord s'établit entre le souverain et son ministre : le cabinet de Versailles acquit une prépondérance marquée; et l'on vit se perfectionner un système de négociation oì les calculs ont plus de force que les menaces, et dans lequel on ne verse plus le sang pour de vains mots de représailles, de vergeance, de grandeur ou de gloire, nuais pour surveiller à la richesse nationale, on pour obéir anx lois de la nécessité.

Les premières années du ministère de $\mathbf{M}$. de Vergennes se passèrent dans le calnue de l’espérance et de la paix. Alors se préparoit au loin cette révolution a jamais fanneuse qui créa dans le Nourean-Monde ce qu'on ne voit plus dans l'ancien, une nation libre (1).

(1) Voyez l'ouvrage intitule: I, Sens commun, par MI. Parxs. "Il n'est, dit-il, an pouroir d'aucume puissance de subjuguer l'Amćrique, si clle ne se subjugue pas elle-aneme par son iricso- 
Dans le dernier siècle, l'untolérance religieuse peupla la Virginie aux dépens de l'Angleterre; dans colui-ci, l'intolérance politique a rompu tons les liens qui subsistoient entre elles. Fière des avautages de lit paix de 1763 dont elle a tant abusé, la cour de Londres taxa ses colonies : non senlement elle ne les consulta point pour régler cet impôt; mais clle usa de violence pour le recueillir : l'envoi d'une flotte et d'une armée fut sa senle réponse anx remontrances des colons anglais, qui résistèrent. Entre la servitude et la guerre y avoit-il à balancer (1)?

lution et par sa timidis. L'anricu moncle, ajoute-1-il, est dans

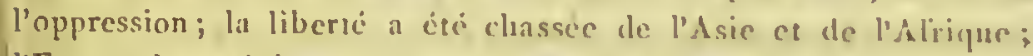
l'Enrope l'a traice comme me etrmgive: l'Angleterre elle-mène l'a bannic: c'est dans les Liats-Unis de l'Ameripute qu'elle a trouve im asile.

(1) Voyez l'ouvrage du docteur Price, insiule : Observations sur la nature de la liberse civile. Tout ce qui coucerne les interds de l'Augleterre et des Élats-Unis de l'Anerique y est raité avec une grande exacrimde. L'anteur y rappello les suites ficlieuses de la guerre sociale cliez les Rounius; il y montre commenı la Yollante, soulevée par l'introuluction des tronpes et par le mipris que l'on fut de ses plaintes, se scepara de la monarclic espagnoie, et il lait roir que les colonies amglaises de l'smérique étoient dans le méme cas relativenent ì la nétropule.

"Two Tracts on civil Liberty, the war will Amprica, and the debts and funauces of the Kingdon; with a general introduction and supplement ». PRICE, eighth edition.

"Oloservations on the importance of the american rerolution, and the means of rendering it a benefit to the world; to wlich is. aclied, a letter to dr. Price, from the late M. Turcot, comptroller geweral of the finarices of lirance; and a translation of a tract published in France in $17^{8} f$, and entitled, the Wheel of fortune Richard ». PRICE. 
Depuis long-temps les productions de l'Amérique se vendoient dans tous les ports au profit des marchands européens, et les chaînes de sa dépendance se serroient aı gré d'un petit nombre d'hommes avides ct corrompus. Une révolution heureuse promet ì tontes les partics de ces vastes contrées l'entière réformation de ces désordres; mais eût-on pensé (1) que le despotisme du peuple anglais y auroit donné lo premier exemple dı pouvoir arbitraire arrêté dans ses entreprises, lmunilié dans ses prétentions, et réduit par la force à reconnoitre les droits de l'humanité?

Quelle carrière pour l'historien qui développeroit les circonstances dont il ne m'est permis de faire qu'une courte mention dans cet éloge!

D'une part, sourd aux éloquentes réclamations des Chatam (2), des Richmond, des Rokingham (3), lc sénat anglais adopte un systène d'oppression dont le succès n'auroit pu être que funcste à sa puissance : un orgucil sans frein, une cupidité sans bornes, ont excité ce délire; et les citoyens d'une île étroite, déja tyrans des mers, veulent asservir le continént. I.e port de Boston (4) est envalii, et ses habitans sont retenus,

(1) L'abbe Dubos, dans m omvage intitule : Les interéis de l'Angleterre mal cnteudus, et M. l'albe Raynal, ont prédit te sonlévement et l'indépendance des colonies anglaises.

(2) In dignilé, dit alors le lord Clıanu, consisto dans la droiture, la bassesse daus l'oppression, et l'homence dums la justice.

(3) MML. Jinx et Buke avoient fait des motions semblables daus la clamulore des communas.

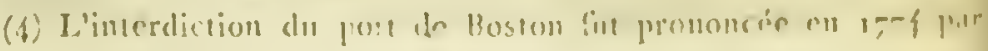


malgré la foi des traités. Par un abus inoni du ponvoir (1), on déclare libres les nègres (2) et les esclaves qui serviront pour le roi contre leurs maîtres. Les hibliothèques publiques de Trenton et de PrinceJ'own (3) sont livrées au pillage; le fimenx iustrument solaire de litten-Honse est brisé; le sang de tous les âges, de tons les sexes, inonde les Jerseys ravagés prar les Hessois; les femmes, les enfins, les rieillards sont massacrés à l'atfinire des Cidres: les villes de Nortolk, de Sulfolk et de Fair-Ficld sont réduites en cendres; les noms de Vanglan et de 'Tiyon, chef's de ces expéditions barbares, sont routés à l'exécration publique; l'acte de Québęc (4) condamne ì la somnission la plus absolue les habitans du Canadir (5), que de vinnes pronesses avoient flattés d'mu meilleur sont : les Acaliens sont

le parlemenı d'Angletere, malure: les réclamations du duc de Michuond, et des lords Manchester, Rokingham et Schellurne.

(1) Dans les expéditions du geinéral Burgoy̧ue et du rolonel Saint-Liger, les Indiens employes an service des Anglais commirent de graudes cruaulés.

(a) Cet édit fut rend te 7 noveml)re 1775 . (Histoire des tronbles de l'Amérique, par Fr. Souns̀s, 10m. I, p. 3̄oo.)

(3) Il sembloit que l'armece anglaise fïl lit guerre aux arts et aux sciences. ( Ibid. tom. I, pag. 21 et 22.)

(i) L'acte de Québec est datẻ de l'année 1775.

(5) Le lord Chatam aroit dit que la cession du Canada, faite parr la France it l'Angleterre, deroit eire funeste it cette dernic̀re. L'auteur des lettres imprimées sous le nom de Mortcalax étoit du nème avis. Le Cancla une fois conquis, les colons anglais n'ont plus eu besoin de l'appui de la métropole, dont ils ont seconc le joug. 
chassés de leurs foyers; et tandis que, par une impiété dont il y a pen d'exemples, on arrache ces cultivateurs à leurs champs (1) pour leur substituer des protégés de la cour de Loudres, le républicain impitoyable calcule sans se troubler ce que rapporte cliacun de ces crimes (2).

D'une autre part, les laborieux entans de Penn, les peuples des denx Carolines, auxquels Locke donna des lois (3) ; celui de la Virginie, si maltraité par ses gouverneurs; celui de Massachusset; les colons de la Georgie; et tous ceux qui, depuis les Apalaches et la Delaware, habitent jusqu'à la côte occidentale de l'Atlantique, frémissent à la lecture des bills du parlement, et sur-tout à la vue des soldats envoyés à grands frais pour les assassiner. Leurs représentans s'assemblent (4); et, réunis, ces peuples sont étonnés de leurs forces. Le massacre de Lexington les détermine (5) : pour la

(1) Ce fut on $1_{7} 69$ que la cour de Londres rommit cette injustice.

(2) Vers la fin de l'annéc 17,8 , le Congrès publia un manifeste pour rappeler toutes les atrocités commises par les Anglais alans cette guerre.

(3) Ce fut en 1663 que Locke rédigen un plan de législation pour Ins denx Carolines.

(4) Ce fut le 5 septembre $777\{$ que Inuze colonies qui s'étnient jusyue-lí tonjours disputécs sur les limites de leurs terres rt sur Ieur religion se rémirent. La première assembléc de leurs représentius se tint à Plitarlelplic.

Ise premicr acte public du Congrès est datr du 17 sepermbre 1774 . Par cotte déliberation, le Cougres appronvoit la rouduite des labitans de. Massachnsset, qui s'upposoicnt aux bills du parlencut.

(5) Lafinire de texington ent lien le is avril $17,5.5$. 
prenière fois peut-être, le dien des combats est invoqué par des cours droits et vrainent paisibles: ils s'arment, non qu'ils ainent la guerre, ils l'ont en horreur; mais ils chérissent la liberté, qu'ils préfèreut à tout. Décidés at se défendre, on les voit iarement attitquer; ils ne montrent ni passion, ni fureur; le canatire de leur courage est la constance: c'est la raison et 1101 l'enthousiasme qui les conduit; ce n'est point it un chef de révoltés, c'est an plus nodéré des citoyens qu'ils obéissent; des sages les pirésident; des philosophes sont leurs anbassadenr's; leurs actes sont des monumens d'éloquence et de justice : soit equ'ils déclarent on (qu'ils motivent leur indépendance (1); soit qüils s'eftorcent d'étendre jusqu'à leurs roisins le grand bienfait de la liberté (2); soit qu’ils se lient par des lois, on qu'ils invitent chacun it rendre un libre hommage an dien

(1) L'acte d'indépendance du Congre's esı date du f juillet $1-76$. MA. Jeffersou, Adaus, Franckliu, Scherman et Liviugsıon, avoicut été cliargés de reiliger cel acle. (Histoire des 1roubles de

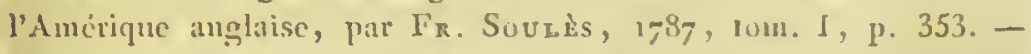
Hisloire des événemens militaires et polihiques de la dernière guerre daus les quatre parlies du monde, par MI. де Loxgchasps, $2787,10 \mathrm{~m}$. I, pag. 8.5.)

(2) De tous les papicrs publiés par lc Congrès, il n'y en a point qui montre plus l'lubileté des rédactenrs que le rescrit adressé aux Canadiens. Ils lcur citwicn plusieurs passages lirés des écrits de Montesquicu pour les invitcr ì secouer le joug de l'Angleterre; mais le nom ef l'autorile de ce philosophe, qui devoient aroir une grande force sur des cours vraineu français, ne produisirent point l'effet desiré. Le Canada demeura sonmis à la conr de Londres. 
de l'nuivers (1), ils sont tonjours vrais, toujours sublimes, toujours lumains. On pourra les priver de la vie, mais on ne les subjugnera point, et ils sont andessus des revers. Ils ont perdu 'Ticondérago, et l'armnée est détruite; Vaslington demeure, et une armée nouvelle se range antour de lui. Des vieillards portant des crêpes funèbres s'enrôlent et forment une compagnie (2); les femmes ont pris le parti d'me cause si belle, et les drapeanx sont l'ouvrage de leurs mains (3). An milieu des siéges et des combats, ces'guerriers s'arrêtent pour lionorer la mort des défenseurs de la patrie; Nelson prononce l'éloge de Warenq, et Duché celui de Montgonmeri, auquel Francklin élève un tombeau. De tels hommes avoient entrepris de briser les chaines du Nonvean-Monde (厽), dont ils étoient les libératcurs et l'exemple.

(1) Acte de la république de Virginis qui. établit la liber:é de religion. (Histoire des troubles de l'Auérique anglaiss, par Fr. Soulis, tom. IV, pag. 2.58.)

- (a) Mistnire des froubles de l'Amérique anylaise, écrite sur leq mémoires les plus authentiques; par $F_{R}$. Souris, 1787 , Inแ. I, pag. 169.

(3) Ce sont les fommes ie la Pensylvanie qui ont lirodi les drapeaux des trompes mationales. (Hist. des troubles de l'Amérique angliase, par Fr. Soul.is, 1737, 10m. I, pag. 169.)

(4) En 1754 11. Francklin avoit coumuniqus an goureruent Slirley les raisons qui devoient empeleler de taxer les colouies.

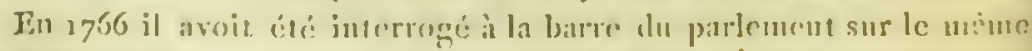

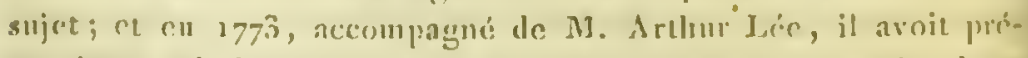

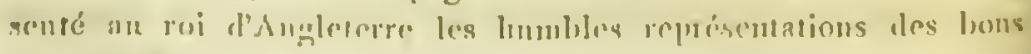
penples de l'Amérique. 
Th́moin de ces troubles, et voyant ces fiers rivanx' se livrer des batailles toujours perdues pour eux, et tonjonrs gagnées pour elle, la Trance deroit reponsser les coups qu'on lui portoit, et s'assurer un allié puissant in-delit des mers. On se plait ì répéter que Lonis XIV força le nonce du pape et le doge de Gènes it venir, en snpplinns, hir demanter pardon d'une injure. Combien paroitra plus touchante l'époque il lagnelle la cour de Lomis XVI fut l'asile des députés de l'Annérique! Lilistoire dira que Francklin (1) y fut accueilli, j’ai presque dit lonoré, par le jeune nonarque, sous l'égide duquel ce vieillard illustre venoit nettre l'enfince d'um peuple nonven.

C'ćtoit travailler en mène-temps aux intérèts et à la gloire de la France, que de l'engager ì servir les Anuéricoins(2) contre l'Angleterre. Les intentions duroi fincent

(1) Le al mars $177^{\circ}$, M. de Vergeunes prisemra an roi MII. Francklin, Silas Deane, et Arlunr Lée, ministres pléuipolenniaires des États-Uuis d'Antérique.

(2) Cenx qui voudront comnoitre la révolution de l'Amérique limut les ourrages intitules:

Essatis historiques et politiques sur les Anglo-Américains, par

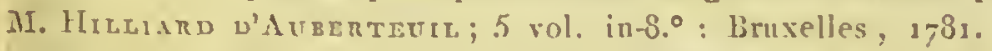

Ilistoire de la deruide guerre entre la Grande-Bretagne et les États-Unis de l'Amérique, la France, l'Espagne et la Hollande,

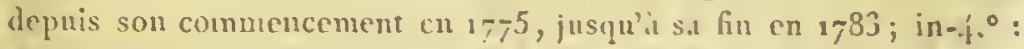
Paris, $178 \%$.

Histoirc des événemens militaires et politiques de la dernière guerre dans les quatre parties du monde, trosisidne édition, par 31. DE Lovganamps; 5 vol. in-83. : Austeriam, 1787.

Histoire des troubles de l'sinérique anglaise, écrite sur les 
bien secondées par M. de Vergennes. Deux écrits (1) exposèrent les griefs de la cour de Versailles et ses réponses aux objections on plutôt aux invectives de celle de Londres. Ce que le parlement d'Angleterre avoit jugé contraire aux vues de la France, ou supériem à son comrage, fut exécuté par elle, et porté audelà des bornes que la politique de ses ennemis avoit tracée. Non senlement le roi reconnut l'indépendance des États-Unis de l'Amérique, mais cncore il la défendit par ses armes (2), il la consolida par ses traités (3), il se déclara l'ami de cette nation qu“il venoit, pour ainsi dire, de créer par son appui, et qu'il fit aussitôt saluer comme son alliée par ses ambassa-

mémoires Irs plus authentiques, par Fr. Sourès; in-8. ${ }^{9}$ : Paris, $1737 ; 3$ rol.

Recherches historiques et politiques sur les États-Unis de l'Amérique septentrionalc, où l'on traite de l'établissement des treize colonies, de leurs rapports ct de leurs dissensions avec la GrandeBretagne, de leur gouvcrnement avant et après la révolution; par un cilnyen de Firginie; avec quatrc Lettres d'un bourgeois de New-Heaven sur l'unité de la législation; in-8. ${ }^{\circ}$ : Paris, 1788 , 4 vol. (Cet ouvrage mérite d'êre distingué parmi tous les autres.)

(1) Exposé des motifs de la conduite du roi relativement à l'Angleterre, in-\{.ํ: Paris, de l'imprimerie roynle, 1779; et Obserrations sur le mémoire justificatif de la cour de Londres, in- $40^{\circ}$ : Paris, de l'imprimeric royale, 1780.

(2) En 1780 le roi accorda aux Américains six vaisscaux de guerre et un corps de \{0oo houmes commandé par MI. de Rochiumbeau.

(3) Le trairé d'annitić et de commerce, ef celui d'alliance défrnsive de la France avec les Jitats-Unis de l'Auciórine, fureut signés le 6 février $17 \%$. 
deurs. Nulle disposition ne fut jamais plus agréable aux Américains, qui reçurent l'cnvoyé de France avec les transports de la joie la plus vive (1). “ Bénis» sons le ciel, s'écrièrent-ils avec un enthonsiasme » religieux; le très-haut a placé l'Annéricue parmi » les puissances de la terre; il lat revit de lit robe de 》souveraineté, et c'est de la France qu'elle la re》 çoit. "

Que l'on considère maintenant avec quel art le cabinet de Versailles circonscrivit la con de Londres, qui demeura sans alliés pendant tonte cette guerre. M. de Vergennes sollicita des ordres qui déclarèrent libres tontes les nuichinudises chargées sur des bàrimens nentres; il força les Hollandais, par les grands avantages (2) que ce règlement devoit lem procurer, it se séparer de l'Angleterce (3); et suus le nom de $\lambda^{-} e z$ sralité armce (4) il entraina la liussie, et successive-

(1) Ce liu le 5 du mois d'uont $177^{8}$ que le Congrès regut a plibadelphie MI. Gínrd, ministre pleniputentiaire de la cour de France. La lette du roi à ses très.chers grands amis et allićs a èté siguce par M. de Vergemes en date du 28 mars 1778.

En 1783 , M.' le chevalier de li Luzerue a remplace .II. Gérard.

(2) La cour de Loudres ronlut forcer les habitans des ProvincesUnies it renoncer ì ces arantages. L'ambassadeur du roi ell Hollande fit connoitre toute l'injustice et l'incouséquence de ces prétentions. Il s'ensuivit une rupture entre l'Augleterre et les Provinces-Unies. Le roi reprit et restitun anx Hollandais, à l'époque de lit paix, les couquêtes que I'Angleterre aroit faites sur cus.

(3) Ce fut le so klécembre 1780 que le roi d'Angleterre déclara la guerre à la Hollanile.

(4) Ce fut en ${ }_{7}$ So que ce traité de confédération fut conclu. 
ment tortes les puissances maritimes, dans une confédération qui hâta la fin de ces troubles, et qui donna le plus grand poids à l'indépendance de l'Amérique. Le roi avoit annoncé que cette indépendance étoit l'objet de la guerre, et cet objet étant rempli, quelque menaçantes que fussent ses forces navales combinées avec celles de l'Espagne, la guerre devoit cesser. Elle cessa en effet, et le traité de 1783 (1) répara l'honneur français, si cruellement blessé vingt années auparavant.

Les motifs qui avoient porté le roi pendant ces troubles à se déclarer le protecteur de Cook, déterminèrent sa conduite dans tous les cas oir sa bienfaisance put venir au secours de l'innocent opprimé. Un événement fâcheux avoit fixé l'attention des perples. Huddy, officier américain, avoit été massacré làchement par les ordres de Lyppincott, officier anglais, et $M$. Washington avoit en vain demandé c1n'on Ini livrât le coupable. Voulant mettre fin à ces attentals, le Congrès avoit résolı que tous les officiers an-

(1) I.es négnciations relatives à la paix commencèrent en 1732.

Les préliminaires furent signess le 1.3 fóvrier 1783 , et le traité définitif le fut le 3 septeutbre de lit même aunces.

Les articles de la paix cutre le roi d'Espague et le roi d'Angleterre finrent signes le 20 jauvier 2783.

Les articles convenus entre le roi d'Angleterre et les litatsUnis d'Ancíriue, dans lesquels le roi d'Angletere recomur l'indépensance de l'Aućrique, furent aussi sigués a Paris le 30 toveubre 1732 ;

Eit les articles méliminares de ha pax emte l'Amgletere et la Lollande furrut arretes le z septeubre 1792. 
glais détenus prisonniers tireroient an sort, et que, ponr xéparation, l'mu d'entre enx perdroit la vie. Le jeme Asgill étoit celui que le hasard aroit désignć pour vicline (1). Il avoit mue mère à lacpuelle il dut me seconde fois le jour. L'infortunée remplit l'Europe de ses plaintes; elle parla de son malheur it coutes les nations; elle redenanda son fils à tontes les puissances; elle écrivit unc lottre déchirmute à MI. de Tergennes, qui la lut ì la recine. Sinns donte il n'est personne qui ne compatisse un claggrin d'me mire éplorce; mais ne faut-il pas ètre nùre prour en connoître tonte l'anertmue? Sa majesté, que des sentincris tendres attachent à ses culins, en finl vivenent émne: la donlenr de Thúrèse Asgill devint lin sienne: l'anonr filial détrnisit entre elles tonte dislance, il confondit les intérêts de denx conrs égalentent sensibles, il trionphar de la laaine d'un grand peuple; stsgill ne fint point sacrifié, el, pon de temps apres, accompragné de sal fa. mille, il vint (2) remercier le ministre dont il avoit si

(1) Voyez, 1.0 l'extrait des gnzeltes angldises cies mois de juillt't et ant 1782 , dans le Alercure de France, eu date du $2 y$ nont 1,73 , et. du mos d'octolore $1783 ; 20^{\circ}$ la letre qu'on a:Iribue ir M. Livington, secritaire du Cougrès pour les affaires cirangéres, page 1 ü de l'onmage de MI. Maỵer, intiuli : Ascint, on les désordres ies

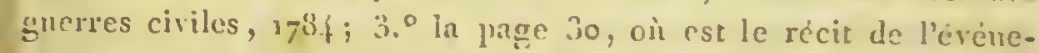
ment; $\left\{0^{\circ}\right.$ lat pagge 67 , où est lia preunidre letre de Thírèse Asp̧ill i $M$. de Tergenues; $5.0^{Q}$ la page $9 \imath$, où sc trouve la lettre de M. de Vergemues à MI. Washington; $60^{\circ}$ la pilge 96 , où est consigncic lat lettre de remerciement de lady Asuill it M. de Vergennes, en date du nuvis de janvier $7,33.3$ - Voyez anssi l'Histoire des troubles do l'Amerique anglnise, par $\mathrm{F}^{\circ}$. Soulìs, tom. $1 \mathrm{~V}$, pay: 76 et 80.

(a) Lin octobre 1733 , it Tontnineblean. 
utilement réclamé l'appui, et se jeter aux pieds de la reine, par qui ce fils et cette mère vivent, pénétrés de reconnoissance pour un bienfait à jamais mémorable dans les fastes de l'humnanité.

Tandis que M. de Vergennes négocioit avec les députés des colonies anglaises, l'électeur Joseplı-Maxinilien de Bavière (1) mourut : il s'en fallut peu que cet événement ne devînt le sujet d'une guerre continentale. L'électeur palatin, héritier de tous ses biens, consentoit à transiger avec la cour de Vienne, qui s'étoit emparće d'une partie de cette succession; mais le duc des Denx-Ponts, héritier éventucl, fort de l'appui dn roi de Prusse, protesta. Comme allié de-la maison d'Autriche et comme garant du traité de Westphalie, le roi avoit des intérêts opposés à concilier, et rien n'étoit plus difficile à tracer que sa conduite. Deux armées nombreuses étoient en présence, et les hostilités avoient éclaté. Le roi joignit sa médiation à celle de l'impératrice de Russie; et la paix de Teschen (2) lui permit de domer toute son altention à la guerre d'Amérique.

De nouvelles discussions étrangères à cette grando entreprise étoient sur le point d'y apporter de nonveaux obstacles. Deux ḱois la Porte et la Russie prirent les armes; deux fois le roi les pacifia; et des conventions explicatives ajoutées au traité do

(1) L'élcctenr Josepl Maximilicn mourut vers la fin du mois de décenlure 1777 .

(2) Ja paix de 'Teschen a éce signée le 13 mui 1779. 
Kainardji (1), ramenèrent le calıne, quii vient encore d'être troublé.

Plusieur's autres négociations importantes occupèrent M. de Vergenues pendint ses demières anmées (2). Dans le midi de l'Europe, il rapprocha le Portugal de la France, qu'il fit accéder en 1783 an traité d'alliance de la cour de Lisbonne avec celle de Madrid; en 1785 il employa ntilement la médiation du roi pour mettre fin aux hostilités déja commises aut sırjet de l'Escant; et peut-ĉtre auroit-il fallu ne se lier ansi avec la Hollande (3) que par des services réciproques et par le souvenir des bienfaits. Il conclut plusieurs traités de connnerce, soit avec l"iupératrice de Russie (4), soit avec le roi de Suide, soit avec le duc de

(1) La négociation relative nu traite de Kainarolji lut confiée ، M. le comte de Saint-Priest, alors ambassaleur du roi à la Purtı.

(2) Mr. de Veruemes a conchu deux traitis de comunerer, l'un arec le tue tle Meckleubourg an 17\%y, l'autre avec la Suèile en 178f. De plus, divers autres traités ont ète signes sous lo nème ministere aver la cour de licune pour plusieurs parties des PaysBas, arec le prince et l'ital de Liége, arec l'électeur de Trives, avec le prince de Nassiul-Salarbruck, avec le duc des Denx-Pouts, arec le prince et l'iglise de Bile, et arec le due de Wurtemberg, relativement an eomte de Moulséliarl.

(3) Le traite te paix de l'empereur avec les Provinces-Unies fut sigué in Fontaintblean le 10 novembre $1,-85$. et dans le m ime jour fint anssi conclu le traite d'alliance entre le roi et les mèmes provinces.

(4) Ie traité de commerce et d'union arec la Russie, signé a Pétersbourg le 31 dẻcembre 1786 vieux stỵle, c'est-à-dire le 11 jnnvier 1787 style nourcau, a eté signé à Tersailles, au commencement de l'année 1787 par M. le comte de Montmorin.

T. 2. 
Mecklenbourg. Enfin la Suisse lui doit un de ces actes de tolérance qu'il est important de recueillir. En 1715 la cour de Versailles s'étoit alliée avec les cantons catholiques; mais elle étoit seulẹment en paix avec les cantons protestans. Sur le rapport de M. de Vergennes, et malgré de grands obstacles, tous les sujets helvétiques furent réunis dans le même traité (1); opération digne du monarque dont la justice vient d'effacer du livre de nos lois une révocation barbare. Que ne peut-on, en l'effaçant aussi de nos annales, la soustraire au souvenir de la postérité!

Le roi, dont je n'ai pu m'empêcher d'assogier l'éloge à celui de son ministre (2), avoit donc réduit ses enne-

(1) Le traité de la France avec les États helvétiques a été conclu le 28 mai 1777 . M. le comte de Vergennes avoit chargé M. le marquis de Vergemes son frère de cette négociation, et le roi donna ì M. le marquis de Vergennes la qualité d'ambassadeur pour signer ce traité. La mort de Louis XV avoit autorisé sa majesté à revoir et à rectifier le traité de 1715 .

(2) Les principaux évẻnemens du ministère de M. de Vergennes peuvent être réduits à six, dans l'ordre suivant :

1. Le traitć d'alliance avec les treize cantons helvériques;

$20^{\circ}$ La guerre d'Amérique, et la paix qui l'a suivie;

3. La conciliation des différens élevés au sujet de la succession de Bavière;

4. La pacification de la Porte et de la Russie, opcirée par la médiation de la France;

5. L'accession de la France au traite d'anitié conclu en $177^{\circ}$ entre l'Espagne et le Portugal;

6. Le traité de paix conclu par la méliation de la France entra l'empereur et les Provinces-Unies.

M. de Vergennes a été ministre des alfaires étrangères depuis le mois de juin 1774 jusqu'en tèrrici 1787. 
mis au silence : les mer's étoient libres; les chaînes dos colonies anglaises de l'Aınérique étoient rompues; les troubles dı Nord et du Levant étoient appaisés; l'Empire et la Prusse avoient quitté les armes; les cours de Vienne, de Berlin, de Munich, de Deux-Ponts, étoient d'accord; et ce vaste repos qui, dans la politique comme daus le systène du monde, nait de l'opposition des puissances, avoit son point d'appui dans le cabinet de Versailles. Tout étant pacifié au-deliors, c'étoit des affaires'du dedans qu'il falloit s'occuper.

La France et l'Angleterre avoient réciproquenent défendu le transport de plusieur's marchandises dont la vente auroit pu former un commerce utile it ces denx royannes. La sévérité des lois prolibitires, que les haines nationales ayoient multipliées, tenoit ces peuples dans un état d'éloignement et d'animosité continuel; des armées de fraudeurs et de commis se combattoient sans cesse, et c'étoit se tromper que de regarder comme étant en paix des nations entre lesquelles une gnerre aussi fìcheuse n'étoit jamais interrompue. On auroit en vain cherché dans les ouvrages desjurisconsultes des autorités contre les prohibitions, puisque Grotins et Wattel en aroient conseillé l'nsage: c'étoit à la raison éclairée par les progrès des lumières qn'il appartenoit de réformer un anssi grand abus. A rec les prohibitions, ont dit les écrivains français (1),

(1) Plusieurs des principes suivans ont été bien déreloppés par les écrivains français, dont les ourrages sont entre les mains de tout le monde. M. l'abbé MIorellet, dont les connoissances sur 


\section{ELOGES HISTORIQUES.}

il n'y a pour les peuples ni repos, ni liberté, ni riclıesse; avec elles on manque dans les arts de modèles, de motifs et de moyens; par elles, la sphère de l'industrie des hommes se rétrécit en même temps que leur activité diminue. Les prohibitions équivalent à un impôt; elles sont des actes d'hostilité contre ceux même qu'elles n'attaquent pas directement; elles excitent des prohibitions réciproques; elles enchérissent les denrées et les marchandises pour la nation qui les exerce; et la seule difficulté de régler leur tarif devroit à jamais les proscrire. Il y a, dit M. Priestley, deux espèces de líberté, la liberté politique, et la liberté civile : celle-ci, qu'il faut au moins que l'on conserve, veut que chacun puisse se loger, se nourrir et se vêtir à son gré. Comment ne voit-on pas que les lois prohibitives tendent à la destruction de son domaine? Les manufactures sont de deux sortes : les unes travaillent pour le peuple, et les autres pour les gens riches. Si les lois que je combats pouvoient être admises, ce seroit sans doute pour les manufactures de la premic̀re classe. Mais n'est-ce pas an peuple sur-tout que la concurrence est nécessaire? Hume distinguoit deux espèces de commerce : l'un, qu'il appeloit naturel; l'autre, qu'il désignoit par le $110 m$ de forcé. Sans les prohibitions celui-ci riexisteroit point, puisque clıague penple feroit ce qui lui conteroit le moins de peine et qui lui rapporteroil le plus de profit. Ainsi les nations

tout ce qui est relatif an commerce sont rids-citendues, a reumi les armumens les plus forts contre les prohibitions. 
oil les arts fleurissent composent en quelque sorte un grand état dont tontes les parties sont intéressées à ce que mulle d'entre elles ne soit mise à la gène (1). Sons ce rapport, disoit Hume, je fais des voux pour la prospérité dn commerce en Angleterre, en Allemague, en Espagne, en Italie, et unêne en France. Y auroit-il rien de plus affrenx, ajontoit-il, que le régine prohibitif adopté par-tont? C'est aux seuls agens du courmerce que ce régime est uttile. Les prohibitions muisent an reste des citoyens en dimimuant le salaire des antvricrs, et en exigeant un emploi forcé des capitaux. Ce ne sont pas les intérèts des marchiands, ce sout cenx des consommatenrs que le gourernement doit ménager : autrement ce n'est pas la nation, ce sont quelques particnliers quilil enrichit. Linfin, dironsnons, oir la dépopulation et la misère furent-elles jamais plns grandes que dans les pays opprimés par de telles lois? N'est-ce pas des prohibitions que naissent les fiaudes arec leurs vexations et leurs dangerenx exemples? Depuis que le funatisme religienx et la fureur des conquètes se sont ralentis, n'est-ce pas la cupidité des marchands qui allume les gucrres et qui épuise les natious? Trois fois, depuis 1749 (2), le sang

(1) Smith on Wealtl.

(2) La guerre terminée en $17 f 8$ a eu pour molif principal la contrebande des Anglais dans les établissemens espagnols de l'Amérique, et la sévérité arec laquelle les raisseaux gardes-còtes espagnols traitoient les vaisseaux qui faisoient le commerce interlope.

La guerre finic par le trailé de 1763 a été faite pour le maintien de la traite exclusive du castor au Canada, pour la péche 
a coulé pour soutenir le monopole dans l'Amériqu et dans l'Inde. Que les hommes cessent de s'égorger! Ne peuvent-ils faire entre eux des échanges sans se servir de leurs épées? qu'ils détruisent plutôt leurs lois prohibitives; que tous les ports soient ouverts à tous les peuples; que le commerce soit libre, et bientôt l'abondance et la concorde travailleront de concert au bonleur de l'humanité (1).

Ainsi raisonnoient les philosophes de l'Angleterre et de la France. Voici ce que M. de Vergennes a proposé. Par un traité de commerce (2), on a substitué de part et d'autre des droits très-modérés à des droits excessifs, et la barrière qui séparoit ces nations (3) n'existe plus : des plaintes se sont fait entendre; mais se pouvoit-il qu'un principe aussi nouveau

sur les cỏtes de l'Acadie et sur le bane de Terre-Neure, et pour le monopole du commeree de l'Inde.

Fnfir la dernière guerre a été, de la part des colonies anglaises, l'eflet du besoin qu'elles avoient de se délivrer des vexations exercées sur elles par la Grande-Bretagne pour le maintien du monopale des nègocians anglais.

(1) "Qni mit jamais à tel prix, dit Montaigne, le service de la mercalenee et de la trafique, tant de villes rasces, tant de nations extcrminces, tant de millions de peuples passés au fil de l'épée, et la plus riclıe et belle partic du monde (l'Asic) bouleversée par la négociation des perles et du poivre."

(2) Le traité de comineree de la France avec l'Angleterre a été conclu le 26 septembre 1786.

(3) Les pruples de l'Angleterre ticnnent peut-être eneore plus que ceux de la France a leurs lois prohibitives. Ces Jois déclaroient coupables de félonic cenx qqui étoient convaincus d'avoir exporté des laines. A la véritć eette partic de la législation s'est 


\section{VERGEN NES.}

s'appliquât aux mouvemens d'une grande administration, sans y apporter d'abord quelque trouble (1)? Que l'on interroge d'ailleurs les penples moins chèrenent pourvus qu'ils ne l'étoient auparavant, de tont ce

adoucie sous le règne de Guillaume III; mais la funition ordonnée alors pour ce délit n'est-clle pans encore trop forte, puisqu'clle consiste daus la coufiscation du bătineut, dans l'auende du triple de la valeur, et dans un eniprisomuenent de trois ans, pour l'rx portateur et pour tous ses complices?

(1) En supposant, comme il paroit probable, que le traité de commerce, tel qu'il a été exécuté, ait donné lien ì des incouréniens, les principes généraux sur lesquels il est cítahli étant confor nnes à ce que prescrivent la justice et les intérutts des peuples, il sera facile al'y apporter les modifications nécessaires prour qu'il en résulte tout le bien que l'on en attend.

Déja la chambre de commerce de Normandie a publié ses réflexions sur ce traité, et sur les changemens qu'elle croit ì propos d'y faire.

Cette chambre propose:

1. D'accorder des prix, des gratifications, et mème des avances sans intérèt à reux qui entrepreulront d'établir en France des manufictures d'une inclustrie nourelle.

$3 .^{\circ}$ D'assurer iles primes aux filbricans, en proportion des ouvriers auxquels ils fourniront de l'uccupation.

3. D'étalblir des gratifications par claque pièce de drap ou d'autres lainages exportés ì l'ètranger.

$44^{\circ}$ De donner des prix, des gratifications et des avances sans intérêt aux entreprencurs de forges et de fonderies qui offriroient de perfectionner lenrs exploitations et leurs ateliers d'après les méthodes anglaises, ou d'après celles qui seront jugées convenables pour les mettre it portée de fournir is notre marine, à nos fabriques et à nos grands ateliers, de belles pièces de fonte et divers ustensiles de fer que les Anglais travaillent aujourd'hui avec tant de supériorité.

5. De favoriser par les mèmes mogens les recherches et les 
qui sert à leurs besoins, et l'on répondra sans peine ì la plupart des objections que le parti contraire \& formées.

M. de Vergennes n'avoit pu vivre avec tant de

exploitations de nouvelles mines de charbon de ierre et d'autres minéraux.

6. De favoriser également la nıltiplication et l'umélioration des races de nos bêtes il laine.

$70^{\circ}$ D'accorler l'exemption de tous droits ì l'entrće et au transit dans le royaume, des matieres premières que nous somnes forcés de tirer de l'étranger.

Ceux qui ont rédigé le traité de commerce ont cru qu'il falloit preudre pour base des droits les primes que l'ón savoit être payées pour la contrehande. On avoit estimé que ces droits pourroient Étre de deux pour cent all-rlessus de la prime d'assurance de la contrelande, et on se flattoit qu'en n'excérlant que de pen ces primes ils scroient exactement acquittés. Mais, d'une part, leur perception a été faite ávec négligence dans nos ports, tandis qu'au contraire les Anglais ont fait payer an-dela du prix convenu duns les leurs. Malgré ces abus, le commerce des vins, des vinaigres, des eaux-de-vie, des huiles, des savons, des linons, est benuconp augmenté, et le cliange est remonté au pair.

Que l'on olsserve encore que les prolıbitions n'étrient point respectées, et qu'il étoit naturel de diriger vers le profit de l'ritat des primes d'assurance que l'on payoit pour le soutien d'un commerce illicite.

On a fait une chjection que l'on répète sourent. Les conventions du traicé de commerce sont, dit-on, très-rlésavantagenses pour la France, parce que les Anglais vendent dans ce royaume it visgr-quatre millions d'lsommes ou d'achetenrs, snndis qu'il n'y a que lutit millions d'hommes ou d'achetenrs en Angleterre. Come inent u'a-ton pas remarqué que la vente u'est point en raison du nombre des lablitans d'un pays, mais qu'elle est sur-tout prom purtionuce a l’aisiume ot il la ricluesse de res lubluibus, el que la France ayant heancoup noins de superflu que l'sugleterre, doit 


\section{VERGENNES.}

souverains, arec tant de ministres; il n'aroit pu connoitre le secret de tant de conseils, sans acquérir le savoir que donuent l'ohservation et le temps: phisienrs fois, et tonjours avec doulenr, il aroit ru se grossic la foudre qui devoit frapper les nations. Il détestoit la guere, parce que c'est un jeu barbare donl la passion est atroce, ou le hisard fait sonvent plus que l'habilcté, et quii, semblable à certaines procédures, dévore cenx dont le sort e'st sommis à ses décisions. M. de Vergenues étoit naturellement doux et rélléchi; il s'éeoit fait de la vigilance et de l'ittention tune hat bitude que rien ne pouvoit troubler; il étoit le véritible chef de ses bureanx et l'ane de ses négociations; ses plans étoient bien conçus, et lorsqun'il les avoit adoptés, il les exécutoit arec courage. Quniqu’il ponssît la discrétion jusqu'an scrupule, il n'étoit point dissimulé, et il n'nsoit d'adresse qu'autant qu'il en filloit pour ne pas rebuter la fortune. Sa retenne aroit ynelque-

avoir anssi moins de sacrifices à faire pour un commerce étranger. (Extrait d'une Réponse an Mémoire de la chanbre de commerce de Normaudie; par .I. Dupont.)

Un avautinge réel, et que l'on ne pent enlerer ì la France, est, comme l'ont remarqué presque tous ceux qui ont á rit sur ce sujet, que la plupart des productions qu'elle exporte, tenant is la nature de son sol, forment un commerce plus sùr et plus indépendaut que celni qui est fondé sur l'iminstrie et sur direrses circonstances qui penvent aisément changer.

Les réformes à taire et les précautions a prendre pour rendre le traite de commerce ntile anx intéréts de la France seront l'ouvrage des états - gèicaux, qui s'occuperont sans doute de cet objet important. 
fois l'apparence de la timidité, quoiqu'elle n'en ett point le caractère (1). Sa conversation n'étoit point sans naturel, quoiqu'elle fût presque toujours sans abandon. On parvenoit sans peine jusqu'il lui; et connme il savoit écouter, on ne le quittoit point mécontent. Il promettoit peu ; mais il tenoit ce qu'il avoit promis. Sa sensibilité influoit quelquefois sur ses jugemens; il croyoit volontiers à l'honnêtetẹ de ceux dont le malhenr l'avoit touché : disposition peu dangereuse en politique, mais qui n'est pas sans inconvénient avec des suppliaus adroits qui savent en profiter. Modeste dans tonte sa conduite, et scrupuleux observateur des devoirs que la religion impose, il ne se tonrmentoit point pour chercher le plaisir; c'étoit au sein de sa famille qu'il le tronvoit et qu'il se délas-

(1) M. le comte de Vergennes montra dans plusieurs négociations une grande fermete.

Lorsque feu M. te comte de Grasse fut pris par les Anglais, M. de Trergennes pria M. de Gréenville, député de la GrandeBretagne, de se rendre chez lui pour parler de la paix; il lui fit lire le bulletin qui annonçoit la prise de l'amiral français, en lui disant : "Cet événcment cst plutôt un affrout qu'un désastre pour " la France; lc roi en est profondément affec:ć; la uation ne "respire que vengernce; elle a les plus grands noyens de se a signaler; ct si le roi n'écoutoit sa modération, dès ce moment " toute conference pour la paix seroit rompue. Gardez-rous, " monsicur, de clecrelser à vous prévaloir de l'accident que la "France éprougre: le roi m'ordonne de vous dire qu'il cousent à "Iis paix, pourvu qu'cl!c soit établic sur les mèmes fondemens "dont on éroit déja convenu; si vous proposex d'y faire le nooindre s clıangement, sa majesté m'ordonne de vous remortre vos passe2 ports; ils sont prèts, les voilit." 
soit de ses nombrenx travanx. Là, comme dans les affaires, il se montroit attentif, exact, modéré; qualités précicuses à ses amis comme à l'état, et qui ont été par-tout la source de.ses succès.

M. de Vergemes s'étoit marié à Constantinople avec mademoiselle Anne de Viviers, d'origine française. Le lien qui les nuissoit étoit du petit nombro de cenx que le temps ne peut affoiblir.

Il revint de Fontaincblean en 1786 , languissant et abattn; pen de temps après il fut atteint de la fière, à laquelle il succomba. M. de Vergenues est mort avec la touchante simplicité d'un pire de fanille, entouré des siens (1) et haigné de leurs larmes. Son épouse, ses denx fils (2) et ses belles-filles lui ont rendı

(1) Monseigneur l'évique de Senlis, H. le counte d'Angivillier, et M. le Marquis de Jaucour, ont reudn i .I. de Vergeunes, pendant le cours de eette ualadic, les soins de la plus tendre amitić.

(2) Ar. de Vergennes a laisse denx fils, dont l'aine, Constantio Gravier, comte de Tergenues, eapitaine colonel des garules de la Porte réformé, mestre de eamp d'infanterie, ministre plénipolen. tiaire du roi près de l'ellecteur de Trives. est marié a demoiselle Lonise-Jeanue-Marie-Catherine de Lenthilhae de Sedidres.

Le ealet, Lonis-Charles-Joseph Gravier, vionmte de Vergennes, mestre de camp cn second du regiment de Bassigny, infanterie, est marié a demoiselle Claire-Gabrielte Pinel de la Palun.

M. le marquis de Vergennes, frère du ministre, a été ambassadeur en Suisse et à Venise, d'où il est revenu en Suisse; il a quatre enfans: saroir, deux fils, dont l'un est maitre des requètes, et depuis sept ans daus la carrière des Intendances; l'autre est colonel en second an régiment de Roval-Taissenu infanterie; et deux filles mariées, l'une à II. le marquis de Ganay, ancien 


\section{0 ÉLOGES HISTORIQUES.}

les soins les plus empressés et les plus tendres. Il a expiré dans leurs bras le 13 février 1737 (1). On n'a point remarqué qu'il tînt beaucoup à la vie, sans doute parce qu'ayant conmu le monde tel qu'il est, il ne pouvoit le. regretter en le quittant. Pour s'y plaire il fant y occuper peu dé place, et s'y concentrer dans ses affections. Mais l'homme puissant que l'exercice et l'étendue de son autorité fatignent, tronve peutêtre dans son dernier terme, vu de près, un repos moins effirayant que le tourbillon où il a vécu.

militaire et gouverneur de la ville d'Antun; l'autre à M. le comte de Montezan, ancien ministre plénipotentiaire à Cologne, et aujourd'lui à Munich.

(1) La place de ministre des affaires étrangères est maintenant occupée par M. le comte de Montmorin, qu'une probité sévère et dles talens reconnus dans les négociations ont rendu digne de ce grand emploi.

Je crois devoir témoigner ici ma reconnoissance à M. de Renneval, premier commis des affaires étrangères, de qui j'ai reçu la plupart des renseignemens qui m'ont été nécessaires pour la rédactior: de la seconde partie de cet éloge. 


\section{NOTICE HISTORIQUE}

\section{SUR LES PRINCIPALES ACADEMIES.}

$\mathrm{U}_{\mathrm{N}}$ bourgeois d'Athènes, appelé Academus ou Ecademus, avoit mue maison dans mu des faubourgs de cette ville célebre, oit Platon enseignoit la philosophie. Cette école portuit le nom de celui anynel le local appartenoit; et ce nom a été donné depuis à plusienrs sectes, à diverses inslitutions fumenses, at il l'est encore aujourd'hui a la plupart des sociétés littératers. Cimon onna la maison d'Académus; il l'embellil de fontaines; il fit planter des allées d'arbres, oil se promenvient les philosoples de ce temps. L'histoire nous apprend qu'ils étoient déja prersecutés, ynoiqu’ils ne persécutassent persome. La Grice se glorifivit de les posséder, et cependant ils aroient souvent it se platindre de la Gréce; ct l'on vit alors se perpétner ce grand combat, que l'on ne verra peut-ètre jannais finir, entre les honnues instunts et conx yui ne le sont pas, c'est-ì-dire entre le saruir et l'ignorance, entre l'erreur et lat vérité.

Nous n'insisteruns point sur l'histoice de ces temps reculés, pendant lesquels les académies, presque entièrement livrées aux questions métapleysiques ou morales, ne s'occupoient ni de physique expérimentale, ni de nédecine.

Ou distinguoit deux acadéruies du temps de 
Cicéron, l'ancienne, et la nouvelle. Les partisans de l'ancienne, fätigués par les sophismes, épuisés par les conjectures, rebutés par les systèmes, avoient refusé leur confince ì tout argument, leur croyance à toute. proposition ; il n'y en avoit aucune qui ne leur parût suspecte, même celle par laquelle ils s'astreignoient à douter. La nouvelle académie admettoit des probabilités; elle ne disputoit que sur les degrés de vraisemblance, et l'on pouvoit, au moins dans cette secte, jouir de la vie et se prêter à des illusions. C'est un singulier spectacle que celui de l'homme abandonné à lui-même courant d'une chimère à une autre, quittant d'anciennes erreurs pour de nouvelles, mais ayant toujours le désir de la vérité, et sentant le besoin de la connoître : car ces philosophes qui doutoient de tout avoient au fond raison d'être mécontens de l'état de leurs connoissances. Cette inquiétude annonce, jusqu'à un certain point, la justesse de leur esprit, comme la confiance de certaines gens dans ce qu'ils savent est une preuve évidente de leur impéritie et de leur irremédiable imbécillité. Plusieurs siècles de ténèbres et d'ignorance succédèrent aux beaux jour's d'Athènes et de Rome; tant de barbarie et de cruantés n'étouffèrent cependant pas tout-à-fait le germe des sciences et des lettres. Comme les Romains s'étoient polis en faisaut la conquête de la Grèce, les étrangers qui s'emparèrent de l'Italie, qui la ravagèrent tant de fois, qui changirent en ruines ces monumeus superbes, qui dénaturèrent jusq̣n'à son idiôme en mêlaut leur jargon à la 


\section{SUR LES ACADÉMIES.}

Langne de Cicéron et de Virgile; ces étrangers qui sembloient avoir été chargés dı soin de venger l'univers en foudroyant ses oppresseurs, participèrent euxmêmes aux arts des vaincus, et prirent quelques-uns de leurs penchans. Mais quoique l'amour des lettres n'ent pas été tout-à - fait détruit ì llome ct dans les autres villes d'Italie, il n'en restoit que de foibles traces lorsqu'en $147^{\circ}$ Antonio Panornita jela dans le royanme de Naples les fondenens de la première académie moderne: Alphonse premier d'Arragon, roi de Naples, lú donna des marques éclatantes de sou appui; et il importe de célébrer le prenier monarque qui a protégé les lettres dans 111 temps où tont se réunissoit ponr les détruire et les rendre suspectes, et oì les sunverains étoient bien éloignés de savoir qu'il étoit de lenr intérèt et de leur gyloire de répandre la lunière parmi les peuples. Tafuri nous a conservé la liste de cette ancienne académie. On y roit, comme daus celle des acadénies modernes, des nons illustres par leur sitvoir, d'autres par leur naissance, d'autres qui ne sont gnère conmus, et dont quelques-urrs méritoient pentêtre une graude renommée, dont ils n'ont point joui.

Les autres académies établies par les Italiens à la renaissance des lettres ont été celle de Lyncei, créée par le prince Casius en 1603 , dont les membres se sont occupés de quelques recherches physiques. - Celle del Cimento, qui a été si célébre à Florence sous le gouvernement des Médicis. - Celle que le duc d'Urbain a fondée. - Enfin celle de Sienne. 
Je ne parle point ici de ce grand nombre d'académies que chacune des villes d'Italic possède, et dont les noms bizarres out été recueillis par l'abbé Puizza : la plupart sont consacrées à des jeux d'esprit, à des combats littéraires dont on blîme avec raison la furme, mais dans lesquels il n'est pas aussi aisć que l'on pense de triompher.

En 1645, Théodoric Haacke jeta à Oxford les premiers fondemens de la Société royale de Londres, qui fut transportéc en 1660 dans cette capitale, oì elle nc cesse de travailler utilement aux progrès des sciences physiques.

En 1651, J. I. Bausclı fut le fondatenr et le président de l'Académic impériale des curienx de la nature, dans laquelle il prit le nom de Jason, chacm de ses membres devant s'y déguiser sous l'emblème de quelque grand personnage de la Fable ou de l'Antiquité. Les savans de l'Allemague alimentèrent principalement son recueil, que l'on ne doit regarder que comme un journal, dont les matérianx nombreux, et souvent intéressans, sont cependant peu soignés, et en général peru choisis.

Depuis loug-temps les lettres étoient honorées en France; Charlemagne les aroit mises en vigneur en accordant des priviléges à cenx qui les cultivoient. Dans le donziùne siècle, l'Université de Paris enseignoit, commo celle de Boulogue en Italic, avec assez de célébrité pour attirer les étrangers de toutes parts. Fraucois I.er rémuit dans un collége qu'il appela rojal 
des professeurs de toutes les sciences et de tous les genres de littérature; projet grand et vaste que tous les siècles envieront à celui qui l'a vu naitre et qui en a pressé l'exécution.

L'Université de Paris étoit alors le senl corps qui portât le nom d'acadénie, academia, $110 m$ qu'elle ne partageoit arec ancun antre, puisque l'établissenent des académies anxquelles ce nom est spécialentent consacré lni est postérieur.

En 1643 , il se tenoit d Paris des assemblées de savans, qui ont reçu successiventent diverses'modifications en 1666 et en 1699, et que l'on a désignées sons le nom d'Académie royale des sciences. Cette instilntion est nue de celles qui ont fait le plus d'homenr et rendu le: phe de services it la France. 'Toutes les bianches de lit physique cultivées it la fois, l'esprit de système anéanti, des méthodes tracées pour tous les genres de tratvaux, un corps dévoné à la recherche des vérités physiques, dont le domaine est si étendu: tels sont les droits de cette académie à la recomnoissance de la nation.

L'exemple donné en France par la capitale fut suivi par différentes villes de ce royaumme, qui établirent dans leur sein des acadénies, dont quelques-unes, telles que celles de Montpellier, de Dijon, etc., publient les travanx de leurs nuembres.

Il semble que tons les sonverains de l'Europe, en établissant des acadénies daus leurs états, se soient disputé l'empire des sciences et des lettres. En 1700,

T. 2 . 
le roi Frédéric I. er fonda l'Académie royale des sciences ci belles lettres de Prusse, dont Leibnitz fut le premier président, et à laquelle le roi actuellement régnant, si avide et si digne de toutes sortes de gloire, a donné en 1744 me nouvelle existence.

En 1712 , le comte de Marsigli s'immortalisa par l'Institut de Bologne, qu'il dota, et qu'il rémit à l'académie érigée en 1690 par Eustache Manfredi.

Le grand homme qui créa pour ainsi dire l'empire de la Russie regarda comme une des conditions nécessaires à son succès l'institution d'une académie à Saint-Pétersbourg, dont l'inauguration fut célébrée en 1725 : et ces mêmes mains qui avoient quitté le sceptree pour tenir les instrumens des arts, ces mains qui ont opéré tant de prodiges, ont encore élevé dans le Nord le premier monument aux sciences. Les souverains de la Russie ont continué de suivre la même marche ; et l'impératrice réguante, non seulement fait fleurir les lettres, mais encore elle montre envers cenx qui les cultivent cette générosité dont l'excès est un de ceux qu'on ne reproche point aux rois, soit parce qu'ils le commettent rarement, soit parce que ses bormes sont très-circonscrites, soit à cause du bien qui ne manque jamais d'en résulter.

La Suede ne tirda pas à s'illustrer par l'établissement d'une académie qui a produit taut de grands hommes. Dis 1720, il paroissoit à Upsal, tous les trois mois, un volume d'actes littéraires. Ciuq annécs après, an 1725, l'acadéruic de cette capitale reçut la sanction 


\section{SUR LES ACADËMIES.}

dn roi et du sérnat, et celle de Stockholn liıt instituée ell 1739 .

Tons les corps out cultivé et cultivent la pliysique, dont la médecine est nne branche. Leurs recueils contiement des observations et des mómoires qui intéressent médiatenent on immédiatement l'art de gnérir, art qui a plus besoin que tout antre de précision dans sa marche, parce qu'il est très-compliqué.

La médecine est-elle antre cliose en effet que l'application de la physique, de l'histuire naturelle, de l'anatomie, de la chimie, de la botanique, it la comnoissance dn corps humain, sain on malade; et ue s'ensuit-il pas que sá perfection dépend de celle de ces différentes sciences saus laquelle il est difficile qu'clle fasse des progris? Je dis difficile, et non pas impossible, parce que, ontre les parties accessoires à l'art de gnérir', et dont cet art a besoin pour former $n$ ensemble, l'observation que présentent les effets des maladies et des remèdes en est la base, et que, considéré sous ce seul rapport, il pent acquérir quelque perfection par l'expérience privée de secours, et sans l'interniede d'aucune autre étude.

On doit donc distingner en médecine les connoissances accessoires et l'observation, que ces connoissances éclairent et rendent plus fructueuse.

Les sciences accessoires à la nôtre se perfectionnent dans les académies; mais la médecine elle-même, ses principes, ses moyens, ses résultats, ne méritoient-ils pas que des institutions publiques fussent consacrées ì 
leur avancemeut? n'étoit-il pas nécessaire de la traiter comme tons les autres arts? Chirac l'avoit pensé, et il avoit proposé l'établissement d'une académie et d'une correspondance de médecine dont le centre devoit être à Paris; projet qui a mérité les éloges des hommes les plus célèbres et des meilleurs juges en matière de science, de Fontenelle, de d'Alembert, de Borden : mais Chirac ne reçut point assez pour fonder cette académie, qui, conme l'a dit Borden, auroit rendu les plus grands services à la médecine, quand bien mêrne elle auroit été composée de médecins étrangers à la Faculté de Paris. Chirac mourut, et l'on assure, ce qui n'est pas croyable, que la plupart des médecins de son temps se félicitèrent de ce qu'il n'avoit pas réussi. On doit sans doute honorer la mémoire de celıx qui ont fait du bien aux lommes; mais c'est lenr en faire que de proposer et de publier un projet utile. Celui de Clirac, dédaigué par plusienrs de ses confrères, fut accueilli et utileurent exécuté par la Peyronnic, fondateur de l'Académic royale de chirurgie, instituée par lettres-patentes en 1748 , et dont les travaux utiles et justement honorés ont justifié les éloges domnés par quelques philosophes an projet de Clirac. C'est une pensée qui doit toujouls être présente à cenx qui contribuent par de grands efforls an succès des étalblissenuens utiles, que le bien que l'on fint on que l'on propose.n'est jamais perdu.

Henrensenent pour la nuédecine que runl obslaclo n'a déconragé, daus l'exécutiou, le plan de Clirac, en 


\section{SUR LES ACADEMIES.}

établissant la Société de médecine, dans laquelle, en renonçant à la présidence perpétuelle de cette compagnie, il ne s'est réservé qu'uue place égale à celle de tous ses confrìres : conduite générense et sage, que le seul amont du bien pent inspirer, et quil est inaccessible anx traits de l'envie.

La Société royale de médecine, institnée d'abord par 111 arrit du conseil de $177^{6}$, ensuite par lettrespatentes de $177^{8}$ et 1780 , est claragée de recucillir les observations faites par les médecins des provinues, de veiller an tratenent des épidínies, et d'en pullier l'histoire; ce qu'elle a déja fait dans cinq volumes in-4..$^{\circ}$ de ses. Mlénoires.

Il y. a donc maiutenant une aradémic de médecine en France. Dija il en existoit nue à bimborrg depuis 1733 , dont les mémoires ont été publiés en sept rolnmes in-12, et tradnits en français par Dennours. Une autre socićté dı mème genre avoit commencé ses séances à Londres en 1753 : elle aroit publié cinq rolunes in-8.o, arec le titre de Medical observations and inquiries, etc.; et sa corresprondance très - étendue avoit réuni une ample moisson de faits qu'elle se proposoit de faire counoitre dans de nourenux recueils. Les médecins du Collége de Londres, de Copenhague, de Berlin, de Breslaw, ont fait paroître, il y a longtemps, de semblables mémoires. Madrid, Modène et Amsterdam, possèdent des sociétés de médecine, établies sur le même plan que celle de Paris, et qui veulent bien communiquer à cette dernière le fruit de 
lenrs recherches. C'est ainsi qu'on a établi de tontes parts des rapports utiles aux sciences en général, et à la médecine en particulier, dont le champ ne peut s'accroître que par la connoissance de ce qui se passe à de grandes distances, relativement à la santé, par des essais, par des expériences sagement concertées, dont la chaîne non interrompue doit être l'ouvrage de plusieurs générations.

Les sciences sont liées, dans les académies, arec les siècles à venir. Dans les écules elles tiennent aux siècles passés; on ne doit s'y occuper que de ce qui est fait, et non de ce qui reste à faire; mais il est nécessaire que l'enseignement suive les progrès des travaux académiques; tout ce qui est connu et publié est de son ressort; son but est inanqué s'il ne montre que d'anciennes erreurs : mais le mal est à son comble quand il combat des vérités nouvelles. On fait souvent ces reproches aux écoles. Sans examiner s'ils sont fondés, disons que rien n'est aussi important que l'enseignement, parce que de lui dépend l'instruction des générations futures; disons qu'il u'y a rien d'anssi négligé ; que l'on devroit en écarter ces cérémonies gothiques, si propres à rendre la science difficile et repoussante; qu'il est temps de porter l'esprit de réforme dans les corps chargés de l'édncation de la jennesse; que celte révolution prochaine ilhustrera la main dont elle sera l'ouvrage. Ajoutons qu'aucune des sciences physiques n'étant actuellement dans mu état stationnaire, celui qui professe doit toujours étn- 


\section{SUR LES ACADÉMIES.}

dier lui-même, pour être en état d'enseigner ; (u'i' ne peut plus y avoir de repos dans la carrière de l'esprit, tant elle est rapide et précipitée; que la pédanterie et l'ignorance qui sont si analognes, le fiux et le demi-savoir qui se rapprochent de taut de nanières, doivent être bamis des écoles avec plus de soin cucore que des académies, parce que dans ces deruières ces qualités vicienses sout tonjours corriggées ou réprimées, an moins par le bon esprit de certaines persomes : an lien que le pédaut des écoles, élevé dans sa chaire, et dominant sur tout, n'a rien quil'arrète, et que, livé tont entier it son penchant, il ne peut que se fortificr et se couplaire de plus en plus dans ses habitudes.

Observous qu'à force de rendre les laugues latiue et grecque difficiles on en éloigne $u$ grand noumbre de personues; ce qui est un grand malheur, parce qu'on ne peut s'en écarter saus perdre de viue les véritables modèles du bon gont; et fuissous en faisant des ræux pour qu'au milieu d'une nation active, mais dout l'esprit facile s'effraie par la fatigue et l'étendue d'un travail ingrat, on rende l'instruction aisce ; pour qu'on en varie les objets, et sur-tout puur qu'on ne néglige point cette belle langue d'Hoinère et de Pindare, d'Hippocrate et d'Arétée; cette belle langue d'un peuple dont on a tant de fois comparé le caractère arec celui des Français : rapprochement lionorable dont ils cesseroient d'être dignes s'ils ignoroient un moment leur entlousiasme pour tout ce qui est grand et beau. Ce n'est pas parce que les Grecs sont anciens qu'il faut les 


\section{NOTICE HISTORIQUE, etc.}

loner, les admirer, et s'efforcer de marcher sur leurs traces : c'est parce que leurs arts ont été les premiers de tous les arts; parce que lenrs oratenrs, animés par de grands intérêts, avoient souvent à opposer leur élociuence à la force des armes, aux menaces des rois puissans, et sur-tout lorsqu'on parle à des médecins; parce que c'est parmi enx qu'ont fleuri ces beaux génies qui, prenant la nature pour guide dès les premiers pas de la science, nous ont tracé une route dont on ne s'est jamais écarté sans commettre des fautes et sans rendre sa marche plus pénible et plus longue. 


\section{RÉFLEXIONS}

\section{SUR LA SOCIABILITÉ DE L'HOMME,}

\section{I.}

SUR L'INFLUENCE DES LETIXIIS ET DES ARTS,

En réponse aux Objections tirćes des écrits de J. J. Koussau.

R

Coussear a dil: "On voit an pen de soin qu'a pris J lat nature de rapproclier les hommes par des besoins „) mutuels, et de leur faciliter l'usage de' la parole, ग combieu elle a peu préparé leur suciabilité (1). Si ग clle a couvert ses op'ratious d’un voile épais, f’a 》été pour leur cu dérober la commoissance, ct cepeu》dant ils n'ont point profité de cette leçon (2) : nés د) de l'oisireté, les sciences et les arts l'entretienuent; ग ils sout incompatibles avec la vertu; la dépravation ग des nucurs est leur ouvrage; ils ont préparé la ruine ग d'Athènes et de Rome. Les hommes n'étoient donc » pas destiués à se réunir, ni à cultiver leur esprit (3) ». Ainsi a parlé Roussean. Celui qui étudiera l'homme

(1) Discours sur l'origine et les fondemens de l'inégalité parmi les hommes, par J. J. Roussi 1 U, in-8. ${ }^{\circ}$ : Amsterd., 1755, p. 60.

(2) Discours couronné en 1750 par l'Académie royale des sciences et des belles lettres de Dijon sur cette question: "Si le retablissement des arts et des sciences a contribué à épurer les mœurs "? in $-8 .^{\circ}, 175$.

(3) Ibid. 
tel que les historiens l'on peint, et tel que les royageurs l'ont observć, dira an contraire : « Les plus an-

j) ciemnes de toutes les traditions montrent les habi-

» tans dı globe soumis à des lois et bâtissant des cités.

„ Le premier qui pénétra dans le Nouveau-Monde y

2) trouva des temples, des palais, des villes et des

» empires. Cook a vu par-tout les liommes rassemblés

» en familles. Par-tout et toujours, l'intérêt de quelque

» jouissance et le sentiment de la jalousie excitèrent

» leurs passions et firent naître leurs querelles. Sont-

2) ils ell petit nombre : la force du colps est la pre-

» mière de toutes les distinctions, comme elle est la

» plus ntile des qualités. Forment-ils un peuple : c'est

» l'énergie de l'ame qui l'emporte et qui commande.

"Mais dans tous les cas ils tendent vers la société,

2) qui tend elle-ıneme à se perfectionner et à s'agrandir.

„C Comment, lorsque ces institutions portent le sceau

»de l'antiquité la plus reculée, loısque nulle trace ne

» s'aperçoit au-delà, ose-t-on avancer qu'elles sont

" contraires au plan de la natıre? N'est-ce pas à la

» constance de ses opérations qu'il appartient de rnani-

» fester ses vues? Quelle terre ent jamais des lıabitans

" sans expression et sans langage? Pourcyuoi la socia-

"bilité des lownmes ne seroit-elle pas, comme celle

"de tous les aniunux, une question de fait que l'ob-

” servation senle pent résondre? et puisqu'on les a ton-

» jours vus rasseublis ne s'ensuit-il pas qu'ils devoient

"l'être?»

Jues lommes dont parle l'histoire sont, dira-t-on, 
bien loin enx-mêmes de cet état de nature tant régretté par Roussean. De quels hommes, de quel état s'agit-il donc? Voudroit-on remonter à ces époques dont il ne reste aucun souvenir? La mêne volonté qui forma les castors et les abeilles jeta sans donte aussi les fondemens de nos sociétés. Mais qui ponrınit dire comment les premiers individus se sont rémnis? Nos réflexions ne doivent donc avoir pour objet que les habitans des terres incultes, cenx des pays nouvellenent ajoutés it notre géographie, cenx des moutagnes on des forèts; que ces hommes vulgairement comms sons le noun de sauvages. Or ils ne vivent point isolés; il u'y eu a point qui soient tout-à-fait dépourrus de l'industrie des arts. Ils abusent de leur force, coume d'autres abusent de leur esprit; et comment croire à la perfection de leur bonlreur lorsqu'on les roit agités par des haines implacables et souvent tourmentés par lenrs besoins?

“ La liberté et la perfectibilité de l'homme sont, dit 》 Ronsseau (1), denx attributs sur lesquels on ne 》 peut élever de contestation ». Ponrquoi en élereroiton darantage sur sa sociabilité, puisqu'elle est également dams sa natmre, et que ce troisième attribut résulte nécessairenent des deux antres?

Les nécessités pliysiques se sont liées arec les nécessités morales, comme les arts mécaniques arec les

(1) Discours sur l'origine et les fondemens de l'inégaliıe parmi les loonmes, par J. J. Roussenu, in - $80^{\circ}$ : Amsterdam, 3755 , pag. 32 et 33 ; et dans les notes, pag. 229. 
arts libéraux, et dans cette chaîne d'essais et de procédés, l'homme s'est montré d'autant plus sociable qu'il a été plus perfectible. On est le maître sans donte de rechercher si c'est un mal que les clioses soient ainsi; mais c'est demander si l'homme a été bieı ou mal eréé (1). Voilì ma réponse.

" Les ames, ajoute Rourseau, se sont toujours cor"s rompues, à mesure que les sciences et les arts ont » fait des progrès (2) ». A la vérité, les mœurs se dépravent à la même époque où les arts fleurissent, et cette identité de circonstances est la source de l'erreur commise par Ronsseau. Il n'a point vu que ces denx effets, saus se rapporter à la même cause, pouroient et devoient mème être souvent réunis. L'un et l'autre supposent un grand concours de peuples, d'efforts et de nouvemers. Mais tandis yue d'mne part, l'abus des jouissances affoiblit et dégrade, de l'antre les arts donnent aux plaisirs et aux jeux de la noblessee ou de la grace; ils sontiennent le conrage en lui préparant des trophées; ils excitent l'imagination, dont ils sont les interprètes. Considérés d̀ cette époque comme modératenrs du bon goot, ils préservent de la cormption dont

(1) " Ce qui est arrivé, sans loute, a du arriver... II n'est "pas temps de relaire le unonde "; a dit ingéniensement l'anteur du Discours sur les avantages ou les désarantagez de la decouverte de l'Amérique; in-8. ${ }^{\circ}$, pag. 7 .

(a) Discours couronné it Dijon en 1750 , in-8.0, sur cclte question : "Si le rétablisacment des sciences et des arts a contribuh ¿ épurer les mours? s 


\section{SUR IES SCIENCES.}

on les avoit mal à propos fait naître, et l'état en reçois tonjours des services proportionnés à lenr culture.

Il est donc contraire à toute viaisemblance que les arts aient été funcstes anx anciennes républiques de la Grèce et de l'Italie. Couverte des lauriers de Marathon et de Platée, riche des conseils de Thémistocle, d'Aristide et de Cimon, Athènes étoit florissante lorsqu'elle remit ì Périclès les rènes de son gouvernement. On reproche ì ce grand homme d'aroir contribué at la chnte de l'état en donnant trop d'attention anx arts. Qu'on lni reproche plutôt d'aroir acheté les suffrages dn penple par de conpables profusions; d'avoir épuisé, danns les mèmes vues, le trésor public par des fètes, par des constructions, par des dépenses de tonte espèce; d'avoir atfoibli la pnissance de l'Aréopage pour ajonter à celle de la multitude qu'il aroit sédnite; d'avoir enfin renuln nécessaire cette guerre du Péloponèse qui coùta si cher à la Grèce. Voilì quels ontété les torts de Périclis. S'il n'avoit aimé que les arts il n'anroit pas commis de telles fintes. Athènes ent à s'en plaindre, non parce qu'il l'a roit embellie, mais parce qu'il vouloit lui comminder.

Cherche-t.on l'exemple d'une république fameuse par la sagesse de ses lois et par l'austérité de ses mœurs, dont la cormption ne sauroit être attribuée à linfnence des beanx arts, qui n'y pénétrèrent jamais: que l'on se rappelle comment Lysandre changea la constitution de Sparte en faisant briller l'or aux yeux de ses fiers habitans. L'ambition et les richesses, voilà les grauds corrupteurs des nations. 
On n'a pas craint d'accuser les arts et les lettres de la décadence de l'empire romain : comme si ģ'avoit ćté l'amour des arts qui conduisit Marius et Sylla; comme si ç'avoit été pour servir les lettres que ce dernier ruina la discipline militaire en Asie, et qu'entrant dans Rome à main armée, il y donna l'exemple affreux des proscriptions! Lorsque les triumvirs se perdirent en:perdant l'état, quelie part les sciences et les arts eurent.ils dans ces grandes et funestes entreprises? Pendant long-temps tout citoyen romain fut soldat : rassemblés loin de leurs foyers, sous des chefs séditieux, les soldats de Rome cessèrent d'être citoyens, et l'on ne voit pas encore comment la culture des arts put contribuer à cet oubli, qui fut la sonrce des plus grands maux. 'Tout étoit déja perdu lorsqu'Auguste s'empara de la dictatnre; et ce beau siècle littéraire, formé des débris de la grandenr romaine, n'eut ancune influence sur les affaires publiques, si ce n'est peut-être que la présence de tant de grauds lionmes dont l'emperenr ambitionnoit les suffrages dît quelquefois le modérer dans ses desseins, et mettre un frein à son audace.

J'ai dit que les progrès des arts n'ont porté ancune atteinte à la puissunce des républiques de la Grèce et de l'Italie : j'ajoute qu'elles en ont reçu de grands services. Quels hommes que Lycurgue, Solou et Numa, législatenrs de ces penples illustıes; que Xénophon, 'L'hucydide et César, lićros et listoriens tont it la fois; que P'éricles et Pllocion aussi éloquens dans lat tribune 
qu'intrépides dans les armées! Quels hommes que Démosthène et Cicéron; que cette foule de consuls et d'empereurs, tout aussi recomnandables par l'étendue de leurs connoissances et la profondenr de leur génic, que par leurs vertus républicaines ou par leurs qualités guerrières! N'est-il pas évident que l'étude des lettres, loin de zunire it leurs succes, les a rendus plus rapides, et que les mains les phus couragenses, si elles n'avoient pas été guidées par le savoir, n'auroient janais opéré tant de prodiges?

Rapprochons-nons des temps gni nous sont mienx commus. C'est après les troubles de lia Ligue, itprès les guerres civiles de la minorité de Lonis XIII et de Louis XIV, que les lettres et les sciences out fait de si grands progrès. En Angleterre, les secousses domúes par Cronwel agitient les esprits et imprimirent un mourement d'oì naquirent l'ordre et la fécondité. Qui oseroit comparer en France le rigue de Louis XIV a cenx de Henri II et de Henri III, et en Angleterre cenx de Charles et de Jacques II anx règnes des Édouard et des Henri?

Il n'en est pas de l'état actuel de l'Europe comme il en étoit du gouvernement cles Grecs et des Romains. Cenx-ci fixent tons les regards de la postérité dans l'intervalle qu'ils ont rempli de leur gloire; il semble qu'alors ils fussent seuls au monde : ils périrent, et les beaux arts disparurent arec eux. Les diverses puissances modernes sont an contraire balancées par une:sorte d'équilibre qui se dérange quelquefois, mais 
qui se rétablit bientôt et qui paroit devoir durer loug temps. Les sciences et les lettres y sont en vigueur, et l'on diroit que des peuples qui les cultivent se compose une grande nation que ses qualités distinguent et mettent ant-dessus de toutes les autres. Ceux qui cherchent dans la nuit des temps quelques témoignages contre les beaux arts ne sont point frappés de cette objection qu'ils ont sous les yeux, ou ils se la dissimulent, faute de savoir y répondre.

En deux mots, les beaux arts sont enfans de l'opulence et dı goût. Ils ne peuvent fleurir qu'au milieu d'un peuple riche, c'est-à-dire déja corrompu. Mais on se rassurera sur leurs effets, en réfléchissant qu'il n'est rien d'aussi barbare que le luxe des nations qui en sont dépourvies, comme rien n'est aussi féroce que leurs comḅats.

Je ne prétends pas dire que l'on n'a jamais abusé et que l'on n'abusera point des lettres et des arts. De quoi n'abuse-t-on pas? Mais je demande que l'on n'accuse point les arts et les lettres des excès que comunettent les aubitieux, les usurpatenrs et les despotes; excis que l'influence des lumières rend tonjours plus rares ou noins fâcheux, loin de les inggraver.

Il ne sera point inutile, pour montrer jusqu'at qnel point Ronsseau étoit prévenu contre les sciences et les arts, de rappeler ici quelques-unes des propositions exagérées qui se tronvent dans ses discours.

En parlant des habitans de l'Orénoque, dout l'usage est de comprincr la tête de leurs enfans en appliqunant 
des ais sur les tempes, “ Ne pourroit - on pas dire, » ajonte-t-il, qu'ils leur assurent an moins par cutte 2) mancuvre une partic de lem. imbécillité et de leur » bonheur originel (1) )? Combieu il faut ètre avenglú pour attacher quelque idée de bonhunr ì ce monstruenx attentat de l'ignorance contre la foiblesse!

Dans $n$ antre article, il s'adresse anx Romains: « Abjurez, leur dit-il, ces vains talens. Jee sent » talent digne de llome est celui de conquérir le nonde m et d'y faire réguer la vertu (2) m. C"est-ì-dire, rederenez durs, grossicrs et harbares; ravanez le monde, et pronvez anx peuples, en faisant la plus malhomiete de tontes les actions, qüils doivent itre modérés et justes. Quels professents de vertu que de parcils conquérans! et quelle contradiction entre le philosophe de Genève, apûtre de ces croisades d'un nonveau genre, et Ronssean écrivant aillens avec tant d'énergie contre l'injustice et les nullhenr's des gileries!

“ L'art de l'imprimerie est, dit-il plus loin, 11 grand 》 mal, un désordre alfreux que les princes repousseront 》 bientòt de leurs États (3). "

Tel est l'asceudant de l'éloquence et de l'attrait

(1) Discours sur les fondemens de l'inégalité parmi les lommes. Edit. supra citat., p. 3 ;.

(2) Discours sur la questiou, "Saroir si le rétablissement des scieuces et des arts a contribué à épurer les mours. 2

(3) Ibid., dans une note.

T. 2. 
162 REFLEXIONS, etc.

avec lesquels il a sontenu des paradoxes, que, malgré l'autorité des faits, et toute la force des raisons qui m'appuient, je suis obligé de solliciter l'indulgence du lecteur, auprès duquel je ne puis avoir d'antre mérito que celui d'avoir osé prendre avec de foibles armes la défense de la vérité. 


\section{DISCOURS}

Lu à l'ouverture de la séance du 26 octobre 1784 , a laquelle le prince Hexir de Prusse assista.

La communication établie entre les penples des diverses contrées est 111 des noyens les plus efficaces ponr accélérer le déreloppenuent de lenrs connoissances. Il se fait ansi un henrenx échange d'instruction et do lmmieres. Ce commerce, le moins contenx, comme il est le plus utile, est devenn presune universel. Ce ne sont pas senlenent aujourd'hni les savans qui travaillent it ses progrès dans lenrs royages. Les souverains, les conquérans eux-mênes se sont chargés de cette honorable fonction, et janais il n’y ent noins d"intervalle entre les trônes et les beanx arts.

Que l'on se rappelle comment les chevalier's les plins illustres par leurs faits d'arues parcouroient autrefuis le nonde. On les fètoit dans les joûtes, dinns les tonrnois: ils ne se montroient que brillans dans lenr parure, suivis de leurs trophées et tonjours prèts aux combits. Anjonrd'hni dépouillés dn faste de leur rang, oubliant l'éclat de leur gloire, n'ayant pour tout cor-tége que lenr renommée, à larquelle ils ne peuvent se soustraire, ils s'arrètent dans les ateliers, dans les demeures consacrées anx arts, dans les académies; ils recherchent l'entretien des plilosophes et des'grands littératenrs: c'est que l'art de gouverner et celui de combattre sont devenus des sciences qui tiennent à toutes les autres, qui se sont perfectionnées en unême-temps, 
dans les mêmes lieux, et quelquefois par les travaux des mêmes hommes.

Après avoir visité l'académie qui veille à la pureté de notre langue, celle qui travaille avec tant de succès à l'avancement des commoissances phyșiques, celle qui consacre avec le burin de l'histoire les exploits des grands capitaines, l'étranger illustre que nous recevons aujourd'hui n'a pas voulu nous priver de l'encouragement que dounent ses regards et son accneil. Il n'a point onblié une académie naissante, qui n'aura pas contenplé sans profit un aussi parfait modèle de courage. Le zèle de nos coopérateur's est grand: combien il va s'accroître encore lorsqu'ils apprendront qu'un héros s'est assis parmi leurs confrères, qu1'il s'y est occupé de lenr's recherclies, et que nous avons vin les lauriers académiques cunoblis par la préscnce de ceux que moissonna la victoirc!

La conservation des hommes est sans doute nue des branches principales de l'adninistration. Veiller all traitement des épidémies, en écrire I'listoire, recneillir par une correspondance étendue les observations nouvelles, les publier en $n$ corps de doctrine, et prévenir les abus de l'empirisme, telles sont les vires de notre institution. Nons les retracer devant un tómoin aussi auguste, c'est prendre de nouvenux engagermens ponr les remplir.

Lorsque nons arons cherché quels pouroicnt être nos modèles dans la carrièce qui s'ourvoil it nons, les societés médicales d'belimbourg et do: Jundres nons one offert un plan dont nous arous profite. Mais 
avonons, et nous anrons du plaisir ì le dire aujourd'luni, du'il existe des traces plus anciennes d'établissemens semblables. Dès 1722 on publioit à Berliu, par décarles, les observations réunies des médecius sur la température de l'air et sur les maladies régnantes (1). D'antres rappelleront an Prince qui nons honore de sa présence les guerriers fauneux dans l'histoire de son pays, on il sera plus fumcux encore: nous wons coutenterons de rendre un houmage public à la ménoire des grands maittres de notre art qui s'y sont illustrés, à celle d'Hoffman (2), si ćlomant par son érudition, et si digne des fivenrs dont il fut comblé par le roi de Prusse Frédéric-Gnillaume, et sur-tont is celle de Stahl, mu des phus heaux génies qui aient parn depunis le renouvellement des lettres, qui, restanratenr de la chimic et législateur en médecine, mérita d'luabiter une conr aussi féconde en grands honnies.

La gloire nationale acquise par des actions d'éclat se communique it toutes les ames; elle reproduit dans les divers ordres de la société les diverses sortes de ghtoire: Ainsi les arts et les sciences fleurissent et sont protégés par Frédéric; ainsi la médecine est lonorée et so perfectiome dans un pays agrandi par ses conquêtes. C'est elle qni veille à la santé des armées, qui sait en écarter les fléaux épidémiques; c'est elle qui apprend à conserver les hommes, instrumens si dociles et si sûrs entre des mains lịbiles ì les diriger dans les combats.

(1) Acta medicoram berolincnsium.

(2) Frédéric Hoflman. 
Ces détails intéressans, ces soins affectueux pouvoientils échapper au génćral qu'ıne longue expérience a formé; à cclui dout le juge le plus respectable a dit ce qu'on ne peut appliquer à nul autre capitaine, qu'il n'a pas commis la faute la plus légère dans ses longs ct gloricux exploits (1)? Le guerrier le plus sage pour'roitil n'être pas aussi le plus lumain? La plupart croicnt avoir tout fait lorsqu'ils ont battú lenrs cnnemis; ils ne voient rien au-delà des houncurs du triomphe. Combicn est plus grand celui qui, couvert de lauriers, se trouble à l'aspect de tant de victimes imunolées dans un seul jour, s'afflige à la vue des hôpitaux (2), et dont le cour génércux ct sensible s'aperçoit alors qu'il manque quelque chose au bonheur de la victoirc!

(1) On sait que le roi de Prusse a rendu ce témoignage éclatant de son estime'aux grands talens et ì la prudence consomnéc d. son illustre frère.

(2) En complimentant le prince Henri sur le gain d'une bataille: " Est-il, lui disoit-on, un bonheur comparable à celni d'un général " qui vient de remporter une victoire "? - "Ce bonlseur est grand, " répond le prince; mais il y a, le lendemain, la visite de l'bù"pital." 


\section{ÉLOGES HISTORIQUES.}

QUATRIEME SECTION.

\section{PHYSIOLOGISTES mer MÉDECINS.}

AVERTISSEMENT.

$\mathrm{E}_{\mathrm{N}}$ désignaint cette quatrième section des líloges historiques de $\operatorname{VICQ}-\mathrm{D}^{\prime} \mathrm{A} z \mathrm{Yr}$, sous le titre de Mídecins et de Physiozogistrs, nous paroissons établir une distinction entre les savans qui s'occupent des lois vitales et ceux qui, faisant de ces lois une application éclairéc et utile à l'état de l'homme souffrant, méritent le titre de médecin, trop souvent usurpé par l'ignorance et le charlatanisme.

En effet, nous admettons cette distinction ; et quoique la médecine et la physiologie s'éclairent réciproquement, quoique l'on ne puisse même exercer l'art de guérir qu'après de longues méditations sur les phénomènes de l'organisation et de la vie : cependant la médecine proprement dite et la physiologie sont deux parties bien distinctes de la philosophie naturelle; et quelques plysiciens, tels que Spallanzani, Fontana, 
Duhamel, Lavoisier, etc., ont été jllysiologistes suns être médecins.

La physiologiene doit donc pas être regardée, dans l'état actuel des connoissances, comme une simple di vision de la médecine. On pourroit même dire que la physiologie, ou plutôt les sciences physiologiques, la philosophie de la nature vivante, forment, dans le tableau général des connoissances lrumaines, une division principale, un point de ralliement auquel plusieurs divisions secondaires doivent être rapportées.

Ces sciences physiologiques, qu'il importe de considérer sous ce point de vue général et philosophique, peuvent être divisées, comme les mathématiques, en deux grandes sections; savoir, 1. les sciences physiologiques pures; $20^{\circ}$ les sciences physiologiques mixtes et appliquées.

Les sciences physiologigues pures embrassent toute la nature organisée, ou s'occupent plus particulièrenent de quelques - unes de ses parties, et présentent cn conséquence plusieurs sous-divisions, telles que la pliysiologie générale ou philosophie de la nature vivante proprement dite (1), la physique végétale, l'anatonie

(1) Dins cetle inumiration iles differentes parties des sriences physiolnginues, nows procidons it la manicire de Bacon; ct parmi les connoissances acquises nous plagons des scicuces qui sont 
et la physiologie comparéc, l'anatomic et la physiologic humaines.

Les sciences physiologiques mixtes ou appliquées offrent aussi plusieurs branclıes; sayoir,

1.0 L'agriculture;

2. et 3. L'hygiène et la médecine vétérinaines;

4. L'lygicne de l'homme;

5. La nuédecine proprenent dite, qui a plusieurs sons-divisions, telles que l'histoire des maladies (nosographie), la matic̀re médicale et la chirurgie;

6. La médeciue légale, ou l'application des sciences plrysiologiques et médicales d̀ la lénislation et ì la jurisprudence;

7. La physiologic ì l'usnge des philosophes, ou la comoissance des rapports du physique.et du moral de l'homme;

8.o L'anatomie et la phỵsiologic à l'usage des peintres et des artistes en général.

En observant dans tous ses détails et sous une foule de points de rue différens l'organisation de l'homme, qui est la plus parfaite, et dont les phénouènes sont si variés, les médecins ont dû s'élever par un grand nombre de faits à des

plutôt entrerues que formées; des sciences à suppléer, suivant l'expression de l'illustre chancelier, et sur la formation ou le perfectionnement desquelles il importe d'appeler toutes les études et les mélitations. 
idées générales sur les lois de la vie, en mieux connoître l'essence, et démêler ces principes et ces vérités, que l'on peut regarder comme l'origine des sciences physiologiques.

Parmi les médecins dont Vicq-d'Azyr a fair l'éloge historique, on doit distinguer toutefois, sous le rapport de la physiologie, Haller, Hunter, Lorry, Maret, Lamure, dont plusieurs travaux ont plus particulièrement contribué aux progrès de l'étude des lois vitales. Les autres, tels que Le Roi, Pringle, Serrao, Sanches, ont donné une autre direction à leurs recherches, et le résultat de leurs travaux ne peut être considéré que relativement à la médecine proprement dite, que ces savans ont enrichie par d'importantes observations: différence que nous avons cherché à indiquer en désignant cette quatrième section sous le titre de MÉñcINs et de Puxsiomogistes.

Cette section est beaucoup plus étendue que les précédentes, qui attestent d'ailleurs que la Société royale et son illustre secrétaire ne méconnoissant pas les rapports de l'art de guérir avec les autres genres de savoir, s'étoient approprié cn quelque sorte, par d'lieureuses associations, les hommes et les sciences qui pouvoient répandre le plus de lumic̀res sur les différcntes parties de th inédecinc. 


\section{ARNAUD DE NOBLEVILLE.}

Louis-Daniet, Arnaud de Noblemitue, doyen dix collége de médecine d'Orléans, naquit dans cette ville le 24 déceutbre 1701 .

Après y avoir suivi le cours ordinaire des études, son père, qui le destiuoit au commerce, l'envoya it Nantes clicz 1 négociant de ses aunis. Il y séjourua pendant deux années et il revint cusuite à Orlénus, oì il aida sou pire daus le travail d'une mannfacture (1) que ce dernicr y avoit établie.

M. de Nobleville étoit né sans ambition; il partageoit ainsi son temps cutre cette occupation ct l'ćtude des lettres. Content d'une heureuse obscurité, il savoit que tout état dont l'exercice peut être utile aux hommes est honorable ponr un citoyen.

Il donnoit anx mathématiques tout le temps dont il pouvoit disposer : il prit bientôt pour cette science le gont le plus vif. C'est en effet l'étude qui convient le mieux au petit nombre de personnes qui recherchent la vérité pour elle-même et sans aucun autre intérêt que celui de la connoître et de l'aimer. M. de Nobleville, pressé par ses amis, vint ì Paris pour se livrer avec plus de succès à son penchant; et il fut reçu chez

(1) C'étoit une raffincrie de sucre. 
M. Clairaut, père du célébre académicien de ce nom, oì il trouva tout ce qui pouvoit exciter son émulation ct perfectionner ses conmoissances.

Il suivit en $17^{32}$ un cours de chimie, dont M. Lémeri étoit alors professeur au Jardin dı roi : il fut très-assidu pendant la même année aux leçons de botanique de MM. de Jussieu, dont le non étoit alor's, conme il l'est encore aujourd'hni, l'homneur de la botanique française; il devint même leur ami. Une suite de cette louable curiosité qui lui faisoit désirer de s'instruire dans toutes les sciences naturelles, le porta ’à entendre M. Ferrein, qui enseignoit alors l'anatomie arec célébrité. Ainsi M. de Noblerille, très-versé daus toutes les branches de la pliysique relatives à la médecine, se trouva, sinon malgré lui, aı moins saus en avoir fait le projet, conduit à l'étude de cette science. Il s'y livra enfin arec 111 avantage d'autant plus grand, qu'ayant l'esprit forné par les comnoissances exactes de la géométric, il devoit ètre très-éloigné de ce gon̂t systématique qui a retardé si long-temps les progrés de notre art.

M. de Nobleville étudia la médecine pendant onze amnées dans les amplitliéâtres, dans les bibliotlièques et dans les hopitanx, moins conme mu homme qui vouloit la pratiquer, que comme ayant um grand désir de ]'apprendre. Son dessein étoit mêne de se contenter des connoissances profondes qu'il y aroit acpuises, sans en rechercher les titres; mais ses pareus l'engágècul i prendre celuide docteur : il se présenta

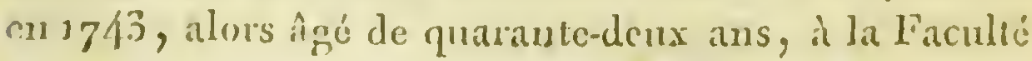


PHYSIOT. ET MÉD. $-\Lambda R N \Lambda U D .17^{3}$ de Reims, quir n'aroit pas contmne de receroir des candidats de cet âge. Il y fut bien accueilli, et l'amnée suivante les médecins d'Orléans l'agrégèrent à leur collégge.

Sa r'éputation l'avoit devancé dans cette ville. M. Paljot, alors intendaut, le pria d'accepter la place de nédecin de sa généralité, dont les devoirs effrayoient lit modestie de M. de Nobleville.

La bienfaisance est la vertu des anes donces et sensibles; elle devoit dunc ère celle de notre acadénicien ; elle avoit mêne sno lni toute la force que les passions prement ordinairement sur les hommes. Il s"annonça à Orléans comme le médecin des paurres. "Q Due mes » confrères, disoit-il, se chan'gent dn traitement des 2) personnes opulentes, je nue dévone entic'renent à 》 celles yui sont dans l'nindigence, et on ne ne dispus tera point cette part que je une snis finte ». Plusienrs citoyens aisés se plaignirent anèrement de cette préférence, soit parce que le mérite de M. de Nubleville étoit comm des gens du monde, soit parce que ponr l'ordinaire ils désirent vivenzent tout ce qui paroît s'éloigner d'eux, et qu'ils ont beancoup de peine à obtenir.

Mais M. de Nobleville saroit que les paurres ont besoin qu'on les nourrisse arant de les traiter; ils'épuisoit en charités.

C'anroit été pen pour lui de consommer ainsi pendant claque année un revenu assez considérable, et de rendre anx indigens des services dont sa mort auroit óté le terme; i] roulut que ses bieụfaits hii survéçussent, 
et il les perpétua en achetant une maison grande et commode qu'il destina aux assemblées du Collége de nédecine, et sur-tont aux consultations gratuites que les niembres de cette compagnie y doment chaque semaine, depuis cette époque, en favenr des pauvres, à l'exemple de la Faculté de médecine de Paris. Une des conditions de cette institution est que, si le Collége de médecine d'Orléans cesse on néglige ces consultations, la maison appartiendra à l'hôpital général de la ville. Cette clause paroîtra dure à cenx que l'esprit de corps domine et aveugle; mais M. de Nobleville n'ignoroit pas qu'il étoit citoyen avant d'ètre nuédecin, et que les devoirs de l'humanité sont toujonrs les premiers que l'on ait ì remplir.

M. de Nobleville prit sur-tont en considération les asiles dans lesquels, quoiqne tout appartienne anx pauvres et qu'ils en soient en quelque sorte les propriétaires, ce sont cependant eux que l'on traite ordinairement le plus mal. Il fut nommé administratenr de l'hôtel-dieu d'Orléans, et il établit dans cette maison une économie qui ne pouvoit être que le finit de l'activité la plıs grande et dn zèle le plns éclairé.

Il vivoit avec une socur respectable qui veilloit a l'exécution de ses volontés, et qui en assuroit le succès par ses soins.

Nons avons loué d'abord dans M. de Nobleville le bon citoyen et l'honme charitable, parce que le premicr houmage appintient it la rertu : consiclérons maintenint ses travaux littéraires.

Le prenice onviage yu'il a public eu 1747 , de 
PHYSIOL. ET MÉD. - $\triangle$ RNAUD. ${ }_{175}$ concert avec le Collége de médecine d'Orléans, a pour titre : Manuel des Danes de charité, on Formules de médecines faciles à préparer. La quatrième édition de ce recueil a été faite à Paris en 1768 , et il a été tradnit en italien et en hollandois. L'antenr y a joint un petit Traité de la saignuée. On a tronvé ce précis si bien finit, que c'est le premier, et quelquefois mème le senl livre que l'ou nrette entre les mains des élèves en chirurgie dans les provinces. Ce nanuel devoit servir de base anx consultations gratuites du Collége de médecine d'Orléans, et l'on peut le regarder conme le frnit du zèle de M. de Nobleville pour le soulagement des pranvres. Ce médecin s’étoit proposé de nrettre cliaqunte citoyen en état de leur donner des secomrs dans leurs maladies; il espéroit, comme le titre de l'ourrage l'undique, ponvoir communiquer des lumières suffisantes it ce sexe compatissant, qui, par sa sensibilité et la doncenr de son caractère, paroit plutòt destiné à consoler les indigens qu'à les gnérir. Ou ne peus qu'applaudir aux intentions de M. de Nobleville et at celles de tons les autenrs qui ont fait des efforts pour mettre ainsi la médecine à la portée de tout le monde; mais une entreprise de ce genre ne peut avoir de succès. Comment en effet ne voit.on pas que de semblables traités, ontre l'unconvénient qu'ils ont de unultiplier cette classe d'hommes très-dangereuse, sur-tout en médecine, qui se croieut savans sans étude, ne renferment que la moindre partie de ce quils devroient contenir pour remplir leur but? Quel avantage peut-on retirer de l'expositiou des médicamens lorsque l'on -ignore 
les circonstances dans lesquelles on doit les prescrire? Sans cette connoissance, la première est non seulement inutile; elle est encore d'antant plus dangereuse, qu'elle donne moins de ressources aux citoyeus honnêtes pour bien mériter des lommes, qu'elle n'en fournit aux ignorans pour les tromper.

L'Académie royale des sciences avoit alors à Orléans pour correspondant M. de Salerne, médecin habile et ami de M. de Nobleville : ils se rémnirent pour l'exécution d'un projet difficile, on pourroit peut-être dire ingrat. Feu M. Geoffroy faisoit depuis plusieurs années des leçons très-snivies sur les propriétés des médicamens, et il travailloit à un cours très-ćtendı de matière médicale. Ses cahiers sur les nuinćranx et sur une partie des végétaux éloient égalentent estimés par les ćlèves et par les savans. La mort de l'anteur interJompit cet important ouvrage ; il seroit pent-être resté incomplet, et nos descendans l'auroient regardé comme un monument honorable pour la mémoire de M. Geoffroy, et en mêne temps comme une occasion de reproche pour ses contemporains, si MM. de Nobleville et de Salerue n'avoient pas en le conrage de justifier à ce sujet notre siècle vis-ì-vis du la postérité. Ils ne se sont point flattés d'égaler en labileté la main hardie qui a tracé le plan de l'édifice; et il y a peutétre plus de mérite qu'on ne pense ì valincre ainsi son anonr-propre, en travaillant d'après mu modicle qu'on est certain de ne pas égaler.

La suite des végétanx parut cu 1756 , en trois volunes in-12; nt six aus après l'Listoire naturelle des animanx 
fut publiée en six volumes de mêne fornat, inxquels un écrivain lrabile (1) a ajonté deux tables de tont l'ouvrage, dont l'ensemble est sans contredit le recneil le plus complet que nous ayous sur la matière médicale.

MM. de Nobleville et de Salerne n'out pas senlement indiqué les propriétés des substances animales; ils ont encore domé sm. l'anatomie des quad rupèdes des détails intéressaus et des observations exactes. Ils out évité me fiute que M. Geoffroy u'anroit pas conmise si les progrès de la chimie avoient été plus avancés. Les premicrs volnunes de sa Matière médicale sont surchargés d'analyses, presque toutes faites au fen, et qui ne jettent aucun jour sur les vertus des médicamens. Les continnaten's en ont senti l'imitilité ; et ils ont été très-circouspects à ce sujet.

Un de nos plixs benux génies a menacé les métaphysiciens et les gens a systimes de renfermer dans $n$ n petit nombre de pages toutes les vérités conmues. Il semble que Lommins ait exécuté ce projet, relativement à cette partie de la médecine qui traite des synptomes des maladies et du jugenent que l'on doit en porter. Son onvrage est écrit en latin, et il en avoit déja paru une traduction en français, dont le public n'avoit pas été satisfait. En 1760 le libraire en promit une plus exacte, et il en cliargea l'abbé Mascrier. Heurensement M. de Nobleville dirigea un travail qui ne

(1) M. Goulin, rloctenr en médecine, auteur de plusieurs ourauges estimés.

T. 2. 
ponvoit être bien fait que par un médecin habile. La seconde édition dı Tableau des maladies, de Lommius, soignée par M. de Nobleville, fut très-accueillie.

On sait que $M$. Ferrein a enseigné long-temps la médecine pratique de la manière la plus brillante, soit aı Collége royal, soit dans son amphithéâtre particulier. Quelques-uns de ses élèves avoient recueilli ses préceptes, et ils conservoient avec soin ce trésor littéraire, qui étoit peu répandu, mais très-recherché: $\mathbf{M}$. de Nobleville ayant appris que M. Ferrein ne songeoit point à le rendre public, s'empressa d'y suppléer en 1769. Ce cours de médecine fut imprimé en trois rolumes in-12. M. de Nobleville, alors âgé de soixantehuit ans, avoit pour le succès de cette production tout le zèle que peut inspirer l'ouvrage d'un maître que l'on respecte. M. Ferrein lui en témoigna sa reconnoissance. Nous ne dissimulerons point que ce traité n’a pas répondu tout-à-fait à la r'éputation de l'auteur. Des principes clairs et une grande méthode le rendent recommandable pour les commençans. Les lecons de M. Ferrein étoient en quelque sorte un commentaire de la doctrine de Boërraháve, que l'on adniroitalors avec enthousiasne. Ce savant a lait en médecine à pen près la mênue révolution que Descartes 'rn plyysigue. 'Tuns les denx ont pris avec chalen les intérits de la vérité, mais on s'est aperçu qu'il lemest anssi sonvent atrivé de substitner nue erren nonvelle et brillante unc errenr trop ancienne el dont on étoil cumayé.

Jinufhence du sol et des salisons sur les maladies, dont nos correspondans s'occupent arec tant de zible, 


\section{PHYSIOL. ET MED. - ARYAUD. 179}

n'avoit point échappé à M. de Nobleville; il fit en 1744 un travail dims ce gerre, relatif à la ville d'Orléins, et il le communiqua à l'Académie royale des sciences, quil lui donna son approbation.

Ponr se livrer à tant de travaux, M. de Nobleville avoit besoin de tont son temps, et il viroit loin de tonte société : mais ce n'étoit point nu de ces hommes qui finent le commerce du monde pour ne s'occuper que d'enx-mênes; il ne méditoit an contraire dans sat solitude que sur les moyens de se rendre utile; il aroit tonjonrs conservé celte gaieté donec que ímne la rraie philosophie: grand amateur de la musique, il avoit poussé trì-loin ses connoissaluces dans cet art angrédble, qui lui servoit quelquefois de délassenent.

Ce fint sans donte par une snite dr ce gout qu'il s'appliqua dans sa retraite à élever et à observer l'espece d'oisenn que les naturalistes et les poëtes appellent de concert le chantre de la nature. 'Tont ce yni concerne la chasse, la nourriture, les annour's, la ponte ot l'édncation dn rossignol, est exposé darns un onvrage écrit arec élégance, et rempli d'observations fines ct délicates, qur'il a publié à ce sujet en $177^{3}$. En cherchant à rendre le rossignol intéressant, M. de Noblerille n'a pas dédaigné de songer an sort de son captif, et il a indiqué le moyen de le faire chanter sourent et longtemps, en lni procurant mne vie commode et ficile. Il a mème décrit arec nne sagacité surprenante les maladies dont cet oiseau est attaqué, et il a fait connoître des procédés simples et ingénienx ponr le guérir, ou au noins pour diminuer ses maux. 
M. de Nobleville a passé ses dernières années dans une maison située presque hors de la ville et près d'un jardin où il cultivoit quelques plantes étrangères. Sa vie a toujours été un modèle de bienfaisance et de vertu. La sagesse et l'exactitude de son régime avoient fait espérer qu'elle auroit été prolongée plus long-temps. Il fut frappé d'apoplexie le 29janvier 1778 . Cette mort imprévue, mais à laquelle il étoit préparé par une piété solide et vraiment chrétienne, l'enleva, étant âgé de soixante-douze ans, à ses concitoyens, auxquels le souvenir de ses services rendoit sa vieillesse précieuse et respectable, et sur-tout aux pauvres, dont les larmes et les regrets auroient été le seul éloge désiré par. $M$. de Nobleville, si sa modestie lui avoit laissé entrevoir qu'il en méritoit un. 
PHYSIOLOGISTES ET MÉDECINS. 181

\section{BARBEU DUBOURG.}

Jaceues Barau Duboura, doctenr-régent de la Facnlté de médecine de Paris, membre de la Société royale des sciences de Montpellier, de la Société médicale de Londres, de l'Acarlémie des sciences de Stockholn et de la Société philosophique de Philadelphie, rnaquit à Mayenne le 35 férrier 1709.

Un esprit prompt et mobile auquel $1 m$ senl genre d'occupation u'a jamais suffi, une mémoire houreuse, nne ame facile à enflammer, mu penchant naturel pour tout ce qui portoit le caractère de la graudeur, et surtont un coenr droit, telles sont les qualités que l'on a tonjours recounnes daus le saraut dont l'éloge m'est confié.

Ses premières études furent très-rapides. Ayant fini à quinze ans son cours de philosophie, il toucha peutêtre trop tôt à cette époque dans laquelle un jeune homme incertain, sans expérience, subjugué nécessairement par l'imitatiou, ne connoissant ni les lois qui gonvernent les différeus.ordres de l'état, ni celles que sa propre constitution lui prescrit, ose cependant faire un choix, duquel dépend son existence et souvent le bonheur de ceux dout il est environné. Ainsi deux des frères de M. Dubourg, auxquels il étoit tendrement attaché, s'étant voués à l'état ecclésiastiquie, l'amitié 
fit naître eu lıi le même peuchant, et il crut être né pour snivre le même parti. Bientôt l'étude de la théologie fut la seule dont il s'occupa; il remonta même aux sources les plus anciennes at les plıs pures de cette science sucrée, en apprenant la langue hébrä̈que, et i) y fit de si grands progrès qu'il a été souvent consulté sur l'interprétation des passages les plus difficiles.

'Tant qu'il ne fallut que de la piété, des mœurs et de l'applicalion, M. Dubourg se regarda comme vraiment appelé au sacerdoce; mais il fut éclairé sur sa vocation lorsqu'on exigea de, lui le serment irrévocable qui lie pour tonjours le prêtre à l'autel, et que l'on ne prononce jamais saus s'exposer à être sacrilège, si l'ou n'a pas le courage de s'élever au-dessus de soimême à mesure qu'on se rapproche de la divinité. M. Dubourg ne put se déterminer à prendre de tels engagemens, et il quitıa à regret un état dont il ue se crut pas digue.

Cette méprise lo rendit plus circouspect sur le choix qu'il aroit à faire, et qu'il résolut de différer. La littérature lui offrit un clump vaste, agréable à cultiver, et d'autant plus conforme a son peucliant, qu'il favorisoit l'iudépendance qui a toujours été la base de son caractere. Il donna sur-tout beancoup de teups à la lechure des prëtes et des listoriens; il prit enfin du gon̂t pour l'étude de la pliysigue et de la nuédecine; mais il ue se présenta qu'à l'âge de trente-luxit ans it la Faculı́ de médecine de Pairis, qui le reçut en 1748. Il pronvar dans les theses qu'il sontint qu'il ne nanquoit ui de celle force qui est nécessaire pour com- 


\section{PHYSIOL. ET MED. - DUBOURG. 183}

battre les préjugés, ni de cette adresse qni säit orner un systeme et qui se propose moins de convaincre que de persuader (1). On recomnoit la première daus sa thèse sur le pen de danger des amies climatériyues; la seconde brille dans la nunière ingéniense avec la'puelle l'antenr a essayé de pronrer que les organes destinés aux fonctions vitales sont sujets à me sorte de repos ou de sommeil.

Arant d'entrer en licence, M. Dnbontan aroit donné des preuves non épuivorines de son altachement pour lat Faculté de médecine, en prenant sa défense contre le Collíge de chirurgie (2). Henrensenent cette discnssion et tons les mémoires qu’elle a occasionnés sont onbliés du public inpartial et jullicienx, qui sait tonjours distingner les intérèts des savans d'avec cenx de la science. Quelque lonables qu'aient été les intentions ct le zéle de M. Duhourg, nous nons garderons bien d'insister sur ces détails et de faire renaitre des impressions relatives ì des circonstances passées, qui ont dì nécessairement disparoitre avec elles et dont le temps a profondément effacé la trace.

(1) Les lheses que MI. Duboura a soutenues sont les suivantes:

1. Daturne etiam vitaliunt organorum sommus? aff. $17\{6$.

3." Utrim anni climatcrici cetcris periculosiores? neg. 174.

3.० An variolarum morbus absque cruptione? aff. 17 7\%

4. An trachceotomice munc scalpellum, nunc trigonus mucro? affirmat. $17 \not 8$.

(2) Lettre, etc. i l'abbe Desfoutaines, au sujet de la maitriseès-arts; in-12, $17\{3$.

Deux lettres à unc dame au sujet d'une expérience de chirurghie faite à la Charite le 22 juil $17 f f$; in- $80^{\circ}$, Paris. 
Sa réception dans la Faculté de médecine n'interrompit point ses travaux littéraires. La correspondance qu'il entretenoit avec les savans les plus distingnés 'd'Angleterre et d'Italie l'avoit mis dans la nécessité d'apprendre les langues propres à ces contrées. Le célèbre vicomte Bolingbroke, dont il a été l'ami, lui avoit inspiré le goût de la littérature anglaise. Les Lettres de ce lord sur l'histoire offrent nn grand nombre de traits hardis, de vues neuves et originales, d'assertions fortes et piquantes, qu'un style négligé fait ressortir d'une manière plus marquée. Un ouvrage de ce genre devoit plaire à $M$. Dubourg, qui le tradnisit avec succès d'après l'édition que M. Pope en avoit donnée en 1738 (1). Il joignit à la fin de ce recueil la traduction d'nne lettre très-ingéniense et très-philosophique écrite par le lord Batlıurst, sur les avantages de la retraike, qui nous rend à nous-mêmes en nous livrant aux doux loisirs de la méditation; sur l'utilité de l'étude qui, en nous donnant plus de moyens pour devenir bons et heurenx, nous apprend en même temps à bien mériter des hommes et à nous en passer autant qu'il est possible, et sur l'exil, également profitable au sage comme à l'iusensé, puisque l'un y trouve torjours son repos, et l'autre très-sourent sa raison.

L'homme, qui n'occupe qu'mu point et quine séjourne qu'un instant dans l'mivers, a sı, par son industric

(3) Lettres sur l'histoire, traduites de Bolingluroke; 2 rol. in-12, 1752. 
PHYSIOL. ET MÉD. - DUBOURG. 185 et par son infatigable curiosité, comnoître les rapports des parties qui le composent et déterminer les époques des changemens qu'elles ont éprouvés. Deux scieuces appelées, l'nne la géographic, l'antre la chronologie, ont été le résultat de ces recherches. C'est sur elles que la comnoissance de l'histoire est fondée; tonte l'étendue dı globe n'est, dans le sens de la première, q11'nu espace circonscrit qu'elle mesure arec précision suivant les dimensious de sil longuen et de sa largenr, sur lequel l'inmensité des mers, le conrs des fleuves et l'encliaiuement des montagnes s'aperçoivent en $u$ m iustant, et qui présente en $n$ n seul tablean tous les clinats connus, rangés suivant la proportion de lenrs distances. La seconde retratce la snite des évémemens: moins composée que la géographie, les objets clont elle traite n'ont, conme le temps, qqu'me senle dimension, celle de lenr duréc. La chronologie n'aroit cependant pas eucore été réduite en tables. M. Dubourg a en le unérite de concevoir et d'exécuter cette entreprise en trente-cinq planclıes, précédées d'un disconrs insrructif (1), et qui, étant rémies et ronlées sur denx cylindres, imitent la révolution des siècles et composent un tablean chronologique qui s'étend jusques à l'année 1753 , daus laquelle l'antenr ćcrivoit.

Dien qui est antéricur à tons les temps, se trouve placé avant enx. L'origine et l'anéautissement des

(1) Chronographie, on Description des temps, contenant la suite des souverains de l'unirers, etc. $\Lambda$ Paris, chez Milje Bihéron, 1753. 
empires, la succession des souverains, le développe. nient et l'accroissenient de l'espèce liumaine dans le sein de la paix et de l'abondance, ses émigrations, son dépérissement sons un ciel peu favorable, sa destruction dans les horreurs des siéges et des combats, le sollvenir des belles actions, les monnunens élevés par les grauds liommes, le petit nombre de cenx que la reconnoissance a consacrés à leur mémoire, les temps oì ils ont vécu, tont y est distribué avec ordre et frappe successivement les yeux de l'observatcur. Trois époques principales, la création dn monde, la fondation de Rome, et la nássance de Jósus-Christ, font la division de ce tablean. En le parconrant on s'arrête avec complaisance sur tout ce qui tient aux princes vertueux et bienfaisans, et l'on voit que la du rée des empires est, ainsi que celle de la vie humaine, prolongée par un régime égal et par des travaux modérés, et que rien n'est plus propre ì l'abréger que l'indolence qui engourdit tous les ressorts, on la trop grande activitć qui épuise les forces.

L'autenr tronva beaucourp de difficultés dans l'exécution de ce projet. Outre nn nombre infini de dates qu'il fut obligé de vérifier, il fallut qu'il créàt en quelque sorte un nonvel alphabet pour désigner par des signes convems les bonnes on mauvaises actions, le genre d'occupations et le sort des persomnages les plus importans dont il devoit parler. Ainsi, lorsyn'on sait quelle est la valeur de ses caractères, on recomnoit au premier conp d'xil, parmi les homnes qui out gonverné leurs semblables, conx qui nnéritent des hom- 
PHYSIOL. ET MED. - DUBOURG. 187 . mages on dn mépris. Puissent les grands de la terre ne jamais oublier qu'outre le témoignage de leur conscience qui les juge, et l'antorıté de l'Etı'e suprème qui les réconpense on les punit, ils ont encoreà craindre le tribunal de la postérité, qui trausmettra d'âge en âge leurs vertus on leurs vices! Ou ne sera pas surpris sans doute de la liberté avec laquelle nous nous expliquons it ce sujel: il est des vérités qui ne peurent être dites que sous le règue des bons rois; elles sont l'éloge le plus digne de leur délicatesse et de leur justice. Ines productions de M. Dubonrig étoient variées eomme ses gonts. Ayant passé plusienrs années ì classer les grands homunes suivaut les époques anxquelles ils ont vécn; s'étant faligné dans la profondeur de l'autiquité la plus reculée, il falloit du repos at son esprit, qui cependant ne ponvoit rester oisif. Ce fut sans donte pour se procurer ce délassencul qu'après avoir été l'historien de tontes les untions et de tons les siccles, il devint le rédacten d'un journal de médeciue, intitulé Gazette d'Epidaure. Cet ourrage (1) périodique, qui a parn pendant trois années, et diuns lequel ou trouve par-tont de la décence et souvent de la gaicté, a servi à répandre des préceptes utiles et à recueillir des observations intéressantes.

Bientôt un sujet plus important occupa M. Dubourg. Une question nédico-légale sur la durée de la grossesse et sur le terme de l'acconchement divisoit les

(1) Gazette d'Épidaure, on Recueil hebdomadaire des nourelles de médecine, etc., 4 vol. in-8. $:$ Paris, $1 ; 61-63$. 
médecins et les chirurgiens les plus célèbres de la capi. tale. On se sonvient que plusieurs montrèrent alors plus de chalenr que l'on n'en met ordinairement lorsqu'on est conduit par les seuls intérêts de la vérité. Notre académicien réunit en 1765 toutes les pièces relatives à cette discussion dans un mémoire trèsdétaillé (1). Les éclaircissemens que le raisonnement, l'observation et l'analogie peuvent fournir, sont présentés avec méthode dans trois sections différentes.

La formation des graines ev la germination dans les végétaux, le développenent des œufs dans les insectes et dans les oiseaux, le terme de la portée dans les quadrupèdes, enfin la durée de la grossesse dans l'espèce humaine, étant, quel que soit d'ailleurs le vœu de la nature, susceptibles de variations dont l'existence est démontrée, mais dont l'observation n'a point encore déterminé l'étendue, M. Dubourg pensoit avec raison que les connoissances physiologiques étoient trop peu avancées pour qu'il fût possible de décider une question aussi importante. L'on a dans ces recherches deux écueils à éviter, celui de prodiguer à un enfant étranger des biens dont il ne doit pas avoir la jonissance, et celui de priver nun enfant légitime du nom et de la fortune de ses ancêtres, en courrant celle qui lui a donné le jour d'un opprobre incffaçable. Quel lomme sera assez téméraire pour fixer des limites entre deux points, an sujet desquels

(1) Recherches sur la duríc de la grossesse et le terme de l'ac. eonchement. Amstcriam, 1765. 


\section{PHYSIOL. ET MÉD. - DUBOURG. ${ }_{18}$ ?}

l'expérience est elle-même environnée de tant d'incertitude? In attendant que la physique exacte ait fourni une base solide sur laquelle la rigueur de la loi puisse établir 111 jugement certain, ne doit-on pas prendre le parti le plus doux et le plus honorable pour l'humanité; et n'est-il pas consolant pour nous de croire que l'on se trompera moins en traitant toutes les mères comme fidèles aux devoirs sacrés de la tendresse et de la vertu, qu'en les soupconuant toutes de vol et d'adultère?

Cet ouvrage très-estimable seroit absolument exempt de reproches, si l'auteur en avoit supprimé quelques notes, dans lesquelles il u'a pas traité un de ses confrères avec tous les égards qui lui étoient dus. Comment M. Dubourg ponvilt-il ignorer que la critique ancère est mue arme absolument inutile ponr la conviction, et qui est presque toujours plus dangereuse pour celui qui s'en sert, que pour cenx contre lesquels elle est dirigée?

La botanique tenoit le premier rang parmi les travaux auxquels M. Dubourg se lirroit; mais il l'envisageoit sous l'aspect le plus utile: son projet étoit d'en répandie le gout et les connoissances parmi les gens An monde, et sur-tout dans cette classe de citoyens qui recueillent et conservent les végétaux dont on a coutume de faire usage en médecine. Son jardin, oì il cultiroit les plantes usuelles, étoit ourert aux étudians, alx amateurs et aux herboristes, que M. Dubourg se proposoit principalement de former. Tandis que les botinistes dn premier ordre cher- 
clioient à rétablir l'ancienue nomenclature grecque, M. Dubourg, plus modeste, couservoit avec soin les noms français, et il en créoit même lorsqu'il n'y en avoit point d'adoptés. Le traité (1) dans lequel cette nouvelle méthode est consignće parut en $17^{6} 7$ : l'auteur le dédia à sa femme. " Le public, dit-il dans » l'épître dédicatoire, u'a pas plıs de foi aux époux 》 heuréux, que de commisération pour les époux 》) malhenreux $\nu$. Son dessein n'étoit pas de combaltre cette opinion, mais senlement d'offrir à la persomue qu'il ämoit le plus celui de ses ouvrages auquel il étoit le plus attaché.

Le second volume de ce traité renferme plusieurs lettres curieuses sur le choix des bons remèdes, qui sont, suivaut l'expression de Vedelius, ainsi que les vrais amis, en très-petil nombre; sur la nature de certaines maladies qui ne requièrent aucun traitement, et sur la nécessité d'inspecter les boutiques des herboristes. La Faculté de médecine de Paris a rempli les vues de M. Dubourg, en domuant à la réception de ces artistes toute l'attention qu'elle étend aux objets utiles dont l'administuation lenr est confiée.

De nuême qu’il y a des productions végétales et animales communes ì tous les pays, il y a aussi res principes généranx que la raison dicte à tons les hommes pour éclairer leur conduite et assurer leur

(1) Le Botaniste frangais, comprenant loutes les planfes comnunes et usuclles, disposées suivant me nourelle métiode, et décries es langage vulgaire; 2 rol, in-12. 


\section{PHYSIOL. ET MÉD. - DUBOURG. 191}

bonlieur. M. Dubonrg essaya de les rassembler daus min ouvrage particulier (1). Parmi les détails que ce traité renferme, il est de notre devoir de ne nons arrêter qu'aux idées de l'auleur sur le commerce maritime. M. Dubourg expose comment chaque peuple cst fondé, pour protéger son industrie, il s'appropries une partie de la mer qui baigne ses ports; mais il firt sentir combicn il est essentiol et conforme at la mature que la ner reste libre, et combien il y a d'orgneil et d'extravagance it se dite les rois d'mu élément anssi indépendant, qui ne reconnoît que lat loi de la gravitation miverselle, ancquel la main de l'lomme n'a jannais inpriné la trace de sa donination, qui connmande plutôt qu'il u'obéit anx vaisseanx qui le sillomrent, et sirr lequel les succès sont aussi inconstins que les flots dont il est agité.

L'époqque la plus némorable de la vie de M. Dinbonrg a été sa liaison arec ce pliilosophe yni semble être né ponr allumer le flambean des sciences en Ancirique, pour y transporter les arts et l'industric de l'ancien monde, et sur-lont pour briser les preniers ameanx de ces chaines que le despotisme d'mu peuple libre s'efforçoit d'étendre an-deli des mers et d'appesantir sur sa palrie.

Les progrès des arts et des sciences n'étoient jamais oubliés dans la correspondance de M. Dubonrg avec son respectable anni. L’électricité positive ou négative

(1) Petit Code de la reison humaine, on Exposition succincte de ce que la raison dicle a tous les hommes, etc. 1773. 
substituée au système des affluences et des effluences; son application au corps humain pour le traitement des maladies; la distinction de deux espèces de paralysies, l'une accompagnée de contraction et l'autre de relâchement, cette demière étant plus curable par l'électricité; des réflexions sur la diversité que la différente nature des verres apporte dans les expériences électriques, un grain de sable, ou tout autre corps étranger, recevant dans la charge un certaine quantité de fluide qui peut se dégager subitement et briser le verre dans les parois duquel il étoit renfermé; la description d'un paratonnerre construit d'après les principes de M. Franklin; des recherches sur les moyens de rappeler à la vie les personnes suffoquées par la foudre, ou des animaux tués par l'étincelle électrique; des remarques sur la population ct sur les manufactures des Etats-Unis de l'Amérique comparées avec celles de l'Europe; des considérations qu'il avoit déja communiquées a la Faculté de médeciue de Paris sur l'inoculation en général; les détails des succès de cette méthoile pratiquée à Boston, la proportion des guéris et dos morts étant de 800 à 6 ; des expériences sur l'art de nager; des réflexions sur la construction de l'harmonica et sur la manière d'en tirer des sons: tel est le tableau du commerce littéraire que M. Dubourg a entretenu avec M. Franklin. Commoissant les lumières et la complaisance de ce savant, il no craignoit pas de lui proposer les questions les plus difficiles; il étoit bien assuré dé recrroir toujours les réponses les plus satisfaisautes. Ces lettres, jointes aux 
PHYSIOL. ET MÉD. - DUBOURG. $19^{3}$ autres mémoires de M. Franklin, composent le recneil intéressant dont MI. Dubourg a donné en 1773 une traduction française (1) beancoup plus complite que l'édition anglaise antécédente. Ce travail resserra encore les liens qui existoient déja entre ces deux plyysiciens. Sumblable i denx corps qui se rencontrant avec une vitesse inégale, la prartagent entre enx ponr se monvoir ensuite nuifornénent, les anes des denx anis se choquent et se pénetrent, de sorto que celle qui a le plus d'énergie s'enpare de l'autro pour lui communiquer son impulsion. Ainsi le génic de M. Franklin anima M. Dubourg, qui comptoit parmi ses plaisirs et ses chagrins les plus vivenuent sentis les succès ou les mallieurs de la patrie, si chère à son ani, et qui se glorifioit d'avoir été en France le prenici allie des Américans.

Lá dernière production de M. Dubourg a été dictée par sa tendresse pont M. Mir de la Motte, son neven, dont il gnidoit les pas dans la carrie're de la médecine, et ancquel il en a exposé les principes sons la forme d'aphorismes (2), qui ont été lus dans nos séances. M. Dubourg aroit commencé l'édncation de son neven en établissant, relativement aux connoissances médicales, des linites déterminées entre ce qui est bien comm, ce qui n'est que probable, ce qui est dontenx et incertain. Ce genre d'instruction seroit

(1) OEUrres de II. Fraxckix, traduites de l'anglais, arec des additions, 1 rol. in $\left\{.0^{\circ}\right.$.

(a) Aphorisunes de nédecine, manuscrits.

T. 2. 


\section{EIOGES HISTORIQUES.}

moins séduisant, mais phus solide que celui qui est généralement adopté. Il apprendroit aux étudians à faire usage de leur raison, et sur-tout à se défier de lenr esprit et de celui des autres.

Un goût très-vif pour tout ce qui pouvoit piquer la curiosité des physiciens avoit engagé M. Dubourg à faire des expériences difficiles, longues et très-coûteuses, sur la nature du sol le plus propre à produire des grains de différentes espèces, et sur la construction des fours à poulets. A la vérité ces travaux ne l'ont pas conduit aux résultats qu'il cherchoit; mais il a eu la boune foi de l'avouer : et si l'on divit les plus grands éloges à l'homme habile qui exécute de la manière la plus complète un projet utilement courn, il seroit injuste d'en refuser à l'homme nodeste qui, après avoir pris beancoup de pcine et fait de grandes dépenses, aime mienx convenir qu'il s'est trompé, que de s'exposer à tromper les auties, et qui ne craint ricn tant que de faire tourner au profit de l'erreur des expériences et des travaux uniquentent consacrés à la reclierche de la vérité.

M. Dubourg, par la sensibilité de son ame, par la douceur de son caractère, et par sa tolérance dans les affaires d'opinion, étoit bien digne d'être recherché et d'avoir des annis. Il se montra toujour's trìs-délicat darıs ce choix. ce J'aimerois mienx, répétoit-il souvent, » avoir un hounête homme ponr enueni, qu'un fripon ग pour anii. s

Nons ne passerons point sons silence les circonstances qui ont arcounpagné sa réception daus la So- 
PHYSIOL. ET MEDD. - DUBOURG. 195 ciété. Il n'a demandé une place d'associé ordinaire qu'après avoir étć pendant quelque temps très-exact it nos assemblées. La Compagnie le comptoit au nombre de ses coopératenrs avant de l'avoir recu parmi ses membres, et sa nomination a été de notre part et de la sieme un gáge réciproque d'estime et d'attachement.

11 avoit long-temps pratiqué la médecine avec antant de zèle que de désintéressement. Il renonrça perrdant les dernières années de sa vie à cette pénilile occupation, et il ne s'écartuit de cette rígle qu'il s'étoit prescrite, qu'en faven des paurres et de ses an is : les mos et les autres ont tonjours en 111 droit égal anx seconrs qu'il étoit en son ponvoir de len厂 procurer.

Son andem pour l'étule étoit tempérée par une gaieté donce (1), qui lui offroit tonjonrs après le travail un délassement assuré. Il s’est livré avec empressement it tontes les recherches dont la Societé l'a chargé, et la mort l'a surpris an milien d'une commission très-fatigante, dont il remplissoit les devoirs avec rigueur. Il fut attaqué, le prenier décembre 1779 , d'me fièvre maligne, ì laquelle il a succombé le treizième jour de cette maladie, alors ìgé de soisantedix ans et neuf mois.

M. Dubourg ne reçut point en naissant ces rares dispositions qui sont la source du génic; mais il les dut

(1) On pent citer dans ce genre le Calendrier de Philardelphie: Bouillon, ${ }^{7} 77^{3}$. 
196 ÉLOGES HISTORIQUES.

à la nature de talens que le travail a cultivés et rendus fructueux. Son nom sera inscrit parmi ceux des citoyens utiles et des littérateurs les plus zélés (1) : lié avec celui de M. Franklin, il attirera les regards de la postérité, qui n'oubliera point l'ami de ce grand hoinme.

(1) M. Dubourg a publié, $1^{\circ}$. des Objections à M. Basselin sup la quadrature du cercle; $2{ }^{\circ}$ une Lettre à M:te $* * *$ stir les vents. Enfiu on troure dans sa bibliothèque une édition de l'Esprit des lois, de Montesquieu, sur laquelle on lit des réflexions trèsjudicieuses. 
PHYSIOLOGISTES ET MÉDECITS. 197

\section{BOUILLET.}

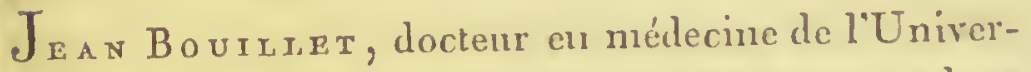
sité de Montpellier, le plns ancien des correspondans de l'Acadénie royale des sciences, professe tur de mathématiqnes et secrétaire de l'Académie de Béziers, na quit à Servian, près de cette ville, le 6 mars 1690 , de Jean Bonillet, cultivatem, et de Catherine Lonnear, fille. du juge royal du lien. 11 comptoit parni ses parens un grand nombre de ces liommes estimables qui horment toute lenr ambition à une abondante récolte; of en remontant des lienx où sa réputation l'a fait connoitre jusqu'à celui de sa naissance, on y trouve son nom égalennent chéri par ses concitoyens ì Bézicrs, et ì Servian par un peuple de laboureurs qui ue savent cstimer que des vertus.

Le curé de ce village, qui étoit un des amis de son pìre, se cliargea de sa première éducation, et bientùt après il fint envoyé an collége de Béziers, oì il se distingua par son application à létude et par ses succès.

Que l'on ne croie pas cependaut que nous regardions ces avantages comme une preure réelle de sa prééminence sur ses condisciples : les conronnes acadéniques ne sont pas tonjours réservées ì cenx dont le front a été ceint des lanriers des écoles. Un jugement droit, une bonne mémoire, et de l'opiniâtreté au travail, 
suffisent ordinairement pour s'y distinguer : on admira de boume heure ces qualités daus M. Bonillet, que nous n'annonçons pás comme un homme de génie, mais comme un savant modeste, et versé dans plusieurs genres de comnoissances.

Ses parcus l'avoient destiné dès son enfance à l'étıde des lois; nu pencliant auquel ils furent obligés de céder le conduisit à celle rle la médecine, dont il reçut les premières leçons en 1707, dans la célèbre Université de Montpellisr.

Le froid de l'hiver de 1709 sera à jamais mémorable par sa rigueur : les circonstances qui l'accoinpagnèreut le rendirent funeste pour tontes les prodnctions végétales, et sur-tout pour les oliviers, qui sont la sorrce d'une grande richesse dams le Languedoc. Lc père de M. Bouillet, ainsi privé d'une partie de safor'une, vit avec regret le doctorat de son fils différé jusqu'en 1711.

Pourquoi le rrai mérite ne peut-il pas toujours obtenir un titre qui devroit en être la récompense et le caractère, tancis qu'il reste si souvent à l'ignorance des ressources pour s'en pourvoir?

Après avoir été regu docteur, M. Bonillet se retira à Servian, son lien natal, et s'y fixa jusqu'en 1715. Là, éloigné de tont conumerce importun, il se liva entieremcont à l'éunde de la médecise, sux laquelle il voulut réféchir profoudénuent et long-temps. 11 aimoit assez ses concitoyens pour ne pas se permeitre de fitive sur cux l'cssai d'une pratiçue trop précipitće. Lorsqu'il eut puisć pendant plusieus années dans les bons auteurs 
PHYSIOL. ET MED. - BOUILLET. 199 les connoissances nécessaires qu'me théoric sage pent senle fournir , quii servent comme de base ì notre expérience, sans lesquelles elle n'est qu'un tissud de liasards et auxquelles la routine et l'empirisme ne suppléeront jamais, il vint s'établir à Béziers, persuadé que ses confrères l'aideroient de leur's conseils dans les cas doutenx. Il suivit en cela nue conduite bien opposée d celle que quelques anciens riglemens prescrivent aux médecius dans plusicurs graudes villes du royaune. Ils doivent pratiquer pendant quelques amnées dans les campagnes roisines, oil ils sont isolés et absolument livrés àlenr inexpérience : il semble qu'ils aient la permission tacite de s'y exercer aux déperns de la partic la plus saine et la plus précieuse de l'état, et que la nuédecine ait besnin, pour être pratiquée avec intelligence, de pareils expédicus, unii sont aussi flétrissans pour elle qu'ils sont insultans ponr l'hunnanitée.

M. Bonillet avoit alors vingt-cing ans : des circonstances henreuses le lièrent'arec M. de Mairan. L'amitié d'mn grand homme, dit nu philosophe madene, est nu bienfait des dienx; elle élève l'ane en lui donnant nue impulsion noble et hardic; elle excite l'émulation en fais:unt apercevoir la carriere inmense qu'il fant parconrir ponr arriver à la célćbritć ; elle est tont à la fois nn. plaisir bien délicat pour celni qui en est digne, et nn aiguillon très-puissant ponr celui qui est capable d'en profiter. M. Bonillet éprouva ces différentes impressions, et il aimoit à répéter sonvent que, sans les encourageniens et l'exemple donnés par son illustre ami, il n'auroit jamais osé entreprendre les 
travaux nombreux dont nous allons offrir un tableau succinct.

Son premier essai fut un mémoire sur la communication des fermens, qu'il présenta en 1715 à l'Acadéunie de Bordeaux pour concourir au prix qu'elle avoit proposé cette année. Quloique cette dissertation ait été préférée par l'académie, sans doute parce qu'elle renferme des explications ingénieuses, nous devous à la vérité de ne point dissimuler combien les assertions qui en font la base sont dénuées de fondement. On y trouve la théorie de Descartes appliquée à tous les phénomènes de la fermentation; et on sera surpris, dans quelques siècles, si cet ouvrage est connu de la postérité, que I. Bouillet ait si peu profité de ceux de Beccher et de Stahl (1).

En 1720 (2), l'Académie de Bordeaux ayant proposé pour sujet d'un prix de déterminer quelle est la cause de la pesanteur, M. Bouillet, encouragé par les honneurs d'un premier triomphe, osa en désirer un second.

(1) Le premier a suivi une marclic licn différente de celle de M. Bouillct. Plus fécond pent-être que tous ceux qui ont écrit sur cette matière lorsqu'il cxpose très an long ct avec une abondance singulière les phénomènes de la fermentation, il u'ose pas méme se permettre des conjectures sur leurs canses. Le second développe et explique arec toutc la rraiscmblance possible lc choc des éléncns dans unc masse en fermentation, leur désunion ct leur rénnion pour former dc nouveaux coupposés.

(2) En ${ }^{2} 783$, il communiqua it l'Académie de Montpellier 111 ITénnire sur la digestion. Cette compagnie lui en a témoigué sa satisfaction, en le reccrant, la même annéc, au nombrc de ses associćs. 
PHYSIOL. ET MÉD. - BOUILLET. 201 Il l'obtint de la ntanière la plus complete ( 1 ): ce fut encore a l'hypothèse de Descartes quil il ent recours pour expliquer un probleme dont on aroit déja trouvé la solntion daus les principes de l'attraction newtonienne. Il est vrai qu'en 1720 clle n'avoit presque ancrtu partisan en France; les tourbillons faisoient cncore l'admiration des écoles, et clraque plrysicien s'efforçoit de leur donner une impulsion relative à son systeme. Notre académicieu, en se livrant alors à ses conjectures (2), snivit donc le torrent, dont il n'apparticnt

(1) Son mimoire sur la cause de la pesanteur fut d'abord imprime ì Borleaux et ensuite is Bézicrs.

(2) La pesanteur est, suivant M. Boullet, le mouvement des corps vers le centre de leur tourbillon, ou l'chort qu'ils font, lorspu'ils sont retenus, pour se mouvoir dans ce sens. M. Bunillet établit coume un principe que l'impulsion d'un autre corps peut senle les déterminer ì se déplacer ainsi. Il ne s'étnit point aperşu que celte supposition ne fait qque reculer la difficulté, et qu'il doit y aroir un terme au-delì duquel le mouvement ne peut être l'effet d'une inpulsion mécanique. M. Bouillet supposoil un corps plicé dans un des torrens des petits tourbillons: il est impossible, disoit-il, qu'il n'en diniune pas le monvement et la résistance. Les conches placérs an-dessous jouissant alors d'une force relativenent plus grande, doivent rẻagir, se porter au-dessus de ce corps et le précipiter. MI. Boullet trouroit dans la première des coucles les plus élevées, qu'il supposoit plus forte, la raison pour laquelle le corps ne monte pas au lieu de descendre; car tel est le sort des explications systematiques, que l'inagination, après en avoir disposé l'ensemble, prosluit rolontiers une fiction nouvelle, si elle devient nécessnire pour en étayer les londemens. MI. Bouillet n'auroit pas montré tant de chaleur pour cette opinion, s'il aroit réfléchi que la matière appelée subtile, aranı toujours été supposée capable de pénétrer tous les corps, n'est nullement propre à leur donner l'impulsion de la pesanteur. D'ailleurs la descente des 
qu'aux opinions des hommes de génie d'être la source et dont eux seuls peuvent s'écarter.

Des objets plus pressans l'occupèrent bientôt. En $17^{20}$ et dans le commencement de $17^{21}$, la peste de la Provence et du Gévaudan menacoit le Languedoc. Déja les administrateurs des différens cantons de cette province s'étoient concertés pour prendie des mesures communes contre ce fléau. M. Bouillet fut consulté : il publia à cet effet en 1721 un mémoire instructif dans lequel on trouve, en plusieurs endroits, l'expression que donne l'amour de la patrie. Plaignons-le de ce qu'avec des intentions aussi louables il s'est trompé sur les moyens.

M. Chirac avoit député, par ordre dı gouvernement, des médecins à Marseille pour secourir les pestiférés. Avant leur départ, il lenr avoit répété plusienrs fois que la maladie qu'ils alloient combattre n'étoit pas contagieuse. Il avoit ajouté que leur devoir étoit sur-tout de détruire ce préjugé et de ramener le calme. On ne voyoit pas que ce calme perfide angmenteroit nécessairement le nombre des victimes en nultipliant les sources de la contagion! En vain elle faisoit de tons côtés des progrés rapides; en vain les galères et plusienrs

graves derroit être, d'après ces principes, d'autant plus prompte qu'ils auroient moins de masse sous un mćme rolume. Enfin l'objection que Mr. d'Alembert a faite aux Cartésiens dans son 'Traité des fluides, jouit ici de toute sa force; elle consiste it prouver que dans ces différentes suppositions les corps descendroient vers l'axe et non vers le centre de la terre, cn tombint sous les paralldles à l'équateur. 
PHYSIOT. F'T METD. - BOUMLET. 20.3

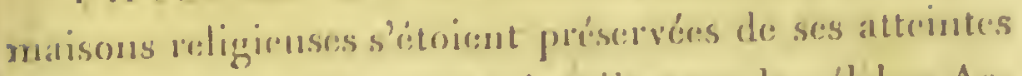
pau des precantions sages; inutilement le célebre $\Lambda$ struc disoit à tonte l'Furope que, puand bien mêne la roulagion s'existroit pas, il seroit prodent do: la sup-

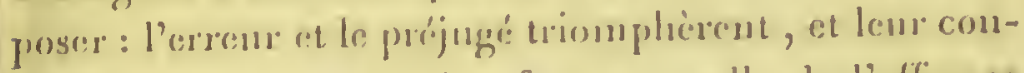
tagion furt celte fois plus forte que celle de l'alfiense maladie qui ravageonil Marscille. An milien dre la désoJation, lorsqu'mu virus destructens arvit infecté pres-

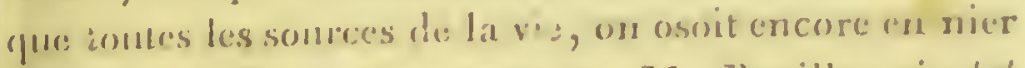
l'existruce! List-il étomuant que M. Bonillet ait étó tromper far des assertions anssi hardies? Mitis ial pesto n'ayaus pas précetré juspu'a Bcericers, l'opinion qu'il avoit suloptée n'ent aucuus: sute ficlicuse, et ce ue fint qu'nu tribut payé à l'antorité de M. Chirac, alors yremicr miedecis.

(ne les tempss sout chungós! et combien cenx de nos confrives qui occupent res places inportantes opposent de bienfaits à tant de fantes et dabus commis avaut (")x !

En 1725, M. Bouillet adressa une lettre an doctenr Penua, médecin consultant du prince Monaro, dans Japurelle il indiqua les renedes qui penvent étre sulostitués à la rlubarobe, dont le prix étoit execssif et que I'on tronvoit, d'ailleurs, presque par-tout de mauvaise qualité. Notre antenr fit alors connoître plusicurs substances anèeres et purgatives qui peuvent la suppléer. En effet, on se manque point de purgatifs; unais, comme l'a très-bien remarıuć MI. de Fontenelle, on manque bien plutôt d'une conduite qui en prévienne le besoin trop fréquent. 
Déja M. Bouillet s'étoit reudu digne de plusieurs titres littéraires. La Société royale des sciences de Montpellier lni aroit conféré celui de son associé en 1719 , et celle de Bordeaux en 1720. L'Académie royale des sciences l'avoit choisi en 1722 pour un de ses correspondans, et dans la même année il avoit été nommé par le roi secrétaire de l'académie de Béziers, place dont il a rempli les fonctions avec distinction pendant cinquante-cinq ans. Comment n'auroit-il pas mis tout son zèle et toute sa gloire à être l'organe d'un corps dont l'institution étoit en partie son ouvrage?

M. de Mairan l'avoit aidé de son crédit dans cette entreprise utile, et tous les deux s'étoient réunis pour rendre à la ville de Béziers un service inestimable, celui d'y répandre les connoissances littéraires et d'y établir un tribunal redoutable pour l'ignorance et les préjugés, fléanx d'autant plus funestes, que le peuple est souvent assez aveugle pour les chérir et pour les regarder comme essentiels à son bonhenr.

M. Bouillet, depuis cette époque si honorable pour sa mémoire, ne cessa de diriger ses travaux vers le salut public, soit en donnant en 1733 une instruction sur la manière de traiter la petite-vérole et sur les dangers du régime échauffant, qui étoit alors fort en nsage; soit en faisant en 1735 la description d'un catarre comnu sous le nonu de coup de vent (1), qui règne

(1) En I $_{38}$ une maladic à peu près du mêne genrese déclara à Bériers. I.c famenx P. Bridaine y prèchoit alors me mission. Ic peuple se rassembloit en foule pour l'entendre, et on ne manquoit 


\section{PHYSIOL. ET MÉD. - BOUILLET. 205}

souvent à Béziers, et qu'il atribua à la rapidié avec laquelle les vents chauds et froids se succèdent daus ce pays; soit en publiaut ses observations sur mue fière verminerse qui fit des ravages ì Bézicrs en $17^{36} \mathrm{et}$ dont il fut lui-nène atteint; soit enfin en assurant, d'après ses observations en 1730, que le quinquina pent être donné arec succés dius le traitement de plusiemrs fievres rémittentes, pratique qui étoit alors trèspeu répandue (1).

jamais, dit Mr. Bouillet, d'ètre attaqui du catarre en sortant : de sorte que, ajoute-t-il, ceux-là furent principalement exempts de l'épielémie qui u'avoient pus été fort assiclus anx sermons. On trouve dans l'histoire plusieurs titits analogues is celui-ci. Nons mous contenterons de ripporter les suivans. Parpier nous apprend qu'en ifo3 le rlume qui regnuit alors aflligea tellement w.M. les

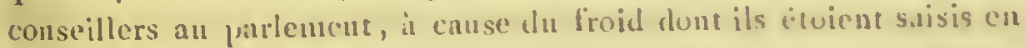
sortaut de l'audience, que, le 26 uvril, le greffier ne poubvil conclure tant on toussoit. En 1.\{27, vers la Saint-liemi, d'après le mème auteur, une épidenie catarrale, appelée le ladendo, étoit necumprignece d'une toux si violente, qua'étant is l'inglise (ce sont les propres expressious de l'antcur), on he pous oil entendre ce que le sermonnewr disoit, par la grande noise des tousseders; to nes et laz bouche étoient cnfles, chacun aroit unte grosse irogne, et le peuple, en sortant, s'cntremocquoit l'un de l'autre.

(1) En 1731 , il donna aver succés le kerucs mineral dans le traitcment de certains maux de gorge épidèmiques, accompagnés d'alsces aux auygdales. Deja Helvetius aroit suiri une uéthode scmblable. En 1733 et 1733 , en faisaut appliquer des vésicatoircs et en dounant de la thériaque, il gnerit beancoup de malades attaqués d'une perripnenmonie pen iuflummatoire et pour laquclle on arvit mal i propos multiplie les saignèes. Voyez une thèse soutenue en 1737 par M. Beruard de Jussiell; ce traitement, connu de Vallériola, y est prescrit.

Une épidćmie régna à Bèsiers en 17 fo: le frodr! de cet lipes 
L'Académie des sciences et belles lettres de Béziers avoit eu assez de temps pour recneillir un certain nombre de mémoires, que M. Bouillet publia, en qualité de secrétaire, en 1736.

Quelques aunées après, en 1744 , il rénnit dans le premier volıme de ses Élémens de médecine pratique plusieurs dissertations qu'il avoit lues dans les séances de l'Acadénie de Béziers, et il y joignit une description des maladies qui avoient régné dans cette ville depuis 1730 . Ces mémoires intéressans sont précédés par différens morceaux d'Hippocrate, de Baillou, de Lomnius et de Sthal, qui y sont rangés suivant l'ordre élénentaire. Son intention étoit de suppléer à la bibliothèque pratique (1) de Manget par un ouvrage moixs étendu; mais il ne vouloit point s'exposer au reproche d'avoir dénaturé les auteurs qu'il proposoit pour modéles. Aussi nous regardons cet ouvrage comme trèssupérieur à ces compilations trop communes maintenant, dans lesquelles les plagiats sont distribués avec

fitt très-vif, et l'on remarqua que pendant sa plus grande rigueur il perissoit plus de monde qu'auparavant. Une observation de celte nature a été faite en Nussie lorsque la dernicre peste y regnoit, et dans uns provinces méridionales lorsqu'elles étoient dérastées par l'épizootic.

Il publia en 174 4 une instruction sur le traitement of la rage: ce sont les frictions mercurielles et le remèle de Paulmier qu'il conscille.

(1) On lit dans cet ouvrage quelques explications plỵsiologiques qui n'out actuellentent aucun partisan. Suivaut M. Bouillet, l'eau ct la pifuite penveut passer du cerveau dans ies narines par certains trons do: lat base du crine. 
PHYSIOL. ET MÉD. - BOUILLET. 207 un titre fastueux suivant l'odre de l'alphabet ou de la chronologie: conme si, ponr réduire en petit un tablcar dent l'ersemble est bien présenté, sans lui faire perdre de son expression, il ne filloit pas être soi-même ıun grand inaître !

Lorsque le remède de mademoiselle Stephens fixa pour la prenicire fois l'attention des médecins en France, M. Bonillet, persuladé avec raison que la gontte et certaines espèces d’asthune dépendent dans quelques sujets d'une cause analogue ì celle du calcul, essaya de donner ce renuide pour le traitement de ces deux maladies, et il réussit. Il employa aussi avec le plus grand succes le savou uni an miel. MM. Ferrein et Bernatrd de Jussien, qui furent rommés ses commissaires par l'Acadénie, assurèrent que des tentatives faites d'après ses vues avoient surpassé leur attente.

L'explication que M. Bonillet a dounée de ces diff:rens phúnomines mérite quelque attention. () sait que le doctenr Halès est mu des premiers qui aient mu des idées justes sur l'air considéré comme principe. M. Bonillet aroit bien médité ses onvrages, et, suivant lui, si lẹs substances alkalines et calcaires agisseut sur le calcul, c’est en se clrargeaurt de l'air, qui y est, suivant l'expression dont il s'est servi, fixé ou mouillé. Une thicoric anssi sage et qui aroit alors trèspeu de partisans annonce des connoissances très-précises et une graude justesse d'esprit.

Les champignors de manvaise qualité sont d'autans phus ì craindre que l'on n'a point encore fait comnoitre leurs caracteres d'une manière positive. Un objet anssi 
utile ne pouvoit échapper aux recherches de M. Bouillet: sa curiosité le conduisit à des expériences sur le suc des champignons, qu'il se contenta de unêler avec les acides et avec l'esprit de vin ; mais il n'a pointessayé de les dépouiller de leur partie vireuse par la voie des dissolvans et d'en faire prendre le suc à différens animaux. C'est ce que M. Paulet, membre de la Socićté, a entrepris et exécuté dans un ouvrage que le public désire depuis long-temps (1).

M. Boullet auroit dû se contenter de prouver par un grand nombre de reclierclies utiles combien la médecine pent rendre de services réels à l'humauité, sans se domner la peinc d'en démontrer les avantages dans un discours très savant, qui a été publié en tête de ses Elémens de médecine. Aucune des anecdotes lonorables pour cette science $n^{\prime} y$ est oubliće; tout ce qui a été dit et écrit contre elle y est discuté avec riguenr. Il revint à peu près au même sujet en 1745 , dans un discours qu'il prononça publiquenent à l'Académie de Béziers poux démontrer que la médecine est foudéc sur des principes certains.

liempli de la diguité de son état, il s'éleva avecforce

(1) Outre que M. Panlet a divisé les champignons en arois classes, dont il a démontré les genres et les espèces avec plus d'exacritude qu'on ne l'a fail avant lui, il résılie de ses rxperiencesque tous les claunpignous bubenx soul suspects, et que plusicurs de ceux qui sont. rangés dans cenc finnille contirnnent une partic gommorésincuse fuc l'on peut. leur enlever par différens procédés, qui est mestricre pour les animanx auxyuels on en fait avaler, et dont l'anidote est l'étler vitrolique. 


\section{PHYSIOL. ET MÉD. - BOUILLET. 209}

contre ses détracteurs. Cet excès de sensibilité étoit l'effet d'un caractère sérieux et de l'estime que M. Bourllet avoit pour lui-mêne; sentinent sans lequel on ne mérite jamais celle de sa natiorr.

Aur reste, en soutenant peut-être avec trop de chaleur que l'on reproche mal à propos à la médecine d'être simplement conjecturale, il étoit fondé sur des raisons dont la force ne pent être sentie que par ceux qui sont vraiment en état de la connoitre et de l'apprécier. Il est vrai que les antres sciences n'ont pu l'atteirdre et l'ourt rarement éclairée; mais parce qu'elle ne s'est jamais perfectionıéequ'en se liv'ant à elle-mềne, err a-t-elle moins des principes qui lui sourt propres et des vérités établies par l'expérience? Les lois des corps animés qu'clle considère ne sont-elles pas très-différentes de celles des corps inorganiques avec lesquelles on les a trop long-temps confondues; et l'observation enfin l'a-t-elle moins enrichic que les antres branches de la physique?

Si quelqu'mr révoque endonte ce que rrous avançours, qu'il consulte les fastes de notre art : il y trourera les descriptions d'un grand nombre de maladies, faites avec tant de vérité, que depuis vingt-denx siècles leur marche et leur traitement r'ont point offert de différences frapparrtes. Sont-ce là de simples conjectures? Que l'on cesse dorrc d'imputer à la médecine des fautes dorrt on se rend soi-mème coupable lorsque l'on fait assez peu de cas de sa santé pour accorder à l'intrigue, à la recommandation, et mène quelquefors à l'importunité, une confiance qui r'est due qu'aux hommes vraiment T. 8. 


\section{ELOGES HISTORIQUES.}

savans et vertueux : et où peul-on en trouver un plus grand nombre que dans cette capitale, où une Faculté, respectable par son antiquité, recommandable par lá pureté de sa doctrine, célébre par les grands médecins qu'elle a produits, et par ceux qu'elle possède aujourd'hui dans son sein, continue de s'occuper avec la pluś grande activité du soin de foimer des sujets dignee d'une école aussi illustre?

En 1752 M. Bouillet trouva occasion de donner une nouvelle preuve de son zèle. Lue village de Gabian, situé ł̀ quelques lieues de Béziers, est connu par ses eaux minérales et par le pétrole qu'il fournit abondamment. M. Beausset de Roquefort, alors évêque de Béziers, en ayant fait réparer la source, M. Bouillet se chargea avec empressement d'annoncer cet acto de bienfaisance dans un mémoire qu'il publia vers la fin de la même année (I).

M. Bouillet consignoit dans un journal tenu très-

(1) En 1717 , un médecin nommé Rivière donna à la Sociétó royale des sciences de Montpellier la description de Ja source de Gabian. Elle fournissoit alors cluaque année trente-six quintaux d'hnile ninéralc. En 2752 elle n'en fournissoit que trois ì quatro quintaux', etmaintenant la quantité qui en coule est encore moindre; mais ce pétrole a toujours conservé sa force, et il diffère en cela de celui du mont Giblus, dans le duché de Modène, sur lequel François Arioste a publié une lettre en 1460 , et qui, au rapport de Mamazzini, avoit beauconp perdu de sa force lorsque cet auteur écrivoit. M. Bouillet s'étoit assuré par l'expérience de l'efícacité du pétrole de Gabian pour guérir les maladies cutanées, pour fondre les tumeurs frojles et pour détruire les vers; sa vapeurest anssi regardéce comne un reniède antiscptique. 
PHYSIOL. ET MÉD. - BOUILLET. 211 exactement toutes les observations curieuses qu'il avoit occasion de faire. En 1765 , étant alors âgé de 75 ans, il publia celles qui sont relatives à l'infiltration de la peau. Dans un ouvrage imprinié en mème temps et en tête dugnel sont les noms de MM. Bonillet père et fils, on trouve une observation importante sur la care de l'hydropisie de poitrine. Lor'sque plusieurs signes font présumer l'existence d'un épanchement aqneux dans cette cavité, il n'y a, suivant leur doctrine, aucun danger à finire la pouction du thorax, si heureusement pratiquée par feu M. Moraud. En effet, en se servant avec précaution du trocar, sur-tout si on estine l'épaissenr des parois de la poitrine, le plus grand mal qui puisse arriver, c'est d'effleurer le poumon; ce qui n'expose à ancum inconvénieut notable, puisqu'ancun vaisseau sangnin considérable ne pent être ouvert: qu'est-ce qu'un danger de cette nature, auprès de celui dont le malade est menacé?

En $177^{\circ}, \mathrm{M}$. Bouillet prit connoissance des ouvrages de MM. Cantwel, le Camus, et sur-tout de ceux de M. Paulet, qui, après avoir réuni des prenves pour démontrer que la petite-vérole se propage par le seul contact des corps imprégnés de son virus, propose un plan d'administration qu'il croit capable de détruire ce fléau. M. Bouillet sentit tous les avantages de ce projet utile; il publia neème à ce sujet un mémoire et il se servit de tout le crédit que son grand âge et une longue expérience lui donnoient sur l'esprit des magistrats de Béziers, ponr obtenir les ordres nécessaires au succès de son entreprise. Bientôt les habitans de cette ville furent 
instruits du nom et de la demeure de ceux qui étoient attaqués de la petite-vérole; et il fut défendu à toute persome ayant encore des pustules ou croûtes de paroître en public. Ainsi M. Bouillet avoit encore à l'îge de quatre-vingts ans assez de vigueur pour en communiquer aux autres, assez.d'impartialité pour adopter des vérités nouvelles, et assez de zèle pour échauffer les magistrats de Béziers sur un projet dont il n'étoit pas l'auteur. Au reste, cette espèce de réparation étoit nécessaire pour faire oublier qu'à trente-deux ans il avoit nié la contagion de la peste.

Au milieu de tant d'occupations; M. Bouillet avoit trouvé le temps de fournir quelques articles qui sont insérés dans le sixième volume de l'Encyclopédie.

Jusqu'ici nous ne l'avons considéré que comme médecin (1); présentons-le maintenant comme géomètre et comme astronome. Ses premières années avoient été consacrées à l'étude de la physique. La chaire de mathématiques qu'il occupa pendant long-temps le ramenoit nécessairement à ce travail qu'il chérissoit. En

(1) Parmi les ouvrages de M. Bonillet, il y en a deux auxquels nous désirerions lien qu'il n'êt point participé. Le premier est l'examen de plusieurs cas de conscience tendant à prouver que l'on ne peut, sans commettre un péclié, appeler un clirurgien pour faire la médecine, on un inédecin pour exercer la clirurgic. Le second est une réplique contre les maîtres en chirurgic do 3éziers, dans laquelle il auroit peut-ètre en raison, si l'on pouroit l'avoir dans une discussion pareille. Il n'aroit pas réfléchi que le pulblic, qui n'aiıne pas à faire les fonctions pénililes de juge austère et impartial, se contente de saisir les ridicules de part ct d'autre, de sorte que sourent lorsque l'on troit se renger, on s'lumilie. 


\section{PHYSIOL. ET MÉD. - BOUILLET. 213}

1722 il fit sur l'immersion de Saturne nue observation très-curicuse, et depuis il communiqua d l'Acádémie rcyale des sciences plusicur's travaıx astronominues dont il est fait mention dans les Mém. des sariuss étrangers.

Legrand attacliement de M. Bonillet pour l'Acadénio de Béziers étoit le motif puissant qui l'aninoit daus tons ses travanx. Les derniers momens de sa vie ont été consacrés à lui en donner des prenves. Il choisit lıi-même parmi ses livres, quelques jonrs avant de monrir, denx cents volumes des plus précieux, qu'il la pria d'accepter, et il partagea ainsi sa bibliothèque entre ses enfans, au nombre desquels l'Académie devoit être comptée.

Charque année de sa vic a donc été marquée par des bienfaits; la circonstance dans laquelle il a été attaqué de la maladie qui l'a fait périr, offre mêne le trai le plus frappant de son éloge. S'étant levé de très-giand matin pendant les premiers jours d'aoult pour fairo une observation d'astronoınie très-intéressaute, il fut attaqué d'ım catarre que de nonvelles iuprndences dans le même genre angnientèrent; il consentit enfin à rester chez lui, seulement à condition que messicurs ses fils suivroicut l'observation qu'il aroit commencée et lui en rendroient compte; ce qui fut exécuté : mais la maladic ayant fait des progrès, il s'empressa de remplir de la nanière la plıs édifiante les devoirs de la religion, et il mourut rictime de son zèle pour l'astronomie, le 13 aont 1777 , àgé de quatre-ringt-quatre ans.

Il s'étoit marié le 25 aout 1724 . Il a eu deux fils et trois filles. Un de ses fils le remplace à Béziers, où. il jouit de la réputation la mieux méritée. 


\section{EIOGES HISTORIQUES.}

M. Bouillet avoit eu onze frères ou sœurs. Neuf sont morts après avoir atteint la quatre-vingtième année, et des deux qui survivent, l'un a quatre-vingt-quatre ans et l'autre quatre-vingt-quatorze. On a eu plusieurs fois occasion d'observer qu'il y a des races d'hommes très-vivaces : c'est un bonheur pour l'humanité lorsque cette propriété singulière sert à perpétuer la science et la vertu.

Indépendamment de plusieurs faits de médecine pratique que M. Bouillet a communiqués à la Société, il lui a aussi envoyé la suite de ses observations sur la constitution des différentes années depuis 1746 jusques à 1769 ; ouvrage d'autant plus précieux, qu'il fait suite avec le premier et le second volume de ses Élémens de médecine pratique.

La Société s'applaudit de ce que son premier hommage a été rendu à un observateur infatigable, et surtout à.un homme qui a bien mérité de sa patrie. Le génie ne manque jamais d'éloge; mais il est rare qu'une vie simple, active, sans éclat, et consacrée, loin de la capitale, à la recherche de la vérité, ne soit pas oubliée. Nous nous estimerons heureux toutes les fois que nous pourrons faire connoître les serrices rendus par des citoyens vertueux et modestes; et nous le ferons d'antant plus volontiers, que leur éloge devant êtro simple comme eux, ne lequiert, pour être fait dignement et pour être écouté avec indulgence, qu'ure ame honnête et des auditeurs scnsibles à l'attrait de la ver'ıl. 


\section{PHYSIOLOGISTES ET MÉDECINS. 215}

\section{FOTHERGILL.}

Jen Fotringrix, agrégé au Collége des médecins de Londres, membie honoraire de cclni d'Edimbourg, de la Société royale de Londres, président de la Société de médecine de la mème ville, membre de celle de Philadelphic, associé étranger de la Société royale de médecine, nacpinit le 8 mars 1712 à Carrend, près de Richenont dans le comté d'Yorck, de Jean Fothergill et de Marguerite Hourgt. Son enfance fut confiéc anx soins de son grand-pere, riche habitant dn Cheshire, et il fit ses premières études ì Sedberg, dans me maison dirigée par les quakers.

Il cst facile de juger par les premiers penchans qurelle sera la trempe du caractère. Si l'enfant que rous observez s'ément an récit des belles actions; si ses yeux se baiguent de plenrs auprès des malheureux; si la peine ou la joic de ses proches s'étendent jusqu'à lui, n'cn dontez point, son ame éprourcra cette réaction, cette sympathic, si propres à diminuer le poids de nos chagrins, qui s'affoiblissent en se partageant, et à multiplier nos plaisirs, qui s'accroissent au contraire par la communication.

M. Fothergill fit voir dès l'âge le plus tendre que la bienveillance seroit le mohile de sa vie entière. Une sensibilité profonde lui rendoit communes les impres- 
sions dont il étoit environné; il n'avoit de jouissance que celles de ses jeunes amis, il n'étoit heurenx que de leur bonlieur.

Ces qualités morales peuvent seules donner au médecin toute l'élévation et l'énergie dont il est susceptible. M. Fothergill choisit cet état comme celui où il auroit le plus d'occasions de se rendre utile à l'humanité. Cette passion, car c'en étoit une en lui, ne permet point ì ceux qui en connoissent les charmes de rester dans l'inaction. Ce n'est pas assez pour eux de n'être point frappés par le spectacle de la misère; encore moins a-t-on à leur reprocher de le fuir; stratagème inhumain qui ne convient qu'à la dureté lorsqu'ello n'est pas encore sûre d'elle-même : il leur suffit de savoir qu'il y a des infortunés, pour qu'ils sentent le besoin de les secourir; et après le plaisir extrême que leur causeroit la destruction entière des fléanx dont l'humanité est affligée, le plus grand, le plus pur qu'ils puissent éprouver est celui de les adoucir par la consolation et les bienfaits.

M. Fothergill a été pendant trente années le médecin le plus célèbre de la ville de Londres; et l'on sait avec quelle libéralité les médecins sont récompensés dans ur pays où le peuple, suivant qu'il est affecté, recherche avec la même impatience et la vie et la mort. Pendant tout ce temps, on a vu M. Fothergill distribuer anx indigens des sommes prodiguées par les riches: clles lui étoient données; et il les receroit d'autaut plus volontiers, qu'il n'en étoit en quclque sorte que lo dépositaire. Il ne cessa de remplir les deroirs d'une 


\section{PHYS. ET MED. - FOTHERGILL.}

médiation aussi noble qu'utile entre deux ordres pour lesquels il ne peut y avoir d'autre rapprochement que celui de ces hommes rares qui tiennent entre enx itn juste milieu, puisque, comblés de biens, soit par la fortune, soit par leurs talens, et dépouillés par lenr générosité, ils passent successivemeut de l'une de ces classes dans l'antre pour les honorer et les servir toutes les deux.

Les doctetırs Thompson, Elliot, Hird et Lettsom (1), qui ont etı part à son anitié, et dlont la voix s'est élevée pour célébrer sa mémoire, ne se sont pas contentés de nous offrir cette idée de son caractère; ils ont domué, par le développerrent de sa conduite, la preuve la plits complète de lenrs assertions.

Aussitôt que M. Fothergill eut pris la résolution d'étudier en médecine, ses parens le mirent en pension cltez M. Benjannin Barthelett, apothicaire fanteux iे

(1) Voyez An affectionate to tribute the memory of the late d. ${ }^{r}$ Jonh Fothergill : by W. Hirl, in-4. ${ }^{\circ}$, London 1781 .

The life and chartcter of $\mathrm{d} .^{\mathrm{r}}$ Fothergill : by Gilbert Thompson. London, in-8. ${ }^{\circ}{ }_{17} 83$.

The life of the antor by $\mathrm{l}^{\mathrm{x}}$ Elliot, pour être mis en tête des ouvrages de MI. Fothergill.

Et $d{ }^{r}$ Letsom's Memoirs of the late $d 0^{r}$ Jonlt Fothergill, etc.

MIM. Elliot et Lettsom ont projeté dles éditions complètes des mémoires et obserrations de feu MI. Fothergill. Celle de M. Lettsoun a parı. Ce dernier étoit le digne ami et le disciple de cet illustre médecin. Il a publié de plus un catalogue raisonné des plantes du jardin d'Upton. Hortus uptoncnsis or a Catalogue of Stove and Green-House plants, in d.r Fothergill's garden at Uptoul at the timo of decease 1781 . Je tlois à MI. Lettsom la plus grande partic des ren. seignemens qque j'ai reçus sur la vie de MI. Fothergill. 
Bradfort, dans le comté d'Yorck, et duquel les doctenrrss Hillary et Clıoley avoient déja reçı avec succès les premières notions de notre art. M. Barthelett (1) lui fit connoître la nature et les diverses préparationsdes substances médicamenteuses, et il lui apprit à faire luimême le mélange et la combinaison des différentes dro-. gues; détails sans lesquels les praticiens les plus célè-. bres d'ailleurs sont quelquefois privés des ressources les: plus importantes; détails peut-être un peu trop négligés dans un moment où les jeunes médecins, entière-. ment abandonnés aux grandes théories chimiques, daignent à peine songer aux procédés de la pharmacie (2).

M. Fothergill passa ensuite plusieurs années à Edimbourg, dont l'Université partageoit alors avec celle de Leyde la célébrité de l'enseignement. Les docteurs Monro, Alston, Rhuterford, Sinclair et Plummer, qui se glorifioient d'avoir été disciples de Boërrlıave, lui transmirent tont ce qui peut en médecine être communiqué par des préceptes. Il prit auprès d'eux cet essor que donne uue grande émulation; car l'avantage le plus marqué des leçons d'un illustre professeur ne

(1) Et non Barclay", comme on l'a écrit daus un éloge de M. Fotliergill. Il y entra à l'àge de 16 ans, et il y lit. son appreutissage avec le mêne soin que s'il s'étoit clestiné à la plarnacie.

- (2) Si janais on fait une réforme dans l'éducation médicale, il faudra sans doute exiger des élèves qu'ils passent un certain temps dans le laboratoire des pharnaciens et dans les liôpitaux, afin que, cultivant une science de faits, ils s'accoutument i recueillir ceux qui doivent servir de base à une pratique éclairce et sans lesquels il ne peut y avoir de véritable instruction. 
PHYS. ET MÉD. - FOTHERGILL. 219 se borue pas aux paroles qu'il profere. Rien n'inspire tant l'amour de l'étude et de la gloire que la fréquentation des grands hommes; et ce 'n'est pas lorsque l'élève sait tout ce qui a été l'objet de l'enseigneinent, qu'il est le plus près d'en tirer un grand parti, mais lorsqu'il aperçoit combien son maître est lui-même supéricur à ses propres leçons, et combien il est difficile de franchir cet espace et de s'élever à cette hauteur.

Le germe des talens qui devoient $11 n$ jour illustrer M. Fothergill n'éclıappa point ì la sagacité dı docteur Monro, qui lui dévoila en quelque sorte le secret de sa destince. Il bornoit tous ses projets at pratiquer la muédecine dans une petite ville dn comté d'Yorck; mais ce professeur lui fit concevoir de plus liantes espérances. M. Fothergill dut ì cette impulsion ses premiers pas dans une carrière que, sans cet encouragement, il n'auroit janais parcourue. Excité par le docteur Monro, il prolongea le temps de ses études à Edimbourg, où il fut reçu docteur en 1736 , après avoir soutenu, sur l'action des émétiques, une thèse estimée (1), qiuo M. Smellie a insérée dans sa Collection.

Les lirres d'Hippocrate, d'Arétée et de Celse étoient cenx anxquels il revenoit et où il trouvoit toujours de nouvelles instructions. Il aimoit à comparer les faits recneillis par ces anciens maîtres arec cenx dont les modernes ont été les témoins. Cette grande uniformité dans les opérations de la nature, qu'un intervalle de

(1) Dissertatio inauguralis de emeticontm usu in variis morbis tractandis. Edimb. 1;36. 
tant de siècles $n^{\prime} a$ point altérée, lui apprenoit à eon. noître la valeur des bonnes observations. Il vint à Londres en $17^{50}$; il y suivit la pratique des médecins dans l'hôpital de Saint-Thomas, et il partit peu de temps après pour l'Allemagne qu'il parcourut dans toute son étendue.

Il communiqua dे ses amis, dans une lettre latine (1) écrite avec beaucoup de finesse, ses réflexions politiques sur l'administration de ce pays, et sur le caractère de ses luabitans; elles ne furent point à leur avantage. Un jeune républicain qui voyage dans les diverses parties de l'Allemagne, doit y être souvent choqué par l'excessive dépendance des vassanx. Occupé de grands projets pour l'avancement des connoissances, M. Fothergill crut s'aperceroir qu'ou s'y livroit avec trop de patience et de soin à des recherches qu'il regardoit comme minutieuses et peu utiles; et il reprochoit à la plupart des physiciens et des littérateurs de ces contrées de s'appesantir trop sur les détails; mais l'édifice des sciences, qui s'élève de toutes parts, ue peut être achevé sans des travaux de tous les genres: les peuples $n^{\prime} y$ contribuent pas toujours en raison de leurs talens naturels; lenrs productions portent, ainsi que lenx caractère, l'empreinte des différentes puissances qui les gouvernent; et la reconnoissance qui leır appartient no doit pas être seulement mesurée sur ce qui résulte de

(1) Cette lettre a été adressée par M. Fothergill, Ie 7 septembre 17 \{̧o, a son nmi M. Cuming, médecin a Dorcliester. Elle m'a étú communiquéc par M. Lettsom qui l'a publićc. 
PHYS.ET MÉD. - FOTHERGILL. 221 leur's efforts, mais sur ces efforts eux-mêmes et sur le courage avec lequel ils surmontent les obstacles qu'on oppose à leur activité. M. Fothergill passa quelque temps en France, et retourna ì Londres où il so fixa.

Quclqu'instruit que soit un jeune médecin, il redoute tonjours l'iustant oì il doit agir pour la première fois; on, après avoir écouté et lu, il faut juger et clioisir. Scrupuleux observatenr des règles de l'art, et craignant de se tromper dans leur application, il examine avec le plus graud soin et ne prononce qu'arec eftroi: il a sans cesse devant les yeux les obstacles qui naisseut de la complication des accidens, et les obligations que son devoir lui impose. Il emploie pen de remèdes par timidité, comme le médecin expérimentó cn conscille pen par clioix. L'un épie la nature et agit rarement, parce qu'il ne se croit pas assez éclairé sur ses besoins; l'antre connoit ses efforts et se borne d seconder ses mouvemens; il agit rarement aussi parce qu'il craint de les troubler: tous les deux ont une grande réserve, parce qu'ils ont les mêmes principes et qu'ils tendent au mème but. L'ignorantau contraire commence avec liardiesse et finit avec audace.

M. Fothergill prit un parti très-sage: il étndia d'abord la nature et les effets des maladies les plus aiguës, dont les progrès rapides donnent le moins de temps à la réflexiou: il les obserra de préférence dans les hôpitaux; et lorsqu'il se livra à la pratique de la médecine, il avoit prévu les cas les plus embarrassans et aplani une des plus grandes difficultés qui s'y rencontrent. 
Cette sagesse tourna au profit des pauvres, au soulagement desquels M. Fothergill s'étoit entièrement dévoué : les soins qu'il leur donnoit n'étoient pas pour lui un moyen de parvenir"; c'étoit une occupation chère à son cœur. Si les fonctions de inédecin sont belles, c'est moins en effet dans les palais et parmi les grandeur's, où les motif's, soit apparens, soit récls de l'intérêt, ne laissent aucune place à ceux de l'humanité que dans la demeure étroite et malsaine du pauvre. Là point de protecteur, point de cupidité; la renommée n'approche point de ces asiles; tout s'y tait, hormis la douleur qui les fait si souvent retentir de ses sanglots: les victimes de la misère, celles de la maladie et de la mort, entassées, confondues, y offrent un tableau déchirant et terrible: c'est-là qu'il est possible de faire lo bien, où l'homme peut secourir l'homme, sans concours et même sans témoins; c'est là que se plaisent la générosité, la vraic bienfaisance, la tendre pitié; c'est là que l'on est sûr de trouver des larmes à essuyer, des infortunés à plaindre. Disons-le à la louange des médecins : quel autre ordre de citoyens remplit ces devoirs augustes avec autant de zc̀le et de courage? Quel autre peut se dire aussi souvent à la fun de la journée? « J'ai „ fait lous mes efforts pour défendre la pauvreté contre " la misère et la douleur; le repos que je vais gonter ə) sera doux, puisque j'ai répandu le calme daus le sein » des mallicurenx ». Ces travanx, ces plaisirs sont ceux de presque tous les ministres de santé; ils ne peuvent trouver les premières lecous de l'expérience que dans la classe la plus indigente du jenple, qui leur eu donue 


\section{PHYS. ET MÉD. - FOTHERGILL. 223}

en même temps de bienfaisance et de vertu. M. Fothergill, tout entier à ses fonctions, ne désiroit pas un meilleur sort; ses vœux se bornoient ì roir se succéder des jours aussi utilement tissus. Son grand zòle le trahit enfin, en lui donnant de la célébrité; mais il u'eut pas l'ingratitude trop ordinaire d'oublier le pauvre, auquel il devoit son instruction et la partic la plus pure de son bonlieur.

Un mal de gorge gangrénenx, après avoir fait péril quelques enfans ì Londres en 1739 et 1740 , reparut en 1742 et devint épidémique en $1746(1)$ : un virus âcre et putride en constituoit la natture ; son conrs étoit rapide, et la gangrène survenoit en trés-pen de tenups. Les ravages de cette épidénie commençoient dinspirer de l'effroi, parce qu'on n'avoit pas cncore déterminé les remèdes conrenables à sou traitement. La mìne maladie avoit été observé à Naples (2) par Severinus,

(1) L'épidémie continua pendant les deux années suivantes.

(2) Le mal de gorge gangréneux arvit régné en Espague pour la première fois en 1610 . Il aroit paru a Naples en 1618 ; il y avoit été trìs-répandu pendant plus de ringt années; il avoit été bien décrit par les médecins contemporains. Dans les iles de l'Archipel, on employoit arec succes, dans son traitement, des inoyens qui aroient beaucoup de rapport avec ceux que M. Fothergill es aures ont mis heureusement en usage. On ne praliquoit aucune saignée : on relevoit les forces en donnant des esprits rolatils et de la thériaque; on tourhoit l'arricre-bouche arec une dissolution de styrax. Il n'y a pas loin de cette méthode à celle qui a été tracée par les médecins modernes. Les lecteurs sont invités à comparer les observations de Forestus et de Severinus arec ce que 'Boyer et Astruc en ont écrit, et ce qu'en ont dit ces derniers avec 
et elle avoit sur-tout été bien décrite par les médecins espagnols. M. Fothergill remarqua que la saignée accéléroit ses progrès, que les purgatifs augmentoient la fluxion et que les rafraîchissans diminuoient les forces vitales déja trop affoiblies. Il fit de nouveaux essais qui le conduisirent à une méthode heureuse. Les vomitifs donnés avec ménagement, une petite quantité de vin ajoutée aux boissons, les acides minéraux, qu'il préféra dans ce cas aux acides tirés des végétaux, et les amers, furent les moyens qu'il substitua aux premiers, et il guérit presque tous les malades confiés à ses soins. Bientôt le public l'arracha à son obscurité, à son indépendance; il fut appelé de toutes parts: on le cherchoit d'autant plus qu'il étoit plus difficile de l'avoir. Depuis ce moment jusqu'à l'époque de sa dernière maladie, la foule conserva la même impulsion et ses bienfaits furent l'origine de sa célébrité.

Ce seroit une recherche curieuse et utile que l'examen des grandes réputations et de leurs causes. Tel fleuve roule avec fracas des eaux impures; un autre s'enorgueillit de celles qui lui sont étrangères: voilà quel est l'emblème des réputations usurpées.

M. Fothergill publia en 1748 ses réflexions (1) sur

ce qui a été publié par M. Fothergill : ils verrout que des raisonnemens theoriques trés-vicicux ont écarté les médecins pendant long-tenups de la route tracéc par l'expérience, ot que la méthode de M. Fothergill a eu principalement le mérite de les rappeler à cette route qu'ils n'auroient janais de quitter.

(1) An account of the putride sorethroat. Cet ourrage a eté traduit en français par M. de la Chapelle. 
PHYS. ET MÉD. - FOTHERGILL. 225 In nature et le traitement du mal de gorge gangréneux. Cet ouvrage fut traduiten français et bien reçu à Paris, où la méthode de M. Boyer (1) n'avoit pas eu de sttccès (2).

(1) M. Marteau, mélecin franggais, a publié peu de temps apris un ouvrage daus lequel on trouve les réflexious les plus sages sur le mal de gorge gangréneux. On a aussi vu une épidémie de cette nature régner à diverses reprises parmi les bestiaux. Elle est très-funeste, et les principes de sou traitement sout les mèmes que ceux de l'angina maligna, qui attayue les hommes.

(2) Il est de notre justice d'ajouter que, suisaut l'upinion de plusienrs savans, et sur-tout de M. Elliot (royre l'Eloge de M. Fothergill par ce dernier), ce fiut le feu d.5 I.eatherliud qui

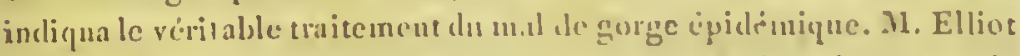
assure que ce nédecin ue voulue point dtre cite dus l'ourage de M. Fotheraill, qui ini lit inutilement les plus sives instances punr en obtenir la permission, et qui dans les dornires éditions de ce traité, lui a rendı la plus grande justice.

On trouve les détails suivans daus le Treatise on the disease called a cold, in-8., 1761 ; par le ductenr Chandeler : j'aicru dervir les traduire et les rapporter ici.

"En jauvier 17.10, wu enfant confic d mes soins btant mort de w cette maladie (le mal de gorge gangréneux) dans l'espace de w quelques lieures, malgre les apprarences les plus flattenses; et un w autre enfant de la mème famille en ayant été attaqué immécliaw tement après, je priai les parens de permettre que j'appellasse " en consultation quelque habile médecin, leur répétant ce que "j'avois déja décluré, que j'ètois absolument hors d'état de reudre "raison de la mort du premier et qu'il y aroit dans cette maladie " "luelque chose d'entièrcment noureau et inconnu pour moi. Nous " choisimes le docteur Leatherland comue consultant. Ce savant " médecin, sur le récit que je lui fis de tout ce qui s'étoit passé "dansle cas du premier enfaut et de la manière dont le second a aroit été atteint, porta le mème pronostic pour celui-ci; pré") diction qui s'accomplit dans toutes ses circonstances. Le docteu! 
Eucouragé par cet accueil, M. Fothergill continua de donner chaque mois au public un tableau comparé de l'état de l'atmosphère et des maladies régnantes (1). Cet ouvrage, commencé en $17^{51}$, fut interrompu en 1756 .

Sa bienfaisance et son habileté connues dans toute la ville lui méritèrent bientôt une considération générale. Il est impossible que le caractère des hommes publics reste long-temps ignoré : sans cesse observés par des personnes qui sont intéressées à les bien voir, enl vain ils voudroient se cacher ou feindre. Un médecin très-employé ne peut sur-tout se dérober à la pénétration de ses malades; ils découvrent bientôt s'il est doux, généreux, compatissant, ou s'il est sévère, dur, opiniâtre. Ce n'est pas que cette connoissance influe beaucoup sur le choix que l'on a fait; on sait au moins s'il

*) Leatherland, comme il me le dit alors à l'occasion de la maladie " et de la mort de deux fils de feu très-honorable Henri Pellıam ») qui étoit arrivée ì la fin de l'année précédente 3739 , n’arcit " épargné ni soins, ni peines, en parcourant les écriviins anciens » et modernes pour voir s'il n'y découvriroit point quelques traces $\omega$ de cette remarquable et terrible maladic; et, après de longues " recherches, il avoit eu le bonheur de tronver qu'elle étoit exacv tement décrite dans les écrivains esp̧agnols, et celui de nous en s indiquer le traitement."

(1) M. Fothergill publia ces observations dans le Gentleman's magazine. L'anteur vit avec peine que le lut de son entrep̧rise étoit manqué; il avoit espéré que les múrlecins les plus lıabiles des différens pays suivroient son exemple et qu'il en résulteroit un recueil de faits très-précieux pour l'art de guérir. M. Fothergill y mit le courage de plusieurs annes, et il cessal cufu un tavail ntile pour lequel il n'aroit point tronyó de cooprerateurs. 
PHYS. ET MÉD. - FOTHERGILL. 297

faut pâlir ou se rassurer, parler ou se taire, en présence de celni que l'on a fait l'arbitre de ses jours : on apprend à s'égayer avec lui s'il est aimable, ou ì préverrir son lumeur, s'il est mu de ces hommes sinistres qui, ajoutant la peur, le plus grand de tous les maux, aux infirmités dont l'espèce humaine est assaillie, semblent ignorer qu'effrayer un moribond est, de tontes les actions, la plus lîche et la plus barbare.

M. Fothergill, dit M. Tompson, anteur d'un éloge de ce médecin, prononcé devant la Société ruédicale de Londres, prenoit un réritalule intérêt à la santé de ses malades. Sa contenance noble et assurée, son langage rlonx et affable inspiroient du conrage dans ces momens terribles oì tons les liens de l'existence sembleut se resserrer par un dernier effort, oì l'ani que l'on va perdre, devenu le centre de toutes les douleurs, éprouve lni senl le clagrin de tous les assistans avec le sien propre, qui doit les surpasser tons. Pen d'hommes savent monrir, a dit la Bruyire: ne ponrroit-on pas ajonter qu'il y cn a moins encore qui sachent comment la mort doit être traitée dans leurs semblables? Ces plemrs que l'on verse arec ume sorte d'enpressement, ces sanglots que l'on étontfe arec bruit; tont cet appareil que préscnte-t-il? sinon le tablean d'une mort procliaine, mis sons les yeux de celui qui en est menacé. Ne semble-t-il pas que l'on cherclre des applandissemens pour prix de ses larmes, sans songer conıbien elles sont amères à celui qui en est le sujet? Dans ce moment, comme dans tant d'antres, nous ne demandons qu'à être trompés pour ț̣̂e moins mallieureur. 
Observez ce malade: ses yeux suivent les vôtres pour -y tronver de l'espérance. Pansez ses blessures avec le même soin que s'il pouvoit être guéri; soyez assez ,adroit pour qu'il devienne hii-mêne votre consolateur, et que le dernier regard de votre ami soit calme ct sans effroi.

C'est au médecin sensible et courageux, témoin de ces scènes déchirantes, à en diminuer les impressions par la sagesse de ses conseils. Celui que nous regrettons possédoit ce talent, et il en a toujours fait un heureux usage.

Si l'on réféchit à l'élévation de ce caractère, on ne sera point étonné de l'estime que le peuple de Londres a toujours témoignée à M. Fothergill. Cettc grande réputation devint bientôt pour lui nue source d'inquiétnde; il craignit mêne qu'elle n'cût diminué le plaisir qu'il goûtoit à faire le bien. " Avant que mon nom fût .) connu, disoit-il, j’éprouvois en soulageant les mal》) henreux une jouissance plus pure : en faisant les „ mêmes choses je n'ai plus le mêrne mérite, parce m qu'il me semble toujour's que j'obéis à l'annour-pro?) pre ». Les vertus ont en effet avec lintérêt, soit pillliculier, soit public, des liaisons si intines et si nécessaires, qu'il est difficile d'établir dans ses propres actious des limites entre ce que l'anour du bicn y apporle et ce qui tient à l'anour de soi-mêne: mais cette reclierche n'est-elle pas superflue, puisque l'intérêt bien entendu conduit l'honune à la bienfaisance, à la prubité, tandis qu'il y est cutraincé par un penchant irrésistible? Henreux colui qui, comme M. Fothergill, 
PHYS. ET MÉD. - FOTHERGILL. 229

avant sa célébrité, se plaît ì répandre le bonhenr sans avoir jamais été troublé par l'examen de ses motifs, et sans avoir altéré son plaisir en cherchant en quelque. sorte à le décomposer.

M. Fothergill obtint en 1746 le grade de licencié (1) dans le Collége royal des médecins de Londres. Il fut reçn nembre de la Société royale de la mème ville, et lunit anuées après le Collége des médecins d'Edimbourg l'aggrégea comme honoritire.

Il existoit depuis guelque tenıps ì Londres, sons le nom de Société médicale, une compagnic différente dn Collége royal de médecine de cette ville: il étoit inportant pour mue acadénie de ce gerure de compter parmi ses membres le médecin le plus célébre de lis capitale. M. Fothergill se rendit, e'n 1763 , à l'iuvitalion qui lıi fiut faite; il y accepta nue place et devint le plus zélé de ses nembres. Les homures illustres, en s'iniposant le fardean dn travail acadínique, se inontrent reronnoissans envers les scicnces et les lettres dont ils tienneut tout leur éclat; ils leur renlent une partie des secours qu'ils en ont recus; se refuser à leurs progrie, ce seroit de lenr part nu acte d'ingratitude; s'y opposer, c'en seroit un d'injustice.

M. Fothergill ne vonlut pas même qu'on pitt lui reprocher de l'indifférence sur le sort d'nut établissement anssi utile: an milien de ses nombrenses occupations,

(1) Après la mort du baronnet sir Guillaume Duncan, les licenciés Ir choisirent unanimement pour leur président, et il a conservé cette,place, jusqu'i sa mort. 
il trouvoit le temips d'assister à ses assemblées. Il répé= toit souvent que toute entreprise contraire aux intérêts des sciences est un attentat contre l'lumanité. A cette intégrité qui constitue l'homnête citoyen et qui ne suffit pas à l'homme public, il joignoit cette probité active et éclairée qui ne laisse jamais échapper la moindre occasion de faire le bien.

Parmi les services qu'il rendit ì la Société médicale de Londres, aucun ne mérita plus de reconnoissance de sa part que la communication de ses inémoires, qui se trouvent en très-grand nombre daus les cinq volumes publiés par cette compagnie. On peut les diviser en deux classes: les mis étoient l'ouvrage de ses correspondans, qu'il présentoit à la Société et qu'il rédigeoit souvent avant d'en faire la lecture; les autres étoient le sien propre. Nous parcourrons successivement et brièvement ces deux ordres ( 1 ).

(1) Les mémoires et obscrvations que M. Fothergill a lus dans les assemblóes de la Sociéré de médecine de Londres, et qui ont été insérés dans les cinq volumes publiés par cette conıpagnie sous le titre de Medical observations and inquiries, etc., contiennent des réflexions si judicieusés et des vérités si utiles, qu'on ne sauroit trop les faire connoitte.

II. Fothergill donne dans le premier volume, d'après le docteur Russel, la description de la plante dite scammonéc. Il assure qu'il en a semé des graines en Angleterre, et que la plante qui en est résultée a produit les mêmes effets que la scammonée qui croit aux environs d'Alep. On a fait la même observation dans les colonies anglaises.

M. Fothergill a traité avec succès de la manidre suivante un enfant nouvenu-né aitaqué du tétanos. Il lui a lait prendre une infission de rhubarbe a lapuelle il aroit ajouté quelques graius de 
PHYS. ET MÉD. - FOTHERGILL. 23̂̀

M. Fothergill a employé avec succès la décoction de quinquina pour la guérison des ophthalmies scrophuleuses, et des gonflemens de la parotide qui survien-

musc et une petite quantitć d'huile de tartre par défaillance : on donuoit en unême temp̧s des lavemens préparés avec une infusion de camomille et un peul de savou.

On trouve dlans le premirr volume un mémoire très-étendu de M. Fothergill sur l'usagr du quinquina daus le traitement des scrophules. Fin iffí on lui présenta un eufant de quatorze mois, nttaqué d'une ophthalmie scropluteuse, et qui avoit rn meme temps les glandes du con engorgées. M. Fothergill lui fit prendre trois fois ir jour une cuillerée de décnction de quinquina, il laquelle on ajoutoit six on dix gouttes de baune polychreste, dans l'intention de relitcler le ventre : de deux nuits l'une, il faisoit prendre une pilule d'un grain de calomelas. Io nual crila assez promptement; il reparut quelqnes mois apre's : il fut traité de la meme manière, et il n'y ent plus de récidive.

De plusieurs autres observations, M. Fothergill conclut que le quinquina euploye dans le traitement des écronelles suspend presque tmijours les pregrès du mal; qu'il doune du ressort it des malades aftuiblis et dont la fibre est plus ou moius relâclue; qu'eu rendaut ainsi du ton, il lavorise l'effet des autres remedes, et qu'ainsi il fournit un point d'appui utile et souveut nécesmire clans le traitenient.

Il donnoit ordinairement le quinquina sous la forme suivante.

Recipe puli, cort. per unc. $i$. coque in aq. purce lib. ij ad lib. $j$ sub finem adde rad. glycyrr. incis semi-unc. colaturet adde aq. nuc, unc. ij Mr. capiat. coch. ij, iij. wel iv cusm, tinct guaiac. vol. gutt. $x, x a$, ad lix usque, bis terie quotidie.

M. Fothergill n'employoit point le quinquina dans tous les cas de maladies scropliuleuses où les os étoient affectès, ni lorsqu'il y aroit des tumeurs profondément situées sons les muscles ou dans les articles; il le regardoit alors comme inutile.

Le second volume ne contient que des lettres et des obserrations qui ne sont point particulières à M. Fothergill; il les a 
nent aux éctonelleux : il y a joint l'usage du calomélas el celtui dı soufre doré d'antimoine. Dans ces deux cas, tout annonce que l'inertie des fibres est compliquée

seulement reçues de ses correspondans, et communiquées a la Suciélé de nuédecine.

Dans le troisième rolume (des Observations et reclierclies par une Société de médecins de Londres), on lit deux ménoires de M. Fothergill : le premier a rapport au traitement de la coqueluche on toux convulsive. Le médicament que l'anteur recommande, et que plusicurs autres médecins ont employé à sa recommandation avec un très-grand succès, cst une préparation antimoniale selon la formule suivante.

Prenez de poudre d'yeux d'écrevisses, un demi-gros; de tartre émétique deux grains; mêlez exactement.

Chaque grain de cettc poudre contient nn dix-luitième de grain de tartre stibić. Si on a besoin d'une dose moins fortc de cette dernicire préparation, on augmente la close de la poudre absorbante; de sorte que, par ce mélange, on peut diviser l'émétique en doses aussi petites que l'on veut.

On donne un grain et demi ou deux grains de ce mélange, auquel on ajoute cinc à six grains le poudre absorbante, à un enfant âgé l'un an; on lni fait prendre ce remède dans la matinée entre le déjeûuer et le diner clans une petite cuillerée de lait ou d'ean. On angmente la dose sclon que l'àge est plus avancé. Pendant la nuit, si la fière est considérable, on donnera la moitie de la dose de la pondre ci-dessus, en y ajoutant quelques grains de nitre ou de poudre de contrayerva. L'elfet qui en résulte est une douce moiteur.

Après quelques jours de l'usage de ce remède, l'enfant éproure moins de gêne dans la respiration, les accès de tonx sont noins fréquens et la fièvre moins forte: on diminue alors le nombre des prises, et ce qu'nn donnoit en un jour sert pour deux : on continue ainsi jusqu'ì parfaite guérison. J'ai plusienrs fois conployé ce mélange aver succis, non senlement dans le irnitement de la coqueluclie, mais entore dans les cas nir le ventre des enfans commensoit a s'obstruer : le larre stibic at trés-petites dose's a produit alors les 


\section{PHYS. ET MÉD. - FOTHERGILL. 233}

avec l'úpaississement des humeurs. C'est, dit-il, sur les premières qu'il fant porter l'action des médicamens: en leur donmant du ressort, on dissipe l'engorgement

meillours effets. Mr. Folleregill a remarqqui qque cette preparation, donnce de lis manière qu'il a iudiquée, l'emportoit sur l'oxymel scyllitique et l'ipécacuanha : cependane il observe yus sá méthode n'est pas applicable daus tous les cas et qu'elle u'crelut point les antres remèles, tols que l'application dies coutharieles, l'usage du quinquina, du musc et du castorciun, selun les indicatious qui se prisentent.

Le second article offe des observations sur l'usage de la cignë.

Quoique Mr. Fothergill ne soit jannais parvenu it guirir un cancer par le moyen de la ciguë; cependant il assure que sou nsage a souvent diminné les donleurs, empichic les progries de l'ulcerre et rendu la suppuration meilleure, en igard is la coulenr, is la cousistance et à l'odeur. L'unteur cite plusicurs observatuns tant sur les ulcères cancérenx, que sur cenx qui sont srroplulenx. sur les rhumatismes ot la pluthisic. Dans tous ces cas, il en il obtenu de triss-bons effets. Il semarque que l'extrait de cigui courient rarement aux enfins et aux adultes, qui ont le gene nerveux trissensible; que, pour avoir un extrait plus actil de cette plitnte, il fant la cueillir lorsq̨u'clle est diuns tonto sa vigueur et que sa fleur commence is se linuer; que la meilleure matuitre d'en faire lextrait est d'employer le noius de chaleur possible, et de la finire bouillir le moins que l'on peut; enfin qu'il faut cummencer par unc petite dose qu'on angmente graluellenent.

Le quatriche rolune contient plusienrs mémoires intiressans. Les principaux syuptỏmes de l'hydrocépale interne sont rapportés daus l'cloge de iI. Folhergill, tels que ce nédecin les a tracés. Ses remarqques sont en general conformes it relles que Robert Whiytt a faites sur er geure de maladie; il en a sculenent tiré sons quelques rapports des conclusions différentes. Il regarele les vers comme nne des causes occasionnelles les plus ordinaires de l'hyclrocépluale. Quoiquil se manifeste, selon lui, le plus sonvent depuis cinq ans jusqu'ì dix. it l'a cependant ubservè deux livis dans des sujets de dix-sept à dix-ncuf ans; les restes de la petite-rérole mal jugće 
que de légers évacuans peuvent diminuer d'ailleurs as mesurc que les fibres reviennent sur elles-mêmes.

lui ont parn souvent y conduire. Suirant le docteur Whytt, ce mal se forme lentement et il est au moins plusicurs mois à se développer. M. Fothergill l'a vu enlever en quatorze jours des malades qui jonissoient anparavant de la meilleure santé. La tếte est presque toujours la dernicre partie dont ils se plaignent. La nuque, les épanles, et quelquefois les jambes, sont pendant un certain temps le siége de la doulenr: des maux de tête se font sentir vers la fin, en traversant principalement les tempes et en partant souvent du fiont. Les malades poussent quelque fois des cris aigus, et plusieurs sont assoupis dans les intervalles des douleurs. Le pouls s'accélère; Ia respiration est laborieuse; le sommeil est court et tronblé; les pupilles sont dilatées; les excrémens sortent enfin involontairement, tandis que, daus les premiers temps, la constipation a été opiniâtre. Cette maladie attaque souvent les enfans dans l'époque de la plus belle santé, et les plıs pétulans sont ceux qui y sont les plus sujets.

Les cillomélas, le tartre stibié, la teinture de rhubarbe, les symapisınes, les vésicatoires, étoient en général les remèdes qu'il cmployoit dans le traitement de cette maladic. Il est important de tenir le ventre libre. En général il se conduisoit comme s'il y avoit cu complication avec des vers, ou comme si une autre cause avoit exigé les reınèles uécessaires pour prodnire des évacuntions.

Parmi les observations de M. Fothergill sur le traitement de la sciatique, une est sur-tout intéressante, et j'en rapporıcrai l'extrait.

Une personne touraientée par une maladie de ce genre, cruelle ct opiniâtre, aroit inutilement enployé tous les reuèdes en usage: elle étoit réduite à prendre de l'opium pour calmer les douleurs vives qu'elle ressentoit. M. Fothergill lui fit donner chaque nuit une des pilules suivantes.

Recipe calomel. levig. grana decem, terebcul. de Chio, quant. suff., fiant pilule: decm non deaurande.

Les évacuntions alvines que M. Fothergill se proposoit d'exciter n’enrent point lieu. Il se détermina alors a lihire prendre deux grains de calomélas prudant une nuit, et un seulement pendant la nuit 
PHYS. ET MÉD. - FOTHERGILL. 235

Il est très-difficile de reconnoître par les symptômes particuliers la maladie que Robert Witth a nommće

suivante : le mal diminna un peu. M. Fothergill poussa la dose du calomélas jusqu'ì six grains par jour, trois graius le matin et trois la nuit; mais il u'y ent ancune augmentation dans la quantité des selles, ui daus celle desurines : cependaut la doulenrdiminua d'nne mauière trìs-marqquée, les forces revinrent, l'appétit se ritablit, le malade put sortir, et il n'a épronvé depuis aucun accident de cette nature. M. Fothergill n'en conclut pas qu'ou puisse impunément donner chnque jour six grains de calomélas it tous les malades qui sont daus ce cas; mais il croit qu'il est utile ul'augmenter par doses graduées, jusqu'a ce que l'on ait trouvé celle qui couvient aux malades.

Il a cmployé avec snceés une prẹparation de même geure dlaus lc traitcmeut du lumbago et lans celui des affections vermineuses des enfans. Au lieu de la térébenthine, e’ertoit souvent la conserve de roses qu'il ajoutoit au calomelas, et il faisoit quelqquelois hoire par-dessus le mélange suivant.

Recipe aq. alexit. simp. semi-unc. alexit. spir. semi-drach. vin. antimon. gutt. $x x x$. tinct. thebaic. $x \times x y$ syr. simp. una drach. $m$.

Il supprimoit l'antimoine et les anolins lorsque lit doulcur aroit beaucoup diminuc. Ilest saus doute très-important, lorsqu'on donne long-temps le calomélas a nu malade, de prévenir les accidens de la salivation.

Daus ses renarques sur le trnitement de l'hydropisie, MI. Fothergill se plaint avec raison que l'opereration de la ponction est presque toujours trop retardée. Lorsqu'après avoir employé les préparationg de scille, les sels alkalins, le baume de térébenthine et les purgatifs corroborans et drastiques, MI. Fothergill u'obtenoit ancun succels marqué, il ne différoit point ì faire pratiguer la ponction, après laquelle il faisoit prendre des remedles toniques ou des cordiaux pour fortifier les vaisseaux absorbans, et il ne refusoit point de boisson aux malades que la soif tourmentoit.

MI. Fothergill aroit traité un grand nombre de personnes attaquées de la consomption. Il s'élère avec autant de force quo de 
hydrocéphale interne on liydropisie des ventricules du cervean. M. Fothergill, qui l'avoit observée plusienrs

raison contre l'abus que l'on fait des substances basalmiques dans le traitement de cette maladic.

Les suites de la rougeole et des maux de gorge en général, celles de tontes les maladies éruptives et vircuses, celles des maladies inflammatoires de la poitrine et les suppressions d'évacuations quelconques, sont les causes qui produisent le plus souvent la phthisie pulmonairc. Toutes les fluxions calarrhales prolongécs qui la précédent sont accompagnées d'une toux plus ou moins forte qui mérite la plus grande attention de la part du médecin. Les rafraichissans, les petites saignćes, la diète la plus sévère, ct sur-tout l'abstinence totale de la viande, sont absolunent indispensables. Les semences fraiches de parot blanc, dans la proportion d'une demi-once sur une pinte d'cau, font une émulsion que M. Fothergill a cmployéc dans ce cás avec le plus grand succès; mais il est rare qu'on veuille prendre des précautions aussi rigoureuses pour une toux qui, négligsée, ne dégénère que trop sonvent en plithisic.

Les maux de jambes sont fréquens et assez graves dans plusieurs cantons de l'Angleterre: !e ineilleur procédé pour les guérir consiste, suivant M. Fothergill, après avoir diminué l'inflammation par les ćmolliens, à étendre sur l'ulcère un linge très-fin, trempé dans l'enu régéto-minérale de Gonlard, à placer ensuite une plaque de plomb mince sontenue par un bandage. On agit en unême tenips, s'il est nécessaire, sur les lumenrs par l'intermède des dépuratifs et on applique un cautère, si les ulcères étoient anciens et opiuiàres. L'emploi du bandage dans ce cas n'est pas nouvean: Wisman, célèbre chirurgien anglais, en a recommandé l'usnge dans son deuxiène livre de chirargie, et il a décrit un. brodequin qu'il employnit dans les mones vues.

Le cinfuièue et dernier volume des Mémoires de In Société de médecine de Londres en contient plusienrs de M. Fothergill, non seinlement sur la médecine pratique, mais encore sur plusienrs oljets intéressaus d'histnire naturelle.

Ce médecin n'a rien laissé à désirer sur tout ce qui concerne la 
PHYS. ET MÉD. - FOTHERGILL. 237 fois dans les adultes, en a développé le caractère. Ses ravages sont souvent très-prompts: une douleur qui

description, l'analyse et les propriétés médicales dir cortex winteranus. Cette substance qui est envoyce du détroit de Mirgellan doit âtre distinguée de celle appelée cancilla alba, qui est une prodluction de la Jatnä̈que et des autres iles uccidentales. On pent voir, page 48 du cinquième volune, l'exposition des curactíres butauiques de l'arbre a uquel cette écurce appartient; et, page 56 , rout ce qui concerne sa nature et ses propricités chimiques.

Il résulte des expériences du ductenr Morris quu le corlex - vintcranus est une substance astringente ct qui pent citre employéc non senlement en mélecine, mais eurore dans certaines manufactures. L'eun, mirue salie, comme dissolsant, en tire une maticre extructicc aboudante. Les parties gommenses et resinenses y sout mélées éuscullde. L'iuliusion et la décoction de cette écorce sont d'un goht agréille, et elle peut ère substitne à l. graine sle circlanome, pour masquer le mauvais gonit de l'unfusion de séné; elle peut anssi ètre employée dans la préparation de la teinture de rlublorlse.

M. Forhergill a clonué des reuseignemens aussi curieux qu'exacis sur la substance appeléce terra juponica ou, cachou. Il a expose zous les caractères butauiques de la plunte de laquelle on retire cet extrait. Celte plaute est une mimosa de Linnaus. L'opération employce par les maturels dn gays pour obtenir cette substance est détaillée avec le plus gramal suin par Mr. Fothergill. Elle se fait dans l'Indoustan, proviuce du Bahara, sur la còte occirlentale du Bengale : on y emploie l'extrait dont il s'agit dans le's uintures et eu médecine. Ils le regardent comme un calmant; ils en doment mèue jusqu'it la dose de denx onces chaçne jour anx cheraux vicienx pour les dounter, et elle est le principal ingrédient d'un onguent très-célèbre dlans ce pays pour le traitement des plaies et ulcères : il est conposé de quatre gros de vitriol blen, de quatre onces de terra japonicu, de neuf gros d'alun, et de quatre onces de résine blanche, le tout rédust ell poutre; on y ajoute dix onces d'luile d'olive et une suffisante quantité d'eau ponr la coctiou. M. Fothergill a fait, dans le ciuquième volume, 
arrache quelquefois des cris s'étend du front vers les tempes; les battemens du pouls sont accélérés; la chaleur augmente sur-tout à la tête; l'uuspiration est profonde et irrégulière; les membres deviennent souffrans

l'histoire dl'une maladie qu'il a décrite sous le nom d'angina pectoris.

Ses principaux symptòmes sont énoncés dans l'article de l'èloge oǹ il en est question: ils consistent principalement dans une grande difficulté de respirer, qui, pendant les clerniers temps, est augmentée par le plus léger mouvement, et dans un penchant irrésistible au sonmeil. A l'ouverture dn corps de ceux qui succombent a cette malaclie, on trouve un amas très-considérable de graisse clans la poitrine et aux environs du péricarde. Dans ce cas, comme daus tous ceux où l'abonclance excessive de la graisse menaşoit de quelque danger, MI. Fothergill conseilloit la diète végétale seule, l'usage des eaux ninérales légèrement ferrugineuses, et les martiaux à des doses modérées. Il est important que les personnes attaquées de ce vice ne boivent jamais aueune liqueur fermentée, et soient en garde contre la colère et autres passions violentes, qui peuvent leur être funestes.

Les mémoires dn même auteur sur les précautions qu'il convient de prendre pour conserver la santé des femmes, considérées dans l'àge appelé critique; sur l'utilité des lègers calmans, des petites saignées du bras et des purgatifs employés dans ces circonstances; et sur les maladies des peintres qui emploient des couleurs préparées à l'eau, sont aussi très-intéressans, et composent la plus grande partie dn cinquième volume de la Société de médecine de Londres, auquel nous renvoyons pour les détails.

J'ai pensé que II. le docteur Fothergill ayant écrit ses ourrages en anglais, cenx anxquels cette langue n'est pas familière me sauroient gré de leur eu avoir offert un extrait.

En ${ }^{7}$ 秝 M. Fothergill publiat dans les Transactions philosopliques un essai sur l'origine de l'ambre et des observations sur la manne: Olsservations ou the manna persicunt. En $17\{5$, il $y$ insirit une Irttre an docteur Mead, et des observations sur le truitement de cliverses aspliyxites. 
PHYS. ET MÉD. - FOTHERGILL. 239 perudant le sommeil, qui ( 1 ) est court et troublé ; les yeux ue sont pas tout-i-fait recouverts par les paupières; les prunclles sont dilatées, et la sensation opérée par la lumière est quelquefois doulourense. La pusition horizontale est celle que les malndes sonffreut le plus volontiers. Les forces enfin s'épuiseut et les paupières deviement paralytiques. 'Tel est l'analyse d'un des tableaux les plus finis que l'ou ait jamais tracés en médecine. C'est en snivint une marclıe semblable que cette science se perfectionnera, et c'est sous cet aspect que doivent être jugés cenx qui lui cousacrent leurs veilles. On répète qu'elle ne fait point de progrès; tet quelques médecins igruoraus, jugeant de l'état acturel do notre art par celui de leurs lumieres, se joignent it la nurltiturde pour lui faire ce reproche. Mais que l'on réfléclisse sur le nombre des maladies qui nous attaquent de toutes parts; il n'y en a aucume dont les variations et les symptônes n'aieut été décrits avec la plus scinpuleuse exactitude, et dout un nédecin attentif no puisse recomnoìtre les caractères et les muauces les plurs délicates. An mérite de ces observations exactes et nuultiplićes, que l'on ajonte celui des essais nombreux, faits daus le traitement de ces différentes maladies avec leurs résultats, et l'on sera étonué de l'immeusité des fiats dont la médecine s'est enrichie de puis Hippocrate. C'est sur-tout la métlıde de ce grand homıe qu'il faut pré-

(1) Plusieurs de ces sỵmptòmes sont communs aur maladies rermineuses; mais la douleur des nembres et le mal de tèle continnel doiyent sur-tout fixer l'attention du médecin. 
férer à toutes les autres : il 11'a pas tout fuit; mais il a indiqué les moyens de tout faire; et cenx qui sont d'une opinion différente, ou ne savent pas quels sont sesécrits, ou n'ont pas lu ceux qui ont été publiés après hni, ou, ce qui est le plus probable, ne connoissent ni les uns ni les autres (1).

La consomption, qui est une véritable plithisic, étant très-commune à Londres, M. Fothergill rı'a en que trop souvent occasion de la traiter. Il a fait les réflexions les plus judicieuses sur les remèdes employés pour la combattre. Quoique les fièvres hectiques aicut un retonr marqué, et que sous ce rapport elles soient analognes aux intermittentes; le quinquiua, loin de soulager cenx qui cu sont atteints, aggrave les accidens. L'évémencnt est le même lorsque la toux est sèclie, et lorsque des douleurs aiguës et passagères se font ressentir dans la poitrine, lorsque le pouls devient plus fréquent, et que la difficulté de lis respirationaugmente. L'usagge de ce nnédicanent convient an coutraire daus les cás où une déperdition quelconque de substance ayant précédé, le nualade étant affoibli, et la fièvre n'existant point oụ étant légère, on craint un affaissement qui porrroit derenir mortel.

(1) Fothergill a très-bien décrit, dans les Mémoires de la Société de médecine de Londres, le rhumatisme fébrile de la face; il en a fait comnoitre les accidens et les varićtés. O॥ lim aussi avec plofit ses réflexions sur les elfets sédatifs de l'extrait de ciguë, e:t sur le raitement de: la rage pour la guérisou de laquelle les baius de mer, suivant lui, nont aucume efficacile; tandis yue les caluans, la lotion de la plaie et la destruction de ses bords liu le moyeu des cilustiques, sout très-utiles. 


\section{PHYS. ET MÉD. - FOTHERGILL. 241}

L'art d'observer exige moins nne pénétration, une sagacité particulières, comme plusieurs le disent, qu'un esprit actif, impartial, des yenx attentifs et me grande patience. C'est la distraction qui rend le plus sonvent ce travail incomplet; elle tient ì la paresse, si naturelle à l'homme, te que l'on pent regarder conme le plus grand ennemi des succès daus tous les genres. Rien ne pronve mieux combien M. Fothergill apportoit de soin dans le traitentent de ses malades, que l'exactitude a vec laquelle il a rentarqué des circonstances nouvelles datus plusienrs lésions déja trís-connues. C'est ainsi qu'il a observé et décrit, sous le nom d'angrina pectoris, unse sorte d'étonffement on de suffocation (1) accounagnée de spasmes, dans laquelle on épronve le mùme sentiment que si la poitrine étoit serrée par mue ligatme, et dont une surabondance de graisse accumuléc dans les viscéres de lia poitrine, et sur-tont hors dn péricarde, est la principale canse (2).

(1) Les malades ne peuvent marcher que lentement; il leur est sur-tont impossible de hater le pas lorsque le terrain est inégral et un peu montueux: la plus légère agitalion leur canse une syncope. MI. Fothergill a communique i diverses reprises des obserFalione sur cette maladie d̀ la Société unédicale de Loudres.

Case of augina pectoris with remarks. -Farther account of the angina pectoris, tom. $V$ des MIedical observations, etc.

(a) M. Fothergill partagevit ses travaux eutre les compagnics auxųuelles il appartenoit. La Société d'Edimbourg a reçu de lui des observations sur les sels neutres des plantes. Elle les a pu. blices dlins son cinquième volume. MI. Futheroill donnoit la terre folice comme un remede altérant, jusqu’à deux on mème trois gros; et comme purgatif, lepuis trois jusqu"d six gros.

T. 2. 
L'art salutaire de rappeler les noyés à la vie doit ses premiers principes aux savans français. M. Fothergill s'en est occupé très-utilement en Angleterre. Il est pentêtre le premier qui ait fait comoître les avantages de l'insufflation de l'air dans les poumons des personnes suffoquées, et il a eu la satisfaction de voir ses conseils adoptés en mêrne temps par le gouvernement et par lé peuple.

Sa vigilance s'est étendue à tous les objets d'administration relatifs à la médecine. Il a écrit sur la nécessité de transporter les sépultures hors des villes (1). Ayant été cliargé, en 1774, par la chambre des communes de travailler à la réforme des prisons, il a rétabli la salubrité dans ces asiles, où la santé du citoyen renfermé sous la protection des lois est un dépôt qui leur est confié et dont elles répondent. La Compagnie a vil avec plaisir ces heureux changemens opérés ì Paris comme à Londres par un de ses assosiés (2).

La grande réputation de M. Fothergill et son affabilité faisoient rechercher sa correspondance par les médecins et les chirurgiens les plus habiles de l'Angleterre. Il recevoit lenrs mérnoires et les communiquoit à la Société médicale, qui les publioit danss ses volımes. On y remarque sur-tont des réflexions de M. Lionel

(1) In. Fothergill a public deux letures anonymes sur les précautions i prendre pour rendre les incendies moins fréqueus i Loulres.

(2) On se souviendra toujours avec recounoissance des scrvices que M. Colombier, l'un de nos assncićs ordinaires, a reudus dans crte partic de J'arbuinistration médicale en France. 
PHYS. ET MÉD. - FOTHERGILL. 243

Chalıners, de Charles-Town, sur la guérison de plusicurs nonvean-nés attaqués du tétanos, et les tables de M. Percival, médecin, et notre associé à Manchester, contenant la liste comparée des persomes mortes de la petite vérole et de la rougeole dans les différens ìges de la vic. Les conséquences en sont anssi curienses qu'intéressantes. Il en résulte qu'il ne ment point d'enfans de la petite-vérole anı-dessous de trois mois. M. Monro en a inoculé donze dans les premiers quinze jonrs après leur naissance; ancun u'n été atteint de ce nal. Pendant les dix-lnit nois suivans, la nature prépare la dentition; le danger de l'inoculation est alor's tres-grand, et il dimime ver's la fin de cette époque: de sorte que le ternps le phus favorable pour la pratiquer est l'untervalle compris entre la seconde et la quatrième anuée pour les enfius robustes, ot depuis la troisiene jusqu à la sixième pour cenx qui sont plus délicats. Les trois cinquniènes de cenx qui nuenrent de la petite-vérole périssent avant la troisiène amnée ; ct, parmi les personues attaquées de la rougeole, certe proportion est la moitié. Il mentr plus d'hommes que de femmes de lis rongeole, et c'est le contraire pour la petite-vérole (1). Enfin, le nombre des rictimes de la rougeole est, dans la patrie de l'auteur, it cenx qui menrent de la petite-vérole, comme un à cinq et liuit dixiènes.

(1) Le nombre des personnes mortes de la petite-vérole à Londres pendanı dix années est à celui des morts occasionnérs par d'aures malaties, comme un a neul; et, dans une paroisse de campagre du comté d'Yorck, cctte proportion a été d'un à dix-neuf. 
L'utilité des tables dans lesquelles on fait mention des causes de mort ne se borne pas à cet nsage. On peut, en les compulsant, savoir combien les épidémies, la phthisic, le scorbut et les antres maladies graves enlèvent de personnes; dans quelles saisons et dans quel âge ces différens maux sont les plus funestes. Nous voyons avec regret la France privée de cet avantage dont on jouit en Angleterre et en Hollande. On compte à peine plus d'un siècle depuis que les époques de la naissance et de la mort des citoyens sont constatées d'une manière authentique et légale. Les ministres de la religion, à laquelle toute notre existence est dévouée, veillent plus particulièrement sur les denx extrémités de notre carrière. On ne croit pas trop attendre de tenr zèle en leur proposant et à l'administration, d'ajouter sur leurs registres les noms des maladies regardéę comme des causes de mort. Il n'y en a qu'un petit nombre que les familles croient avoir intérêt de cacher, et l'exécution de ce projet, quelque parti que l'on prît à cet égard, ne pourroit en sonffirir. De quel droit an reste s'efforceroit-on de voiler celui de tons nos instans. qui est le moins à nous? De mêmo que l'homme en société ne naît pas, il ne menrt pas non plus pour lui senl. S'il périt victime du désordre, pourquoi voudroitón en dérober la comnoissance an législatenr, qui ne pent se détermincr à réprinuer les abus ru'apris en aroir vu tous les effets, et au public aucunel il suffiroit pentv̂tre de les dénoncer pour les rendre plus odienx et plus rines?

M. Johthergill ne bornoit pas sa correspondance it 
PHYS. ET MED. - FOTHERGILL. 345 l'Angleterre; il l'étendoit à tontes les partirs du globe. Le doctenr liussel lui envoya d'Alep la description de la plante yui fournit la scamnonée; il reçnt d'Afrique la gomme rouge astringente de Gambo, dont l'usage est recommandé dans le traitenent de la diarrhée. Les renseiguemens qu'il prit sur l'écorce de WVinter le mireut à portée d'en publier me histoire exacte, soit comme naturaliste, soit comme médecin. Ce fut en 1577 que le capitaine Jean Vinter (1) fit connoître cette écorce, sur laquelle on recut su 1692 de nouveanx renseignemens dout les botanistes ne liurent point satislats. Wallis ayaut rapporté en 1768 des échantillous plus complets de l'écorce dont il s'agit, et les ayant remis at M. Fothergill, fou M. Solinder voulut. bien, d'après son invitation, décrire l'arbre, les flen's et le fruit, et le doctenr Moris en fit l'analyse chimique. Ces recherches, rémines par M. Fothergill, composent 111 mémoire très-curienx qui se tronve dans le cinquiène volume de la Société médicale de Londres. On y apprend que la canelle blanche qui nons est apportée de la Jamaïque et des antres îles occidentales diffère essentiellement de l'écorce de WVinter, et que cette dernière est un astringent nou seulement utile en médecine,

(1) Il en rapporta des échantillons qui ont été décrits par Clusius. Il en fut fiit mention de nouveau dans une relation de la décon. verte de la Virginie (Relation d'Amadas et de Barlou) : mais, arant 1691 , on u'avoit encore aucune description botanique de cette écorce. A cette époque, George Handonsand en rapporta plusienrs morceilux du détroit de Magellan, et il les remit à la Snciété royale de Londres, qui publia tous les détails foumis par ce rọageur. 


\section{ELOGES HISTORIQUES.}

mais qui pourroit eucore être employé dans les arts.

Enfin on doit à son zèle et ì sa correspondance des connoissances exactes sur l'origine jusqu'alors ignorée de la substance appelée terra japonica on cachou. Cette substance est un extrait de la partie lignense la plus solide d'un arbre du genre des mimosa de Limnæus. L'auteur, après en avoir déterminé les caractères botaniques et en avoir indiqué les vertus, ajoute que les guérisseurs de ce pays font de grands et inutiles raisonnemens sur l'action et la ilature des remèdes, q117ils diviseut, conume les maladies, en froids et en chauds. Les médecins nègres ont donc aussi leurs systèmes; et ce qui est bien glorieux pour eıx, mais très-humiliant pour nons, c'est que ces systènes aicnt tant de ressemblance avec les nôtres.

M. Fothergill avoit toujours en on cru avoir beancoup d'amis. Ponrquoi se refuseroit-on an plaisir de penser qu'il y en a de véritables? Que les personnes anxyluelles ce sentimont n'est pas nécessaire ne l'enlèvent pas au moins à ceux qui le chérissent: les cœurs durs et froids se plaignent à tort de n'en point trouver de seusibles. Ces demicrs se resserrent d leur approche et ne s'épanonissent qu'auprés de cenx qui leur ressemblent: en s'attirant mutucllement, ils sont uns par nue force qui n'agit et ne se manifeste que pour enx. M. Fothergill ayaut survécn à denx de ses amis, Jes docteurs Russel et Collinson, s'empressa de leur rendre un dernier devoir en écrivant len éloge ( I). Les

(1) Voyez. Some accoum of late Peter Colliuson, cic., in a letues 
PHYS. ET MÉD. - FOTHERGILL. 247 auteurs de ces sortes d'écrits, très-conmmuns en Angleterre, s'étendent peu sur les ouvrages de celui-ci qu'ils ont perdu: c'est l'ani et non l'homme de lettres qu'ils regrettent, et c'est par couséquent son caractère et non son esprit qu'ils ont à louer.

On lit dans cehir de liussel me aneclote que nous croyons digne de tronver place ici. Ce nuédecin célèbre jonissoit it Alep de toute la considération que domnent le savoir et la probité. Le pacha le traitoit de la manìre la plus distingnéc; il nsoit mêne, pour lui témoigner son estine, d'mn moyen également honorable pont tous deux : il ne manquoit jannas, horsyu'il accordoit une grace et qu'il avoit occasion de faire 111 henrenx, d'inviter M. Kussel à se rendre ì son palais pour en être témoin. Ce gonvernenr nettoit $n$ granul prix ì l'anitié dn plilosoplie; elle lni tenoit lien de l'opiniou publique dans 111 pays oil il n'est pas permis an public d'en avoir me, et il croyoit ne ponvoir micux faire ponr l'obtenir que de se parer en quelque sorte

to a frieud. London, $177^{\circ}$, in- $4^{\circ}-$ An essai on the character of the late Alexauler Russel, etc. London, 1770 .

Dans l'éloge de Collinson on trouve deux remarques bien importanies, l'une sur la manière de conduire les troupeanx, qui doit ètre en Angleterre le contraire de ce qu'elle est en Esprane; c'est-à-dire que daus la Grande-Bretagne, dont les laines sont très-humides pendant l'hiver, les moutons doirent passer cette saison sur les montagnes. L'autre réflexion concerne le vin que l'on prépare en Amérique arec des raisins qui croissent natnrel. lement dans les bois. M. Fothergill s'est joint à Collinson pour invirer les habitans it cultiver la vigne suivant la méthode des pays chands, en la faisant monter aux arbres. 
deses hicnfaits, seul genve de sćduction et de galanterie qu'il soit permis aux grands d'employer ct aux sages d'applaudix.

Le goût dominant de M. Fothergill, après celui de la médecine, étoit l'étude de la botanique. Quoiqu'il ne négligeât point la connoissance des caractères et l'examen des différentes parties des plantes, c'étoit la culture dont il s'occupoit le plus. Le premier travail ne pent en effet être regardé comme un délasscment; le second offre des plaisirs purs et variés; il tient ì l'agriculture, cette première source de nos jouissances, cet art si ancien, si lıonoré dans nos écrits et si peu eneouragé dans nos campagnes. M. Fothergill acheta en 1762 un cliamp très-vastc à Upton en Essex, où il exécuta lc grand projet.qüil avoit conçu depuis plusieurs années.

Quelques plantes croissent indiffércmment dans tous les pays, et clraque climat en nourit qui lui sont propres. Attachées par des liens fixes au sol qui les a vu naitre, elles sembloient devoir lui appartenir exclusivement et n'être pas destinécs ì végéter daus des régious lointaines. 'Tel paroissoit être an noins le prenicer plan de la natme ; maisclle avoit fait l'homunecuricux, impatient, mobile. Cette nuobilité s'est étendue sur toutes les parties du globe, et les richesses des deux mondrs ont íté surprises de se voir confondues. An milien de ce désordre, dont l'intérêt est le noteur, desêtres bienfaisans ont clıcrché quel avantage réel on poutroit retirer de ces grands débris.

Notre Eunope est privéc de plusicurs plantes et d’ar- 
PHYS. ET MED. - FOTHERGILL. 249 bres très-importans à la médecine et anx arts : ce seroit 1111 grand bien de les y introduire et de les y acclinuter. M. Fothergill s'étoit proposé ce but désirable; et pour le remplir il avoit établi un des plus ınagnifiques jardins qui acent jannis existé, d'ou il distrihnoit chaque anméc dans les trois royanmes et daus les colonies angloises nu grand nombre de plintes utiles. Saus la gucre actuclle il auroit élevé et pent-être douné à l'Europe deux arbres funcux, le fruit ì pain et le mangoustau. Il récompensoit magnifiquement les personues qui lui procuroient des végétanx rares; il faisoit mêne voyager des botanistes à ses dépens, el le cálébre M. Banks, qui est garant de ces détails, a écrit qu'à l'époque de la mort de M. Fothergill il y avoit encore mu de ces maturalistes en Afrique. Jusqu ici ces grands traits de générosité aroient été rúservés pour lionorer l'histoire des sourerains ( 1 ).

Tels étoient les délassenrens de ce citoyen estimable. On ne sait qui méritoit le plus d’éloge de son activité on de ses loisirs. 11 ne bornoit pas lì sun zèle: la peine qu'il prenvit à cultiver ces plantes auroit été perduc s'il n'cn avoit pas conservé les dessins. II choisit pour ce trarail les plus habiles artistes de Loudres; et, lorsque la mort l'a surpris, il aroit déja plus de douze cents planches peintes sur rélin. Elles sont maintenant conservées dans les cabinets de limpératrice de Russie. Ces restes, joints à ceux de plusienrs

(1) En 1781 , un botaniste royagcoit en Afrique aux dépens de MII. Fothergill et Banks. 
autres savans, sont sur-tout précieux dans un pays oủ les lettres n'ont point encore jeté des racines profondes. Tout ce qui vient des glands lommes est une sorte de ferment qui tend à reproduire le génic; ct comment les sciences ne fleuriroicnt-elles pas daus un royaume dont on a vu la sonveraine recueillir avec respect ces bibliothìques célèbres (1), auxquelles il senıble que les ombres de leurs illustres possesseurs soient encore attachées et qui seront ì jamais un foyer d'émulation et de lumières. Hemrenx les savans près de cette source de bienfaits, qui sans doute ne se répand au loin qu'après avoir fécondé ses bords !

Les mêmes soins qui avoient rénni dans le jardiu d'Upton des plantes rares, enrichirent le cabinet de M. Fothergill des productions des autres règnes : on y voyoit sur-tout les minéraux, les coquillages, les coralines, les insectes les plus curieux. Cette collection (2) étoit, au rapport de M. Solander, une des plus complètes qu'ıl y ent à Londres.

Que l'on ne croie pas au reste que le senl mérite de M. Fothergill en listoire naturelle ait été de suffre

(1) On sait que l'impératrice de toutes les Russies a acheté les bibliotieques de Voltaire et de Haller, et que plusicurs anuces auparavant elle avoit pris le's mesures les plus géncireuses pour s'assurer celle d'un de nos plus illustres littérateurs.

(2) M. Fotlıergill a inséré dans son testiment un article par lequel il a oftert a M. Hunser cette collection it 500 guineses audessons du prix qu'clle seroit estiméc. Son intention étoit de eonserver ce calpinct aux savans, et de domer it sou ani, qui - accepti cette clause, un temoignage de son souvenir, sans 
PHYS. ET MÉD. - FOTHERGILL. 251 par ses libéralités anx dépenses énormes que son cabinet et son jardin exigeoient. On sait en Angleterre combien Ellis ( 1 ) a dn ì ses conseils dans lat rédaction de son histoire des coralines. Les planches destinées an grand Traité de Jean Miller (2) sur la botanique ont été dessinées sous les yenx de MI. Fothrergill, et penvent être regardíes en partie comme son onvrage.

Lorsqu'il pouvoit dérober quelques momens it la pratique de la médecine, il les passoit dans son jardin d'Upton an miliess des végétaux étrangers (3) dont il avoit formé de nombrenses colonies, et parmi des flenrs qu'un art industrienx lui offroit dans tons les temps de l'anncé. La belle saison, qui semble faire le tour dn globe, est comme fixée dans nos serres; mais à côté de sa riante inagge sont les tristes dépouilles do

cependant sonstraire à sa succession une somme considérable qu'il avoit destiuée it des rnes d'utilité publique.

II. Fothergill arnit réun dins un calsinet me superbe collection de norcenux alestines ì l'étude de la matière médicale; il en a fait présent au Collège de médecine d'Elimbourg, où elle doit servir à l'enseignement.

(1) On consultera aussi la préface que MI. Fothergill a mise a la téte du royage de Sydney Perkinson aux mers du Sud. Voyez anssi l'Historia plantanum Siberice de Gmelin. Perp. 1747. Voyez An account of some observations amd experiments made in Siberia extracted froin the preface tho the Flora siberica.

(2) Ce traitć devoit être fait suivant la méthode de Linnæus, qui en avoit agréé le plau et approuvé plusieurs morceaux qu'on lui avoit communiqués.

(3) C'est aux soins du doctenr Russel et de M. Fothergill que les Anglais ont l'obligation de voir la culture et la préparation de la rlubarbe perfectionnée dans leur climat. 
2.52

l'hiver : l'homme s'aperçoit aisément que ses moyens sont très-bornés, et qu'il n'appartient qu'à la natıre de faire un printemps dont les beautés soicnt pures et grandes sans effort comme sans mélange.

Plusieurs années se passèrent duns cette activité. Une carrière aussi remplie ne paroîtra sans doute à quelquesuns qu'un enchaînement de fatignes; mnais le désœuvrement et l'emui ne sont-ils pas deux desplus grands malheurs auxquels nons puissions être livrés? L'emploi continuel des facultés, l'exercice non interrompu des forces ne donnent-ils pas à l'ame un sentiment de vigueur que l'on doit regarder comme un bonheur réel? D'ailleurs, quel rapport y a-t-il entre les amusemens des hommes oisifs et cenx de ce petit nombre d'êtres dont l'ame conserve, acquiert mêne de l'énergie au milieu des occupations nombreuses qui les pressent de toutes parts sans jamais les surcharger? Le plaisir est pour ceux-ci nn éclair qui lesfrappe d'une étincelle vive et brillante; pour les premicrs, c'est 1 jour obscur dans lequel ils se fatiguent à chercher une heur qui les fuit.

M. Fothergill vit que ses forces diminnoient: il quitta le centre de la ville pour se loger dans m faubourg; et il résolut, en 1765, de suspendre chaque annce ses occupatious pendant deux mois, et de passer ce temps it Lée-Hall oin il lowa me terre. Ce fint pour lui un moyen d'stendes la culture des plantes et des arbres exoliques. Ce pays lui offroit: cucore d'autres charmes; it avoit étŕs son bercean. L'homme selonrne volouticers an loyer de ses peres; ì unesure quil il arance 
PHYS. ET MED. - FOTHERGILL. 253 dans sa carrière, il décrit une ligne dont on te voit quelquefois renouer avec plaisir les denx extrénitús. Arrivé an point d'où il étoit parti, il embrasse tout l'espace de sa durée: ces mêmes licux témoins de la foiblesse de son enfance, le devieunent de sa caducité et semblent lui demander compte de ses amuées de vigneur: quels que soient sa fortme, son rang ousa célébrité, il ne lui reste que des remords on sa vertu. M. Fothergill jonissoit dans cette relraite du repos des ames homnêtes, et ses amis out toujours remaryunó qu'il en revenoit chaque amóe mieux porlaut et phis gini (1).

(1) En 1766, M. Fothergill éprousa un chugrin tres-rit. Le nomuné Samunel Leeds, quaker, qui aroit passé toute sa jeunesse? comme ouvrier daus lat houtique d'un marchind de brossea, fist reçu doctenr fu medecine en Licosse, et nonmé médecin d'un des hòpitanx de Louldes; ce que 11. Forhergill vit avec peine. Leed's donna bientût des preures d'ignorance et fut prive de son emploi; il fiut mème réglè que dorénavant aucun uédecin ne pratiqueroit dans les hópitaux de Londres sans aroir subi un examen devant le Collége des médecins de cette ville. Tout le pronde applitulit it cetre sage disposition; minis Leeds prit U. Fothergill a parti : il l'accusa derant la Société des quaker's de l'aroir desservi et de n'avoir point fait, pour empècher sa disgrace, des efforts qui u'auroient pas été sans succès. MI. Fothergill, auquel l'iupéritie de Lecis étoit connue, déclisra qu'il appronvoit la conduite des administratenrs de l'hòpital, et qu'il n'aroit pu, saus frémir, roir le soin tes malides confiè à un médecin de la sorte. L'intrigue de Leeds l'enpoita, et M. Fothergill fut condiunne par les quakers is une aumende très-forte, que, sans l'appui du lord Mainsfield, il auroit été obligé de payer it Leeds. Cette anecdote nous proure q̨u'en Angleterre conıme en France ou rẹ oit des docteurs bien jynoraus. qui trourent, conme ici; de puissans protecteurs. 


\section{4}

ELOGES HISTORIQUES.

Il trouvoit à son retour toute sa réputation; ce qui étonnera ceux auxquels la dépendance de notre état est connue: la moindre absence est souvent punie par l'onbli. M. Fothergill n'éprouva point un pareil sort, peut-être parce qu'on savoit qu'il étoit trop au-dessus de cette infortune.

Il nous reste à le faire connoitre dans ses rapports avec la religion. Au milieu d'un peuple libre il s'est élevé une secte plus jalouse encore de sa liberté, dont les partisans ont osé dire que tous les hommes sont égaux : suivant eux, c'est s'avilir que de faire un serment; on doit avoir en horreur les désastres affreux des guerres et les dissensions ruineuses des procès; toute politesse doit être bannie du langage, comme étant un commerce de mensonge ou de frivolité; l'homme sur-tout ne se combera jamais devant son semblable, pas mêmę devant les rois; son front, élevé vers le ciel, ne doit s'abaisser que devant Dieu. Tons cenx qui reconnoissent son existence sont traités par cux comme des frères; ils plaignent seulement les peiples pour lesquels la divinité est enveloppée de trop épaisses tó nèbres: ils l'adorent dans des temples; mais, ivres de Jenr indépendance, ilsn'y out admis ni prètres ni ministres, et chacm se croit digne de présenter son offrande et de. recevoir inmédiatement l'inspiration sacrée.

On jugebienque M. Fothergill étoit quaker sans être tremblenr. Ce firt lui qui fit an roi le complinent d'usage lors de son avénement an trône; il le rédigea avec un stylo antmut ormé que sa fonction le permentoit, et il en éloigna conte sévérité, cette rudesse gui aroient 


\section{PHYS. ET MED. - FOTHERGILL. 255}

jusque-là caractérisé les productions des quakers (1).

Il se trouvoit cependant quelquefois fort embarrassé par la bizarrerie des contumes auxinnelles il s'étoit astreint. Appelé par des persomnes de la plus gramele quílité et ne pouvant òter son chapean ni s'incliner devant cenx qu'il visitoit, il devoit, sur-tout lorsqu'ils étoicnt étrangers, être souvent accusé de manquer anx égards établis dans le monde. 11 y suppléoit par nue grande alfabilité, qui marynoit asses d'intérèt pour tenir lien de la révérence ordinaire. Il s'approchoit du maldcle arec tant d'empressement, qu'il paroissoit it phusicurs avoir senlement onblic de faire le salut ; en min mot, il avoit tronvé le moyen d'etre affectucux sans ètre poli: bien différent de tant d'antres qui, mulgré leur politrsse, sont très-doloigués d'ètre affectnenx.

Denx conditions devoicut sur-tont l'attacher an parti des quakers, parce qu'elle's étoient absolument conformes ì son caractère : il admettoit arec enx la tolérance la plus cntière, et il s'abandomoit anx monremens de lin charité la plus étendue. Le senl récit de quelques-nues de ses actions étonue et paroit surpasser tonte croyance. 'Tantôt il encourage les instituteurs; il fait un essai dout le succès l'engage ì fouder à Ackwortz, daus le comté d'Yorck, nne maison d'édncation gratuite pour les cnfaus des pauvres quakers; il est luinène l'éditeur des lirres destinés à leur instruction:

(1) La dernière lettre circulaire qu'il fut chargé d'écrire dans l'assembléc geneirale des quakers a Whit-Suntide, fut rirement alliquie daus le Gentleman's magazine. 
tantôt il fait imprimer à ses fíais la nouvelle traduction de l'Ancien et du Noureau Testament par Antoine Purwer (1), si estiné dans son ordre. Le malhenreux Knight gémit dans l'infortune; M. Fothergill, après lui avoir prodigué tous les secours pécuniaires, y ajoute les consolations de la sensibilité; il le visite souvent; il se renferme et pleure avec lui. Le capitaine Carrer vit long-temps de ses largesses, et c'est la veuve de ce militaire qui le publie. Un terrain situé à l'abri dı nord, près de Thames, lui paroît propre à la culture de quelques arbres étrangers; il l'achète: mais pour en prendre possession il faut en chasser une famille indigente accoutumée à y trouver sa subsistance. Son marché est fait, il y tient, è ce n'est que pour faire le bonheur de cette fanille, en lui assurant la jouissance d'un cliamp qu'un autre acquéreur moins délicat auroit pu lui ravir. Mes vœux sont à leur comble, s'écrie-t-il; au lieu de végétaux que j'aurois plantés, ce sont des hommes que je uourris. Enfur les malheurs de la guerre fixent sou attention sur la détresse des quakers de la Pensylvanie; il leur fait parvenir des sommes considérables, et päend toutes sortes de précautions pour leur cacher la main yui les soulage.

(1) Inmi Purwer, quaker célibre, avoit exercé pendanılougtemps un métier ì Londres, et il étoit déja avancé cu age lorsqu'il apprit les langues orientales, le latiu et le grtec, dans le dessein de connoitre éguleurut le seus lincial de l'Aucien el du Nonvean Testament. Ia: suceds le plus brillant a couronme son entroprise: la traduction qu'il ru a faite est trisestince. lille a dé imprime en 1765, en denx volumes in-fulio, et nux dépeus de. 11 . Ivilserpill. 
PHYS. ET MÉD. - FOTHERGILL. 257

Combien il a gémi de fois sur cette guterre contre nature (1)! Ces expressions sont littéralement traduites des Mémoires sur la vie de M. Fothergill. Qucl spectacle en effet! Tandis qu'un peuple républicain s'efforce d'étendre au-delà des mers les chaìnes de sa dépendance, c'est un monarque qui fonde et protège la liberté dans le Nouveau-Monde. Lorsqu'enfin cette liberté scra consolidée, lorsque le bruit des armes aura cessé (2), vouldra-t-on entendre le vœu général? Il tend à une paix durable entre deux nations qui ont le mème anom de la gloire, les mèmes lettres, la même philosophie. L'une, plus calme, rend justice is sa rivale, qu'elle voit toujours sans jalousic et souvent arec admiration. L'autre, pleine d'ardeur et d'inipaticnce, est toujours agitée par nn sentinent d'inquiétude, et pent-être d'ininitié; il semble que la paix n’ait jamais été que daus ses engagemens et point dans son cœur. Ce peuple, qui, comme tous les autres, n'est dirigé dans ses opinious que par cenx qui pensent et qui l'éclairent, scroit bientôt désabusć si les gens de lettres, si les hommes instruits, faits pour lui domer l'impulsion, étoient eux-mèmes pénétrés des sentinuens de confiance que nous ne nianquons jamais de leur témoigner : ils roient arec quelle franchise nous partageons leurs regrets, en louant les vertus de leurs grands hommes ; puissions-

(1) Unnatural war. Voyez la vie de MI. Pothergill, par le docteuz Elliot.

(2) Le lecteur roudra bien se sourenir que cet éloge á été In en 1782 . 
nons en avoir une de plus à célébrer en eux: cette im: partialité qui, sans aucune acception de lieux, de gouvernement et de circonstance, recherche, estime, honore l'esprit et les talens; qui ne se renferme pointdans la sphère de la propriété, et qui après avoir payé à l'amour-propre national un tribut légitime, fait de chacun l'éloge qui lui est dû!

Quelques services que M. Fothergill ait rendus, il n'a exécuté que la plus petite partie des projets utiles qu'il avoit formés. Parmi ses entreprises qui n'ont point eu de succès, aucune ne méritoit plus d'en avoir ct ne lui a causé plus de regrets que celle dont le but étoit la proscription de la traite des nègres. Ce trafic honteux et coupable réduit les hommes à la condition des brutes en les faisant esclaves; il les réunit en vils troupeaux que d'autres hommes ne rougissent pas d'accabler de fers, et de traîner ainsi d'un continent à l'autre. La cupidité, qui calcule leurs travawx et leurs souffrances, les attache à une terre ingrate qui n'enrichit que leurs oppresseurs, à un sol qui ne les a point vu naître et qui ne peut à leur gré les roir assez tôt mourir. Co grand crime des peuples commerçans ne peut être détruit que par les souverains. M. Fothergill avoit pensé qu'il seroit plus facile de le faire cesser en prouvant que les mêmes vues penvent être remplies sans y aroir lecouls.

La canne à sucre, pour la culture de laquelle on emploie ces violences, est pent-être originaire d' $\Lambda$ sio cet d' $\Lambda$ frique; an moins elle y croit de temps inuménorial: c'est de li qu'ello a íló Iransportéc en Espague, 
PHYS. ET MED. - FOTHERGILL. 259 вux îles Canaries, et enfin en Anérique; de sorte que, par une combinaison de circonstances singulières, l'avidité enropéenne a transporté à grands frais des végétaux et des colons étrangers dans le nouveau continent, an lieu d'employer les uns et les autres dans celni qui leur étoit propre.

M. Fothergill avoit proposé de rétablir cet ordre en faisnut cultiver la canne à sucre en Afrique (1); ce qui conteroit moins d'efforts à l'art, en épargnant de grandes contrariétés à la nature. De riches négocians ș'étoient joints à hii pour eu faire nu essai (2) digne d'une seconde tentative. Cette clisse d'infortunés qui, converte des chaìnes de l'intérêt, est bien éloignnée do

(1) Plusieurs négocians anglais ont formé le tuene projet; ils ont mème enroyé des royageurs, chargés de prendre des renseiguemens sur tout ce qui $y$ est relatif. It est bieu à désirer qu'on s'en occupe efficaceurent.

(a) MI. Lettsom, auteur d'un éloge de ce sarant, nons a transmis le détail de l'événement qui douna lieu à ce projet. Il est peu connu en France, et nous le rapporterons, persuadé qu'on ne peut être trop long lorsqu'on plaide la cause de l'humanité. Un des plus puissans princes de la Guinée, roi d'Akonie, après aroir fait, en 1727 , la conquête du roỵame de Whida, députa un de ses principaux sujets pour aller a Loudres proposer au gourernement la culture de la came à sucre, comme un objet de commerce qui n'aroit besoin que du crédit des puissances de l'Europe. On apirit, quelques aunées après, que l'envoyé, comblé de richesses pour ce royage, s'étoit retiré dans les Barbades sans aroir rempli la belle commission dont il avo:t étè chargé. Né esclave, il n'aroit point compris les desseins de son maitre. Pour assurer sa liberté, il avoit sacrifié celle de ses frères; car ce sentiment est le premier des besoins, et il n'y a point d'amour de la gloire dans une ame flètrie par la dépendance et la captirité. 
croire qu'il puisse y avoir des êtres généreur au monde, doit donc aussi de la reconnoissance à M. Fothergill. C'est à nous d'acquitter cette dette en attendant qu'une main plus heureuse leur rende le sentiment avec lat liberté.

M. Fotliergill ne s'est point marié. Quelle affection! quelle fortune auroit-il pu réserver à une épouse, à des enfans, lui qui s'étoit voué tout entier au soulagement de l'humanité pauvre et souffrante?

Une maladie de vessie, après avoir duré pendant plusieurs années, le fit périr le 26 décembre 1780 (1). Les pleurs des indigens, la consternation de ceux dont il avoit eu la confiance, $\in$ t ils étoient en très-grand nombre; des éloges écrits, publiés de toutes parts et gravés dans tous les cœurs, tout annonça à l'Angleterre qu'elle avoit perdu un de ses meilleurs citoyens. Ses funérailles furent honorées d'une pompe publique, distinction qu'un cri général d'admiration et d'enthousiasme peut seul décerner, et que la bienfaisance partage avec le génie (2). L'épitaphe mise sur son tombeau est simple et sans aucune autre éloquence que celle qui naît du souvenir des bonnes œuvres: CI GIT LE DOCTEUR ГотHERGILL, QUI DEPENSA DEUX CRNT MILLE GUINÉES JoUr LE SOULAGRMENT DES MALHEUREUX (3).

(1) Il étoit alors Agé de 69 ans.

(2) Son corpus a été inlumé it Winchmore.Hill.

(3) Après avoir pourvu a la subsistance d'une søur qu'il chérissoit tendrement, il a donnc, de concert arec elle, tout son bion aux pauvres: il a fait drs legs cousilléribles aux colléges de Williansbourg, dn New-Yurck et de Philadelplie. 
PHYS. ET MÉD. - FOTHERGILL. 362 M. Fothrergill étoit très-attaché à la Société: en lui adressant ses ouvrages, il lui a plusieurs fois communiqué des réflexions utiles sur ses travaux. An défint de ses conseils dont sa perte nous prive, nons avons recueilli ses actions : elles inspirent égalenucnt l'amour de l'étude et celui de la vertu.

La place d'associé étranger, vacante par la mort de M. Fothergill, est maintenant remplie par M. van Swinden, physicien à Groningue, qui l'occupe au nom de la Société mnédicale de la Haye. 


\section{GAUBIUS.}

$\mathbf{J}$ ÉRôm - D et ancien recteur de l'Université de Leyde, membre de la Société royale de Londres (1), de celle de Zélande (2), de Roterdam (3) et d'Édimbourg (4), agrégé au Collége royal des médecins de la même ville (5), des Académies de Harlem (6), de Pétersbourg (7) et de Manheim (8), associé étranger de la Société royale de médecine (9), naquit à Heidelberg, ancienne capitale du Bas-Palatinat, le 24 février 1705.

Avant d'entrer dans les détails de sa vie et de ses ouvrages, il est indispensable de tracer les malheurs de ses parens et ceux de sa patrie.

(1) Il y fut reçu cn 1765.

(2) Il fut admis en 1769 dans la Société établic à Wlissingen en Zélande.

(3) En 1771, dans la Société de philosophie expérimentale établic à Rotcrdan.

(4) $\operatorname{En} 1776$.

(5) En 1773 .

(6) En 17.52, daus PAcadćmie des sciences de Harlen.

(7) $\operatorname{En} 1750$.

(8) En 1776 , tans l'Académic électorale palatine des sriences et belles-letres de Manhrim.

(i) En ${ }^{2777}$, il fut nonmé, par le rri, associé étranger de la Société royale de médecine de Paris. 
PHYSIOL. ET MÉD. - GAUBIUS. 263

La ville d'Heidelberg avoit été embellie par les électeurs palatius; ils y avoient établi une Université, et fondé une bibliothèque célèbre (1) par le clıoix des lives et manuscrits que Maximilien, duc de Bavière, enleva et fit transporter à Rome, oì elle fitt déposée dans celle du Vatican. L'incertitude des religions que les souverains y frent dominer successivement, et les désastres des guerres, achevèrent de rumer cette ville, qui fut presque entièrencnt détruite en 1693.

Elle n'avoit point, ponr se défendre contre la barbaric, ces ressources multipliées et presque indestructibles dont jouissent les grands et anciens établissemens, oì le cliamp des sciences est si bien cultivé qu'clles résistent à toutes les entraves qu'ou leur oppose, et dans lesquels l'existence des beanx arts a je ne sais quoi d'immortel qu'ancun effort lumain ne peut anéantir.

Jean-Gaspard Gambe, grand-père de celui auquel cet éloge est consacré, étoit coloncl de cavaleric. Il laissa quatre enfans, avec unc pension très-modique qu'ils perdirent à la mort de l'électeur Charles.

Christophe Gaube, le plus jeune, se joignit à plısienrs de ses concitoyens; et rémis ils osc̀rent entreprendre de réparer les fautes de leurs princes, cn ramenant les arts et le commerce au milieu des débris dont ils étoieut environnés : car l'artisan industrieux

(r) Cet événement cut lieu pendant les guerres élevées pour la succession de la Bohème. Le duc Maximilien fit présent de cette bibliothèque au Saint-Père. 
est dans les villes ce qu'est le cultivateur infatigable daus les campagnes : ce sont eux dont les grands font toujours les objets de leur persécution ou les instrumens de leur amour-propre; et lorsque le calme est rétabli, on voit ce peuple, renaissant de ses propres cendres, courir à ses travaux, et préparer de nouvelles dépouilles à de nouveaux ravisscurs.

Christophe Gaube se livra à son goût pour les arts; il établit à Heidelberg plusieurs manufactures, et il y trouva une aisance qu'il n'auroit dû tenir que de ses ancêtres. Ce citoyen courageux étoit le père de M. Jérôme-David Gaubius. Quoique zélé protestant, il cónfia l'éducation de son fils aux Jésuites, qui, toujours empressés d'agrandir leur domaine, n'avoient pas manqué d'établir un collége daus la nouvelle ville d'Heidelberg. La douceur et l'affabilité étoient des moyens que ces pères savoient employer à propos; ils s'en servirent daus cette occasion avec le plus grand succès; leır collége fut bientôt rempli des jeunes gens les plus distingnés de la ville et des envirous. Aucun ne montra plus de dispositions et de talent que M. Jéróme-David Gaubius, et aucun ne fint antant accueilli de ses maîtres. Les ógards que ses pères avoient pour lui, la satisfaction du jeune homme, tout parut suspect au père de M. Gaubius; il craignit qu'ils n'eussent formé lo projet de lui faire abjurer sa religion, et il résolut do ne pas le laisser plus long-temps à lenr école.

A la même époque, lo fumoux Frauke, poussó par un zèle qui tenoit de l'entlousiasue pour l'instruction de la jenmesse protestante, avoit établi it Halle 


\section{PHYSIOL. ET MÉD. - GAUBIUS. 265}

un grand collége sous le nom de Pedagogium ou Orphanotrophium, dans lequel il traitoit les eufans avec toute la rigneur de l'intolérance. Il existe sans doute des rapports entre les différens âges de la vie, et il est sage de prendre des précantions pour que le premier contribue an bonleur de tous les autres : mais vonloir le sacrifier entièrement à cette vue; enchaùner la mobilité de l'enfauce; substituer la lentenr et la mélancolie de l'âge nuñ à la sirillie et aux ćlans des premières sensations, l'accablement à la gaieté la plus f'ranche et la plus maïve; imposer silence à des orgaues qui s'essaient et qui sont comme les touches d'une mémoire viament active; affiger enfin, tommenter un itre, qui, s'il survit, portera tonjours l'empreinte dı malheur et de la dureté dont on anra flétri sou existence : c'est le propre de la pédanterie renforcée par l'ignorance et le fanatisine.

L'école de Franke méritoit quelques-uns de ces reproches; sa sévérité étoit aussi capable de rassurer les protestans inquiets sur l'édncation religieuse de leurs enfans, que ficite pour inspirer à ceux-ci de la crainte et de l'effroi. M. Gaubius, que son père y aroit enroyé, se sourenoit trop de la manière douce et obligeante arec laquelle ses premiers maitres l'aroient accueilli, pour n'être pas vivement affligé des procédés de son nouvel instituteur. Rival des Jésuites, il s'efforçoit de les surpasser par des pratiques austères; mais ses idées n'étoient que sombres et tristes, au lieu d'être profondes et étendues, et M. Gaubius ne fit que s'ennuyer is son école. Franke prit, comme il arrive souvent, 
cette déplaisance pour de l'incapacité, et il consentit volontiers à ce que le jeune homme retournât à Heidelberg. Ils se quittèrent peu satisfaits l'un de l'autre. M. Gaubius toutefois avoit bien jugé son maître, par lequel il n'aroit puint été apprécié.

Sa famille, persuadée, d'après le rapport de Franke, qu'il n'étoit point propre aux travaux pour lesquels il falloit de l'étude et de l'application, fit tous ses efforts pour le déterminer à prendre le parti du commerce, comme un genre d'occupation qui exige moins de talent et d'esprit. Cette opinion très-répandue est-clle fondée, et la science du négociant est-elle donc si facile? La connoissance des différens sols, de leurs productions, des goûts et des habitudes des peuples; l'art d'appliquer le calcul aux hasards, ne supposent-ils pas tolljours une précision dans le jugement, uxle sagesse dans les entreprises, et une force de tête qui, appliquée à d'autres objets, embrasseroit peut-être une surface beaucoup plus étendıe qu'on ne pense? M. Gaubius résista à tontes les instances de son père, qui l'envoya ì Amsterdam pour y continuer ses études.

Il y fut reç par un de ses oncles, Jean Gaube, qui y exerçoit la médecine avec distinction (1) : c'étoit ce pareut qui aroit ajouté au nom de sa famille la finale

(1) M. Jean Gaulius a joui de la plus grande réputation à Amsterdan, oì il a pratiqué la médecine pendont prds de cinquante. a anécs. On a de lui trois leures lalines, écrites au célèbre Ruysch, qui irouvent dans la collection des ouvriges de cet automiste, avec le titre suivant: Johannis Gaubii Fpistola problematica, 1" $2 .{ }^{2}$ ct $3,^{2}$ 
PHYSIOL. ET MÉD. - GAUBIUS. 267 en $u s$, si long-temps adoptée, même en France, lorsquo le goût des langnes anciennes y dominoit assez pour que l'on 11'osât avoir de l'esprit que sous des fórmes et avec des tonrmures latines. Les érudits affectoient alors de tenir an moins par la terminaison de leurs noms à l'ancienne Rome. On a de bonne heure secouć ce jong en France, et cette indépendance littéraire dont on y a douné le premicr cxemple est d'autant plus remarquable, que notre langue, peu nombreuse et peu sonone en elle-même, ne pent devoir qu':uı génie de la nation ses richesses et sa célébrité.

M. Gaubins prit bientôt auprès de son oncle le gout de la médecine; il passa d'abord nne année à Harderowic, où il suivit les leçons du célébre de Moor, professeur très-habile.

Boërrhaave remplissoit alors touste l'Europe de sa renommée: l'école de Leyde, oí il enseignoit, étoit devenue celle de tons les étrangers. M. Gaubius désiroit virement d'y être admis. Sa famille y ayant consenti il s'y rendit anssitôt. Dans la foule qui se presse autour d'un grand homme, il est facile de distinguer cenx qui offrent à ses taleus un hommage éclairé, d'avec les ignorans et les flatteurs qui l'environnent comme un être rare, et qui, semblables aux idolatres, ne conmoissent que les apparences extérieures du dieu qu'ils encensent avec enthousiasme. Boërrhaare remarqua M. Gaubius; il aimoit à parler avec lui, à luj donner des explications particulières; il royoit sans doute avec plaisir se développer dans son disciple ces qualités qui devoient un jour le placer au premier rang. 


\section{8 ÉLOGES HISTORIQUES.}

Deux grands hommes se présentent mutuellement un objet de surprise et sourent même de jalousie ; mais les succès des élèves appartiennent à leurs maîtres. Ceuxci aiment à les couvrir de leur propre gloire; ils sont flattés de rencontrer ces dispositions heureuses; cette énergie qui établit entre les esprits d'un ordre supérieur des rapports et une sorte d'intelligence, et c'est pour ellx une grande satisfaction de pouvoir confier avec fruit ces idées chéries, dont la suite et l'enchaînement supposent dans ceux qui les écoutent, de la finesse, de la pénétration et même de la docilité.

Tel étoit M. Gaubius à l'égard de Boërrhaare, qui lui témoignoit l'affection la plus distingnée. Il prit sous ses yeux le grade de docteur en 1725 (1), et il publia alors une Dissertation sur les parties solides du corps humain (2). On entrevoit dans cet onvrage que l'auteur étoit déja disposé à s'éloigner du système des mécaniciens, et à considérer la nature avec les yeux d'un observateur cxact et sans prévention.

M. Gaubius quitta eusuite la Hollande pour voyager en France, ò̀ il passa une année; il y entendit les plus habiles professeurs (3) en anatomie et en chirurgie; il étudia particulièrement l'art des accouchemens; il fut très-assidu anx hôpilanx, et il conserva pendant tonte

(1) Le 2 aont.

(2) Specimen inaugurale, exhibens ideam gencralem solidarum corporis humani partium.

(3) Il conserva des linisons intimes arcc le célèbre Taillant et - vec feu M. Morand. 
PHYSIOL. ET MED. - GAUBIUS. 269 sin vie beaucoup de reconnoissance pour ceux dont il y avoit suivi les leçons. Ainsi ım disciple, $m$ ami de Boërrhaave crut devoir séjonmer ì Paris pour y perfectionner ses connoissances en médecine. En rendant ì un savant hollandois le tribut d'éloges qu'il mérite, ne craignons pas de dire que de tons les arts auxquels les Français sont propres, il n'en est ancun dans lequel ils excellent antant que dans celni de l'enseiguement, soit de vive voix, soit par écrit.

La justesse des idées, le choix et la clarté des expressions, la métluode de l'exposition, sont en effet les qualités qui caractérisent les leçons et les ouvrages de nos grands maîtres. Ce désir de plaire que l'on a tant do fois reproché it notre nation, et qui apris tont ne pent être blîmé que dans cenx qui manquent de moyens ou de succès en ce genre, a été heurensement appliquó anx sciences elles-mênes; et la manière de les rendre aimables et faciles n'est conume wulle part comme dans cette capitale. Les cours particuliers y ont torjours été recommandables; l'instruction que l'on y troure n'est fondée que sur l'observation; c'est la science des faits que l'on vient y étudier; le professeur y est déponillé de tout appareil étranger ì l'art qu'il enseigne, pour n'ètre que l'homme de l'expérience et de la raison; on ose l'interoger, inème le contredire; en un mot, il n'a de supériorité que celle de ses connoissances, avonée par des anditeurs qui l'ont choisi librement. II. Gaubius fut très-satisfait de cette espèce d'enseignement; et il retourna à Heidelberg, après avoir passé quelque temps d Strashourg. 
Il fut accueilli par sa famille avec mue joic qui devoit être bientôt troublée par son départ. Son goût pour les sciences, et plus encore les intérêts de son cœur, ne lini permettoient pas d'être long-temps éloigné de la Hollande. M. Jean Gaubius d'Amsterdam avoit une fille aimable et vertueuse, à laquelle il ne inanquoit qu'un époux digne d'elle pour réunir tont ce que l'on peut souhaiter à la beauté. Ce parent généreux désiroit que son neveu, dont il connoissoit les excellentes qualités, fût aimé de sa fille; mais il se garda bien de leur faire connoitre son projet. Il savoit que l'amour est un sentiment absolument indépendant, qui ne reut subsister que par lui-même, qui se plaît à cacher son origine et ses progrès, et que l'on détruit quelquefois en voulant le favoriser. M. Jean Gaubius se contenta de leur donner, sans affectation, la permission de se voir. Leur penchant fit le reste; ct, grâces aux soins de cet lomue estimable, ils trouvèrent le bonheur le plus touchant dans une passion qui, mal dirigce, nc fait que des malheureux. Les parens et les institutenrs ne devroient-ils pas la regarder comme une sorte de maladic morale, comparable, sons quelques rapports, à ces maux physiques dont on ne prévient le dauger qu'en s'y soumettant avec art et précantion? Lenr contagion ost également répandue et presque inćvitable; les funestes impressions de la première misent autant à la paix et à la pureté de l'aue, que celle de la seconde à l'élégance et à la beanté des formes extéricures: l'une et l'autre dégénèrent sonvent cn des vires opiniatres, qui, s'accroissant arec l'àge, ne 


\section{PHYSIOL. ET MÉD. - GAUBIUS. 271}

font de la vie entière qu'un tissn de sonffrances et de douleurs. M. Gaubius évita tous ces écueils; il dut à la sage prévoyance de son oncle et son état et la tranquillité de sa vie. Il épousa Mademoiselle Gallbins (1), dont il étoit tendrement aimé ; et an bouheur de la posséder long-temps il a joint celui de ne pas lui survivre.

Revenu a Amsterdam, il coutinua de se liver d l'étnde de la climie, de l'histoire naturelle et de l'anatonie, tandis que M. Jean Gaubius lui fonrnissoit l'occasion de s'exercer daus la pratique. Peude temps après, il fut nomuné nédecin de la ville de Deventer en OverYssel, où il se rendit après en avoir informé Boürrhase, qui promit de ne le jamais perdre de vue dans quelque pays qu'il fint fixé, et qui lui tint en effet parole.

Pendant son séjour ì Deventer, il s'occupa principalement de l'étnde de la pharmacie. Une circonstance mallhemreuse le rappela à Amsterdam en 1727. Des fièvres bilienses et putrides y faisoient alors des ravages très-meurtriers; il vola anssitôt an secours des taabitans ; et, quelque préciense que fùt sa vie à la fille de l'oncle respectable quilui tenoit lieu de père, il ne se lassa point de la prodigner dans le traitement de cette épidémie, dont la durée s'étendit jusqu'en 1729. Sans cesse aux prises avec cet emmeni, il ne se donna pendant ces

(2) Il épousis en 1735 sa cousine germaine mademoiselle Consrance Gaubius, qui lui a surrécu; il a eu six enfans, dont il n'a conserré que mademoiselle Marie-Amélie Gaubius, qui a épousé M. Henri Twent, docteur en droit, conseiller, écheria de la yille de Leygde. 
deux années aucun repos. Il renonça à l'étude et à tout travail autre que celui dont le désastre public lui faisoit une loi. Pendant tout ce temps, il n'épronva que de légères indispositions. C'est une sorte de miracle que de voir les médecins placés dans le foyer de la contagion, tout couverts; pénétrés même de ses miasmes, échapper souvent à ses coups. Ces différens virus étant du nombre de ceux qui agissent sur les nerfs, n'est-il pas vraisemblable que ces organes raffermis par le courage, et fortifiés par un bon régime, s'accoutument peu à peu à leurs impressions de Inanière à pouvoir enfin les braver? ou, si cette raison ne paroît pas suffisante, pourquoi se refuseroit-on à croirc que la Providence couvre de son égide une classe d'hommes qui sont les instrumens de sa bienfaisance au milieu des fléaux de l'humanité? Car il est tris-important que les ministres de la santé publique ne se laissent point atteindre par la fiayeur, que leur's secours soient offerts par une inaiu intrépide, et qu'ils ressentent en euxmêmes cette force réelle et expansive que donne la fermeté, et qui, se répandant du centre vers la circunférence, est toujours prête ì repousser la contagion dont elle est environnée.

La vicillesse commencoit à s'appesautir sur Bö̈rrhaave: cet illustre professeur s'en apergut un des prenuicrs, et il résolunt aussitôt de mettre de la proportion entre les forces qui lui restoient et le fardeau quielles aroient à sontenir. Pour s'observer ausi soi-mêne, et pour être en quelque sorte ténoin de sa propre décadence, il faut antant de raison que d'inspartialité. Boërrhaave, 
PHYSIOL. ET MÉD. - GAUBIUS. $2-3$

qui enseignoit alors toutes les parties de la múdecise, excepté l'anatomie, renoura anx cliaires de botanigue et de chimie. M. Gitubius lui succédal dirus les fouctious de celle-ci (1). Il est d'usage à Leyde de ne point nommer les étrangers anx places de l'Uuiversité. On fit une exception en favenr de M. Gaubius, que Bö̈rhlaave avoit présenté, el qui, dans le trailument de la lougne et fichense épidémie d'Amsterdam, aroit d'aillenrs montré tatut de zile, qüil unéritoil bien d'être traité connue un des citoyeus de la républinue.

Ses succès justifiéreut le choix des cumateurs de l'Uuiversité, qui, trois aumées après, lui confërèreut la place de professeur eu médecine (3). Il devint alors le colligne de sou maitre, qui surrécut qualte aus à cette nomiuation, et qui jont du plasisir àno forné lnimême un successeur digñe de la chare qu'il arvit rendue si homorable, mais si ditficile à occuper.

La Faculté de Leyde n'étoit alors composée que de cinq professeurs, Bö̈rulıtave, Albiuıs, Gaubius (3),

(1) Il en prit possession lo premier mai $1,-31$, en qqualité de lecteur de chimie. AI. Adrien ran hoyen fut nommé lecteur de botanique, à la place de Buërrhane. MI. Gaubius publin alors un discours d'inanguration, ayaut le titre suivant : $H$. Gaubii Oratio inauguralis, qud ostcildiur chcmiam aribus academicis esse inserendam, L. B. 1731 .

(2) Il fut nomme, le 20 septembre 17.34 , professeur ordinaire de médecine et de climie; et il prononca en cette qualité, le 36 octobre suivant, son disconrs d'inanguration, intitule De vana vilce longa à chenicis promissce expectatione, L. B. 1734.

(3) Outre les leçons publiques dont M. Gaubius étoit clargé, T. 2 . 
Osterdyk et van Royen; elle n'étonnoit point par la longueur de sa liste, mais par le grand nombre de ses. élèves et par la multiplicité des secours qu'elle ne ces-. soit de leur offrir.

Trois ouvrages ont établi solidement la réputationı de M. Gaubius. Le premier est un traité dans lequell il a donné des préceptes très-sages et très-savans sur l'art de prescrire les formules des inédicamens (1). Lat médecine est sous cet aspect la science des petites, choses, dont aucune ne peut être impunément négli-. gée. Réunir des substances dont le rapprochement fait: par l'art ne soit point contraire aux lois de la nature:: avoir toujours présentes les observations des plus célèbres praticiens sur les effets des préparations médici-. nales tirées des trois règnes; déterminer, en les con-. seillant, jusqu'à l'instant où il convient d'en faire nsage ; veiller enfin à ce qu'elles soient présentées sous, la forme la moins propre à dégon̂ter le malade : telles sont les précantions que l'on a droit d'attendre d'un médecin instruit. Les formules étant l'arme journalière qu'il emploie dans le trailement des maladies, c'est par sa nıanière de s'en servir que l'on peut recon-. noître son expérieuce et son liabileté.

Il faut éviter sur-tout deux extrênes dans ce gelle. Le premier, et le plus condanumble sans donte, e'st

il fit pendant plusieurs années des cours particuliers de médecinepratique, qui étoient très-suivis par les étudians.

(1) Voyez l'ouvrage intitulé, MTethodus concinnandi furmulas medicamentorum. La troisidme edition de cet curbage al paru a J.eyde en 1767 . 
PHYSIOL. ET MED. - GAUBIUS. 275

cette hardiesse qui n'est pas même troublée par la connoissance intine des dangers qu'elle fait courir; le second tient à une ignorance timide, qui reste dans le repos lorsqu'il fandroit agir, et dont toute l'adresso consiste à s'emparer des succès de la nature. Le véritable médecin, dit M. Gaubius, tonjours attentif a l'état des forces vitales, est aussi réservé lorsq̨u'elles n'ont pas besoin de son secour's, qu'il est aclif lors: qu'il fant les soutenir ou les nuodérer' : l'iguorant, au contraire, ne sachaut oì il faut qu'il s'arrête, cache son insuffisance sous le voile d'une prudence aflectée, ou sous les dehor's d'une fiusse sécurité.

L'autre but très-utile que M. Gaubius s'est proposé dans la rédaction de cet ouvrage a été de rendre les formules plus simples. La multiplicité des substances dont une senle préparation étoit conposée empèchoit de saroir à quelle drogue on à quelle combinaison ses propriétés ponvoient être dues; il n'y aroit pas jusqu'aux pierres précieuses et à l'or, que l'on avoit placés au nombre des médicamens, comme s'il avoit été arrêté que ces objets de luxe dussent être la cause de tous les délires possibles. Déja Stahl, Boërrhaave et Geoffroy avoient fait dans la matière médicale des réformes utiles : ne peut-on pas espérer que cette science, en se perfectionnant, deriendra plus simple et plus active, et que l'on effacera de nos pharmacopées ces formules monstrueuses qu'il est facile de reconnoìtre, ne fût-ce que par l'espèce de culte qu'on leur rend pour des erreurs très-anciennement accréditées?

Lorsqu'on lit la plupart des traités de médecine des- 
tinés à l'enseignement, même ceux de Rivière et d'Astruc, on u'y trouve que des distinctions subtiles, des divisions sans fin: les causes sont ce que ces auteurs ont traité le plus longıement; et cette profusion de paroles est bien étonnante sur un article qui, étant le moins conuu, doit être le plus court dans tous les livies. M. Gaubius commenta pendant long-temps dans ses leçons les Instituts de Boërrhaave, qui s'éloignoient déja beaucoup de la forme adoptée dans les écoles. Après un intervalle de vingt années, il publia enfin son Traité de pathologie (1), qui est maintenant adopté daus plusieurs Facultés, et dont on peut dire, ce qui convient à si peu d'autres onvrages, que les découvertes nouvelles ajouterout à sa doctrine et la modifieront sans la détruire:

M. Gaubius crut ce délai nécessaire pour se justifier d'avoir osé contredire Boërrhaave darıs quelques points: il en différoit sur-tout en ce que, n'expliquant point toutes les fonctions des animanx par les lois de la nécanique, il admettoit en enx cet agent, ce principe vivifiant (2) qui anime la plus belle partie de la nature,

(1) Voyez l'ouvrage intitulé, Tnstilutiones palhologict medicinalis, Iugd. Batav. 1758. La scconde cilition, revue et corrigée, est de 1775. Lat troisicme, daus laquclle il y a quelpues chatngemens et des additions, d́oit presque adievé lorsqu'il monrut. Iille sera biemtò publiée par le célébre MI. Ilahu, neven de fou M. Gaubius, et son digue successeur dans les charres de mb́lecine et de chimic. M. Hahn a ajouté à cette edition une introduction nonvelle: qa'il u’a cuvoyéc.

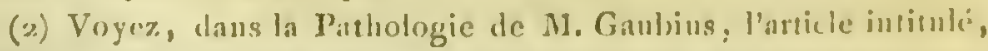
Norbi solidi vivi, pag. 5.3, 54, 5.5, 11.08 $169,175,179,130$, e1c. 
PHYSIOL. ET MÉD. - GAUBIUS. 277 àont les monvemens spontanés sont soumis à des lois. qui hiri sont propres, et sans lequel tous les êtres muets, sourds, insensibles, inanimés, obéiroient en silence à l'inpulsion uniforme et immuable de la gravitation minverselle.

Van Helmont et Stahl aroient onvert cette belle carric̀re; mais Boürrliaave seétoit opposé de toutes ses forces à l'extension de leur système. M. Gaubius, plus modéré que Stalıl, plus impartial que son maître, a rapporté plusicurs effets an principe constituant de la vie, sans en approfondir la nature, et sans le confondre avec d'antres agens aussi peu commis que lui.

Le troisième onvrage diuns lequel M. Gaulhins a montré les comnoissances les plus étemulues et les plus variées en physiqne et en médecine, est le recueil (un il a priblié en $177^{1}$ sons te nom d'Adversaria (1). Les richesses qu'il contient sont si nombrenses, qu'il est égalenent difficile, dinns. la mention que je dois cu faire, et d'en dire assez, et de n'en pas dire trop.

On y trouve une aualyse bien faite des caux de la mer qui baigne les còtes septentrionales de la Hollande. Chaque livre de ces eanx conticut trois gros dix-sept grains de sel marin, dix gros d'un sel séléniteux (2),

Hoec considcranti obscurum esse nequit quanti momenti cùm in sanilatc, cùm in morbis, ex principio vilali profluant. Nititur ed magna pars viriun naturce humance conservatricius, destructicium, medicalricium, etc.

(1) H. D. Gaubii Adversariornm varii argumenti, lib. unus, imprimé is Leyde en $177^{l}$, in- $4^{\circ}, 20^{\circ}$ édit. en 1779.

(a) Il n'en a pas désigné la terre avec assez d'exactitude。 


\section{ELOGES HISTORIQUES.}

mêne quantité d'un sel qu'il a nommé alumineux muriatique (1), et dont les cristaux ressemblent à ceux $\mathrm{du}$ horax brut ou tincal, et vingt-quatre grains de sel admirable de glauber. M. Gaubius n'y a point découvert de substance bitumineuse, et il attribue l'amertume de ces eaux aux sels qu'elles dissolvent (2).

Lorsqu'on réfléchit sur leur efficacité dans le traitement de certaines obstructions, des scrophnles et de plusieurs maladies cutanées, on ne peut s'empècher d'être surpris qu'ıne aussi légère dose de sels produise des effets si marqués. Combien de fois les médecins qui habitent les plages maritimes n'ont-ils pas eu recours à l'art pour composer des boissoris moins efficaces que celles dont le bassin immense de l'Océan leur offroit abondamnent les secours! M. Gaubius, qui a confirmé les observations de Russel (3), leur cn a fait connoître l'usage, et il a donné en même temps une belle théorie sur l'action des apéritifs pris dans cette classe.

M. Pringle ayant démoutré quo l'eau qui contient moins de quinze grains de sel par once est septique, celle de la mer doit, suivant M. Gaubins, être regardée comme jouissant de cotte proprićté; elle agit sur les lımeurs animales épaissies, en leur faisant ćprou.

(1) C'est ainsi qu'il a appelé ce scl.

(2) Cet auteur a spécialement recoumandé l'usage de l'eau de mer dans le traitement des scrophules et de plusienrs autres maladics.

(3) M. Gaubius dit expressément, dans cet article, de ses Adversaria, que ces expériences, trutées on Hollande, sont d'itcord avec colles dr M. Prissonnier, faites en France sur le méme sujet. 
rer un mouvement de fermentation qui les rend plus fluides, plıs mobiles en mềne temps, et susceptibles d'être plus facilement évacuées (1).

On lit dans un antre article des recherches sur la mature des cristaux salins, observés par M. Slare dans la très-ancicune lmile de canelle (2), et que M. Gaubius croyoit être du camplire. L'huile essenticlle d'orange lui a présenté un phénomècue analogue; il a tronvé au fond d'un flacon rempli de cette Inile (3) depnis plus de donze ans un sel formé de petites ćcirilles cassantes, aromatiques, saus ìcreté, solubles daus l'eau et daus l'esprit de vin, finsibles à une donce chaleur, volatiles sans ètre inflammibles, mais angunentant la flamue des corps en combustion exposés it lenrs vapenrs. Ce sel est patrticulier it l'luile issentielle d'orange.

L'analyse végétale doit encore ì M. Ganbins d'antres déconvertes. Les noix muscades, concassées arvant d’ètre somuises à la distillation (4), aprè's aroir laissé ćchnpper leur lunile essentielle, fournissent une subslance formée de petites lannes blanclies, concrètes,

(1) M. Gaubius ajoute que, par cette méme raison, les eaux le la mer ne sont point infectées par le grand nombre d'animaux et de planles qui s'y décomposent, parce que la septicité de ces caux accélérant la putréfaction des corps, la inatière volatile se dénage et se dissipe arec beancoup de rapidite.

(a) Trans. philos, abridg. vol. III. pag. 362.

(3) Il a souvent donnẻ arcc succès aux personnes attaquées de colique renteuse quelques goutes d'huile essentielle d'orange mêlées avec du sucre.

(₹) Distillées entières, elles ne donnent point d'huile essentielle. 
insolubles dans 'l'eau, solubles dans l'esprit de vin, fusibles, et qui sont un véritable beure volatil. A près la distillation il en reste une autre solide, jaunâtre, et quï diffère beauconp de celui que l'on tire par expression. L'anteur a terminé ces détails par une division nuéthodique des sucs huilenx végétaux en sept genres (1), à raison de leur forme et de leur consistance.

L'analyse dı poivre a donné à M. Gaubins des résultats inléressans. La saveur de cette substance es: due à une partie résineuse que l'esprit de vin dissout fitcilement : le poivre airsi épuisé fournit, lorsqu'on le traitc avec l'eau, un extrait insipide et inodore; ct il fant plus de quarante-trois distillations pour lui enlever toute sa partie âcre, lorsqu'il n'a point éprouré auparavant l'action de l'esprit de vin (2).

On sait que Neumann (3) a retiré du camphre de

(1) Sa division est la suivante $: 10^{\bullet}$ les luniles féticles; $2^{\circ}$. les baumes natifs fluides et visqueux; $3^{\circ}$. les poir ou sucs épaissis et tenaces; $4^{\circ}$. les benrres ou sucs mous et sans ténacité; $50^{\circ}$ les cires solides, sèches et cassantes, et devenant molles par le tact; 6. Ies camphres gras ct cristallins; 7.0 Ies résines firagiles à la manière du verre

(2) La combustion de ses cendres, après qu'il a sulbi l'action de l'eau senle, ne fouruit point de sels: on y trouve an comtraire un peu d'alkali minéral et de sel marin, lorsqqu'il a été traité arec les spirituenx. On a assuré ì M. Gaubius que, dans le transport, on l'arrose arec de l'ean de mer; ce qui pourroit bien être la canse du sel marin qu'nu y dérouvre. La partic résinense counpose la septiune partic de son poids.

(3) Miscell. Mcrnl. 6011. JII, 1. 70. Vojez ausbi ce que M. Nas. graf a écrit sur te même suja.t. 
PHYSIOL. ET MED. - GAUBIUS. $28 \mathbf{1}$ inhinile de thym. M. Gaubius en a trouvé par l'analy'se dans la menthe poivrée. La plus récente en foumit moins, de mêne que les vienx camphriers sont les plus féconds.

Parmi les prodnctions apporlées des Indes orientales en Hollande, M. Gaubins remarepui une racine, dite de Jcan Lopez, qui y est usite dans le traitement de la diarrhée et de la dyssenterie. Les essais qu'il che fit furent très-henrenx (1): sou nsage ayant róussi daus des cas où le simationba et le colombo avoient été inmtilement cmployés, il se détermina à en laire connoître les doses et lat préparation (2). (ietle racine (3) n'a par elle-mème ni savenr, ni odeur. Liestral aquenx en est noiritre, fude ut 111 pen anuel. La savenr de l'extrait spirituenx a quelyues rimports avec celle de l'opium (4): inalheureusenent l'arbre qui la fonruit est trìs - éloigné de nos climats, et cette substance angmente le nombre des remides exotiques contre lesquels soblivent quelques physiciens, préten-

(1) Plusieurs médecins de différentes villes de la Ifollande, engagés par MI. Gaulvius à s'en scrvir, en obtiurent égalentent des elfets satisfaisans.

(a) Tinctura conficiatur in hunc modum : R. rad. Lopez pulver. draguam unam et semi.; spirit. rini vulgar. uncias duas et semi. : in phialam chemican imnissa leni calore digerantur spatio $\$ 8$ horarrum; dein cola et serra. Ter in die manè horâ undecimá, quartâ à meridie, et septimid respertinat cochlearculum paulo rino rubro dilutum propinetur. Adiers. pag. 87.

(2) Les tiges les moins grosses semblent aroir plus de vertn.

(3) Brùlée it ten ourert, cette racine donne, par le lavage, de l'alkali fixe mineral ot in peu de sel marin. 
2012

\section{ELOGES HISTORIQUES.}

daut que la nature a placé dans tous les pays les productions nécessaires au traitement des maladies que l'on y observe. Non seulement l'cxpérience n'a point confirmé cette assertion, mais encore il cst tris-probable que les plarutes les plus éloiguées doivent avoir le plus d'efficacité, parce que leur nature étant plus différente de la nôtre, doit cxercer sur clle une action plus énergique. La navigation et le mélange des lommes n'ont-ils pas fait d'ailleurs un même peuple de tousles liabitans du globe? et puisque les deux continens sc sont corrompus par leuı's ricliesses, n'est-il pas sage de recueillir arec cinpressement le peu de secours qu'ils se présentent, ne fùt-ce que pour balancer au inoius nue partie des maux qu'ils se scront faits?

Personne n'étoit plus convaincu que $M$. Gaubius, de l'utilité de ces recherches. Il avoit établi entre Leyde et Bataria une correspondance qui y étoit relative, et il ne cessoit d'cxlıorter les médecins et les chirurgicns qui partoient pour les Indes à preudre des renseignemens sur les remèdes qui y étoient le plus umiversellenrent et le plus anciennement eniployés. Qu'y a-til en effet de plus précicux que les résultats de l'cxpérience de plusieurs siècles et de plusienrs géuérations? Et n'est-ce pas en réumissant aiusi les vérités éparses, que l'on peut traviller avec fruit anx progries d'unc science dout la nuarche a laut de fois étu retardéc par l'ahus des méthodes scientifiques? L'lomme abandonné à lı-mêne a reçu de la ruature nnc industric qui le porte à essayer, Jorsqu'il est malade, diflérens moyens de gurúrison; el ces observations primitives, 


\section{PHYSIOL. ET MÉD. - GAUBIUS.}

qui servent d'élémens et de base à la scicnce lorsqu'elle se dévcloppe, en deviennent les débris lorsqu'elle s'anéantit. Elles semblent être l'apanage de l'humianité souffrante, at laquelle nulle rérolution we peut les enlever; elles sont comme inlıérentes an sol quii les a produites, et l'esclave est sonvent celni qui s'en souvient le unieux et qui est le plus versé dans leur application. Ce sont des faits de cette nature qu'Hippocrate a rassemblés eu Grèce, et curil est inportant de recucillir dans tous les pays labités par les hommes.

Cette source est pure, et l'ou peut presque toujours y puiser sans crainte. Il eu est meitutre daus laquelle, an unilien des dlangers et des mensongess, on décoltrie quelquncfois des combinaisons heureuses et des moyens efficaces: c'est le charlatanisme, espèce de monstre, contre lequel tout le monde crie en général, mais que chacun accucille cu particulicr, et qui troure si facilement des prồneurs. M. Gaubius, qui ne négligeoit rien de ce qui ponvoit contribuer à l'avancencut de la médecine, observa arec surprise les heureux effets d'une poudre qu'un curpirique appelé Ludman distribuoit (1) comme antispasmodique, so:ns le nom de lune fixée. M. Gaubius la reconmunt aisénent pour des flenrs de zinc : il en fit diverses éprenves, et il s'aperçut qu’d la dose d'uu grain elle faisoit romir les personnes délicates, et que, dounée à un demi ou ì un quart de grain unc on phisieurs fois dans la journée, elle étoit

(1) A Ansteriam. 
calmante, sur-tout dans le trailement des convulsione auxquelles les enfars sont sujets.

Nous regrettous de ne pouvoir suivie l'aulenr dans les autres articles de ses Adrersaria, sur la distillation de l'luile de vitriol, sur le borax, sur le sel arnmoniac, et sur l'usage d'un instrument (1) propre à introduire la funcée de labac dans les intestins.

M. Gaubius a prononcé plusieurs discours dans l'Université de Leyde, qui Jui ont mérité de justes applandissemens.

Dans l'u1, intitulé De regimine mentis quod medicorum est, il a traité un sujet très-philosophique. L'homme y est considéré comme un être mixte, composé de deux principes très-distincts, mais qui s'accompagnent et se pénètrent si intimement, qu'il ı'y a ancune partie du corps humain où l'esprit et la matic̀re ne manifestent leurs impressions et leur influence réciproque. Ces deux agens sont lićs par les lois qui constituent la vie, et chaque molécule organique semble être animée par une force qui tient à tous les deirx.

M. Gaubins soumet ensuitc à l'aualyse la plus rigourense les différentes expressions ct les sculimeus arloptés pour expliquer l'nuion de l'ame avec le corps. Celni-ci doit-il être regardé comme une prison où elle soit retenue et connue encliaînée? étrange prison que

(1) I'auleur a pris toutes les précaulions nderssaires pour prévenir les inconvinicus auxquels la plupntt de ces machines sone exposćes. 
PHYSIOL. ET MED. - GAUBIUS. 285 l'on aime souvent beancoup trop, et que l'on quitte avec tant de regret ! Le corps seroit-il seulement la demenre de l'ane? singulier domicile, dont le plus léger dérangenent enlève ou rend à sou hucite lia sagesse et la raison! Le principe immatériel commanderoit-il d toutes les fonctions, comme Stahl l'a voulu? on seroit-il disposé par nue harmonie prinitive pour snivre, dans ses alfections et ses rolont's, les munvemens de la inachine ì lanpuelle il est attachis, connue ıu philosophe célibre l'a, je ne dirai pas pensé, mais écrit? La prenière de ces deux opinions est déuncutie par les actes oryanilyues et involontaires; lat seconde est phus compliquéce que la clıse unème qu’elle explique. Ne nous suffit-il pas de saroir, al dit MI. Gaubius, qu'une main tonte-puissante a joint l'ane au corps, et que ces deux principes se coutrebsilaurgaut unutuellement, l'ane est elle-nème du ressort de la médeciue, puisqu'il est possible d'agir sur elle par le moyen des organes, arec lesquels elle a des rapports déterminés?

La Mettrie, qui ne royoit dans les animanx que des machines, et dans la plupart des plyysiciens que des matérialistes, ne intunqua pas de ranger MI. Gaubius dans une classe où, quel que fìt son cutètement, il lui répugnoit de rester scul. M. Gaubius se plaignit amèrement de cette témérité, et il crut devoir se justifier de cette imputation dans un second discours sur la mème matière, qu'il prononça plusieurs années après (1).

(2) M. Gaubius prononģa son premier discours De regimins 
Ces dissertations de M. Gaubins joignent le mérite de l'expression à celui de la pensée; elles sont écrites avec précision et pureté. Il dut sans doute à son éloquence et à sa grande réputation l'honneur d'avoir été élevé trois fois au rectorat. Clef d'un peuple ardent et docile, maître d'un empire qui s'étend sur le plus bel âge de la vie, et auquel les premières années de tout homme instruit ont appartenu, celui qui occupe cette place jouit de droits et de priviléges que l'on peut regarder comme un lommage rendu par la nation entière au génie des sciences et de la liberté. Ce feu divin que l'homme a reçu du ciel est un dépôt confié par le souverain aux corps enseignans; et les lionneurs qu'on leur rend sont l'expression de la reconnoissance publique, en mème temps qu'ils servent d'encouragement pour l'étude.

Ce n'étoit point assez que les lettres et les beaux arts eussent un berceau, il falloit qu'on leur élevât des temples. Du seiu des universités les plus anciennes et les plus célèbres, on a vu sortir des colonies savantes, qui, sous le nom d'académies, en ont répandu le gofit, et ont travaillé ì leurs progrès. Dans cellesci, la simplicité des usages anuonce que des hommes d'un îge mûr se sont réunis pour se livrer en conınun

mentis quod medicorum est, le 8 février 7747 , en quittant pour la premic̀e fois le rectorat; il prononça son second discours sur la mème matière, De regimine mentis, etc. daus le mois de férrier 1763 , it la fin de son second rectorat. Ces deux discours, réim. prinés en $37(n)$, ont été depuis traduits en plusicurs langues. Ils contiennent les rrais principes de la psycologie médicale. 
PHYSIOL. ET MED. - GAUBIUS. 287

à la recherche de la vérité : daus les autres, on reconnoît, par la pompe qui accompagne toutes les cérémonies, que l'on s'est proposé de fixer l'attention d'une jemnesse distraite et nobile, et de hıi en imposer nuêue par cet appareil.

L'Université de Leyde est me de celles dont les fìtes ont le plus de magnificence, soit par le soin qu'on y apporte, soit par l'intérèt que le peuple y prend. A la fin de claque siecle depuis son institution, elle ouvre un jubilé. On appelle de ce nom nue lìte établie pour célébrer son origine et ses traraux. MI. Gaubius fiut chargé en $177^{5}$, à la fiu de sou troisione rectorat, de prononcer un discours daus cette solemité( 1 ). If exposa avec force les époques les plus honorables à la nation et ì la compagnie dont il étoit l'organe.

Ce savant a conmmuiqué plusienrs némoires ì l'Acadénuie de Hirlenu, qui les a jubliés daus son recueil. Il y a, eutr'antres, consigné les détails d'une inoculation dont il s'en étoit peu fallu que les snites n'eussent été funestes. Elles l'aroieut tellement frappé, qu'il n'a jamais osé, depuis cet événement, pratiquer luimême l'inoculation, qu'il conseilloit toutefois, en indiquant les précautious nécessaires pour son succès.

On doit compter parıni les travaux littéraires de

(1) Le discours quïl prononça alors le 8 lérrier 1775 , jour du 8econd grand jubilé de l'Université de Leyde, est intilulé : Oratio panegyrica in auspicium tertii soculi Academia batave, quice Leydce est autoritate publich, elc. recitata in-fol. Il contient des recherches historiques très-curieuses sur les progrès des sciences el des letures en Hollande. 
M. Gaubius les éditions de divers ouvrages. Tels sont le farneux traité de Prosper Alpin sur les pronostics (1), la Docimasic de Cramer (2), la Bible de la nature de Swammerdam, à la traduction de laquelle M. Gaubius a eu la plus grande part.

Sa réputation s'étoit étendue dans les pays les plus éloignés : la feue impératrice Élisabetl lui avoit fait les offres les plus avantageuses pour l'engager à se fixer en Russie avec la qualité de son prenier médecin, et il avoit reçu depuis les marques de la considération la plus distinguée de la part de l'impératrice actuellement régnante. On sait avec quel empressement cette soureraine recherche tont ce qui porte l'enpreinte de la science et de la valeur. Persuadée que l'ignorance est également contraire aux intérêts bien entendus des rois et des sujets, elle appelle de toutes parts les lettres et la philosophie, qu'elle emploie comme un grand moyen de civiliser les lommes; et elle continue de la manière la plıs lienrense ume grande expérience politique, dont le résullat est que le germe des sciences, transporté avec précantion, conservé avec soin, croît, se fortifie, et répand déja la plus donce inflıence dans

(1) I'r. Alpini de pressagiendá vila et morte cegrolantium libri vij, cum pra:fatione H. Boerhanave; editio allera leydensis, cujus terlum recensuil, passim emendavil, supplevil, cilala Hippocratis loca accuravil Hicr. Dav, Gaubius. Lund. Bar. 1733 .

(a) Toan. Alndr. Crameri Eilemenla arlis docimastica, duobus eomis eollpurehensa, quorum prior theoriam, posterior prasim sxhibet.

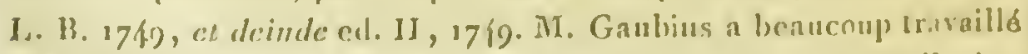
avec l'autcur de cet ouvrage, à la rédlaction duq̨ucl il a contribue. 
PHYSIOL. ET MÉD. - GAUBIUS. 289 des pays stériles et glacés, tandis qu'il se dessèche, languit et menrt, fante de culture, dauns ces climats riants et féconds, on le beau génie des Grecs, attestú senlement par des inscriptions et des ruines, offre cncore à la barbarie elle-mène un objet de respect et do vénération publiçue.

Nous n'avons loné jusqun'ici dans M. Ganbins qune les talens accessoires à celui qu'il possédoit au plus haunt degré : c'étoit sur-tont daus la pratique de notre art qu'il excelloit. Il y portoit cette fúcondité de moyeus que donue une vaste érudition, avec celte sagesse sans laquelle la science ne produit quelcquefois que de la témérité.

La place de premier médecin de Guillaume V, prince d'Orange, alors mineur, ćtoit vacaute eu 1760 : c'étoit anx États-Généraux it y nommer. On sait combien sout imposantes ces assemblées dans lesquelles les députés d'une nation se réunissent pour travailler an bonheur de tous. Il s'agissoit de choisir un médecin anquel pussent être confiés les jour's précieux. d'un jenne prince, dout l'ige tendre exigeoit de lenr part un surcroit d'attention et de soins. MI. Gaubins réunit tons les suffrages, et on reruit entre ses mains l'eufant si cher à tous les ordres de l'état. Tnt-il jamais un premier médecin nommé d'une manière aussi auguste? Ce moment le plus beau de sa vie, loin d'exciter son amour-propre, ne fit que domner ume nourelle énergic à sa reconnoissance et à sa sensibilité. Il bénit cent fois ln mémoire de.Boërrhaave, au souvenir duquel il rap- 
portoit toujours les bienfaits qu'il recevoit de la république.

Malgré cette nouvelle faveur, il continua ses leçons à l'Université (1). Ce zèle fut remarqué par le prince, qui ne put connoître un lomme aussi estimable sans s'y attacher particulièrement. M. Gaubius saisit une occasion qui se présenta pour lui en témoigner sa reconnoissance. Le prince étant parvenu en 1768 à la majorité, honora de sa présence les fêtes que l'Université de Leyde donna à cette occasion. M. Gaubius, alors âgé de 61 ans, se sonvint que dans sa jeunesse il avoit composé des vers latins avec quelques succès, et il osa former le projet d'un nouveau poëme sur la majorité de Guillaume V, commandant une nation riche sans luxe et libre sans ivresse : il espéra que l'intérêt le plus vif, inspiré par la circonstance, l'esprit patriotique, et l'amour de la liberté, suppléeroient an feu des premiers ans, et qu'un sujet de cette nature se défendroit assez contre les premières impressions de la vieillesse. Il ne fut pas trompé dans son attente. Son poëme, publić à la suite d'un discours de M. Veiss, professeur en droit public, qui avoit été prononcé dans la même fête, fut bien accueilli; on y trouva de la noblesse, de l'harmonie et même de la sensibilité.

Déja les amateurs de la poésie latine aroient porté le jugement le plus avantageux sur des vers qu'il aroit

(1) Il confinua ses fonclions de professcur jusqqu'i l'ige de zo ans, et il fut iéclark énérice au mois de seprembre $: 77^{5}$. 
PHYSIOL. ET MED. — GAUBIUS. 291 composés dans un moneut d'enthonsiasme pour l'histoire naturelle, et qu'on lit en tête dı prennier rolınıe de Seba. Cette science, qu'il a toujours beancoup aimée, hui servoit de délassement an milieu d'occupations plus sérieuses. Il avoit fait dans tous les geures, et sur-tont en minéralogie, une des plus riches collections conmes (1). Il se plaisoit it la faire voir aux étrangers : pour lesquels ce cabinet, quelqu'iutéressant qu'il fint, auroit perdu une grande partie lle sa valeur, sans les explicatious de MI. Gaubius, bien différent de tant d'autres, qui ne sont que des moyens assurés pour ammoncer ì grands fruis l'iguorance do leurs propriéticires.

Ce sarant a compté parmi ses entemis lles hommes d'un mérite distingué : heureusenent nons igunrons les notifs et l'origiue de ces divisions. La distance des lieux produit a pau près le mî̀ue effet que celle des temps, par laquelle ces petits intérèts sout anéantis. Qu'il nous sulfise de plaindre l'humanité, toujours agitée par des ornges qu'elle excite, et dont le néaut est assez démontré par le pen de cas que l'on en fait, et par le peu de sonvenir que l'on eu garde.

M. Gaubius a surrécu à tous ses collègues dans la Faculté de Leyde, dont il a ru toutes les chaires occupées par ses disciples. Les antres professeurs des $\mathrm{Fa}$ cultés de la Hollande et de l'Allemagne s'étoient éga-

(1) Il y avoit joint des discriptions abrégées fondécs sur l'analyse cbimique. 


\section{ELOGES HISTORIQUES.}

lement formés à son école; il n'y avoit pas un médecin qui ne se félicitât d'avoir suivi sés lesçons; ils le consultoient de toutes parts; ils ne s'en rapportoient qu'à ses avis dans les cas'les plus difficiles; et M. Gaubius: réunissoit toutes les jouissances d'une vieillesse robuste, savante et respectée.

Il est donc dans les différens âges de la vie des consolations et des récompenses pour ces hommes courageux qui se dévouent tout entiers au travail et à l'ćtude ! L'ardente jeunesse se presse de vivre; "elle prodigue des années pour quelques momens de gloire, et jamais elle ne se plaint lorsqu'elle a frappé ce but. Dans l'âge mûr on commence à jouir du passé, on commoît mienx la valeur du présent, et l'on espère encore de l'arenir. Dans la vieillesse, à mesure que l'existence plrysique s'éteint, l'homme illustré par ses talens voit s'accroître la vaste carrière de la célébrité : le court arenir qui lui reste se confond aisément avec celıi que la postérité lui prépare, et s'agrandit par cette compensation heurense; tout l'invite à se rappeler a vec délices les époques les plus brillantes de son listoire, et pent-être l'hábitude que l'on a de virre, jointe à cetto donce illusion, est-clle plus que suffisante dans ces dernicrs momens pour détourner l'idée importunc et fatigante d'une mort prochaine.

La santé de M. Gaubius ne s'altéra point scrusiblement jusqu'à l'age de 70 ans. Quelques accis de goutte, qui se ternninoient par un flux hémorroïdal, le tourmentirent alors à direrses reprises. Il fut atta- 


\section{PHYSIOL. ET MED. - GAUBIUS. 293}

qué dans le mois de novembre 1780 , au retour de la Haye, d'une fievre maligne avec des redonblemens en ticrce, qu'il prit pour unc maladie de ce dernier genre, mais simple, M. Gaubins ne pouvoit faire nue méprise aussi grave que sur lui-nème. Les soins les plus assidus et les plus éclitirés de ses confrìres ne purent lui conserver lis vie; il monrut le 29 novenubre de la nuène annéce, ìgé de 75 ans.

M. Gaulbius a laissé une très-grande fortume ì nume fille nuique. En ce point comme en plusienrs autres, son sort a ressemblé à celui de son maître Boërrhaave. Plus lieurenx que lui tontefois, il a vu sa fille mariée, et il a cmbrassé ses petits-fils. Son gendre, M. Henri Twent, docteur en droit et écherin de la ville de Leyde, y jonit de la considération la plus distinguée.

La mort de M. Gaubins a été nun sujet d'affliction pour toute la Hollande; il a élé plenré par une famille nombreuse dout il étoit le protectenr et l'appui. Les liens de tendresse qui s'étendoicnt à son éponse et ì à tons les sicns avoient fait naître entrc cux cette douce intimité que l'union des cliefs produit toujours, et quii ne peut subsistcr sans clle. Parmi les larmes que sa mort a fait répaudre, on a remarqué arec attcndrissement celles des paurres, sur lesquels il avoit abondamment versé ses bienfaits.

Les sciences ont fait depuis quelques années de grandes pertes : nous citerons, pour nous renfermer daus notre sujet, Morgagni, van Swieten, Albinus, 
294 ÉLOGES HISTORIQUES.

Haller, Linnæus, de Jussien, Pringle, Gaubins : quel noms et quels regrets! Si on ajoute à cette liste celle des hommes illustres récemment enlevés aux lettres et à la philosophie, on prendra de notre siècle une idée bien différente de celle que veulent en donner certains détracteurs qui, jaloux de sa gloire, à laquelle ils n'ont aucume part, et ne pouvant s'élever jusqu'à lui, font des efforts inutiles pour le rabaisser et le mettre à leur niveau. 


\section{MEDECINS ET PIIYSIOLOGISTES. 295}

\section{GIROD.}

SI quelqu'nn a des droits à un éloge public, n'est-ce pas le citoyen modeste qu'me province entière désigne comure son bienfaitenr; qui méprisa la forture et ne chercha point la gloire; auquel une utile témérité fit braver mille fois la mort; qui concentrant dans sa patrie ses travanx et ses vertus, ne vécut que pour elle et mourut en la serrant?

Tel fut Jean - Franģors-Xavir Gron, citoyelu de Besançon, docteur en médecine, inspectenr pour le traitement des maladies épidéniques de la FrancheComté, associé régniicole de la Société royale de médecine.

Son nom n'a point été répété par les cent bonches de la Renommée; mais il n'y a pas dans sa province nu senl cultivateur quil l'ignore et qui le prononce sans attendrissement. Ses succès, quoique très-importans pour l'état, n'ont point été vantés par ces euthousiastes qui jugent les talens et créent des répulations; mais il n'y a pas dans la Franche-Comté de village où sa mémoire ne soit honorée, et où sa mort n'ait causé des regrets.

Son père, qui étoit médecin, résidoit à Mignovillard, village situé près de Salins où il naquit en 1735 .

A près avoir été reçu docteur en médecine dans l'Uni- 


\section{ELOGES HISTORIQUES.}

versité de Besançon, et y avoir fréquenté les hôpitaux, il se refusa = ilx instances de son père qui avoit formé le projet de l'envoyer à Paris. Ce voyage auroit exigé des sacrifices onéreux à ses frères; $M$. Girod ne voulut jamais $\mathrm{y}$ consentir. Il se retira à Mignovillard, où il partageoit son temps entre l'étude de la médecine et colle des mathématiques. Heureux dans cette retraite, il faisoit le bien et cherchoit la vérité. Il n'achetoit et ne lisoit qu'un petit nombre de livres. Il avoit peu d'amis, peu de fortune et peu de besoins.

Cette simplicité, cette exactitude qui l'avoient accoutumé à ne donner aux choses que leur juste valeur, lui faisoient préférer le séjour des champs à celui des villes. Plus elles étoient peuplées, plus il avoit de répugnance à les habiter. Pressés dans leur enceinte, les hommes lui paroissoient devoir plutôtéprouver le besoin de se fuir, que le désir de se rapprocher : sentiment que chacun partage dans les campagnes et qui dispose à la bienfaisance, à la compassion et à l'humanité.

Hewreusement M. France, médecin en clief des épidémies de la province, lui ouvrit nue carrière digne de ses talens et de son zéle. Il lui offrit et lui obtint saplace; et M. Girod partit pour Besancon, après avoir laissé soll patrimoine ì ses fières.

Les secomrs peuvent être alministrés anx habitans les carnpagnes attaqués d'épidémies, on par des médecins résidens ayant chacun nu arrondissenent déterminć, ou par des médecins clargés spécialenent de cet objet, et stipendiés pour s'y livrer muiguenent. Co deruicr plan fiut préféré par M. Girod, commo 
le plus utile : on est plus sûr, en le suivant, de faire un bon choix. Des nuédecins formés dans ce genre sout plus éclairés sur l'usage des moyeus, et plus devonés au traitement des malides.

Pour remplir ces rues, M. de Lacoré, intendant de la province, cliargen quatre médecius de veiller, conjointement avec l'inspectenr, an traiternent des épidemies de la gúnéralité, qui est devenu depuis cette éporue moins conleux, plus miforme, et qui nuérite d'être proposé comme un modèle anx administraten's des autres provinces du royanme.

Nonuné médecin en chef des épidénies en 1763, NI. Girod en a rempli les devoirs juspu'en 1783 ; et pendant ees viugt aunées il a vécu dans 111 combat perpétuel avec denx des plus grands flénux qui puissent affliger le peuple, lis contagion et la wisise.

Les liabitans des campagnes affligées se rassennbloient antunr de lui, et ils l'écontoient counne nu oracle. Ils le consultoient arec hardiesse, parce que. son extérienr éloit modeste et simple; ils exícutoient rigomreusement ses avis, parce qu"ils comoissoient son lrabileté, parce qu'il ne les trompoil jamais et sur-tout parce qu'il restoit arec emx, quu'il s'associoit à leurs fatigutes, à leurs dangers, à leurs malheurs.

La Société royale de médecine, en inscrivant le nown de M. Girod sur ses registres, désira de commoitre le résultat de ses nombrenses observations; il nous répondit par un mémoire très-détaillé, dans lequel il insistoit principalement sur les maux que produisent les purgatifs donnés arant la crise des fièrres, qu'il a 


\section{8 ÉLOGES HISTORIQUES.}

vue le plus souvent arriver du quatorze au vingtunième jour. Il a réduit, par un terme moyen, les pertes qu'il a faites dans le traitement des épidémies, à un quatorzième. Il a observé que les vieillards couroient les plus grands risques; que les personnes âgées de qua-. rante à cinquaute ans en couroient de moyens. Il a évalué à un deux - centième ceux qui concernoient l'âge de quinze à vingt-cinq ans. Ils étoient presque nuls pour les enfans de cinq à six ans; et les enfansà la mamelle n'étoient même jamais atteints de la contagion. M. Girod a remarqué que les femmes grosses attaquées de ces fièvres, soit qu'elles avortassent cu non dans le cours de la maladie, n'en périssoient jamais; sorte de privilége qu'il a vu s'étendre aux nourrices de denx ou de trois mois. Est-ce à l'humeur laiteuse dont sont imprégnés les fluides des enfans, des nourrices et des femmes grosses, que l'on doit cet étonnant résultat? Telle étoit la conjecture de ce médecin, qui avoit déja commencé des essais propres à fixer son opinion sur cette matière lorsque la mort l'a enlevé.

Voyageant sans cesse dans sa province, et la confiance publique le suivant par-tont, il en profitoit pour éclairer les peuples sur leurs preniers besoins. Il com battoit les préjugís; il détrnisoit les erreurs; il faisoit fuir devant lui ces troupes de charlatans maladroits, qui, n'ayant pas assez d'esprit pour tromper les habitans des villes, inondent les campagnes et vendent au lahourenr crédule de l'espérance et des poisons. T'onjours nodéré, toujours de sang-froid, comme il n'aroit que des vérités ¿ répandre, il ne recouroit point aux prestiges de 


\section{PHYSIOL. ET MÉD. - GIROD.}

l'éloquence, ni à la chaleur de l'enthonsiasme. M. Girod éloit nn de ces lommes rares qui joignent un grand zèle à nue grande simplicité, et tels que la viaie philosophic pourroit les choisir pour en faire les apôtres de la raison.

Parmi les grands services qu'il a rendus, on doit sur-tont compter l'établissenent de l'inoculation daus sa patrio. Un des enfans de M. le marquis de la Perrière étoit nort en 1765 ì Besançon de la petitevérole artificielle; et un second avoir été sur le point d'en périr. Ce fut sous de pareils auspices que M. Girod ent la hatriesse de praticuer et le bonhenr de faire adopter cette méthode. Il inocula avec le plus grand succès douze enfans à Mignovillard. Déja la fî̀cherse inpression produite prar la mort du fils de M. de la Perrière étoit effacée : il fut assez adroit pour mettre dans ses intérèts, c'est-d-dire dans cenx du public et de la vérité, les curés, les seigneurs des paroisses, les médecins des villes et les chirurgiens des villages, qui devinrent ses plus zélés coopératenrs. Bientôt les habitans des campagnes, dont il avoit et méritoit la confiance, loin de mettre obstacle à ses vues, lui amenèrent en foule leurs enfans. Puisque M. Girod le veut, disoient ces bonnes gens, les roilà; qu'il en soit le maître et qu'il en dispose.

Ainsi, tandis que les savans se disputoient; tandis que le législateur balançoit entre denx partis opposés; tandis que dans les villes les plus célèbres par les progrès des sciences un petit nombre de citoyens se décidoit à peine pour une pratique dont tant de faits démon- 


\section{Soo ÉLOGES HISTORIQUES.}

trent l'utilité, un senl homme avoit persuadé une province entière, établi sur des fondemens inébranlables et mis à la portée de tout le monde une vérité des plus importantes au salut du genre liumain. Plus de vingt-cinq mille personnes inoculées en FranclicComté depuis 1765 jusqu'en 1782 , c'est-à-dire plusieur's milliers d'hommes forts, robustes, utiles, un peuple de laborreurs conservés par ses soins, et qui le bénissoient dans leurs foyers : voilà quels sont les droits de $M$. Girod à la reconnoissance publique. Une nation juste et qui sentisoit le prix d'un tel bienfait ne manqueroit pas d'élever un monument on de consacrer une médaille an médecin qui a le premier répandu l'inoculation dans les campagnes.

M. Girod, loin de dissimuler les risques auxquels la contagion de la petite-vérole artificielle cxpose dans les villes, en a traité très au long dans un mémoire qu'il nous a lu sur ce sujet. Il couseilloit sur-tont d'y recourir dans un canton lorsque la petile-vérole naturelle commençoit à y régner épidémiquement, ou lo»squ'on étoit nenacé par.la proxinité de son foyer. Employée de cette manière, l'inoculation diminue les dangers et la durée de l'épidemie. Il la pratiqua d'abord par incision et bientôt après par piqûres, dont il porta successivenent le nombre jusqu'à quatre, ayant observé que l'éruption éloit alors moins abondante, et les accidens plus rares.

I'inoculation a suivi dans la Franche-Connté nue marche digne d'être remarquée. Elle s'est étenduc des campagues aux villes et des artisaus anx gens riches 


\section{PHYSIOL. ET MED. - GIROD. 301}

ou aisés. Lorsque cenx-ci réclamoicnt les soins de M. Girod pour leurs cnfans, il ne les refusoit point; mais il n'acceptoit jamais d'honoraires. Il conservoit ainsi tonte sa liberté et ue s'astreiguoit point it la gêne de ces attentions uninutienses qui l'auroient enlevé à ses plns chìres occupations. M. Girod étoit le médeciu dı peuple, dont les grands et les riches ne lui paroissoient former que la plus petite partie, parce qu'il ne considéroit que le nombre, et que ne voulant participer ni al leur crédit, ni al leur fortme, ils nétoient pour lui que des hommes ordinaires, tandis qu'il deroit lenr paroitre nu honme bien rare el bien singulier.

Il est facile de juger qu'nu médecin anssi vrai, aussi scrupulenx, n'avoit de secret pour persome : il ne faisoit prendre aucune pondre mystériense it ses inoculés; il ne préparoit point cenx qui se portoient bien, parce qu'il ne croyoit pas qu'il pât y aroir un état préc férable à celni d'une santé parfaite; eu un mot, il étoit inocnlateur sans ètre charlatan.

On avoit publić qu'il résultoit des calculs faits en Angleterre qua la vie noyenue des personnes inocnlées étoit plus courte que celle des autres lommes, et cette nonvelle avoit été accréditée par les ennemis tonjours nombrenx des nonveautés ntiles; M. Girod crut qu'il étoit de son devoir de vérifier ce fait. Il partit aussitòt pour Londres, et il en revint arec des prenves évidentes de la fausseté de cette assertion.

Le croiroit-on? tant et de si grands services étoient ignorés hors de la prorince à laquelle ils aroient été 


\section{3o2 ÉLOGES HISTORIQUES.}

rendus, et ils le seroient peut-être encore, si la Société royale de médecine re les avoit pas fait connoître, en adjugeant à M. Girod deux de ses prix d'encouragement. Il les a reçıs dans cette inême salle où nous sommes assemblés, au milieu des applaudissemens publics dont il étoit digne depuis si long-temps et qu'il entendoit pour la première fois.

La Société doit prendre à la gloire de ce médecin un intérêt d'autant plus vif, que lui-mnême y en mettoit peu; il n'a fait que la mériter; et en nous laissant le soin de l'obtenir, il rous a confié un emploi lıonorable et facile, puisqu'il nous a suffi de le montrer tel qu'il étoit, et que d'ailleurs le savoir et le bienfait qui se cachent sont sur-tout ceux qu'il faut louer et placer au premier rang.

Ce citoyen estimable a eu la satisfaction de voir la fin de sa carrière honorée par les différens ordres de l'état. Le roi lui accorda en 1783 des lettres de noblesse, et la ville de Besançon, dans le territoire de laquelle il avoit traité plusieurs épidémies, lui conféra le titre de citoyen : en lui assignant une place parmi ceux (qu'il avoit utilement servis, elle lui offril me des récompenses si propres à être le salaire des belles actions et à remplir une grande ame, parce qu'elles supposent un concours de suffiages, de sentimens et de vacux qui sont le but de la véritable gloire et qu'il n'appartient qu'à elle de réunir.

Ces diverses circonstauces exigèrent qu'il fit $u n$ voyage à Paris. 11 y inocula trìs-heureusement plu- 


\section{PHYSIOL. ET MÉD. - GIROD. $3 \circ 3$}

sieurs pesonnes de marque, qui s'efforcèrent en vain de le retenir : les honneurs dont il avoit été comblé n'avoient fait qu'enflammer son zéle.

A peine de retour daus la Franclie-Comté, où il arriva en juillet 1783 , il apprend qu'une épidémic de fièvres internittentes pernicieuses régnoit à Chatenoy, bailliage de Dole: il vole aussitôt an secours des mialades. Attaqué lni-mème de cette fière après six semaines de fatignes, il vit par la marche des accidens qu'elle lni seroit funeste; et il l'annouģa it M. France son ami, entre les bras dnquel il mournt à la fin du septième accis, ainsi qu'il l’avoit prévu. Dans la rémission qui précéda cet accès, M. France essaya de lni offrir 1111 rayon d'espoir. « Ne nous y trompons point, mon ami, lui dit M. Girod: le glaive qui n'est que suspendu va frapper; nais ne use plains point, je nenrs sur le clianup de bataille. Si les cordiaux que tu me donnes prolongent ma vie de quelques instans, je les chérirai, puisque je dois les passer arec toi. »

Une plns belle fin ne pouvoit terminer une aussi belle carrière. On pent dire de lni ce qui convient it si peu de personues, que sa vie et sa mort ont été dignes l'une de l'autre.

Qu'il nons soit permis de remarquer ici que la suite des éloges lus daus nos séauces offre déja plusieurs exemples d'un dévonement semblable. Osons prédiro que celui-ci ne sera pas le dernior. 


\section{HALLER.}

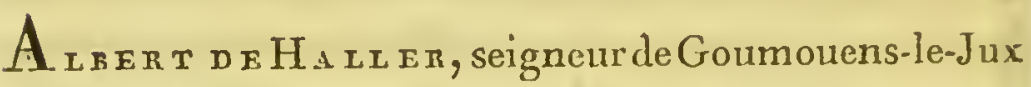
et d'Eucaglens, conseiller d'état, premier médecin du roi de la Grande-Bretagne à Gottingue, chevalier de l'étoile polaire, membre du conseil souverain ì Berne, un des huit associés étrangers de l'Académie royale des sciences, président de la Société économique de Berne et de la Société royale des sciences de Gottingue, et: membre de presque toutes les autres académies de l'Europe (1), naquit à Berne, le 16 octobre 1708 , de Nicolas-.

(1) Il fut reçu membre de l'Académie d'Upsal en 1734 , de la Société allemande de Leipsick en 1739 , de la Société royale de: Londres en 1743 , de celle de Stockliolm en 1747 . En 1749 , le roii de Prusse lui donna une place dans l'Acadénie de Berlin, et luis en offrit la présidence. En 1750 , les chirurgiens ayant été réunis, en corps, il en fut nomıé président. En 1751 , il fut reçu à l'Académie des curieux de la nature et à l'Institut de Bologne. En 17,52, il fut agrégé à l'Acarlémie royale de chirurgie de Paris, et à la Société physico-médicale de Bdle. Fin 1754, il fut choisi pour ctre un des huit associés étrangers de l'Académie des sciences le Paris. En 1755 , on lui oflrit la place de clancelier de l'Université de Gottingue, vacante par la mort de Mosheim; mais it la refisa, de meme que celle de clancelicr et de curateur de l'Université de: Halle. Il entra la mene annce dans le Conseil de santé de la république de Berne, et il fut nommé membre des Arcades, sous le noun d'Isicrale Emireo. Il fut reçn ell 375 g membre de l'Académic botaniggue de Florence et de celle de Baricre. Il entra en 
PHYSIOL. ET MÉD. - HALLER. 305

Eummanuel Haller, avocat et chancelier du comté de Baden, etd'Anne-Marie Engel, fille de Matthieu Engel, membre dn conseil souverain, et qui a long-temps occupé à Unter la place d'avoyer, une des phis considérables de la Suisse. En rapportant ici ces titres, nous ne croyous pas ajouter à la gloire de M. de Haller, puisque, si sa naissance êt été moins distingnéc, il seroit pent-être moins surprenant à nos yeux.

La fiunille des Haller, comptéc depuis long-teups parmi les patriciennes, s'est toujours distingnée par son zèle pour la religion. Ces impressions, yni se perpélnent si facilenent, avoient conservé toute lenr force sur l'esprit du père de M. de Haller. Il avoit quatre enfans, dont celui aurpiel cet éloge est consacréé étoit le plus jeunc. Il confra leur éducation à un précepteur nommé Abraham Baillodz, homne sombre, mélancoliqune, sévère à l'excès, mais fort sarant en matière de religion et très-versé daus la connoissance des langues. NI. de Haller étant le plus jenne et sans donte le plus sensible étoit anssi le plus timide et le plus malheurcux. Malgré l'état de sonffrance et de douleur que des organes foibles et délicats doirent ressentir lorsqu'ils sont livrés à

376-ł dans la Société économique de Zurich, et dans celle de Harlem et de Zell en 1765 ; en $177^{2}$, daus le Collége des mèdecins d'Édimbourg. En 1773 , il fut agrégé dans les Académies de Padoue et de Copenhague. En $1-75$, il fut fait président de la Société économique de Berne. En ${ }_{17}-6$, il fut reçu dans la Société des médecins d'Élimbourg, dans la Société économique de Carinthie, et dans la Société royale de médecine de Paris. En 1777. il fut almis dans l'Académic de Pétersbourg et daus la Sociétó patriotique de Hesse-Hombourg. 


\section{So6 ÉLOGES HISTORIQUES.}

des nains dures et mercenaires, son enfance fut un prodige; nous n'oserions pas même en annoncer les détails, si la Suisse entière n'étoit notre garant.

Aussitôt qu'il sut écrire, il rangea par ordre alphabétique tous les mots qu'il apprenoit et dont on lui faisoit l'explication. Il composa ainsi une espèce de vocabulaire chaldaïque, hébreu et grec, auquel il a souvent eu recours dans un âge plus avancé.

A dix ans il composa des ver's latins et allemands qui étonnèrent ses maîtres; il se vengea aussi de la dureté de son précepteur, en peignant dans une satire latine tout le ridicule de son pédantisme. A douze ans il aroit extrait des dictionnaires de Moréri, et surtout de celui de Bayle, l'histoire des hommes les plus célèbres dans les sciences. Ainsi le tableau dı premier âge, qui dans les hommes ordinaires ne présente qu'un tissu de foiblesses, offre dans M. de Haller les premier's élans d'une ame forte et vigoureuse et le développement du génie.

Son père, qui tenoit tout sou bien de ses places, mourut pen de temps après, et le laissa à l'âge de treize ans presque sans fortume. Ces événemens sont conlmuns dans les états républicains, où la considération étant personnelle, les fils, qui n'héritent presque jamais des places de leurs pères, sont réduits à les mériter par de nonveanx services. Le jenne de Haller, que ses parens destinoient al l'état ecclésiastique, fut obligéd'achever ses études avec les enfius du peuple daus le collége. Le trait suivant lui attira l'attenlion de ses proféssenu's et l'admiration de ses condisciples. On hui aroit donmé 


\section{PHYSIOL. ET MÉD. - HALLER. 307}

une leçon à traduire en latin; il la rapporta traduite en grec avec la plus grande pureté.

Ayant fini ses classes à quatorze ans, M. de Haller obtint de sa faurille la permission d'aller passer quelque temps à Bienne chez le docteur Neulanms, savant médecin, et père d'un de ses jeunes annis. Le besoin d'acquérir de nonvelles connoissances lui fit désirer ile faire ce voyage; mais M. Nenlıams s'étant contenté de lini expliquer la philosophie de Descartes, et ce genre d'instruction ne lui ayant pas offert assez d'attraits pour le distraire de ses occupations fivorites, il continna de se livrer à l'étude des langues et aux charmes de la poésie. Puisque sa naissance aroit été farorisée par les Muses, il lenr devoit an moins l'hommage de ses preniè̀res anmées.

Il éprouva à Bieme nu mallheur imprévu. Le feu ayant pris ì la nuaison dauns laquelle il demenroit, il n'eut que le temps de se sanver avec ce qu'il aroit de plus précieux, c'est-it-dire ses poésies. Relisant quelque temps après les vers qü il aroit ainsi dérobés aux flammes et sur-tout plisieurs satires, geure pour lequel il avoit le goùt le plus vif et le talent le plus décidé, il se déternina à les y livrer de nouveau, et il fut assez courageux pour faire ce sacrifice ì la bonté de son cœur. Il en excepta seulement quelques pièces, qui transmettront saus tache et sans reproche sorr nom it la postérité.

Ses parens exigèrent bientôt qu'il choisît un état. Il dut être d'autant plus embarrassé dans ce choix, quie ses comnoissances acquises, la justesse et l'activité de 


\section{8 ÉLOGES HISTORIQUES.}

son esprit le rendoient également propre à tout. Un penchant naturel, et dont le docteur Neuhams avoit augmenté les dispositions, le détermina pour cette cience qui présente la nature sous l'aspect le plus varié, le plus frappant et le plus utile. Il résolut donc d'étudier en médecine, et il partit dans ce dessein pour Tubinge en 3723. Alexandre Camerarius et George Duvernoi y enseignoient alors avec célébrité. Ce fut d'eux qu'il reçut les premières leçons d'anatomie et de médecine.

En 1724 George-Daniel Coschwitz, professeur dans la Faculté de Halle en Saxe, avoit cru découvrir un conduit salivaire derrière la langue. Duvernoi se joignit à son disciple pour démontrer que ce prétendı conduit n'existe ni dans l'homme ni dans les quadrupèdes (1).

Il arriva à M. de Haller, étant à Tubinge, une aventure qui a fait époque daus sa vie et qui mérite par conséquent de trouver ici sa place. Il fint entraîné dans une de ces parties où la jeunesse, après s'être livrée à l'excès du vin, poursuit tumnltueusement des plaisi's qu'elle n'est plus en état de goûter. M. de Haller fiut d'abord un des acteurs les plıs aninés de cette scène dont il devint bientôt simplement le témoin. Il vit avec honte et avec donlenr dans ses amis et dans lnianême les sens troublés et la raison anéantie. Ce spectacle lui fit horreur; il résolut de ne plus boire de viu et il s'en priva pour tonjou's.

(1) Pcu de temps apress, Walther et Hoister confirmerent son opinion au sujet du conduit de Coschivitz. 
Duvernoi se servoit des Instituts de Bö̈rrhaave pour fiire la hase de ses leçons. Ce fut mu trait de lımière pour M. de Haller, qui résolut aussitôt d'allex à Leyde. Il hrôloit d'entendre l'antenr d'un ouvrage qui l'avoit étomé, et que l'on ponvoit en effet regarder alors comne le meilleur traité de physiologie qui en̂t parı depuis le renouvellement des sciences.

Arrivé à Leyde il s'unpressa de suivre les leçons de Boërrhatve: le maitre et le disciple se virent et s'apprécièrent en un instant.

En même temps qunc 3oönhthave enscignoit la médecine el la botanique à Leyde, Albinus y dénontroit déja l’anatonie. Ces denx sarans donnèrent ì MT. de Haller des marques particulières de leur hienveillance, qui firent maitre en lni l'émulation la plus vive. Mais ce qui lui inspira sur-tont le gont de l'anatomie et la passion du travail, ce fut la vue du superbe cabinet de Kuysch oì, an milien de tant d'organes préparís d'une manière surprenante, an milien de sujets qui y aroient cn quelque sorte reconver muenonvelle vie, il aperçut un vieillard nonagénaire, desséché par les ans, mais toujours laboricux et actif, qui, paroissant comme un enchantenr an milicn de ces merveilles, sembloit avoir joint an secret de les conserver celui de s'immortaliser. lni-nıêne.

Animé par de si beaux modéles, M. de Haller travailla avec tant d'ardenr que sa santé eu fut dérangée. Un voyage fait dans la basse Allemagne arec deux de ses compatriotes la rétablit, et pen de temps après son retour à Leyde le grade de docteur lui fut conféré à 


\section{0 ÉLOGES HISTORIQUES.}

l'âge de dix-neuf ans. Quoique dans une école beaucoup plus brillante quue celle de Duvernoi, les intérêts de son premier maître lui furent toujours présens. Il choisit pour sujet de sa thèse celui qu'il avoit déja discuté à 'Tubinge et qu'il traita dans une plus grande étendite. Il fit voir dans des planclies très-exactes: la veine qui avoit été prise pour un conduit excréteur. Ainsi le premier pas qu'il fit dans l'anatomie fut la proscription d'ıne décoltverte imaginaire. N'est-ce pas en effet un des plus grands services que l'on puisse rendre aux sciences, et l'hommage le plus pur qu'il soit possible d'offrir à la vérité, que de diminuer le nombre des erreurs avec lesquelles elle est si souvent confondue?

Après avoir été reçu docteur, M. de Haller quitta la Hollande, oit il fut regretté par tous les gens de lettres, pour royager en Angleterre. Hans-Sloane occupoit alors la place de président de lạ Société royale, dont Douglass et Cheselden étoient des membres distingués: il se lia intimement arec enx pendant son séjont it Jıondres. Il passa ensuite quelque temps it Oxford, et de là il vint en France oì il connut parliculièrenent MM. Geoffroy, Antoine et Beruard de Jussien, JeanLouis Pétit et Ledran. Il assista sur-toul anx lecous du célèbre Winslow, dont il ainoit ì se dire l'élère (1).

(1) Il a fait lui-menc, dans le second rolune de: sa Bibliothèque anatomique, In récit des difficultés qu'il eproura, étant a Paris, dans ses recherclies sur le corps humilu. Il s'occupoir a la dissection avec un prosecteur nommé Lagarde lorsqu'm parlicnlier, voisin de son appartement, cut la témérite de fuire une onverture au mur de séparation. Ne rogant que de l'horrenr et de 


\section{PIYSIOL. ET MÉD. - HALLER. $31 \mathrm{i}$}

Il ne parloit qu'avec vénération d'un homme qui a eu le courage de consacrer sa vie entic̀re ì l'étude et à l'enscignemeut de l'anatomic, sans qu'on puisse luireproclier d'avoir été l'autenr d'un senl systène. M. de Haller proposoit somvent à ses disciples cette reteme pour modèle, et il en a lni-mème fourni l'exenple, antant cependant que la force et l'étendue de son innagination, contre laquelle il devoit aroir tonjours à Intter, le lni ont pernis.

Avant de relommer it Berne, le projet de M. de Haller étoit d'aller en Italie: la foiblesse de sa santé l'ayant empêclé de faire ce voyage, il partit pour la Suisse oì il passa quelque temps auprès du célehre Jean Bernonilli, professeur de mathématiques it Bille. Daus cette école, il ne s'occupa que de la géonétric. Son anc', avide de vérités, se livra entièrement ì ce nourean genre d'étude, et bientôt il auroit onblié celle de la médecine si Jean Bernonilli, en la rappelant à sa memoire, ne nous l'ent rendu (1).

l'effroi dans un spectacle qui u'est en elfet intiressunt que pour les persounes rraimeut instruites, il poursuivit MI. de Haller en justice, etil le contraiguit de rester caché pendant long-temps. MI. de Haller n'a point oublić ce 1 rail; il n'en a jamais parlé sans témoigner toulc la peine qu'il en ressentil. Il s'exprime ì ce sujet de la manière suivante : Mraligna curiositas operarii turbavit qui... nomen meum... detulit, ut graver pernas, ipsas fortè triremcs, effugerem... Bibliolh. anat., ton. II, p. 186 .

(1) M. de Haller ne consentit cependant à le quitter que Iors: qu'il se crut assez iustruit pour rédiger lui-mème les leçons de son illustre maitre; ce qu'il fit daus un manuscrit précienx, auquel il joignit des réflexions sur l'analyse des infiniment petits dụ 


\section{2}

ÉLOGES HISTORIQUES.

Aucur pliysicien n'a tiré plus de parti que lui de sés connoissances en mathématiques pour l'économie animale; il s'en est sur-tout servi pour réfuter les calculs établis par plusieurs auteurs sur de fausses suppositions. Car les sciences exactes, lorsqu'on en abuse, au lien de mener à la vérité, conduisent à l'erreur, et le font d'une manière d'autant plus dangereuse qu'on se flatte d'avoir démontré rigoureusement les faux résultats que l'on annonce (1).

De retour à Berne en 1729, M. de Haller se livra it l'exercice de la médecine avec toute l'activité qui lui étoit naturelle et avec le succès qui l'accompagnoit partout (2). Les ignorans, qui sont ordinairement jaloux et qui n'aiment pas à louer plusicurs talens dans la même personne, l'accusèrent d'avoir donné trop de temps à la théorie: comme si la médecine étoit une science sans principes et comme si c'étoit un devoir de les ignorer ou un crime de les apprendre! Ces propos dont on se sert si solvent pour tromper le public, produisirent tont l'effet que lenrs autenrs deroient c11 attendre: on refusa à $\mathbf{M}$. de Haller la place de médecin

marquis de l'Hôpital, ct qu'il a communiquées depuis à plusicurs savans.

(1) Pendant son sćjour à Bile, en 1728, le doctcur Mieg, qui y professoit l'anatomic, étant devenı malade, pria $\mathbf{~ 1 1 . ~ d e ~}$ Hallex de le remplacer pendant quelque temps; ce qu'il fit arec tant de succìs, que les ćtudians ue purent s'empécher de le regrelter lorsque le docteur Mieg fut gutiri.

(2) Il écrivoit exactement l'hisınire des cas rares quì se présentoient à lui. Ce recucil forme un calier considérable que l'or conserve encore diank sa bibliothéque. 
PHYSIOL. ET MÉD. - HALLER. 3ิ13 d'in hôpital quu'il sollicita en $17^{3} 4$ ( 1). Une iujustice de ce genre u'a rien qui doive étomuer ceux qui sont accontumés an spectacle des choses hmmaines, mais on sera saus doute plus surpris d'appreudre que les administrateurs qui l'avoient comnise emrent le courage de la réparer pen de temps après, en lni donmant cette mème place, qu'il remplit arec distiuction jusqu'en 17336.

Ses talens porr l'anatomie étoient trop marqués pour que la république de Berue ne fìt pas tentée cle les nettre d̀ profit. Elle fit construire en 1734 in anphithéâtre pour les démonstrations d'anatomie dont il fut nomuné professem (2).

Il prononça cette même année, dans $n$ concours pour une chaire de belles lettres, 11 discours dans lequel il traita de la prééminence des anciens sur les moderues, sujet qui a été si vivement discuté par nos littérateurs frauçais: Il employa en fircur de son opiniou des armes bien propres à la combattre, puisçu'il se montra pour le moins le rival de cenx anxqunels il s'efforçoit d'accorder la palme (3).

Ce fut à peu près à cette époque que MI. de Haller (4)

(1) En 1733 il publia un programme, dans lequel il insista sur la résistance que les còtes offrent en s'élevant au diaphragme, qui se contracle dans le même tenı̣s.

(a) Il compnsa, ì la mème époque, un ourrage allemand fort recherché, sur les dangers de l'esprit.

(3) L'Académie d'Upsal le nomma son associé en 1735 . Cette compagnie a joui pendant quarante-quatre ans du plaisir de le compter parmi ses membres.

(4) Depnis 1733 jusqu’à 17 fo, il se livra beaucoup à la poésie. 
publia son recueil d'odes et d'épîtres en ver's allemands, qui ont été traduits depuis dans presque toutes les langues de l'Europe. On y trouve les traits qui le caractérisèrent torjours, une grande sensibilité, de la noblesse, de l'élévation et de la philosophie. On diroit qu'il a dédaigné ces ornemens frivoles ou empruntés que l'esprit s'efforce en vain de mettre à la place du génie. Tantôt il peint la douce fraîcheırr du matin ( 1 ) et l'aspect riant que les campagnes lui ont tant de fois offert lorsqu'il se levoit dès la pointe du jour pour les parconrir. Ailletrs il exprime dans les termes les plus touchans l'eunui qu'il a éprouvé loin de sa patrie, dans ses voyages (2). Que l'on ne regarde pas ces regrets comme l'effet physique de l'influence des climats, auquel l'homme le plus inscrisible ne pent quelquefois se dérober. MI. de Haller aimoit son pays avec transport; et il a d̂̂ jouir d'un plaisir bien délicat, puisqu'il n'a pu se dissimnler qu'il en étoit l'omernent.

Plus loin, il sonmet la gloire et la renommée ì l'cxa-

L'auteur d'un éloge de M. de Haller, imprimé il Genève, et qui étoit un de ses amis, dit qu'il ne s'étoit ocrupé de ce genre de travai! que pour dissiper l'ennui que donne une manraise santé, et pour se consoler des peines que l'envic lui suscitoit saus cesse. On attribua d'aboril ses poésies, qui parurent sans unm, ì Muralt, poëte allemand très-célébre; et les littératcurs allemands de Ia plus grande réputation portèrent sur cette production le jugement lc plus avantngeux.

(1) Traduction frausaise, édition de 1775 , page 1.

Or a fitit en différentes langues vingt-deux éditions des poésies de Haller.

(a) 'raduction riangaisc, ćdition de 3775 , page 5. 


\section{PHYSIOL. ET MÉD. - HALLER. 315}

men le plus impartial et le phis rigonreux (1). Comblé de leurs favenrs, qu'il avoit méritées et obtenues pour ainsi dire dès l'ìge le plus tendre, personne ne pouvoit nienx que lui les apprécier.

Presque tontes sas poésies sont dédićes à un ani . "Si mes chants étoient dignes de la postérité, dit-il an célèbre Gesner (2), je te proposerois avec Sthelin et moi comme munodèle de l'union la plus parfaites. Combien des hommes semblables sont aut-dessus de ces littérateurs, qui, en n: s'occupant que du soin de dévoiler inutuellenent leurs défauts, forcent enfin le public ì mesurer l'estime qu'il leur doit sur celle qui'ils ont réciproquement les uns pour les autres.

Dans nun poëme en trois chants (3), it recherche quetle est l'origine du bien et du unal, et il proure que notre perfection tient ì cette sensibilité qui est la source de nos plaisirs et de nos peines. L'homme instruit y aperçoit en plusieurs endroits la connoissance la plus exacte du corps humuain, cachée sous les traits de la poésie la plus élevée. On peut dire que M. de Haller est le premier qui ait fait marcher d'un pas égal les talens dn poëte arec ceux de l'anatomiste.

Mais le morcenn le plus acheré de tous cenx que M. de Haller a publiés est sans contredit celui dans lequel il a décrit les Alpes et les mœurs de leurs babitans. Plus un sujet étoit grand, plus il convenoit à la

(1) MIeme édition, page 9.

(2) Ibid., page Ifí.

(3) Ibid., page 169 . 
force et à la vigueur de son génie, et plus il lui étoit facile de l'égaler.

Un assemblage majestueux de rochers, de collines et de lacs, dont des forêts sombres terminent les contours, compose le spectacle que les Alpes offren ı̀ l'oil étonné de l'observateur. Ici une montagne présente ses flancs stériles; les glaçons qui y sont accumulés sont peut-être aussi anciens que le sommet qu'ils recouvrent; là il semble que la terre soit en contact avec le ciel; un mont escarpé s'élève au-delà des nuages; ailleurs, du traut d'un roc perpendiculaire, un torrent se précipito à travers mille écueils; des fleuves qui vont au loin tracer les limites des empires y prenuent leur source; l'or le plus pur se mệle avec le limon qu'ils déposent; le berger des Alpes le sait et ne daigne pas le recueillir. Près de là, sur une montagne fertile, on voit une claâne de coteaux agréables et la température y est donce et féconde. Icicroissent les plantes du Nord; là se trourent celles dn Midi; et des clinuts aussi variés ne sont séparés que par une colline ou par nu valloı étroit. Ce fut de la cine de ces montagnes que M. de Haller observa la nature, qu'il la vit sous ces différens aspects, et qu'il aperçut la futilité des systèmes publiés sur la structure du glohe par des hommes ingénieux et hardis, qui comnoissent à peine le point d'où leur imagination s'est ćlancée.

A des talens anssi décidé6 ponr la poésie, M. de Haller joignoit des comoissances très-étendues dans la biographice et dans I'histoire. Il ent occasion de les développer en 1735. Ayant élé nommés alors chef de la 


\section{PHYSIOL. ET MÉD. - HALLER. 317}

bibliothèque publique de Berne, il dressa un catalogne raisonné de tous bes livres que cette collection renferme, et il rangea suivant un nouvel ordre plus de cinq mille médailles anciennes dont il tit une table clironologique.

En 1736, la régence de Hanovre lui offrit une chaire d'anatomie, de botunique et (1) de chirmgie ì Gottingue. La promesse qu'on lui fit de fonrnir à toutes les dépenses nécessaires ponr l'exécution des grands projets qu'il aroit formés, l'eugagea it accepter ces trois places (2).

Il célébra alors dans une ode (3) l'inauguration de l'Université de cette ville, établic et comblée de farerr par le feu roi d'Angleterre, qu'il peignit comme le restauratenr des sciences daus l'électorat de Hanovre et conme un prince jaloux de porter leur influence jusque dans ses dominatious les plus éloignées. En effet, tandis que Haller, appelé par ses bienfaits, établissoit unue acadénie ì Gottingne, Franklin éclairoit déja le Nonvean-Monde, et il étoit alors pernis à l'Angleterre de s'epl glorifier.

M. de Haller comnentoit et expliquoit tous les ans à ses élèves les Iustituts de Boërrhaave: ces leçous

(i) Il sacrifia une partic de la maison qui lui étoit destinée pour l'agrandissement du jarlin de botanique.

(2) Il y eut pour collègues des professeurs celdbres, parmi lesquels on compte les docteurs Richter, Segnerus et Brandelius. Vid. Orat. D. Baldinger, in Laudes meritorum Halleri, Gotting. $277^{8}$, pag, 19.

(3) Edition frangaise, 1775 , pag. 229. 


\section{ELOGES HISTORIQUES.}

eurent le plus grand succès, et en $17^{3} 9$ il se détermina à les publier en six volumes in-12 (1). On y trouve le développement de la doctrine du savant professeur de Leyde, quelquefois obscur dans ses Instituts, et on y découvre le germe des grandes vues de M. de Haller sur sa Physique du corps humain.

Il avoit déja oublié ses talens pour la poésie; il semble même qu'il n'ait pas daigné en conserver les moindres agrémens. Au lien d'un style noble et fécond, il a employé dans ses ouvrages sur les sciences une latimité sèche, quelqucfois embarrassée et à laquelle il faut même être accoutumé pour l'entendre. Mais on est bien dédomnagé de cette légère peine par la profondeur des idées, par l'enchaînement des réflexions et par l'immensité de l'érudition dont ses productions sont remplies.

L'étude de la botarique semble être faite moins que toute autre pour inspirer de l'entlousiasme; cependant plusieurs de ceux qui se sont distingués daus cette science l'ont cultivée avec passion. M. de Haller étoit de ce nombre. Il est en effet difficile d'être voisin des

(1) M. de Ifaller avoit fuit lui-mène, étant ì I_eyde, un Abrégge des principes que Bö̈rhaave y exposoit chaque anuéc. Le docteur Screiber et le professenr Jean Gesner avoicut confié leurs caliers égalcment écriss à Leyde; et le docteur Feldman, qui avoit réuni des extrairs des legons de Bö̈rrhare, rédigés en 1710 , 1712,1731 et 1732 , en aroit fait part it MI. de Haller, qu'il avoit par-la mis ans le cas de comoitre foute la perfection que l'ige et l'expérionce avoient apportée nux opinious de leur maitre commun. Le ciuquidme tome est presque tunt entice de lBoürrlaave, suivant $\mathrm{N}$. de lliller lui-sisosue. 
PHYSIOL. ET MED. - HALLER. 319

Alpes, ou la nature est si belle, sans devenir nun de ses admiraten's (1): les herborisations (2) étoient pour lui un délassement alussi agréable qu’il lui étoit nécessaire. Son ami, M. Gesner, l'accompagnoit sonvent dans ses voyages. Parmi les aneclotes auxquelles ils ont domé lieu, nous en citerons mue qui fera comoitre l'intinuté de len' nuion et l'énergie de leur cartactere. Un jour, après avoir épuisé leurs forces dans une herborisation très-pénible, M. Gesner tomba de fatigue et s'endormit an milien d'une atmosphère glacée. M. de Haller vit avec inquiélude son ami livré à nu somneil que le froid anroit pu rendre fineste. Il chercha comment il pourroit le dérober ì ce danger: bientùt ce noyen se présenta à sa pensée on plutitt ì son caenr. Il se déponilla de ses vêtemens, il en convit Gesuer; et le regardant avec complaisance il jonit de ce spectacle sans se permettre aucun nourement, dans la cribinte d'en interroupre la durée. Que ceux qui connoissent les charmes de l'amitié se peignent le léveil de Gesner, sa surprise et leurs embrassemens; que l'ou se repré-

(1) It commenģa en ${ }_{17 a f}$ ses rop̣ges dans les Alpes, et it forma lui-mème un herbier très-complet, duquel il a extrait les plautes qu'il a décriles.

(2) Enumeratio stirpikem helveticarum. On troure dans la préface, page 3 et suivantes, la description topographique de la Suisse. "Ce pays réunit, dit-il, à de très-petiles dislances les végétaux et les insectes de la Norwege et ceux de l'Italie ». Pour rendre son ourrage plus complet, il y a joint un exposé historique de tout ce qui a élé écrit sur les plautes des Alpes, depuis Otho Brunfelzius jusqu's lui. 


\section{0}

\section{ÉLOGES HISTORIQUES.}

sente enfiu al milieu d'un désert cette scène touchante et si digne d'avoir des admirateurs.

En 1742, M. de Haller fit paroître le fruit de ses voyages en deux volumes in-folio, ornés d'un grand nombre de superbes planches. L'absence ou la présence des étamines du calice, de la corole et des graines, le nombre des étamines comparées avec celui des pétales, le nombre des cotylédons, celui des graines et leur nudité, sont les principaux caractères dont il s'est servi (1). Il publia, l'année suivante, le système de botanique du jardin de Gottingue, dont la disposition étoit son ourrage (7). Deja en 1736, il aroit donné une méthode pour étudier la botanique, dans laquelle il a recommandé l'ordre naturel (3);

(1) M. de Haller, afin de rendre sa méthode plus naturelle, a rapproclić les sections de chaque classe; mais en voulant se procurer cet avantage, il a perdu celui de la clarté et de la précision. Ce reproche est sans doute bien fondé, puisque deux botanistes célèbres, f'eu M. Linnæus et M. Adanson ne sont pas d'accord sur le nombre des classes que M. de Haller a établies, l'un en trouvant quiuze, et l'autre treize seulement. (Familles des plantes, par M. Adanson, préf., pag. 52.)

M. de Haller s'exprime, au sujet de son ouvrage, de la manière suivante: Egomet universalem stirpiun historiam non molior; non tenebar perfectam dare generum distributionem. Sufficere credidi si familiam quamlibet in duas familias disponerem, d quibus proximi distet et difficiliùs dignoscitur. Enumerat. stirp. lielv. prefat.

(2) Enumeratio plantarum horli gotting. 17亿3, Gotting.

En 175 f il tit imprimer un catalogue plus complet, avec la description de yuclques plantes nouvelles.

(3) Tin 17.36 il publia a Gotingue une mélnode pour éndier 10 Lotunignue. De methodo studii bulanici. 


\section{PIYSIOL. ET MÉD. - HALLER. 321}

enfin il a réuni en 1749 ses observations isolées sur divers geures et espèces de plantes et sur leur fiuctification, dans un volnme intitulé: Opuscula botanica.

Ce qui étonne le plus en cxaminant les productions très-nombrenses de $\mathbf{M}$. de Haller, c'est le passage rapide d'm objet à un antre. Profond et sublinte diuns plusienrs genres, il est par-tout an nireau des plus grauds maîtres, et quelquefois il les surpasse.

Ayant pris soin de faire dessiuer et graver les pièces d'anatomic les nienx préparées qui ayoient servi ì ses Icçous, il en est résulté une belle suite de planches qu'il a publiéc, depuis 1743 jusqu'en 1753, en Init caliers, avec des explications très- létaillées et des notes très-savantes (1).

Tons les matomistes conviennent que cet ouvrage est an moins anssi achevé que celui de Cowper, qu il surpasse d'aillenrs par les détails, et il ne le céde en rien anx planches pent-être un pen trop célébres d'Allinins. M. de Haller est le premier qui ait fait aperceroir tonte l'imperfection et l'insuffisance des fintres qui ne représentent qu'm genre de parties isolées. Il perise avec raison qu'il fant en indiquer les rapports et les connexions: de sorte qu"en se proposant de fairc dessiner principalement les artères dans ses Fasciculi, il a été obligé de représenter en mème temps la situation et la forme de tous les viscères du corps lumain (2). On ne peut faire qu'nn reproche à cet ouvrage, c'est qu'il

(1) Fasciculi anatomici, de $17 \mathfrak{t}^{3}$ à 1753.

(2) Dans le premier cahier on remarque une belle planche $d u$ 
ne consiste qu'en notes explicatives; ce qui fatigue beaucoup le lecteur.

La nature, dans tous les règnes, semble s'être prescrit des formes sous lesquelles elle fait constamment paroître ses productions. Cependant elle s'en écarte quelquefois, et il en résulte ce que l'on appelle des monstruosités. Les physiciens sont divisés àce sujet en deux partis : les uns, avec Harvey, Lemery, Hebenstreit et Bonnet, regardent les monstres comme étant toujours le dérangement d'un corps bien organisé dans son principe; les autres, avec Duverney, Méry, Littre et Winslow, admettent des germes primitivement défectueux. M. de Haller a réuni ses observations et ses vues sur ces écarts de la nature dans un ouvrage qui a été imprimé à Gottingue en 1745 (1), et dans lequel il s'est déclaré partisan de l'opinion de Winslow, qu'il a fortifiée par de nouvelles preures.

diaphragme et de la moelle épinière, à laquelle le doctcur Hubcrt a cu la plus grande part; dans le second, une image cxacic de toutes les branches du tronc maxillairc, jusqu'alors peu connu; dans le troisième, les ramifications nombreuses des artires de la face et celles des artères bronchiques ct $œ$ sopliagines, dout personue avant lui n'avoit parlé avec tant d'cxactitude; dans le quatric̀me eufin, l'exposition de toutes les artères de la moelle épinière et de l'ocil, dont Winslow et Heister avoient oublie des rameanx essentiels i comnoìtre.

(1) Il y a beancoup de méthode dans cet ourrage. On y trourc, dnus des sections différentes, l'exposition des monstres qui ont des partics surajontés, et de ceux auxquels il paroit en manquer jurlques-mes. En 1735 il avoit déja public un prouramme iutitule: De l'ontibus monstruosis, el ell $17\{2$ il aroit cu occasion de dissćquer phisicurs autres fuetus monsirueux. 
PHYSIOL. ET MÉD. - HALLER. 323

Ce fut en 1746 qu'il annonça ses expériences sur la respiration. Il prouva alors par des faits très-nombreux que la prenière côte est beancoup moins mobile que les attres; que les espaces intercostaux diminnent dans l'inspiration; que les denx plans de inuscles qui portent le nême nom sont également destinés ì relever les côtes, et qu'enfin ces diver's mouvennens ne deviennent bien seusibles qu'après que l'on a fait unc ouverture à la poitrine de l'animal ( 1 ).

Ce seroit icile lieu de parler des disputes qui se sont élevées entre les doctenrs Hamberger, van Swieten, de Haën, Albinus, la Metrie et de Haller : mais ponrqnoi faire ainsi survivre les persomalités aux persomnes? l'animusité doit-elle se prolonger an-dcli du tombean? Ne mèlons aucune anertumo an récit de la vie de M. de Haller. N'arons-nous pas une moisson assez ample, sans être obligés, pour augmenter sa gloire, de diminuer celle de ses adversaires (2)?

Il est entré arec MM. Whytt, Lanure, Lorry et le Cat, dans un autre genre de discussions littéraires,

(1) Il résulte encore de ses expériences que les dernières fausses còtes s'élèrent aussi dans l'inspiration; que toutes les côtes se rapprochent alors dans le milieu; que, dans les fortes inspirations, les cartilages s'abaissent, et que c'est auprès du sternum seulement que les espaces paroissent quelque fois augmenter.

Lorsqun'il fit rëimprimer les pièces qu'il avoit publiées contre Hamberger, il eu supprina tout ce qui sortoit des bornes de la modération. Hamberger lui-même fint sensible à ce procédé. Albinus le traita plusieurs fois arec peu de ménagement; M. de Haller ne Jui rćpondit qu'ì regret et toujours d'une manière honnête, comme on peut le roir dans plissieurs de ses préfaces. 


\section{4 ÉLOGES HISTORIQUES.}

dont l'amour de la vérité a été le motif de part et d'antre, et oì l'on tronve d'ailleur's ces égards et cette retenue que tous les hommes, et sur-tout les savans se doivent réciproquement.

M. de Haller, après s'être servi pendant vingt ans des Instituts de Boërrhaave dans ses leçons, publia en 1747 une physiologie de sa composition, sous le titre modeste de Prima linea physiologia. Tout est exact et concis dans cet ouvrage; l'auteur est très-réservé sur tout ce qui a quelque rapport aux systèmes. Peutêtre mêne seroit-il à souliaiter qu'il en eût parlé quelquefois, ne fût-ce que.pour les réfuter. Les élèves à l'instruction desquels ces élémens sont destinés soutiennent difficilement la lecture d'un traité où tout est serré, précis et rigoureux : car tel est la nature do l'esprit humain, que la vérité même a besoin de quelques ornemens pour lui plaire.

On doit savoir beaucoup de gré à ceux qui mettent me partie de leur gloire à angmenter celle des autres, soit en traduisant des ouvrages qu'il est bou de faire connoître, soit en réunissant des mémoires dont la collection intéresse les progrès des scicuces on des lettres, soit en faisant revivre des déconvertes oublićes. Ce travail, noins brillant gu'il n'est ntile, a été 111 de ceux auxquels M. de Haller s'est livré le plus rolontiers. Les bornes de cet éloge ne nons permetlent pas mêne de rappeler ici le grand nombre de rolumes dont il a été l'éditenr' (1).

(1) Pendant som scjour à Gottingue ea i7ff, il dunn nue élition 
PHYSIOL. ET MÉD. - HALLER. 325

Dans les préfaces qu'il a mises à la tête, soit de ses propres onviages, soit de cenx qui ont été prbliés par ses soins, et qu'il a réunies dans un volune particulier, intitulé : Opuscules allemands, ou trouve toujours des expressions choisies, des vues neures et des idées plus riantes gue daus ses antres productions. Il semble que ce travail, court et facile pour un homne qui joint de l'esprit à une érudition profonde,

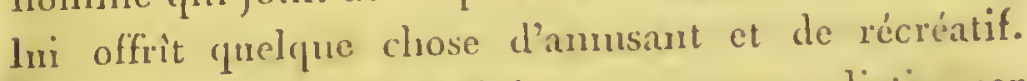
Parmi ses prófices on doit smr-tont en distinguer

trds-auginentéc d'un ourrage de Ruplu fort estime, et intitule: Flora jennensis. Dans la mème année il a public un recueil de Consultutions donnécs par Hö̈rrhane. En 17.45 il a veillés it l'édition d'un ourrage allemaud, dans lequel on a rémni tout ce qui est relatif à lhistoire des dessins et plinclies de botaniyue, et aux arlistes qui s'eu sout occupis en Allemane. En 17.6 Ir Traile de Bö̈rrlaave sur les maladies des jeux, et l'excellente collection de Breslaw ont été rẻimprinés par ses soins. Eu 17 ł7 il a donné uue edition des nowrenux jourmax de Gottingue, et il a mis en tùte. un discours qui comtient des reflexions très-sages sur la censure des limes. Il a aussi été l'éditeur en 17 (1) des poésies de Werlliof; ell $17^{50}$ de la traduction en allenand de l'histoire naturelle de M. le coute de Buffon; d'un ourrage de Formey, intitulé : Triomphe de l'évidence; et d'une Collection de royages, dont il a développé les vues politiques dans une préface en langue allemande. Nous ajoutcrons ici, afin de ue pins revenir sur ce genre de traraux dont les détails nombreux fout naitre dans cenx qui en prennent comnoissance me partic de cette fatigue que l'auteur de tant d'ouvrages a dî éprouver, les éditions du bel ourrage de Rocsel en 1758, celle du Dictionnaire d'histoire naturelle par M. Valmont de Bomare en 1768; celles d'Hippocrate, d'Aretée, d'Alexander Trallianus et de Celse, qui ont paru en $1768,177^{1}, 177^{2}$ et $177^{3}$; et enlin celle de l'ourrage du baron de Sind sur l'art vétérinaire, faite en 177 if a Gottingue. 
une (1) dans laquelle il s'entretient avec M. Guettard, son ami, sur les rapports qui se trouvent entre la tem. pérature de la Suisse et celle du Canada.

L'art difficile de l'enseignement étoit celui que Boërrhave possédoit au plus haut degré : on l'a peut-êtro égalé dans les autres genres, disoit M. de Haller; mais personne ne communiquoit ses idées avec autant d'élégance et de netteté.

Ce jugement doit nous rendre bien précieux les préceptes de ce grand professeur sur la manière d'étudier les différentes parties de la médecine. L'ouvrage dans lequel ils sont consignés a été beaucoup augmenté par M. de Haller. On trouve dans l'édition qu'il en a donnée en deux volumes in-4.0 en ${ }_{17} 51$, un nombre prodigieux d'auteurs à consulter sur cliaque matière. L'absence ou la présence d'une ou de plusieurs étoiles désigne le degré d'approbation que mérite chaque ouvrage. M. de Haller auroit peut-être mieux fait de garder le silence sur les auteurs vivans, parmi lesquels plısienrs ont été choqués de ce que l'étoile ne s'est pas arrêtée sur cux. Des jugemens semblables sont ell effet trop précipités, et ceux qui les portent, quels qu'ils soicnt, méritent des reproches, en ce qu'ils anticipent sur les droits de la postérité.

Un des projets les plus utiles que M. de Haller ait formés a été celni de rénnir en 1 m corps d'ourrage les dissertations que charque Faculté publie, et dont

(1) Celle qui précéde l'édition allemande de l'Histoire naturelle de M. le combe de Bufon mérice aussi d'êre vemarquéc; elle a été elle-meme publićc en fraugrais. 


\section{PHYSIOL. ET MÉD. - HAILER. 327 \\ peu de personnes profitoient auparavant. Il fit im-}

primer celles qui sont relatives à l'anatomie, en huit volumes, celles qui concernent la chirurgio en cinq vol. in $-4 .^{\circ}$, et celles dont la médecine pratiquo est le but principal, et qu'il ne trouva pas en aussi grand nombre qu'il l'avoit imaginé, en sept rolımes: ce travail l'occupa pendant dix années, depnis 1747 jusqu'en 1756.

Denx propriétés particulières aux fibres animales, la sensibilité et l'irritabilité, sont tellement confondues entre elles qu'il étoit très-difficile de les distinguer et de déterminer leur étendue respective. Depuis longtenups M. de Haller méditoit sur cet oljet inportant lorsqu'il publia, étant ì Gottingue en ${ }^{7} 7^{51}$, ses premiers aperçus à ce sujet, auxquels il a domué tout le développement nécessaire eu 1755 et en 1759 . La famille nombreusa des polypes lui avoit offert des phénomènes d'une irritabilité portée an plus haut degré, sans que l'on y trouve ni cerrean ni nerfs. 'Les vers, très-contractiles, dans lesquels les nerfs sont d'une témité excessive, lui avoient présenté une nuance de plus dans leur structure ; il aroit remarqué que les parties qui se meurent le plus souvent et avec le plus de force, telles que le cœur, reçoivent peu de nerfs, et sont peu sensibles. Des expériences très-multipliées lui avoient appris que la contraction, soit naturelle, soit excitée par des stimulans mécaniques; et la sensibilité, sont distribuées inégalennent, et que leurs proportions sont très-différentes dans les corps organiques. Il avoit poussé l'exactitude jusqu'à en détermi- 
328 ÉLOGES HISTORIQUES.

ner l'ordre et les variétés dans tous les organes; il s'étoít assuré que les nerfs, qui sont le siége inmédiat de la sensibilité, ne se resserrent par ancun stimulant coniun; enfin l'effet de certaines maladies étant ou de détruire le monvement dans une partie sans qu'elle cesse d'être sensible, ou la sensibilité sans que le monvement en souffre, il s'étoit convaincu de plus en plus que ces deux modifications de la matière doivent être distinguées avec soin l'une de l'autre.

M. de Haller avoit conclu de ces différentes expériences et observations que la fibre sensible et la fibre irritable diffèrent entre elles autant que la sensation diffère dı mouvement, et qu'il existe dans les animaux uné force particulière, qu'il a désignée sous le nom d'irRitta bilité.

Ce principe est devenu fécond entre ses mains; il lui a servi pour expliquer de la manière la plus natırelle les mouvemens alternatifs des cavités du cœur, et les ondulations péristaltiques des intestius.

L'envic a fait des efforts inutiles pour lui enlever la gloire de cette découverte. Le mérite de son travail consiste dans l'exactitude, dans le nombre et dans la concordance des expériences qu'il a tentécs. Il n'a jamais prétendu avoir dit le premier que le cour et les intestins se contractent lorsqu'ils sout irrités, non plus que Newton 11'a point découvert les premiers effets de la gravitation; mais ces denx grands lionmes ont aperçn des lois générales, et ils ont classé des phénoménes dont les rapports éloient inconmus avant enx. Observons ici qu'il y a plusieurs espèces de décourertes: 
PHYSIOL. ET MÉD. - HALIER. 329

les unes sout dues au hasard ou à l’adresse; les antres sont le fruit dı génie : il est facile de voir dans quel ordre celle de M. Haller doit être rangée.

Indépendaminent de ces grands travaux qui l'ont occupé penulaut son séjour à Gottinghte, c’est-it-dire depuis 1736 jusqu'eu 1753 , il a publié plusieurs autres dissertations qui auroient suffi pour lui nuériter la réputation la plus brillante. Il a dumé des détails trèsintéressans sur la nuaniere dont le sinng circule dans la propre substance du coeur, sur la forme de la valvole d'Eustaclic, considéréc dans les diffírens ìges; sur. la nuenbrane noyenne du fortus, et sur l'espéce de tissu qui réunit le chorion avec l’utérns ; sur les prixcipales racines du réservoir du chyle; sur la mentrane pupillaire découverte par IVacheudorff, et qui bouche l'onverture de la prunclle de l'oil dn foctus avant le sixiène mois; sur l'origine dn nerf intercostal, qui ne communique point avec le nerf ophthalmique; sur certaines productions de l’épiploon voisines dı cœcum ; sur la sensibilité respective du cervenu et du cerrelet; et sur le monvenent découvert par Schliting, que la respiration communique à ces deux organes.

An nuilien de ces occupations M. de Haller troura le temps de former phusienrs établissemens qui manquoient. à Gottingue. Il obtint en $17^{51}$ que les chirurgiens qui n’étoient point rémis en corps fussent érigés cu collége, et il cu fut nommé présidcut. Il le fut aussi de la Société de Gottingne, dont il rédigea les règlemens. On dut ì son crédit l'établissencnt d'un hôpital destiné aux accouchemens, dans lequel on euseigne 
330 ÉLOGES HISTORIQUES.

cet art si important pour l'humanité; il réunit dans un cabinet des préparations d'anatomic très-curieuses, et dont plnsicurs ćtoient son ouvrage. Finfin il fonda une écolc pour des artistes destinés à peindre ou à dessiner des plantes et des animaux; institution dont if n'y a jamais eu d'exemples, et qui prouve combien il avoit mis l'anatomie et la botanique en vigueur à Gottiugue.

Des travaux aussi multipliés et aussi utiles acquirent à M.de Hallcr une très-grande célébrité. Presque toutes les académies de l'Europe s'cmpressèrent de se l'associer. Il reçut aussi de sa patrie une marque de considération à laquelle il fut très-scnsible: en 1745 la république de Berne lui conféra une place dans le conseil souverain.

Georges II, alors roi d'Angleterre, prenoit la plus grande part aux succès de M. de Haller. Étant à Gottingue il le combla de ses bontés: déja en 1739 il l'avoit nommé son premicr médecin dans l'électorat de Hanovre; il lui donna le titre de consciller aulique et demanda pour lui à l'empereur des lettres de noblesse qui furent expédiées de la manic̀re la plus lionorable le 29 avril 1749 . M. de Haller savoit sans donte que l'estime et la considération publique sont des titres supéricurs à cenx que donne la convennnce; mais il respecta les intentions de son bienfaiteur, et il n'eut pas assez d'annonr-propre pour s'y refuser.

Il est cependant une qualité qu'il u'at jamais pu se résoudre à accepter, cquoiqu'elle lui ait été prodignéo tant de fois: c'est celle de baron. On ne peut qu'ap- 


\section{PHYSIOL. ET MÉD. - HALIER. 331}

plaudir à cette modestic. En effet, outre que le nom des savans se répète trop sonvent pour être ainsi sulchargé d'épithìtes et de longueurs, quel titre, dans un pareil assemblage, n'est pas effacé par le nom d'un grand homme? MM. ses fils ont eu la mène délicatesse. Le nom de Haller est pour enx un bien qüils ne veulent altérer par aucur mélange.

Différentes universités envièrent à celle de Gottingue la gloire de posséder M. de Haller. Le cúlébre Tillenius le désigna en 1747 pour ètre son successenr dans la chaire de Botanique à Oxford. L'ammée suirante il fut vivement sollicité pour se fixer à Utrecht en qualité de chancelicr de l'Université, et peu de temps après un prince qui cultive les lettres et qui aime les savans lui proposa les conditious les phus avautatagenses, et la présidence de l'Acarlúmie de Berlin; mais il fint incebranlable.

Il n'y avoit qu'un seul pays que M. de Haller pût préférer à Gottingue, c'étoit sa patric. Il y retourna en $17^{5}$ lorsqu $u^{1} i l$ s'aperçut que ses forces ne pouvoient plus snffice anx travanx dont il été surchargé (1). Son retour à Berne y répaudit la joie la plus rive; peu de temps après, comme membre du conseil souverain, il obtint par le sort la place de gouvernenr de la maison de ville: de sorte que le hasard sembla oonspirer cette fois arec le rou de la uation pour récompenser ce grand homme.

(1) Les trois chaires qu'il occupoit is Gottingue ne lui laissoient point assez de temps pour exécuter les nrands projets qu'sl aroit formés. 
Tout autre que $M$. de Haller se seroit reposé aprés tant de fatignes. C'étoit beaucoup à la vérité d'avoir abandonné les fonctions de professetir et les travaux de la dissection. Le gouvernement de Berne, glorienx d'aroir recouvré un citoyen illustre, et dont les talens deroient lui appartenir, l'employa pendant plusieurs amnées à faire des voyages utiles en même temps au public et à sa santé (1). Mais il reprit bientôt la suite de ses occupations littéraires. Un an après son retour à Berne il publia un recueil d'observations de médecine pratique, intitulé : Opuscula pathologica, dans lequel il a consigné des faits très-curieux et trèsdignes d'être conservés (2). Nous insisterons princi-

(1) En ${ }_{17} 73$ et en ${ }_{275}$ il parqurut plusicurs cantons de la Suisse, el sur-tout les montagnes du gouvernement de Laigle, ponr y chercher de nonvelles sources d'eau salée : celles qu'il y trouva lui parurent trop foibles pour mériter l'attention de la république. En ${ }_{17} 75$ il fui député avec M. Bonsteller à Lausanne pour donner de nouveaux règlemens à l'académic de cette rille. En 1758 il fut envoyé à $\mathrm{Knlm}$ pour examiner des morceaux antiques très-curicu. qui y avoient été tronvés, et dont M. Sclımidt a donné rejunis une descriptiogn intéressante.

(2) Le cervelet, trouvć squirrenx dans un sujet dont les fonctions animales avoient peu souffert; les simus dn cerreau, remplis de claqque còté d'un fluide ân nature différente; le poumon tout gorgé de sang épauclié dans les bronclies à la suite d'une périjuenmonie très-aignë; ce viscère adherent dans presque tous ses points arec la plèvre, saus qu'il en ait résultć une grande gêne pour la respiration; une ligdropisie enkistće de la plère; l'oblitération entic̀re d'une des artìres carotides internes, et d'une veine. jugulaire, la description des hernies de unissance; des expériences qui prousent que tous Ir.8 ralculs de la résicule du fiel ne sont pas induminables; une concrétion calcaire sortic du sein; une 


\section{PHYSIOL. ET MEDD. - HALLER. 333}

palement sur la description d'une épidérnic contagieuse yui parut en 1762 aux environs de Berne, dans le diucèse d'Etives et dans le canton de Gruycieres. Celte maladie se masquoit sous les apparences d'une plenrésie bilieuse, it la guérison de lacquelle les saignées étoient très-contraires. M. de Haller établit mue méthode de traitement qui ent le plus grand succès. Ce trait de sa vie nous est d'intutut plus précicux gutil le rapproche davautage de nos occupations.

L'électricité médicale, rendue maintenant si intéressante par M. Mauduyt, qui, après aroir douté long-temps de ses succés, a élé forcé de les recomoitre, fixat aussi l'attention de MI. de Haller' (1). Il essitya de gnérir lit surdité d'un de ses parens cu lui tirant des étincelles et en lut faisant receroir des commotions; ce qui fint continué pend.unt vingt jours. Quoiqu'il se soit déconragé trop tôt, on s'aperçoit par son récit que la surdité du malade diminnoit seusiblement. Pour cette fois M. de Haller ne mit point dans son travail toute la patience et la circonspection qui lui ont si sonvent réussi, et il porta un jugenent trop

espece de calcul trouré dans une des carités du cour; le sang ru a la snite d'une inflammation, absolument hors des vaisseanx et répandu dans le tissu cellulaire sous la forme d'herborisation, et un tableau de comparaison entre les syuptòmes de la petitererole inoculèe, et de celle qui régna en 1735 a Berne, sont des observations de la plus grande importance, dout nous laissons aux geus de l'art ì tirer les résultats.

(1) L'expérience par laquelle Daniel Bernonilli aroit assuré qu'en tirant des étincelles des oiseaux noyés on peut les rappe. ler à la vie, ne lui riussit point. 
précipité contre l'électricité médicale qu'il n'avoit pas assez suivie.

Éloigné de l'amphithéâtre d'anatomie et du jardin de botanique de Gottingue, on seroit tenté de croire qu'il avoit renoncé à ces deux genres d'étude. Mais il trouva des plantes dans la campagne, des amplibies et des poissons dans les étangs, des quadrupèdes dans les parcs, et il fut amplement dédommagé. Alors il recommenca ses herborisations et ses dissections anatomiques, et il fit sur la circulation, vue au microscope (1), sur l'accroissement des os (2), sur la

(1) Ses expéricnees, faites avec le microseope sur la circulation, pronvent que les globules rouges sont en grand nombre dans les animaux robustes et bien portans; qu'ils sont quelquefois séparçs les uns des autres par un fluide transparent et concrescible; que ces globules sont de forme ronde, et qu'ils ne jouissent d'aucun mouvement de rotation; qu'ils se moulent sur la grandeur des vaisscaux qu'ils parcourent; qu'ils se précipitent vers le licu où l'on a fait une ouvcrture; que tous les courans s'y dirigent; que les vaisseaux paroissent quelquefois n'être pas tout-à-fait remplis; que l'épaisseur des parois surpasse dans certains cas l'étendue du calibre; que la eirculation peut se fitire et s'entretenir avce un fluicle tout-î-fait sćreux, et substitué au sang; et qu'enfin le sang veineux et le sang artériel diffèrent bien peu l'un do l'autre.

(2) Dethlef, alors élève de M. de Haller, fut spéciatencme chargé de suivre ecs expériences. La structure du périoste est suivant lai très-différente de celle des os. Cetıe membrane n'a point d'usage plus important que toutes les antes cxpansions membranenses du corps lumain. Le premicr noyau d'ossification qu'un cerele vasculaire envirounc est toujours plncé on milieu d'un cartilage, sans que le périoste y participe. lenfin la coulcur que la garance donne aux os ne so: borne point à la surface; mais elle 
PHYSIOL. ET MED. - HALLER. 335 génération (1), sur le cerveau et sur les yeux des poissons et des oiseaux (2), des observations qu'il publia depuis $17^{56}$ jusqu'en 1765.

Lors même que M. de Haller étoit retem chez lui, il y trouvoit encore des objets dignes de tonte sa curiosité; son activité savoit tont mettre à profit. Alors il. cherchoit dans l'œuf' la structtre fine et délicate do ses nembranes, leur circulation, leurs duplicatures,

pénetre tout leur tissu. Tels sont les résultats de leurs travaux, qui, comıne on le sait, ne sont pas d'accord arec ceux que l'illustre M. Duhamel a obtenus en $1739,17\{1,17\{3$ et $17\{6$.

(1) Les expériences de M. de Haller sur la génération ont été faites en grand comme celles d'Aristote et de Harrie : c'est la troisidme suite que nous ayons de faits recueillis sur cet objet important. M. de Haller a sacrifié des brebis, des clievres, des vaches qui ont été disséquées ì différentes époques depuis le moment ou elles avoient éti couvertes. Ces recherches nous ont appris que les vésicules des oraires, qui se trouvent mème dans les vierges, ne sont point des œuઈs; que la liqueur qui en sort, pl qui prend ensuite de la consistance, paroit plutòt en tenir lieu; que le corps jaune se torme des debris de la vésicule rompue, et que les trompes ont un mouvement de contraction tres-considérable.

(2) M. de Haller n'a point trouré de circonrolutions, ni de corps calleux, ni de tubercules quadrijunaux dans le cerveau des oiseaux: leur cervelet est très-petit, et les couches optiques sont trèsgrandes. Il $\mathrm{y}$ a beaucoup de poissons dans lesquels on ue trouve point de glande pinéale : dans ces derniers la glande pituitaire fournit des nerfs, et les couches optiques sont excavées. On observe dans leurs yeux un muscle annulaire; la rétine $y$ est dirisée en trois lames, et le corps vitré est entouré d'un cercle vasculaire.

Mémoires de l'Académie royale des sciences, année 1762 . 


\section{6 ÉLOGES IISTORIQUES.}

lenrs rapports avec le germe et les développemens de ce demier, qu'il a beaucoup mieux connus que Malpighi, et qu'il a démontrés en 1757 d'une manière nouvelle. Si ces découvertes en ce genre sout un jour constatées, on pourra dire avec le savant $M$. Bonnet qu'il étoit réservé à $M$. de Haller de trouver dans un œuf la solution du grand problème de la génération.

Il a ajouté les observations suivantes à ce qui a été dit avant lui sur le développement du poulet (1) dans l'œuf. Lorsque le poulet commence à paroître aux yeux de l'observatenr, ses viscères sont très-écartés les uns des antres, et c'est dans leur rapprochement que consistent les premiers progrès de sa formation. Il est alors comme composé de deux' corps distincts, dont l'un est formé par les extrérnités, par la tête, la poitrine et le ventre; l'autre résnlte de l'union des intestins, qui font une saillie très-remarquable avec la membrane ombilicale et le jaune. Leurs vaisseaux sout communs; le pliarinx, l'estomac, lesintestins du poulet et le jaune de l'œuf sont absolument continus: d'oì il conclud, en étendant ces considérations anx autres animaux, que le fotus appartient entièrenent it la femelle, et qu'elle a par conséquent la plus grande part à la

(1) Aristote a vu le premier les mouremens que le cocur du poulet cxécute lorsque, tout érant encore transparent, ils paroissent comme un éclair qui fait son explosion an nilieu d'un fluide. C'est ce qu'on désigne sous le $u$ non de punçum saliens. Allovraude a décrit les insularanes dre l'ouf. Harvér al vu les dillérentes périodes de la formation du cour ; le cerele vasculaire du jaune a éré décrit pur Nicolas Stcnon, et en 1660 Malpighi a domué nue Jescrip. tion plus suiric de l'auf' et du ponlet. 
PHYSIOL. ET MED. - IIALLER. 337 reproduction de l'espècc. Ce système plaira sans doute au sexe qui nous prodigue daus l'îge le plus tendre tant de caresses et de soins, et anquel nous derons un juste tribut d'amour et de recomoissance.

Les travaux nombremx dont nous avons rendu compte ne devoient pas rester isolés : c'étoient autant de matériaux destinés à former un vaste édifice dont M. de Haller avoit tracé le plan, dix ans auparavant, dans son Abrégé de physiologie. Il comnença l'exécution de ce projet en 1757 , et clle fut terminée en 1766. Hurit volumes in- $4 .^{\circ}$ lui suffirent it peine pour exposer ses connoissances sur le mécanisue du corps lumuain. Dans cet ourrage, le plus complet sans donte que nous ayons sur cette natiere, et que l'on peut regarder comme un modèle pour tous les genres; il règne par-tont un ordre étonnant. Les détails des phénomènes, les descriptions anatomiques, l'histoire des découvertes, celle des erreurs de l'esprit lumain célébrées sous le nom de systèmes, tount y est méthodique, tout y est complet. Une rérolution henrense et presque universelle s'est opérée dans la plyysiologie lorsque ce traité a paru. On a abandonné ces vaines suppositions dont l'ignorance on l'liabitnde ont prolongé si long-temps la durée, et l'on a ru la partie élémentaire de notre art changer absolument de face en se dépouillant des richesses imaginaires dout elle étoit surchargée, pour ne recueillir que des faits, et pour jeter avec lenteur, mais arec sûreté, les fondemorus d'une sage théorie.

Ce fut pour se délasser de ces grands traraux quie T. 2. 


\section{8 ÉLOGES HISTORIQUES.}

M. de Haller s'amusa en $177^{2}, 177^{3}$ (1) et 1774 a rédiger ses réflexions sur la meilleure forme possible des trois principanx gouvernemens. Il les publia en trois volumes, qu'il appela ses Romans (2). Ceux qui, trompés par ce titre, y chercheroient des frivolités, seroient bien surpris de n'y trouver que des vues d'administration très-sages, des vérités politiques qu'il a osé dire sous ce déguisement, et sur-tout la morale et les lois en action.

Pell de temps après, il a rédigé plusieurs articles pour le Supplément du Dictionnaire encyclopédique. On en trouve dans les journanx allemands de Gottingue plus de quinze cents dont il est l'auteur.

Les derniers ouvrages qu'il a fait paroître sont ses Bibliothèques de botanique, d'anatomie, de chirurgic et de médecine pratique, en huit volımes in $-4 .^{\circ}$, depuis $177^{2}$ jusqu'en 1777. Un de ces volumes sur

(1) En $177^{3} \mathrm{M}$. de Haller consigna parmi les Mémoires de la Société éconounique de Berne des réflexions très-sages sur la nature de l'épizootic qui a fait depuis quelques amnées tant de rarages en Europe. Il prouva qu'après s'être douné beaucoup de peine pour la détruire en Suisse, la contagion y étoit toujours applortée des frontieres de la France, oì l'on n'avoit pas encore pris des unesures assez, efficaces pour en prévenir la reproduction; et il citablit la récessité des moyens que la Hongrie, les Pays-13as autrirliens, le Brabant, la Suisse et la France emploient actuclleuent de concert.

(2) Ces romans sont Usoug, Alfred, ct Fabius el Cattun. Les derux premiers ont ete traduits en Iranģais, et ils doment In plus hante idlue des connoissances de M. de Haller daus l'bistoire rt daus lia pulirique. 
PHYSIOL. ET MÉD. - HALLER. 3339 la chirurgie est dédié à M. de Lassone, président de cette compagnie, pour lequel il aroit beacoup d'amitić. Possesseur d'une immense collection de livres choisis en tont genre, dont il ne ponvoit se flatter de faire un long nsage, il vonloit jouir du plaisir de les parcourir encore une fois : il voulut rendre anx sciences un dernier hommage, et aux savans un dernicr service, en indiquant les sources où il aroit puisé avec tant de succes.

La république de Berne donna en différens tenups à M. de Haller plusienrs places dans ses tribunaux, et des cunplois dont il s'est tonjours acquitté arec le plus grand zèle (1). La direction de la province de Roche (2) lui fut donnce en 1758; en $17^{62}$ il firt nommé gouvernenr dn canton de l'Aigle (3), anquel il rendit des services importans. La rédaction àn code des lois de cette république fut acherée par ses soins, et il détermina par des essais faits en grand, qu'il communiqua en 1764 à l'académie royale des sciences, la meilleure manière de préparer le sel par évaporation.

C'étoit un singulier spectacle que de roir l'administration des salines et dı sel en Suisse confiée à un savant qui ne s'occupoit que du soin de simplifier les

(1) En 1766 il fut nommé membre du conseil des appellations.

(2) Cetle direction raut 15,000 lir. argent de France; il fajsoic alors imprimer sa grande Physiologie; il y passa six ans.

(3) La description que D.I. de Haller a faite des salines de l'Aigle, n élé traduite en français par M. de Leuze. 


\section{0 ÉLOGES HISTORIQUES.}

opérations par lesquelles on l'obtient, d'en augmenter l'abondance et la pureté, et de le rendre moins coûteux au peuple. On peut dire que M. de Haller a fourni un bel exemple à ceux qui sont chargés de ce département dans les autres royaumes de l'Europe (1).

Les orphelins devant être regardés comme les enfans de la patrie, M. de Haller donna en 1757 le projet (2) d'une maison d'éducation destinée à les recevoir, et dans laquelle les enfans des citoyens pauvres devoient aussi être admis. Il en a été directeur pendant plusieurs années. La république de Berne a de plus établi, d'après son projet, une école où la jeunesse patricienne est instruite dans tous les genres aux dépens du gouvernement, et il a désiré qu'un de ses fils, qui est le plus jeune, y reçût son éducation. Il eut une autre occasion de se montrer juste et bienfaisant. Le clergé du pays de Vaud étoit rédıit depuis long-temps à uue détresse extrême : M. de Haller, qui fut nommé commissaire pour en prendre commoissance, obtint du gouvernement une pension extraordinaire en faveur

(1) Les troubles de la république de Genève et l'établissement de Versoy avoient répandı des inquiétudes en Snisse. On fornta ì ce sujet un conseil seeret composé de quatre personnes. Outre que $M$. de Haller fut un de ecs eommissaires, il rédigea tous les méuoires, et il fut chargé d'aller it Soleure pour s'aboucher avee l'anbissadenr de France. Déja en 37.58 élant à Roehe, il aroit ıerminé plusieurs différens qui s’étoient êlevés au sujet des coufius entre le gonveruement de Borne ct la république du Valias.

(2) Il publia un hecueil de mémnites relatifa at ret éloblissement en ${ }^{7} 58$. C'est mu des projets dont l'execution ladi a cite te plus ygréable. 
PHYSIOL. ET MÉD. - HALLER. 34 L de ce clergé (1). Il savoit que les ministres des antels doivent être sur-tout riches de lenrs vertus, respectahles par la pureté de leurs mœurs et chéris par leurs bienfaits; il savoit que la pauvreté leur sied encore mienx que le luxe et l'opulence : anssi ne vouloit-il pas les eurichir. Son but étoit senlement de pourvoir à leur subsistance, et de les mettre ì portée de fournir à celle des paurres, qui ne peurent atteudre des secours que de ccux qui en connoissent la nécessité.

Le vide que M. de Haller avoit laissé ì Gottingue fit désirer vivement son retour dans cette ville. Le roi d'Angleterre lui offrit it diverses reprises les conditions les plus avantageuses, et, afin de le déteruniner plus facilenent, il écrivit it la république de Berne pour l'engager it faire ce sacrifice. L'impératrice de Jhussie fit anssi tous ses efforts pour l'altirer à Pétersbourg. Cette princesse se sonvenoit saus donte que le czar Pierre avoit consulté Leibuitz sur la ronstitution de ce nouvel empire; elle étoit bien sûre de tronver dans $M$. de Haller un savant et en mème temps in homune d'état. Mais quelle jouissance pent suppléer à celle gu'un citoyen éprouve daus le sein de sa patrie lorsqu'il en est estimé, et sur-tout lorsqu'il a le bonlieur de lui ètre ntile? $\mathrm{M}$. de Haller resta donc attaché à la républiqune de Berne, qui lui en marqua sa recomoissance enlui faisant une pension extraordinaire.

En 1776 le roi de Suède le nomma chevalier de

(1) La république lui accorda un fonds d'un million argent de France. 


\section{2 ÉLOGES HISTORIQUES.}

l'étoile polaire, premier ordre de ce royaume, mais qu'un particulier peut obtenir lorsqu'il a les talens de Linnæus ou de Haller.

L'empereur, qui connoît tout le prix des sciences, et qui recherche avec tant d'empressement les grands hommes, se détourna, dans son dernier voyage pour rendre une visite à $M$. de Haller et pour s'entretenir avec lıi. Il le trouva accablé d'infirmités, et pour ainsi dire au lit de la mort. Le prince et le philosophe furent également émus par cette situation. L'entrevue fut longue, et ils se quittèrent avec un sentiment profond de satisfaction et d'estime. L'empereur, pelı de temps après son retour à Vienne, envoya à M. de Haller plusieurs bouteilles d'un rin trèsprécieux, et une certaine quantité d'excellent quinquina qu'il prévoyoit pouvoir être utilement,employé dans le traitement de sa maladie; mais il n'étoit plus temps : M. de Haller étoit mort quelques jours arant l'arrivée de cet envoi. Il fut ainsi privé du plaisir de recevoir de la part d'un souverain un présent sans faste, et qui, au lieu de porter l'empreinte de la grandeur, n'offroit que celle de la bienfinsance et de l'humanité. L'emperenr a appris avec beaucoup de peine la mort diı savant que nous regrettons, et, jalonx d'en recueillir les restes, il a ordomé que sa bibliotliènue seroit achetée à ses frais, et transportée ì Milan.

La santé de M. de Haller avoit été très-foible jusqu'd vingt ans (1) : is vingt-huit ans, il devint tris-

(1) Il érsir si frible dans son cnfauce qu'il n'avoit pas asscz de 


\section{PHYSIOL. ET MÉD. - HALLER. 343}

robuste; il fut cependant toujours sujet à de fortes nigraines. En 1776, l'humenr goutteuse dont il avoit essuyé les attaques les plus violentes dinus le pays d'Aigle et à Bcx, se porta sur sa vessie, et lui fit éprouver plusieurs inconmodités qui l'obligèrent ì rester absolument cliez lui. L'opium, lont il abusa, firt le seul remède capable de calmer les douleurs cu'il ressentuit : toujours obscrvatemr, aucun des effets de ce remèden'a éclıppé ì son exactitnde; il en a consigné les détails, ainsi que ceux de la maladie qu'il a épronvée, parmi les mémoires de la société de Guttingne. Dans mincorps épnisć sou ane conservoit lonte sa vignenr. Il projeta alors, et il acheva mème an nulien de ses doulen's, lis seconde édition de sa grande Pliysiologie, sous le nom de Funciones corporis humani, de sorte qu'il n’a presque rieu laissé d'incomplet. Il semble que la mort, qui rópargne pas les grands homnes, mais gui n'a ancune prise sur leurs ouvrages, ait respecté cenx de MI. de Haller en lui domnant le le temps d'y mettre la demière main ( 1 ).

Voyant ses forces dimimer de jour en jour, et

furce pour se livrer aux jeux et aux amusemens de son ìge. Pendant son sejjour ì Gotningue il éproura plusienrs fièrres putrides que l'oreur des cadavres occasionna. En 1753 il fut attaqué d'une fièvre miliaire qu'il contracta auprès d'un ami dont il prenoit soin. En 1775 nue unaladie de poitrine le réduisit à l'état le plus fâcheux; il conlinua cependant de présider aux séances de la Sociéré économique de Berue.

(1) Sa Bibliothèque de médecine pratique n'est pas entièrement achevéc, et il se proposoit de publier aussi une Bibliothèque de plżsique. 


\section{4 ÉLOGES HISTORIQUES.}

l'écoulement d'une plaie qui s'étoit ouverte à une de ses jambes augmenter considérablement, il s'aperçut bien qu'il falloit succomber à tant de maux. Désirant en conisoître le terme, il conjura le docteur Rosselet, médecin célèbre de Berrie, et son ami, de lui parler à ce sujet sans déguisement. Comment cacher la vérité à un homme qui a toujonrs eu tant de passion pour elle? L'ami qu'il avoit consulté répondit à sa corifiance et fixa cette époque à la fin de l'automne : M. deHaller l'entendit, lui serra la maiu, et continua de partager ses momens entre des occupations littéraires et des exercices do piété qui lıi avoient tonjours été trèsfamiliers. Un moment avant d'expirer ayant voulu saroir par lui-même quel étoit l'état de son pouls, il dit à M. Rosselet: « Mon ami, l'artère ne bat plus ». Il aperçut ainsi le moment où il alloit cesser de virre, et il mourut, le 12 décembre 1777, âgé de soixanteneuf ans.

Il s'étoit marié trois fois : il ćpousa en 1731 madeinoiselle Marianue VVys, fille du seigneur de Mathod, et il la perdit en 1736 , quelques mois après son arrivée à Gotlingue. C'est elle qu'il a célébrée dans ses poćsies sous les noms de Doris et de Mariaune ( 1 ).

En 1738 ses amis l'engagèrent à épouser madenoiselle Elisabeth Buiher, fille de M. Burilier, conseiller

(1) Il cst impossible de resscutit un amour plus délicat et plus pur que celui qu'il éprouva pour elle; ct l'on ne peut avoir le racur déchiré par des regrets jlus vifs que ceux qu'il a exprimes dans son ode sur la mort de cette ćpouse chéric. 


\section{PHYSIOL. ET MÉD. - HALLER- $3: 45$}

d'état, et bamneret à Berne; elle nourut peu de temps après. Enfin en 1741 il se naria avec mademoiselle Sophic-Amélie Tcichmeyer, fille du doctenr T'eichmeyer, conseiller anlique et professeu de médecine à Yena. Ces trois mariages se sont snccédés rapidement, et les deux odes sur la mort de ses deux femmes, placées à la suite l'une de l'antre dans ses poésies, offrent une contradiction apparente. Mais un saraut qui se renferme daus sa bibliolhèque, loin de tonte société, peut-il se passer d'une compagne qui rende sa solitude aimable? N'ayous pas an reste l'air de le justifier d'une suite d'actions hounêles : cette délicatesse rigonrense que trois mariages semblent offenser, a souvent elle-nueme besoin d'indulgence.

M. de Haller étoit père d'une nombreuse famille. Il a en onze enfaus, vingt petits-fils, denx arrièrepelits-fils, anxquels il a laissé avec son lórilage sou nom et son excuuple.

L'un de ses fils est membre dı conseil souverain et lieutenaut ciril et criminel à Benc; le second, qui jouit d'une estime générale, est ì la tête d'une des principales banques de Paris arec M. Girardot; le troisième est officier daus lo régiment d'Erlac, actuellement en France; le quatrième se destime à l'étude des lois, et tous ses gendres occupent en Suisse des places importantes ( 1 ).

(1) M. de Haller auroit pu acquérir une grande fortune; il a récn riche de ses travaux et des bienfaits de sa patrie. Deux seigneuries peu considcrables et sa bibliothèque sont la plus grande 
M. de Haller a rempli rigoureusement les devoirs de sa religion, qui étoit la réformée; il a publié plusienrs traités pour la défendre; on lui doit même une bonne édition de la Bible. En 1747, La Méthrie ayant voulu lui dédier un ouvrage intitulé L'homme machine, non seulement il refusa cette dédicace, mais il déclara, dans le Journal des Savans et dans la Bibliothèque raisomnée, qu'il ne reconmoissoit point pour son ami l'auteur de semblables assertions (1).

partic du bien qu'il a laissć à ses enfans. Les places qui lui fur nt conférées, et dont plusieurs étoient trés-lucratives, le mirent dans le cas de faire ces acquisitions. Si la mort l'aroit enlevé à son retour de Gottiugue, étant alors âgé de près de cinqurante ans, il auroit laissé ses enfans absolument. sans fortune et à la charge de là république, à laquelle il n'aroit encore rendu presque ancun serrice. Cette iclée ne se présenta jamais à lui sans hii arracher des larmes.

Le roi d'Angleterre lui faisoit une pension dont la république luj permit de jonir; car en Suisse un eitoyen ne peut accepter ancun bienlait d'une puissanec étrangère sans la permission du sénat.

Parmi les amis qui lui ont toujours été tendrement altachés MII. Werlbof, lonnet, Stalin, Gesuer, Rosen, Tissot et Herrenselwwand ont tem le prenticr rang.

Ses élèves les plus cliéris ont été MIIT. Zimmermann, actuellement it Hanovre, oir il remplace feu MI. Werllof; Zin, Meckel, Hubert, le baron d'Asch, Langhans, Dethlef et Sproëgel, parmi lesquels il u'y en a aucun qui ne se soit montré digne d'un pareil maitre, et qui n'ait foit ses prenves.

(1) M. de Haller a toujours vécu de la manière la plus solure et la plus frugale. Il mangeoit pen de viande et ne buvoit. que de l'eau; aussi, dius son Poëue sur les Alpes, loin de plaindre les habitans de ees montagyers de er que la vigne ne croit point dans leur elimat, il regarde ceflo privation commo un bienfait de la nalure. 
PHYSTOL. ET MÉD. - IALTER, 347 M. de Haller écrivoit et parluit l'allemand avec beancoup d'élégance et de pureté. Le doctenr Heyne, célèbre professenr d'éloquence ì Gottingue, assure mêne qu'il a perfectionné et simplifié les tonrs de cette langne, et qu'il l'a enrichic de phisicurs ('xpressions nouvelles. Il savoit anssi le français, l'anglais, l'italien, le danois, le hollandais et le suédois, et il écriroit dans tontes ces langues inx sarans de ces divers pays (1).

On convenoit unanimement ì Berne que personme ne connoissoit mienx que lui a constitution politique de l'Europe, et sur-tont celle de la république. Cependant il ne fut point adnis dans le sénat on petit conseil. Si cet oubli l'afiligea pendant quelques annces, il ne fant pas pour cela, comme quelques-nns l'ont fait, l'accuser d'orgucil et d'ambition : 111 pareil reproche doit ètre réservé pour ceux quii regrettent des places dont ils ne sont pas dignes. An reste, MI. de Hiller ne s'en plaignit jamais. En contimant d'ètre ntile, il remplit les devoirs d'un hon citoyen, qui sont de contribuer de tontes ses forces au bien public, dans quelque ordre que l'ou soit placé, et de ne pas so

(1) Sa mémoire, qui étoit prodigieusc, nc laissoit éclıapper culcun dcs faits qu'il avoit lus ou entendus. Il lui est arrive une fois, en préscnce de MI. Tissot, de rappeler avec la plus grande exactitude à un officier de Charles XII, roi de Suedde, qui faisoit le récit de ses campagncs, tuns les noms relatifs au local, qu'il aroit oublićs : cc qu'il fit axcc taut de précision que le rieux militaire rcsta persuadé quc $M$. de Haller avoit parcouru le pays dont il aroit unc idce si positire. 
croire dispensé d'être juste, parce que l'on a épronvé des injustices.

Les talens distingués de M. de Haller en plusicurs genres ne peurent être révoqués en doute, puisqu'ils sont reconnus (1) par tous les gens de lettres; il ne doit douc pas ĉtre confondu avec ces lommes superficiels qui, désavonés par toutes les classes de savans, et réduits à leur juste valcur, n'ont à cux qu'une masse de systèmes que l'imagination enfante, que le style embellit, et qui, en multiplant et en répandant les erreurs, retardent singulièrement les progrès des sciences.

Pour suffire à tant d'ouvrages la vie de M. de Haller a dî être très-occupée : la lecture des livres nonveanx qui lui étoient envoyés de toutes parts étoit le scul délassement qu'il se permit. Il couclıoit dans sa bibliothèque, et quelquefois il y passoit plusicurs mois sans cul sortir (1) : il y prenoit tonjonrs ses repas, et lorsque sa fanille s'y rendoit pout les partager arec lui, il rénuissoit tout ce qu'il avoit de plus cher an monde.

Nons rapporterons l'aneclote suivante pour donner wue idcéc de son activité. Peu de temps après sour retour de Gottingue à Berne, en montant l'escalier de l'hôtelde-ville il tounba et se cassa le bras droit. Le traitement en fut confić à un clinurgien habile. M. de Hal-

(1) MT. de Ilaller a loujours regreté de ne s'dere point assez nppliqut: an drssin, Inul il a tant. de fois senli la nécessitc daus seg travaux d'muatouic el de botanique. 
PHYSIOL. ET MED. - HALLER. 349 ler l'oublia bientôt pour ne s'occuper que des moy'mus d'y suppléer. Il en vint aisément à bont; et dès le lendemain son chirnrgien le tronva an milien de ses livres, écrivant facilement avec la main gauche; il eut même beaucoup de peine à obtenir le temps nécessaire pour le pansement du bras blessé, que M. de Haller ne regardoit plus que comme un instrument inutile ì ses travanx.

Sun anour excessif pour l'étude avoit influé, non senlenent sur son caractere mais encore sur tout ce qui l'enviromoit; sa maison étoit devenue le sanctuaire des sciences; tout y étoil consacré à leur culte. Des élèves qui travailloient en grand nombie sous ses yenx daus sa bibliothèque et dans son amplithéitre, ses enfins, madane Haller elle-mème, qui aroit appris ì dessiner et à peindre, afin de se rendre utile; ses anis et ses concitoyens, se faisoient un deroir de contribner à ses travanx. Cette impulsion s'étoit communiquée de proche en proche; lui seul recueilloit tout, suffisoit à tout et animoit tout. Placé dans ce centre, tout aussi réagissoit sur lui. Son imagination ne cessoit de lui offir des couleurs vives et soutenues; sa sensibilité, qui étoit extrême, ne laissoit pour lui rien d'indifférent. Il conservoit long-temps les inpres-

(1) MI. de Haller aroit coutume de faire des extraits de tout ce qu'il lisoit : ces extraits étoient rangés par ordre de matières, et il s'en serroit dans le besoin. Ceux qui trarailloient sous ses yeux suivoient la méme marche. C'est ainsi qu'il a acquis cette ćrudition incroyable dont tous ses ouprages sont remplis. 


\section{0}

\section{ELOGES HISTORIQUES.}

sions dont il avoit été affecté, et les bienfaits, ainsi que les offenses, s'elfaçoient difficilement de son souvenir (1).

Il montra dans quelques occasions à ses enfans une volonté absolue, et il exigea d'eux plusieur's sacrifices. Son humeur devint de plus en plus austère vers les dernières années de sa vie. Accablé d'infrrmités, comblé d'ailleurs de dignités et de faveurs; u'ayant pas même la ressource de former de nouveaux désirs, uniquement abandonné à la passion de l'étude, qui n'étoit plus contrebalancée par aucune autre; tout ce qui n'étoit pas lié avec clle ne pouvoit l'émonvoir: ce n'étoit plus le ınême homme, etl'on ne retrouvoit plus en lui le fidèle ani de Gesner et le tendre époux de Marianne.

M. de Haller étoit d'une taille au-dessus de l'ordinaire; il avoit, suivant le rapport de ceux qui l'ont conmu, beaucoup de vivacité dans les yerx, 'de noblesse et d'expression dans la pliysionomic, et il joignoit une grande force à nue prodigieuse aclivité; en un mot, la nature l'avoit traité avec ce soin qu'elle ne prend que pour quelques liommes rares dont cha-

(1) Quviqu'il fot sérienx et réfléchi, cependant la vivaci:é de ses sensations et la variéte de ses connoissances ue permettuient pas a son caractere d'êre tonjours Is mêne. Il eprournit rapidement les alternatives de la peine et du plaisir. Cene in'galité le rembit quelquefois nimable dans la socićc, h laquelle il se livroit rarement; mas sn conversation éroit toujours savaute, cl il portnit, jusque dans l'cxamen des plus petits objets de l'application ct de las profondcur. 
PHYSIOL. ET MED. - HALLER. 351 que siècle s'honore, et dont nons voyons dans le nûtro le nombre dininuer avec tant de regret.

Nous prévenons le public que nous n'arons pas numoncé daus cet éloge, à beaucoup près, tous làs ouvrages de M. de Haller. C'est peut-útre le savant qui a le plus écrit depuis Galien. On peut lui reprocher d'avoir été quelquefois obscur; nuais ses énignes méritent d'être méditées. Ce qui prouve sur-tout la solidité de sa doctrine, c'est que tout est lié dans ses nombrenses productions, et que l'on y trouve par-tont le même esprit, les mêmes vues et la mène wuéthode.

M. de Haller a envoyé ì la Société divers extraits des registres du bureau de santé de Berne, la description d'ume petite-vérole qui a régné en 1776 , et des réflexions sur les moyens de détruire l'épizootie.

La place d'associé étranger, racante par la mort de M. de Haller, a été remplie par M. le docteur Zimmermam, premier médecin dı roi d'Angleterre, et médecin de la ville à Hanorre, et l'un des plus illustres élèves du saraut que l'Europe a perdu. 


\section{HUNTER (GUILAAUME).}

G

Tululaume Hunter, agrégé au Collège royal de médecine de Londres, médecin extraordinaire de la reine d'Angleterre, médecin consultant de l'hôpital des femmes en couche, professeur d'anatomie de l'Académie royale des arts (1), membre de la Société royale (2) et de celle des antiquaires, président de la Société de médecine de Londres (3), associé étranger de l'Académic royale des sciences (4), et de la Société royale de médecine de Paris (5), naquit, le 23 mai 1718 , à Kilbridk, dans la comté de Lanerk, de Jean et d'Agnès Hunter. Son père résidoit dans une petite terre appelée LongCalderrood, qui appartenoit depuis long-tenips à sa famille. Riche dans sa médiocrité par son économie, ce père généreux avoit dix enfans auxquels il doma l'éducation la plus soignée. Heureusement pon' eux, l'état de sa fortme ne lui permit pas de confier ì un autre aucun de ces détails; et tandis que des champs cultivés et transmis par ses ancêtres funmissoient d̀

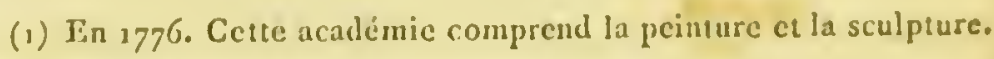

(2) $\operatorname{Fin} 1767$

(3) In janvirr 1781 , a la place de M. Futhergill.

(4) $\operatorname{lin} 3783$.

(5) Lin 1780. 


\section{PHYSIOL. ET MÉD. - HUNTER. 353}

Jeur subsistance, sa tendresse éclairée et active suffisoit à tout ce que l'instruction de dix enfans avoit de pénible; mais il gontoit en même temps ce qu'elle offroit d'agrément et de douceur.

M. Hunter étoit uu des plus jemes (1). Il fut mis à quatorze ans an collége de Glascow oǹ il passa cinq aunées. Son père qui le destinoit à l'état ecclésiastique, dans lequel on lui promettoit les snecies les plus prompts et les plus assurés, lni en fit connoitre en vain tous les avantages. M. Hunter refinsa de se somnettre a un joug qui anroit pesé sur sa vie entiure, et qui, dans des circonstances semblables, ne pent devenir léger que ponr cenx sur lespnels les sermens et la recounoissance n'ont ancun droit. Son esprit, libre et indépendant, avoit d'aillenrs besoin de s'exercer dans une carrière où il fùt permis de clonter, et où l'on clierchàt la vérité par la voie de l'expérience.

M. Cullen, maintenant le Nestor de la médecine, pratiquoit alors à Hamilton. Il inspira bientôt à M. Hunter, qu'un heureux lasard avoit amené près de lui, le gon̂t d'une science dans laquelle il excelloit déja. Le zèle du jeune homıne intéressa si vivement M. Cnllen, que, devenu son maitre et son ami, il le reçut chez lui, ò̀ il passa les trois plus heureuses années de sa vie. C'étoit au moins, ainsi que M. Hunter en parloit, lorsque, jetant un coup d'œil sur le passé, il n'aperceroit point de véritable borheur dans les époques marquées par la réputation et la for-

(1) Il étoit le sixiène de ces dir enfans. 
tune, mais bien dans celle dont la confiance et la tendre amitié lui rappeloient le souvenir sans aucun mélange de trouble ni d'amertume.

Instruit par les savantes conversations de M. Culleı, prévenu par ses sages conseils contre l'attrait dangereux des systèmes, M. Hunter n'avoit ricn à redouter de la médeciue scolastique qu'il étudia à Édimbourg en 1740. Il s'y appliqua sur-tout à l'étude de l'arnatomie, et il suivitles leçons du célèbre Alexandre Monro qu'il a toujours appelé depuis son ancien, son respectable maître.

Les deux amis s'étoient promis de se réunir à $\mathrm{Ha}$ milton, et d'y passer dans le silence des jours tranquilles. Ils étoient réservés pour un sort, je ne dirai pas meilleur, mais plus brillant. Ils devoient acquérir , I'un à Londres, l'autre à Édimbourg, une grande célébrité, et par conséquent éprouver les cliagrins et les dégoûts qui se trouvent tonjours sur le chemin de la gloire. M. Hunter vint à Londres en 1741 sans aucun autre secours qu'un grand zèle et de l'espérance. Cette dernière fut justifiée par les services du docteur Douglass, célèbre accoucheur, et grand anatonisı. Ce médecin étoit si passionué pour les beantés d'Horace dont il ne se lassoit point de lire et de réciter les vers, qu'il avoit résoln d'en recneillir tontes les éditions (1). M. Fonlis, libraire de Glascow, qui hui cn aroit fommi un graud nombre, ] ü écrivit mue letre des

(1) M. Watson, dans Ie purmier volume de son édilion d'llorare, a parlé avecéloge de celles que H. Numblass aroit recueillics arec tant de soins et de peines. 


\section{PHYSIOL. ET MÉD. - HUNTER. 355}

phis pressantes en fareur de M. Hunter, anquel cette recommandation obtint l'accueil le plus distingué. M. Hunter s'eunpressa de relire un poëte sous les auspices dnquel il avoit été si bien reçu. Soit par conformité de goht, soit par un juste retonr, il partagea l'enthousiasme de son bienfaitenr, qu'il remercioit sonvent, en lui adressant quelques-nus de ces beanx vers composés pour Mécène, et qui n’étoient dans la bouche de M. Hunter que les interprètes de l'anitié.

Le doctenr Douglass faisoit sur l'anatonice des os des recherches qu'il n'i pas en le temps d'achever : il fint si content des dispositions de M. Hunter qu'il lni proposa de s'attaclier à son travail, et lui offrit sa maison.

Mais il falloit obtenir le consentenent du pére de M. Hunter : et ce vieillard regarcoit le retour de son fils comme une consolation die ì ses soins, et nécessaire à son grand âge. Si les liens du sang, que l'on réclame et que l'on riole si sourent, sont sacrés, c'est surtout parce qu'ils supposent une bicnfaisance actire, des secours continuels ct de toutc espèce, des yenx toujours ouverts, des entrailles toujours émnes; c'est parce que la tendresse paternelle est viaiment la source de la piété filiale. Le père de M. Hunter aroit acquis par son déronement les droits les plus respectables à l'obéissance de son fils : il les exposa dans une lettre. Le jenne homme fit des représentations et l'emporta; car il n'cst point de sacrifice qu'un père généreux ne soit capable de faire à ses enfans.

Jusque-là les circorsiances ne lui aroient offert que 
des événemens heureux; mais il paya bientôt un tribut à l'infortune. Son père et son bienfaiteur moururent à peu de distance l'un de l'autre. Resté sans appui, il éprouva une de ces secousses, qui, rompant tous les liens de la vie, semblent isoler celui qu'elles affligent, et le laisser seul avec sa douleur.

La veuve de M. Douglass fut toncliéc de la position de M. Hunter; elle lui offrit les mềmes secours, et il continua de veiller à l'éducation du fils de son protecteur.

Les instructions de Monro et de Nichols, et l'exemple de Douglass avoient enflammé son zèle : il s'étoit accoutumé avec eux aux recherches les plus difficiles, et ses premiers travaux prouvèrent qu'il avoit bien. profité de leurs leçons.

On avoit toujours regardé les cartilages qui recouvrent les extrémités des os comıne formés par des lames concentriques appliquées les unes sur les autres: M. Hunter a démontré que leurs filets, semblables à ceux du velours, s'élèvent de l'os comme les poils de cette étoffe sortent de la chaine ; qu'ils sont contrts, d peu près parallèles, très-rapprochés, et placés verticalement sur les extrémités osseuses, auxquelles ils adlicrent. Les observations de M. Hunter, faites en 1743, ont été confirmées peu de temps après par M. de Lassone, qui, daus son second ménoire stur la structure des os, a démontré (1), par le moyen de la calcination,

(1) En 1752. Voyez les Mémuires de l'Acadínie royale des sciences pour celle annéc. 


\section{PHYSIOL. ET MÉD. - IUUTER. 357}

les filets perpendiculaires des mêmes cartilages, qu'il a comparés à ceux de l'émail des dents (1). La Société royale de Londres appronva le mémoire de M. Humter, et le publia dans son liecueil.

Il avoit alors vingt-quatre aus, et les succès ont ì cet âge, un charne qu'on ne pent exprimer, soit parce qu'on les sent d'une manière plus vive on qu'il est plus rare de les obtenir à cette époque; soit parce que joignant l'ilhusion de l'espérance an bonhenr d'une jonissince prématurée, l'imagination embellit le présent par la promesse d'un arenir encore plus brillant, vers lequel notre impaticuce ne nanque jamais de s'ćlancer.

M. Hunter avoit formé le projet d'enseigner l'anatomie, et d'établir une salle publique de dissection. Le célébre Sammel Sharp le nuit bientîl en état d'exécuter ce plan, en le choisissant en 1746 (1) pour son successenr, et en lıi cédant sou amphithéittre.

Quelque honorable que lui parussent la confiance de M. Slarp et des fonctions qu'il désiroit depuns longtemps, son cmbarras fut extrêne lorsqu'il fallnt les remplir. Ce u'étoit pas que les taleus nécessaires lui manquassent : ceux qui fout de semblables entreprises, saus en avoir, ne se trouvent jamais embarrassés; mais il s'agissoit d'occuper la place d'un grand homme; il falloit enseigner tous les détails d'une science sur

(1) MI. Hunter a comparé leur disposition à celles des fleurs corymbilites.

(2) M. Sharp n'enseignoit que la chirurgie. MI. Hunter fit aussi des leçons d'anatomie qui eurent un grand succès. 
laquelle il lui restoit, malgré ses nombrenx travaux, beauconp de recherches à faire ; et le vrai savant est rarement satisfait de ses propres connoissances. Soit qu'il se compare aux grands maîtres de son art : et sous cet aspect il est difficile qu'il se juge favorablement; soit qu'il considère sa supériorité sur ces hommes médiocres et présomptueux qui se font une renommée comme tant d'autres acquièrent des richesses : tout l'invite à la modestie, tout lui retrace le néant de l'orgueil. A la vérité, la ruse de ces derniers, leurs argumens subtils et faux, leur marche incertaine et cachée, le bruit qu'ils font et celui qu'ils font faire, sont propres à récréer l'homme instruit et honnête qui en est le témoin : mais si le spectacle de leurs manœurres l'amuse un moment, bientôt celui de leurs succès le décourage et l'afflige. $M$. Hunter eut de bome heure à combattre ces ennemis communs de la science et de la probité sous le masque desquelles on les reconnoît, en ce qu'ils préferent toujours le profit à l'hommeur lorsqu'ils ont à choisir entre eux.

M. Hunter fit avec le plus grand éclat ses preniers cours d'ana'tomic. Il disoit souvent qu'il n'avoit jamais parlé en public sans avoir épronvé nu1 violent serrennent de cœur. Le public l'en dédommageoit par des applaudissemens, et lui tenoit compte de sa timiditr; ; qualité estimahle lors même qu'elle se tronve arec l'ignorasice, parce qu'elle annonce de la pudeur et de la bonte foi qui ne l'accompagnent pas tonjours.

Les chirmigiens de la marine s'élant réunis en trèsgrand nombre pour suivie les legons de M. Hunter, 


\section{PHYSIOL. ET MÉD. - HUNTER. 359}

ses honoraires montèrent à une somme considérable. Jamais il n'avoit été anssi riche. Entouré de jemnes amis, la plupart sans fortune, il pensa que cette somme suffiroit à leurs besoius et aux siens; mais sa géuérosité et son inexpérience la dissipèrent plus promptement qu'il ne l'avoit acquise. Cet état de détresse lui fit faire les plus séricuses réflexions, et, depuis ce moment, il mit dans ses affaires un ordre que plusienrs out pris pour de l'avarice. Si ce récit ne le justifie pas assez, la suite de cet éloge ne laissera aucun donte sur l'injustice dn reproche. Nous verrons M. Hunter travailler sans reliche et tont sacrifier pour sa gloire; passion qui ne peut exister dans un cœur avili par la soif de l'or.

En 1747 il fut en état de faire la dépense qun'exige l'agrégation an corps des chirurgiens de Londres, et de suffire anx frais d'un royage con̂teux, dans lequel Jean Douglass, fils de son protecteur, l'accompagna. Ils séjoumièrent pendant quelques mois à Paris et à Leyde. M. Hunter fut transporté d'admiration à la vue des injections d'Albimus : celle de la membrane pupillaire lni parut si belle, qu'il la citoit comme ce qu'il aroit vu de plus parfait dans ce genre. Il conçut dès ce moment le projet de faire tous ses efforts pour égaler ce grand anatomiste; projet qu'il ne communiqua qu'après s'être assuré qu'il ne le cédoit à personne dans l'art d'injecter les vaisseanx : ainsi la sagesse ne consiste pas à contraindre son émulation et à s'interdire de grandes vues, mais à se défier assez de soi-même et des autres pour ne montrer que ses tía- 
vaux, sans indiquer le but où ils tendent, et pour dissimuler une fin qui, plus elle est éloignée, plus elle doit être un secret pour tout le monde.

M. Douglass joignoit aux connoissances anatomiques une expérience consommée dans l'art des accouchemens. M. Hunter suivit ce double exemple, et il mérita, dans un âge peu avancé, la réputation d'un des plus habiles accoucheurs de Londres : car, dans cette ville comme à Paris, on n'exige plus qu'ils aient vieilli pour leur accorder de la confiance; et ce changement dans l'opinion publique n'est point une de ces révolutions que la mode amène quelquefois; il est produit par les progrès de l'art lui-même, dont les principes sont plus clairement et plus solidement établis, les manœuvres plus simples et mieux déterminées, et par conséquent l'expérience plus rapidement et plus sûrement acquise.

M. Hunter fut reçu en 1748 un des chirurgiens de l'hôpital de Midlesex, et l'ammée suivante un de ceux de l'hôpital des fenmes en couche. Smellie pratiquoit alors à Londres; et tandis que par ses lecours et par ses écrits son nom étoit famenx dans tonte l'Enrope, l'austérité de ses mours et la rudesse de ses manières avoient rendn son succès incomplet en Angleterre. A cet extérieur sanvage, il ne joignoit ancune qualité piquaute, pas mênue nu peu de méchiunceté: simple et bon en même temps qu'il étoit sćvère, il n'avoit nucun moyeu de plaire daus le monde; anssi l'appeloit-on le plus tard et lo moins qu'il étoit possible, et on sembloit n'altendre qu'un lomme de iné- 


\section{PHYSIOL. ET MÉD. - HUNTER. 361}

rite pour hui donmer la préférence. M. Hunter l'obtint aisément, mais il en jonit avec modestic, et en rendant, toutes les fois qu'il en trouva l'occasion, des hommages empressés aux talens du doctenr Smellic.

Richard Mamningham et le docteur Sandys, trèscélèbres dans l'art des acconchenens, cessèrent anssi de pratiquer à cette époque (1), et M. Hurrter se trouva le premier dans cetre partie inportante et très-lucrative de l'art de guérir.

Il contimal de pratiquer la chirnirgie jusqu'en 1750; il fint alors reçu doctenr en médecine. Ce n'étoit point 111 vain titre qu'il vouloit ajouter à ses antres qualités, mais un droit qu'il avoit besoin d'acquérir pour exelcer sans trouble le nouvel état auquel il devoit se livrer tont entier.

Le doctenr Cullen professoit et pratiquoit la médecine dans l'Université de Glascow lorsque M. Humter s'y présenta. Ces deux amis s'embrassèrent étroitement et se félicitèrent sur lenrs succès mutuels. Leur union n'étoit pas seulement fondée sur ce que deux hommes également heureux, ou plongés dans la même infortune et qu'un même sort rapproche, ont un intérêt commun à ne point se séparer. Les deux amis étoient sûrs de leurs sentimens réciproques; ils avoient subi l'épreuve rigoureuse de l'inégalité des conditions: l'un avoit reçı de l'autre des services impor-

(1) Le premìer mourut peu de temps après, et le second se retira ì la campagne. 
tans, et la reconnoissance resserroit entre eux les liens de l'amitié.

Avant de quitter l'Écosse, il ne put résister au désir de visiter sa famille et de retourner à Longaldervood. Ses entrailles furent émues lorsqu'il revit la maison paternelle; il en sortit baigné de ces larmes qu'une mère ne manque jamais de répandre sur son fils lorsqu'elle croit l'embrasser pour la dernière fois; mais elles coulèrent avec douceur, parce qu'elle le retrouvoit tendre, respectueux, honoré de l'estime publique et comblé des biens de la fortune.

Arrivé à Londres, il succéda au docteur Layard (1) dans la place d'un des médecins de l'hôpital des femmes en couche, où il avoit rempli pendant plusieurs années les fonctions de chirurgien; mais on ne suivit point dans son élection les formalités d'usage : il fut nomué par acclamation, et on porta sur les registres que les administrateurs remercioient M. Humter des soins qu'il avoit déja donnés et de cenx qu'il offroit encore anx malades de la maison. Nous ne parlerions point de cette anecdote, si elle n'ammonçoit que de l'habiletć; la réputation de M. Hunter n'a pas besoin de cette preuve : mais elle nous le représente comme un homme généreux, attentif aux besoins du pauvre; elle nous dévoile sa bienfaisance, sa scusibilité, qualités qu'il est si beau de réunir au savoir, et sans lesquelles

(3) En 375.5

(2) En 1756, le 30 septembre. 


\section{PHYSIOL. ET MÉD. - HUNTER. 363}

mm médecin ne contribue jamais que foiblement au soulagement de l’humanité.

Le Collége royal de médecino l'admit à peu près dans le même temps ì la licence ( 1 ), la Société de médecine de Londres le recut parmi ses membres. Cette académic alors naissante avoit hesoin que ses associés eussent phus que du talent; il leur falloit du comrage pour vinucre les difficultés. MI. Hunter se rénuit au doctenr Fothergill et à plusieurs aulres médecins célìbres; ils firent paroitre un Recueil d'observations que le public agréa, et leurs efforls furent courounés par le succis : car les bous ourrages sout la seule réponse que les corps de cette nature doiveut opposer à leurs détracteurs; toute autre, avec ou sans celle-lì, seroit égalenent superflue.

(1) Les Mémoires de la Société médicalc de Londres contiennent un grand nombre de fiats et d'obscrvations analognes. Foyez 1. The history of an anevrisma of the arta with somc remarcks on anerrism in general, by IV. Hunter. - Nedical obs. and inquirics, tom. I, p. 323.

2. ${ }^{\circ}$ Firther observat. upon a particular of ancrism, by $W$. Hunter. Ibid. tom. II, p. 3yo.

3. An anevrism...... perfectly curatcil by the operations, etc. by MI. Burchall commnnicated, to W. Hunter Ibid. tom. III. p. 106.

$4 .^{\circ}$ The cas of an anerrismal rarix related and descripted in two letters from G. Cleghorn to W. Hunter. Ibid. tom. III, p. 110.

5. A Letter from M. Th. Armiger, surgeon to W. Hunter, or the varicos anevrism. Ibid. tom. IV , p. 38.

6. Aposcript. to te preceding case of the raricos anevrism, by W. Hunicr. Ibid. tnm. IV, p. 388.

7.0 Two letters on the varicos anerrism from M. W. Whytt to W. Huntcr, Ibid. tom. IV. 
Le premier volume des Mémoires de la Société royale de Londres contient les observations de M. Hunter sur la nature et le traitement des anévirismes (1). L'espèce sur laquelle il a fait les remarques les plus neuves est celle que M. Cleghorn, célèbre anatomiste de Dublin, et un de nos associés, a désignée sous le nom d'anévrisme variqueux. Dans ce dernier, l'instrument qui perce les deux parois opposées de la veine et de l'artère leur fait des blessures exactement correspondantes et établit entre ces deux vaisseaux une communication facile : de sorte que le sang artériel coule dans les veines du bras(1), qu'il gonfle sans se répandre dans le tissu cellulaire. Cette maladie que l'on a confondue avec l'anévrisme faux, exige plutôt du ménagement et des soins que les secours d'une clirurgie vraiment actire. Elle offre un de ces cas plus communs qu'on ne pense, dans lesquels, pour être utile au malade, il faut l'abandouner à liu-même, et sous ce rapport il étoit importaut d'en conserver l'histoire; car de tous les reproches c'est celui de l'inaction que les médecins ignorans redoutent le plus sans doute, parce qu'aux yeux des spec-

(1) En y passant il produit un son que l'on entend lorsque l'on prête une oreille attentive. Son jet frappe imuédiatencut la cicatrice de la veine avant de se distribuer dans ses rameanx. II. Hunter s'en est assuré cu appliquant une ligature pour comprimer les veines au-dessons de l'endroit piqué, et en pressant fortement l'artère an-dessus : alors l'espace intermédiaire reste vide; et si lon cesse brusquement la compression faite sur l'artere, le sang est Inucé rapidement et avec bruit par l'ouverture qui çtablit entre les branches artérielles et veineuses un libre passage. 


\section{PHYSIOL. ET MÉD. - HUNTER. 365}

tateurs plus ignorans encore, c'est le seul dont ils ne peuvent se justifier en l'imputant à la nature.

Une pratique très-étendıe fournissoit à M. Hunter des occasions fréquentes d'observer, dont le nombre, quelque grand qu'il soit, ne contient le gernue des vérités nouvelles que pour ceux qui sont propres at les connoître et à les bien juger. Semblibles ì ces lommes qui croient n'avoir besoin que de mémoire lorsque l'esprit est sur-tout en défaut, la plupart se persuadent que pour obtenir des succés dans l'exercice de la médecine il ne lenr manque que des moyens capables de remplir les vues qu'ils se proposent; et ces vues sont presque toujours ce qu'il y a de plus défectuenx. Égarés par cette erreur, ils ne s'occupent qu'ì chercher des procédés nouveanx lorsquı'ils devroient plutôt se livrer à l'étude des maladies et à l'examen de leurs complications pour en déterminer avec précision les espèces. M. Hunter excelloit sur-tont daus ce genre de recherches, sans lequel notre art ne peut se perfectionner. Nous en trouvons une nouvelle preuve dans la maladie qu'il a appelée retroversio uteri, et qui est très-différente dn tenversement de cet organe. C'est vers le troisiène ou quatrième mois de la grossesse qu'elle arrive le plus souvent ( 1 ). Les femmes dont les os du

(1) La matrice, en se développant et en prenant son accroissement ordinaire, réagit plns on moins sur les parties roisines, et l'urètre d́tant comprimé il en résulte, soit unc dysurie, soit une suppression d'urine qui précède la maladie dont il s'agit. La rétropersion de l'utérus n'est pas toujours complète. M. Hunter en a exposé lẹs nuances. On rétablit la matrice dans sa place par des moyens 
bassin forment une cavité bien développée vers le bas, mais trop resserrée dans le détroit supérieur, y sont le plus sujettes. Le conduit urinaire étant comprimé, la vessie se dilate peu à peu et s'étend dans le ventre; elle entraîne avec elle le col de l'utérus et ses annexes; le fond de ce viscère se précipite en bas et en arrière; l'orifice remonte derrière la symphyse du pubis; l'urine ne peut couler, et tous les organes que le bassin contient sont dans un état de gêne qui peut devenir funeste. Plusieurs fenmmes en ayant été les victimes sous les yeux de M. Hunter (1), il en clrercha et il fut assez heureux pour en trouver la cause et le traitement (2).

dont la pratique est en général assez facile, et tous les accidens cessent par cette manœurre. Voyez:

1.0 The history of a fatal inversion of the uterus and rupture of the bladter, by M. Lynn communicated, by W. Hunter, etc. et an appendix to the preceding article, by W. Hunter.-Obs. med. and inquiries, tom. IV, p. 388 et 3 .jo.

2. ${ }^{\circ}$ n accoum of a retroversio uteri by M. Bird communicated by W. Humer. Ibid. tom. V, pag. 110.

3." The cases of a retroversio uteri by M. Hopper, conmunicated by d. Fothergill. Ibid. tom, V, p. 10.

4.0 'Two cases of the retroversio uteri by 11. Grathshore communicated by W. Humter. Ibid. tom. VI, p. 381. - Sumunary remarks on the rotroversio meri, by W. IInter. Ibid. tom. V, p. 388 .

(1) Dans l'hripital des fenunes eu conclue, dont il a été le chirurgien, et consuite le nuédecin.

(2) Il fit voir que pour prévenir cet arcileut des le principe it suffisnil, lorsqu'uns: femne cu énoil mruace, d'empecher par l'iutrorluction de la soncie, l'mine de s'nreumuler daus la vessic. Il exposa dans ses legons et dans ses écrits les procédés que l'on 
PHYSIOL. ET MÉD. - HUNTER. 367

Nous ne dirons pas de lui qu'il a déconvert une maladie nouvelle, ce qui seroit affligeant pour l'humanité; mais qu'il a le premier fait connoître une lésion confondue jusqu'alors parmi les antres maux anxquels les femmes enceintes sont exposées, qui a sonvent été menrtrière, parce qu'on en ignoroit la nature, et dortt il a si bien indiqué les circonstances que les moyens curatifs naissent sans effort de la description, et se présentent d'enx-mêmes à sa lecture.

Tons les faits que M. Hunter a cousignés daus les. Mémoires de la Sociéré de nuédecine, dans cenx de la Société royale de Lordres et dans ses propres écrits, mériteut également d'ètre conuns du public; il n'en a recueilli qu'nn petit nombre, parce qu'il étoit trèsdifficile dans le choix, et 'qu'il regardoit comme superflu, tout exposé, tout discours quii ne détruit aucun prejungé, ou ne fournit ancume instruction nonvelle : leçon utile, et qu'on ne sauroit trop répéter à cenx qui croient tout ce qu'ils ont vu digne d'ètre inscrit dams les fastes de la médecine; heureux encore s'ils n'écrivoient que ce quiils ont vu!

L'exactitude n'étoit pasle seul mérite des productions

deroit suivre pour replacer l'utérus dans sa véritable position (*). Cette olservation, Alont nul auteur n'aroit parlé, fut bientôt confirmée par les médecins et les accoucheurs les plus célèbres, qui lui en témoignèrent leur satisfaction et leur reconnoissance.

(*) Il est imporlant de mettre alors les femmes daus une situation qui favoriso la réduction de la matrice. Quelques-unes des obliquités de l'utirus décrites par Derenter ne semblent-elles pas se rappotter au genre de maladie observé par 31. G. II unter? 
de M. Hunter. On y tronve cette érudition, cette réunion de connoissances qui rend l'objet plus intéressant en le présentant sous plusieurs faces. Ainsi, en parlant de l'anasarque, dans le traitement de laquelle il préféroit, d'après des expériences comparatives, les petites piqûres aux grandes incisions, il a exposé son opinion sur la structure du tissu cellulaire. Suivant lui, tout ce que nos yeux peuvent apercevoir dans cette toile est vasculaire: l'on $n^{\prime} y$ voit rien qui soit inorganique, comme Haller l'a pensé. Les cavités cellulaires où la graisse s'accumule ne lui paroissent pas être les mêmes que celles où les eaux des hydropiques (1) sont épanchées. En décrivant une maladie du tibia, affecté dans toute son épaisseur, il a prouvé que le cal ne pouvoit se former et conserver à la jambe sa longueur naturelle sans que l'ancien os eût été séparé par exfoliation. L'emphysème (2), l'hydropisie de l'ovaire, les maladies du cœur, celle de l'estomac (3), l'incertitude des signes que l'on croit propres à faire reconnoître le meurtre des enfans nouveau - nés, et les luxations (4), ont été successivement le sujet de ses remarques, quoiqu'il regardât, avec Haller, la dure-mère,

(1) Dans l'anasarque et les infiltrations.

(s) Il a guéri un cupliyscine par le moyen des scarifications, recommandées par Ambroise Paré.

(3) Ces observations devoient faire partic du sixicme volume des Medic. observ. and inquiries.

(4) Il pensoit que, dans tous les cas oì la luxation se faisoit arec violence daus l'état de sanié, le ligament capsuluire étoit déchiré. Voyez aussi Kirkland, on fractures. 


\section{PHYSIOL. ET MÉD. - HUNTER. 369}

le. périoste et les tendons ( 1 ), comme insensible dans l'état de santé, et qu'il cût enseigné depnis long-tennps celte doctrinc dans ses leçons, il insistoit ceprendant sur le dariger de leurs blessures, à la suite desunelles non gonflement inflammatoire prodnit presque tonjours de la doulent; et il traitoit ces différuntes questions théoriques comme mu pliysicien exercé dius la pratique de notre art, dont on ue sait pas assez que les comnoissances et les lumieres peruvent éclairer la pliysiologie, sans lui faire comir ancun des dangers auxquels clle a tant de fois exposé la méulecine.

Parmi les maux auxquels l'homune est sujet, quelques-mus naissent et ne finissent qu'arec lui : le ce nombre est l'espéce de hernie ingminale dans lappelle l'intestin n'étant point reconvert par un sac, est contemu dans la tmique raginale (2) elle-snène. Slıap en avoit parlé comne d'un déplacenent accompagné de ruptnre du péritome. Haller avoit porti ses rues plus loin: il avoit observé dans le veutre du foetus l'ouverture qui, si elle ne se ferme pas de bonue licure, favorise la sortic de luintestin et la formation de la hernie appelée de naissance (3). MI. Hunter aroit traité plusieurs malades qui en étoient atteints, et ce fut ì

(1) Dans le quatricme tome des Medical obserr., il rapporte une observation qui contirme son opinion et celle de Haller sus l'insensibilité des tendons.

(2) Cette tunique sert d'enveloppe an testicule.

(3) Il en aroit paric dius une dissertasion en 17 fo, et ensuite en $17.5 \%$

T. 2. 
sa sollicitation que le célèbre M. Jean Hunter son frère, et aussi notre associé, commença ces belles rechérches sur la situation respective des testicules dans le fotus, qui lui ont mérité les suffrages de tous les savans (1). Ainsi, réunis pendant plusieurs années, on les a vus travailler de concert, multiplier les expériences, recueillir des faits, les examiner avec scrupule et les exposer avec une précision et une vérité malheureusément trop rares parıni les écrivains; car le nonbre des mauvais raisonnemens contre lesquels on s'élève avec tant de force, est peut-être moins grand que celui des observations défectueuses; et les erreurs que ces dernières repandent sont les plus dangereuses, parce qu'elles sont les plus difficiles à déraciner.

(1) Voyez Medical commentaries, by W. Hunter, in- $40^{\circ}$, part. 1, pag. 70, of the rupture in which the testis is in contact with the intestine. En $1748 \mathrm{M}$. Sharp dit ì M. Hunter qu'il avoit vu troic fois dans des hernies l'intestin en contact arec le testiculc. Voyez ce que M. Sharp en a écrit, Critical inquiry. London 1750, pag. 3. MI. Hunter, qui le crut avec peine, n'en fut bien convaincu qu'après aroir disséqué un sujet dans lequel cette espèce de liernie avoit lieu des deux cỏtés. M. Cliesclden en parla d'après M. Hunter dans les reinarques ajoutées it la traduction des opérations do I.edran, pag. 363, 17 99. M. Haller en avoit traite d'uue manière bien précise avant que M. Pott cat ricu publié it ce sujet dans ses Opusc. pathol.; cnfin M. Tran Hunter n'a presque rien laissé à désirer sur le développement at les diverses positions dn testicule du foetus, depuis le quatricme nois de la conception jusqu'au terme de l'acenclienent. Voyez, Observ. On the state of the testis in the fretus and on the hernies congente, by Jolun Huwer, in Medical comucnt. P. 75 . J'ai pulblic daus le Recueil de l'Académic royale des sciences des olservations sur le mêtue sujet, qui font suite a celles de M. Jean Hunter. 


\section{PHYSIOL. E'T MÉD. - HUNTER. $377^{\prime}$}

M. Hinter a eu le malhenr d'entrer dans quelques discussions littéraires qui l'ont sans donte mené plus loin qu'il ne l'avoit prévu. Aigri, irrité par les obstacles, son caractère n'étoit phus le même. Ses meilleurs amis nous l'ont peint ì cette époque comme un houme impatient, et ne pouvant supporter la contradiction, quoiqu'il lui arrivit souvent de contredire. L'ouvrage qu'il a écrit arec le plus de soin est celui dans lequel il a rendu compte de sa querelle avec M. Monro. On y trouve de la saillie, du trait, et cette plaisanterie fune et déliée, si nécessatie pour répandre quelque intérèt sur les détails arides et mimutienx dout les auteurs surchargent toujours ces sortes d'écrits. Malheureusement dans cette carricre, que tout homne hounête et délicat devroit s'interdire pour toujours, il fantêtre ou un pen satirique, , u très-emunyenx ; et celui qui prend la plume a bientôt fait son choix. Il s'agissoit de saroir qui de MM. Hunter ou Monro aroit parlé le premier de l'origine et du véritable usage des vaisscanx lymphatiques, des injections de l'épididyme (1) et des conduits excrétoires de la glande lacrymale. Déja Harder avoit observé ces derniers dans le daim, Stenon et Durerney dans le bœut, Santorini et Winslow dans l'homme; mais ils aroient échappé aux recherches de Morgagui, de Haller et de Zinn; et il est permis de se glorifier d'nu succès que ces grands anatomistes n'avoient point obtenu (1). Dès l'année

(1) Il s'agissoit des raisseaux de l'épididyme, et de ceux du corps du testicule.

(2) M. Monro a fait connoitre en 1753 un procédé pour rendre 
1745 , Haller avoit rempli de mercure les vaisseaux de l'épididyme et ceux du testicule; ce qui diminue le prix attaché par MM. Hunter et Monro à cette prétendue déconverte (1).

Lorsque M. Hunter commença à enseigner l'anatomie, on regardoit les vaisseaux lymphatiques comme un prolongement d'un ordre particulier d'artères connues sons le même nom, et on pensoit qu'elles formoient ensemble un système de circulation propre à lia lymphe, et comparable à celui du sang dans les artères rouges. MM. Hunter et Monro prouvèrent que tous les vaisseaux lymphatiques, semblables aux lactées, étoient veineux et absorbans, et qu'ils s'ourroient dans les cavités, et sur toutes les surfaces internes ou externes du corps humain.

- Ils tronvèrent des prenves de cette assertion dans les effets des venins et de plusieurs contagions dont les progrès suivent les traces des vaisseaux et des glandes lymphatiques. La facilité arex laquelle l'injection y pénètre lorsqu'elle est épanchée daus le tissu cellnlaire est une antre démonstrat ion de cette doctrine. Sui: vant eux, les vimes sumgnimes sont incapables do

leur préparation facile; et M. Hunter a prowve qu'il les aroit démontris cu 17 f. Voyez Observations antatomical and plyysiological whrrein d.r Hunter, efc. 1753 ; et les Medical comucntaries de M1. Husicr. Lomblon $17 \mathrm{G}_{2}$.

(1) Des lémoignagres antlentiques ne permetent pins de doures que MM. Hunter ne les aient injucteces en $7_{75}$ (a). I.es observa-

(u) Voyer to cap. I des Modical comment. de M. C. Hunter, 1,68. 


\section{PHYSIOL. ET MED. - HUNTER. 373}

toute absorption, et tous les vaisseaux qui contiennent de la lymplie se rénnissent par enx-mémes, ou par leurs communications, au conduit thorachicgue (1).

Cette opinion, qui est maintenant la plus.généralcment répandue, appartient-elle à M. Hunter ou à M. Monro? Celui-ci l'a publiée daus nue dissertation en 1755 , et deux aus après (2) il en a traité plus eu détail daus mu ouviage trés-curieux sur l'origine de ces vaisseanx. ML. Hunter arvit exposé la nène théorie daus ses lerous dés l'anmée 1746 , et, parmi les témoins qu'il cite pour garans de cette réclamation, on distingue les noms de NIM. Cullen, Black (3), Watson (4). Mitis M. Monro en aroit-il en conmoissance? ... Gardons-nous de répéter ce quils se sont dit mutuellement daus la chaleur d'une dispute dout nons désiterions pouvoir effacer le sonvenir. Ponrquoi

tions de Mr. Monro sur le mène sujpt ont été publièes en 1765 (i) et 1755 (b) : mais ce deruier ne s'est poiut borné a l'injection de ces corps glanduleux; il les a décrils dans plusienrs aniuaux, et l'on peut dire, à sa louange, qu'en le lisant on oublie le sujet de la dispute pour ne s'occuper que du mérite même de ses recherches.

(1) Mcckel ne pensoit pas sur tous ces objets comme MIM. Hunter et Monro.

(2) De venis lymphaficis ct de earum origine. Edimb. $175 \%$

(3) Medical comment., p. 22.

(4) Ibid. p. 9.

(a) Dans les Essais de médecine d'Edimbourg.

(b) Dans une dissertation intitulée : Dissortatio inauguralis de testibus ef somine in variis anmalibus. Edimb. 8755 . 
faut-il que l'histoire des sciences, qui n'est destinée qu'à éclairer les hommes, soit souillée de leurs haines! N'est-ce pas donner trop d'importance à des querelles d'un moment que de vouloir en instruire la postérité? Et ceux qui sc font de semblables procès ne. s'épargneroient-ils pas la peiue de l'information, s'ils réfléclissoient que dans une affaire de ce genre, comme dans tant d'autres, les juges prononcent quelqnefois saus avoir lu les pièces?

L'honneur d'avoir fait comnoître l'origine des vaisseaux lymphatiques n'appartient, au reste, ni à M. Hunter ni à M. Monro : le docteur Nouguez, dans un ouvrage publié en 1726 , à la tête duquel il a pris le titre de démonstrateur d'histoire naturelle au Jardin du roi à Paris, a clairement exposé la fonction absorbante de ces vaisseaux, leurorigine des différeutes cavités et surfaces du corps humain, ct même les usages des artères blanches, avec lesquelles il n'ignoroit pas que les veines lymphatiques n'avoient aucume connexion.

N'oublions pas de dire qu'en rendant cette justice au docteur Nongucz, nous me faisous que traduire les expressions de M. Simmons, savant médecin auglais ( 1 ), et un de nos plus célèbres associés, qui, dans un éloge de M. Hunter, a en le courage d'enlever à donx de ses compatriotes nue découverte que l'opinion publique leur attribue, pour la reudre at un auatomiste

(1) M. Simmons est aussi tris-recommandable par ses connoie sances anatomiques. 


\section{PHYSIOL. ET MÉD. - HUNTER. 375}

français, son véritable auteur. Puisse cet exemple d'impartialité, également honorable pour les deux nations, avoir beancoup d'imitateurs ! Et montronsrous anssi justes que M. Simmons en avount que si le docteur Nouguez a conuu l'origine et les fonctions des vaisseanx lympliatiques avant MNI. Hunter et Nonro, ceux-ci l'ont surpassé, ainsi que la plupart des modernes, dans l'exposttion anatomique de ces mènes raisseanx; et ajontons que M. Hewson (1), digne élève de M. Hunter, en a démoutré le systíno daus l'homure et dius plusien's animaux, avec mne précision qui n'est point assez connue des médecins.

Les déconvertes, les inventions, sout de toutes les propriétés celles que l'homume acquiert et cui'il possède le plus légitimenent; ce sont aussi celles qu'il partage le moius, et qu'il défend arec le plus d'opiniàtreté; saus doute parce qu'étant le fruit de ses idées, de ses combinaisons, leur existence se confond arec la siemne, et que les lui enlerer ce seroit lui ravip une partie de lui-mème. MI. Hunter étoit du nombre de ccux auxquels cette privation auroit le plus conté. M. Jean Hunter son frère lut en 1780, à la Société royale de Londres, mu mémoire sur la structure et les vaisseanx dn placenta, et sur sa connexion avec l'utérns. M. Guillanme Hunter réclama l'antériorité

(t) M. Simmons, dans An account of the and writings of the life late W. Hunter, p. $3 y$, a publié des détails intéressans sur la vie de M. Hewson. On en trouve anssi dans la Traduction latine des Observations de cet anatcmiste par M. Hahn. 
${ }_{37}^{3} 6$ ÉLOGES HISTORIQUUES.

avec chaleur (1), et l'intérêt de la ghoire divisa deux frères, dont aucun motif n'avoit encore altéré l'union. M. Hunter s'étoit sans donte aperçu qu'il poussoit trop loin cette inquiétude; il est an moins permis de le soupçonner, en lisant son supplément à la première partie de ses Commentaires, où il semble vou: Joir s'excuser lorsqu'il dit que l'on ne peut ressentir l'enthousiasme, qui senl accélère le progrès des sciences, s'en tenir fortement à l'honneur d'y avoir contribué, et qu'il n'y a- point de grand anatomiste qui n'ait été engagé dans quelque grande querelle. On peut assurer qu'il x’'a rien manqué à $M$. Hunter, même sous ce demier rapport, pour être mis au premier rang.

L'homme est pour lui-mème une énigme d'autant plus inexplicable, qu'il se considère plus près de son origine ou de sa fin ; et l'agent par lequel sa fibre commence ou cesse de palpiter, les premiers et les deruiers battemens de son cœur sont également soustraits à ses comnoissances et à ses recherches: nuais s'il ne peut s'élever jusqu'à la source de son être, il pent au moins jeter nn regard curicux sur son déreloppement et observer sa décadence.

M. Hunter at rempli le prenier de ces deux objets en publiant son onvrage sur l'utérns, considéré dans l'état de grossesse. La beauté, l'exactitude et le nombre des planches dans lesquelles cet organe et le foctus sont représcntés en graudeur naturelle et à toutes les époques

(1) Le: mrimoire que: M. G. IIunier a lu a ce sujet dans les asscinblices de la Société royale n'a point ćsé publić. 
PHYSIOL. ET MED. - IIUNTER. 377 de leur accroissement, rendent ce traité précicux ì l'anatomie et à la médecinc (1). L'enubryon, recomvert de ses enveloppes, adhère à la face interne de l'utérus par un tissu cotonnenx et vasculaire, dout lexpansion forme une membrane qui se réfléchit sur le corps de l'enfant, et que M. IImnter a désignée sous le nom de decidua (2). C'est dans l'épaisseur de cette menubrane que se développe le placerta, qui pendant les premières semaines u’offre qu'une vésicule appelée ombilicale, et dans lequel M. Hunter a distungué deux portions: l'une, que l'on injecte en poussant le fludde dans les vaisseanx de l'ntérus, anquel clle appartient; l'autre, y̧ui sans doute est l'épanouissement de la vésicule ombilicalc et qui regoit le sang du cordon. Moins l'accroissement de l'enfunt est avancé, plus la membrane cotonneuse, décrite par M. Hunter, adhicre ì l'utérns, et plus l'étendue respectire du placenta est considérable. De la théorie de M. Hunter, ou plutôt de son exposition anatomique (3), se déduit l'explication d'un grand nombre de phénomènes, tels que les donleurs et les dangers de l'avortement, la sortic du foetus dans l'acconchement naturel et la circulation du sang dans des vaissenux, soutenus par nne subștance pulpeuse qui

(1) Il est intitulè : Anatomia uteri gravidi tabulis illustrata. L'autcur l'a commencé en 1751, et publié en 1774 .

(2) En 1739 et 17 fo Haller en aroit parlé sous le titre de Membrana media.

(3) Voyez, dans le tom. I, p. 35 i des Mémoires de la Soc. royale, un abrégé de la doctrine de M. Hunter que j'y ai inséré, en rapportant des obserrations qui me sont particulières sur le méme sujet. 
s'attache étroitement à l'utérus, croìt, se développo avec lui et peut s'en séparer sans qu'il se fasse aucune rupture dans ses fibres : admirable prévoyance de la nature, dont les lois si souvent contredites par les hommes, en ordonnant les rapports des êtres, ont toujours mesuré l'intimité de leur connexion sur ce qu'exigent leurs besoins, c'est-à-dire, leur conservation ou leurs plaisirs.

Les belles planches de M. Hunter seroient encore plus utiles, si les explications qu'il y a jointes étoient accompagnées d'un texte ou description des organes qu'il a si bien représentés. C'étoit aussi son projet; il en avoit même conmencé l'exécution. M. Simmons, en nous transmettant le plan de cet ouvrage, tel qu'il a été écrit de la main de M. Hunter, ajonte que ce savant avoit fait les rècherches les plus multipliés sur la nature, la forme et l'accroissement des concrétions de toute espèce qui se forment dans le corps humain; qu'il les avoit fait dessiner avec beancoup de soin, et '1ne rous ses travanx sont reslés incomplets ( 1 ).

(1) An milieu des élnges mérités que nous donnons à M. Hunter, quil nous soit permis de soumertre a uue juste critique quelquesunes de ses productions.

Dans l'une, il s'est cilevé contre la scetion de la sympliyse du pubis. Cet écrit conticut plutòt l'opiniou de N1. Hunter que ses motils, qui u'y sont que sommairement exposés. Quand bien même les recherches et expéricuers de M. Siganlt sur ectic opuration se róluirnicut it pronver que l'ou a coupe impuncment la

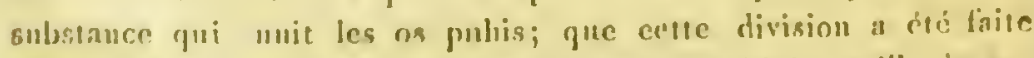
sans qu'anean organe important ait dés déchiré; qu'il s'y est formé mue cicatrice solide, el que l'eirarioument qui en est résuleć, 
PHYSIOL. ET MÉD. - HUNTER. 379 Il n'y a point de comoissance positive qui n'ait détruit quelque fable: toute la force et la hanteur des géants n'ont pu tenir contre les lumières de l'auatomie comparée. Les os únormes du famenx Tentobochus,

quelle qu'iit étć son eitenclue, a rendu ficile un accouchement qui oflroit de grands obstacles : ces résultats, "jui ont tout le mérite de la nouveauté, auroient di mériter i l'inveuteur plus d'égards que M. Hunter ne lui en a tébuignè daus sa refutatiou. Ses réflexions sur l'usage du forceps dluus la pratique des accouchemeus aunonceut d'ailleurs un unideciu sage. Il mertois toute sa gloire et son adresse is s'eu passer, luin de les faire consister comne tant d'autres, ì s'en servir. Nous somutes eucore de son avis lorsqu'il expose coubien il est importaut en midecine de ne publier des procédés qu'aprés leur aroir donné un certain degré de perfection : tant on unit redouter, soit la stupite crédulite ves maliules subjugućs par la mode, et livrés sans réserve aux remédes nouveaux, soit la hardiesse conpable des empiriques, ‘ui, prompts à expérimenter, multiplient en meme temps les essais et les victimes.

Il faut que les homues soient malheureux et infirmes depuis bien long-temps, puisque l'histoire de leurs calamités et de leurs souffrances se perd daus l'obscurité des siccles les plus reculés. In plupart des auteurs avoient pensé que le mal vénérien étoit le pro. duit d'une contagion communiquée à l'Ancieu Moncle par le Noureau, et répandue depuis l'époque dle sa dècourerte. Cette origine a été niéc par quelques écrirains, au nombre desquels II. Hunter s'étoit rangé. Il avoit principalement insisté dans sou mémoire, lu en 177 à la Société royale de Londres, sur l'autorité de Pierre Martyr, que le fen docteur Musgrave lui aroit ensuite rendue suspecte; mais il n'aroit point cité M. Sanchez dans l'ourrage duquel le témoignage de Pierre Martyr est non seulement apprécié, mais qui s'est encore efforcé d'établir que parmi les injustices faites aux habitans du Nouvean IIonde on doit compter l'inculpation qui les acruse de nous aroir fitit ce funeste présent.

M. Simmous assure que M. Hunter n'a point publié sa disser- 
ceux des Mamas ou Mamutes des Ostiaques, ceux que Delisle apporta de Sibérie, et le baron de Longueil (1) des bords de l'Ohyo en Amérique, ont été reconnus pour des os d'éléphant. M. Daubenton (2) les a comparés arec le squelette de celui de la ménagerie royale, disséqué par Duverney, et il n'a observé entre enx que des différences accessoires relatives à la largeur, à la longueur ou à la courbure, et si légères d'ailleurs, que les os de plusieurs squelettes lumains, considérés suivantles mêmes proportions, qui lui ont paru différer plus cntre eux que ceux de ces animaux. Il a tronvé dans les défenses ces plans de fibres qui se coupent et forment des arcades; caractère que l'on sait être celui de l'ivoire, et qui est particulier à l'éléphant. Il lui étoit donc permis de rapporter à cette espèce les grands ossemens qu'il avoit examinés; car il falloit qu'ils enssent appartenu à un éléphant ou à un autre animal qui en̂t plusieurs de ces caractères individuels, et tels qu'ou

tation, parce que le docteur Musgrave lni aroit prouvé que plusicurs Ietires de Pierre Martyr n'avoient été écrites que long-temps après leur date. Voyez ce que M. Sanclicz a dit à ce sujet dans ses Recherches sur l'apprition du mal vénéricn. Nous rcnvoyons aussi le lecteur à l'article de l'Eloge de M. Sanchez, dans lequel cet objet cst traité.

(1) Il a rapporté des os et des défenses qui ressemblent ì conx des éléplians, et des dents qui sont analogurs arec celles de l'hippropotane. C'est ce mélange qui rend les comparaisons difficilcs.

(2) Veycz tom. XI de l'Hisinire naturelle, et les Mémoires de l'Acadénic royale des sciences, 1762 . 
PHYSIOL. ET MÉD. - HUNTER. 381 n'en connoit aucun. Ce dernier sentinent a cependant été adopté pár M. I Iurter, qui a lejeté celui de M. Danbenton, dans $n$ mémoire publié parni cenx de la Société royale de Londres; mais il oflie me difficulté de plus que les autres systèues, celle d'un quadrupède de la plus grande taille, gue loon ne retroure plus; et il ne dome pas nue meilleure explication des changemens qui doivent être arrivés, puisque cet animal, quel qu’il soit, a disparn des cuntrées du Nord, oir l'on n'en rencontre plus que les restes. Content d'en observer la disposition et d'en comparer la forme arec celle des objets qui hui sont analognes, l'anatonuiste, qui s'élèvo rarement au-dessus de l'objet qu'il cousidèe, doit laisser an génie la gloire de rechereher et de nous diro si ces climats qu'mn froid coutimuel resserre out été, dans nu antre ordre de clioses, brilés par les ardenrs du midi; si lì où végète la mousse ranpante ou a vu croitre le lis superbe; si le même sol doit nourrir successivement l'hippopotame et l'ours blanc, on s'il n'est pas possible que certaines races d'animaux acclimatés ¿ lorce de soins aient été détruites par des circonstances particulières dans un pays très-éloigué de celui qui leur étoit destiué par la natnre.

La célébrité littéraire nuit moins à Londres que par-tout ailleurs à celle que donne la pratique de la médecine. L'une et l'autre se réunirent en faveur de M. Hunter, et portèreut sa réputation et sa fortune au plus haut couble: jugeons-le par l'usage qüil fit de șes richesses. Il aimoit l'anatomie avec passion; il 


\section{2}

\section{ÉLOGES HISTORIQUES.}

cultivoit ensemble toutes les branches de l'histoire naturelle; personne n'étoit plus sensible aux beautés de l'ancienne littérature grecque et latine, et dès sa plus tendre jeunesse il avoit recueilli quelques médailles. Auquelde ces goûts se livra-t-il? A tous, parce que tous, parce que soll courage, son activité et ses moyens peuvent y suffire; mais il commencera par celui qu'il sera le plus sage, le plus utile de satisfaire.

Il ne perd point de temps à faire des essais en petit, à réunir des échantillons. Son premier projet est grand et digne, soit de la hardiesse de ses vues, soit des sacrifices qu'il se propose de faire à leurs succès. Il achète un terrain, il y élève à grands frais un monument qu'il consacre à l'anatomie et à l'histoire naturelle. Dans cet édifice où le luxe est permis, parce qu'il le destine à des usages publics, un bel amphithéâtre doit servir à l'enseignement; et dans un superbe cabinet où tout, jusqu'à la lumière, est disposé arec art, scront classés les morceaux de différens genres qu'il rasscmble de toutes parts, les pièces anatomiques qu'il fait préparer, anxquelles il travaille lui-même. Bicutôt il y ajoute les riches collections de Sandys, de Hewson, de Blackall, de Flaconar, anatomistes célébres: les organes du tissu le plus pulpeux,-le plus délicat, disséqués, injectés par ces grands maitres, sont l'angés suirant l'ordre de leurs usages; l'on y roit les iustrunens des différentes fonctions, pris dans tonte l'étendue du règne animal, former des séries croissantes et décroissantes, suivant qu'on s'éloigne ou qu'on se rapproclie do 
PHYSIOL. ET MÉD. - IUNTER. 383

l'homme, qui est le premier modèle. Les artères et les veines remplies d'un fluide étranger; la lymphe remplacée par le inercure, dont l'éclit brille au traver's des membranes; des milliers de ranilications dígangés de leur parenclıynte; des viscères plongés dans des fluides oì ils conservent leur souplesse; les ressorts de la vie et des monvenens déreloppés anx yeux avides des spectateurs; les véritables formes ménagées; la putréfaction suspendue; l'appareil inposant de tant de corps, dout le silence et l'immobilité parlent éloquemuent it la prusce: tout, an unilien de ces merveilles, amonce ì l'houme la grandeur et les bornes de son industrie.

Ce tableau ne comprend qu'une partie du cabinet anatomique de M. Hunter. Auprés des organes considérés dans l'état de santé se trourent ceux que les maladies de différentes espèces ont dénaturés; et ces foyer's de tant de douleurs et de tant de morts étoient des énigmes pour tout antre que pour M. Hunter, qui seul en savoit le. nnot et pouvoit les expliqner.

C'étoit dans ce musée qu'il faisoit ses leçons d'anatomie, de médecine et d'accouchement: ne parlant que de ce qu'il comoissoit bien, ayant autour de lui les preures de ses assertious, et tonjonrs prêt à les démontrer, ses paroles sembloient être autant d'oracles. De là cet empressement arec lequel on a suivi, sur-tout pendant les dernières années de sa vie, les leçons qu'il faisoit en petit nombre, et dans lesquelles il avoit concentré tous ses principes et sa doctrune. Il avoit, comme 
Ruysch, de la véhémence : il s'écrioit souvent avec ce grand homme: Vencz et voyez (1): et il pouroit en effet parler aux yeux. Devenu sćvère dans sa critique autant que dans ses mœurs, il ne faisoit et ne rouloit point qu'on lui fìt de grace. Il regardoit la foiblesse dans le caractère comme un des plus grands défauts, parce qu'clle n'ose faire le bicn ni s'opposer au mal. M. Hunter étoit en médecine et parmi ses confrères unc sorte de censeur pour lequel on n'avoit pas autaut d'amitié qne d'estimc. Ce dernicr scntiment, dont il étoit digne, lui suffisoit, et il y avoit peu de personnesdont il ell attendît un autre: mais ce ressort, cette énergie, dont il aimoit tant à domicr des prenves, sont opposés au désir de plaire, à l'amabilité, qualités douces, affectucuses, anssi sûres d'ubtenir que promptes à inontrer de l'indulgence, et qui répandent sur les imperfections des hommes un voile dont l'illusion les rend plus supportables. Saus doute il auroit mienx valu qu'il cnt rémi la douceur de l'esprit à la vivacité de la penséc, la modération dans les actions ì la hardiesse dans les desseins, l'impartialité du jugement à la clıalcur de l'inagination: mais ce degré de perfection est-il possible? Pent-on reprocher anx hommes vifs et bonillans une impétuosité qui tend d'elle-nème vers le bien et sans laymelle la scine du monde ennuicroit peut-être par son uniformité?

(1) Fenier vide. C'ćtoir te mot de Ruysch. 
PHYSIOL. ET MÉD. - HUXTER. 385

Une belle snite de coranx et de coralines recneillis et mis en ordre par Ellis, les coquilles et les litoplyytes conservés par Fothergill, furent, dans un autre tenups, ajontés a la collection de M. Hunter. Il ne nuit pas moins de choix et de nagnificence dans la disposition des médailles et des livres qui ormoient son cabinet. Les prenières ont été décrites par M. de Combe son ami, dans un bel onrrage (1) que M. Hunter a dédié à la rene d'Angleterre. Parmi res lirres, plusionrs originaux précieux ont été cités par le docteur Harwood(2); et M. Hunter a fait lui-nêne surnue édition de Théocrite qui a paru eu 1495 (3) a Venise, des remarques curicuses qui aroient échappé ì tons les bibliographes. Il étoit trop exact pour annoncer publiquenent nn gont daus lequel il n'uroit pas excelle; et ses connoissances, quelquétrangères quielles paroissent à la médecint, lni furent d’un grand seconrs, soit comme un délassement au milien de ses travaux, soit pour en imposer à ces esprits forts qui niestiment nu médecin qu'antant qüils tronvent en lui un mérite indépendant de son état; soit pour son propre bonhenr, sur-tout dans quelqu'nn de ces instans où l'homme instruit a besoin des consolations de l'amour-propre.

(1) Voyez la préficc de la première édition des Anteurs classiques grecs ct latins, par le docteur Harwood.

(2) Nummorum veitenum populonm et urbium qui in museo Gui.lelimi Hunter assensuluer descriptio, figuris illustrala ojera et sludio Caroli Combe. in-\{. ${ }^{\circ}$. Lond. 1733 .

(i) Grand in-fol. Venise, 145.5 .

т. 2. 
Sans cesse appelé auprès des grands, nommé médeciu de la reine d'Angleterre, il y parut toujours avec ce caractère d'assurance et de fierté qui s'ennoblit lorsqu'on a la liardiesse de le porter à la cour.

Il a tonjours, et sur-tout vers la fin de sa vie, donné de grandes marques de courage etde fermeté. Quoique les attaques de goutte auxquelles il étoit sujet fussent devenues plus fréquentes et plus irrégulières (1), il n'interrompit point ses travaux; et, treize jours arant de succomber aux atteintes de ce mal, il voulut faire une leçon de chirurgie qu'il avoit amoncée. Elle tonchoit à sa fin lorsque, abattu par la douleur, il perdit la parole et s'évanouit au milieu d'un auditoire consterué. Pendant les jours suivans le mal ne fit que s'accroître, mais son ame conserva toute sa force. c'Je voudrois, disoit-il à M. de Combe son ami, qu'il me fùt possible de tenir la plume, j'écrirois combien il est facile et doux de mourir (2) ». Cederuier trait, digne du stoïcisme le plus sévère, nons peint assez le caractère de M. Hunter. Il est des vertus dont le charme atteudrit, parce qu'on trouve en soi quelques-uns des seutimens qui les produisent; il en est d'antres qui causent plus de surprise que d'intérêt, parce qu'elles sont étrangìres au plus grand nombre : converts de chainies de toute

(1) En 1783.

(a) Ii est mort le 30 mars 178\%. M. Simmons, pag. 51 el 52 de lat vie de Mr. Hunter, nous apprend que l'on a trouvé parmi les papiers de cer anntomiste, $0^{0}$ des legons gui scrovient d'introduclion a ses cours; 2." des obserrations sur l'art de's accoucheuneus. 
PHYSIOL. ET MÉD. - HUNTER. 387 espece, comment la plupart des homues ne mourroient-ils pas en esclaves? Mais paruni ces chainnes il en est de si douces, de si respectables, qu'il sera toujours plus facile d'adnirer que l'imiter cenx qui, comme M.Innter, meurent sans regret, parce qu'ils out vécu saus dépendance.

Lorsque M. Hunter fint nonné notre associé étranger, il nous adressa une lettre remarquable prar la nuanière dont il y parloit de sia reconnoissauce et de nos travaux. "Parmi les nuarques de considération que » j'ai reçnes, celles que mes coufrères m'ont donnie'es, ग nons écrivoit-il, n'out tonjours parn les plus agréa» bles, parce curelles sout les uienx sentics et les plus ») difficiles à obtenir. On ni" a dit, ajoutoit-il, que ros » travaux étoient pénibles, mais n'en soyez ni snrpris » un découragés; car le peu de bien que jai fait est ce ग) qui m'a coûté le plus de peiue et ce qui a rencoutré »le plus d'obstacles. »

Le cabinet de M. Hunter doit, conformémeut à ses demières rolontés, rester pendaut trente ans ì Londres, d'où il sera trausporté à Glascow; mais il a perdu la plus grande partie de son mérite. Les morccaux précienx et rares qu'on y admire niont pas été disposés sculement pour plaire aux yeur: chacune des parties de ce bel ensemble étoit, sous la main de M. Hu uter, nu foyer d'instruction et de lumières ; ct leur réunion devoit être considéréc comme uu dépôt où sa mémoire retrouroit le tablenn de toutes ses idées, le précis de toutes ses olscrvations. An milien de son cabinet, M. Hunter étoit plus sarant; ct sa collectiou prenoit 
clle-même nne nouvelle face et inspiroit un nouvel intérêt. Maintenant la chaîne de toutès ces vérités est rompue; tout est muet dans ce vaste édifice, ou plutôt tout y annonce la perte d'un grand homme, dont les débris méritent encore des hommages, en ajoutant à nos regrets. 
PHYSIOL. ET MED. - LAMURE. 389

\section{LAMURE ( $\mathrm{DE})$.}

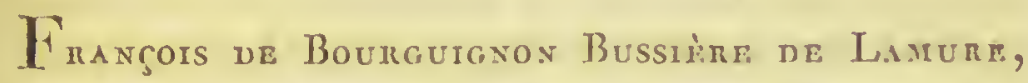
seignenr de Lanure, doyeu des professenrs royaux de l'Université de núdecine de Montpellier, menulue de la Société royale des sciences de la mème ville, affilié régnicole de la Sociétí royale de nuédecine, naquit le 11 juin 1717, au fort Saint-Pierre de lu Martinique, de François de Lamure, commandant dn quartier de Macouba dans la mène ile (1), el de Marianue Ferry.

La famille de M. de Lamure est originaire de Provence, et des titres autlicntiques font remonter sa soblesse jusqu'au quinziène siècle.

Il reçnt sa prenuicre édncation à Nantes (2); il fit ses linmanités à la Flèche (3) d'oǹ il repassa à la Martinique. Revenu en France par Marseille (4), ce fut en $17^{3} 7$ qu'il prit ses premières inscriptions dans l'Université de médecine de Montpellier, où trois années après (5) il reçut le grade de doctenr.

(b) Il étoit cheralier de l'ordre royal et militaire de St.-Louis.

(2) Il y fut envoyé en $272 \%$.

(3) Il y demeura jusqu'à la fin de l'année 1733.

(4) En 1736.

(5) En 17 fo. 
La gucre ayant interrompu toute communication entre l'Amérique et la France, M. de Lamure se tronva dépourvi des secours de sa famille.

Les jeunes gens qui se disposent à paroître sur la scène du monde ont pour l'ordinaire à combattre la bonne ou la mauvaise fortune, et de ces deux ennemis le dernier n'est pas toujours le plus à redonter.

M. de Lamure, reçu docteur à vingt-trois ans, ne trouva ni malades à traiter, ni place à remplir. Les routes nombreuses de l'intrigue répugnoient toutes à sa délicatesse; il ne connoissoit d'ailleurs que les senls étudians en médecine, et il n'étoit connu que d'eux: il ne les quitta point. Il ourrit des conférences daus lesquelles il leur expliquoit les Instituts et les Apho-. rismes de Boërrhaave; le nodique lıonoraire qu'il cn retiroit lui servoit pour sa subsistance, et l'estime qu'il avoit inspirée suffisoit à son ambition; sentiment tonjours foible lorsque les premicrs besoins ne sont pas satisfaits.

En essayant ainsi ses forces, on déconvrit et ils'aperçut qu'elles étoient grandes. Une mémoire des plus heurcuses et un esprit juste, me élocution facile, une manière agréable, du talent avec de la gaicté et dı désintéressement sans fortune, étoient les qualités que l'on remar(puoit en lui. Il commença un coms d'anitomic et de physiologic, qui cut un grand succis; ot les étndians, dont juspru'it cette époque il avoit été l'ami, le recomment alors pour lenr maitre.

Ainsi croissoit sa renommée : il fréquentoit les lıôpi- 
PHYSIOL. ET MEDD. - LAMURE. 391 taux; il méditoit sur l'art de guérir; tont ce que l'étude, l'expérience et la réflexion lui montroient d'utile et de vrai, il s'empressoit de le transmettre à ses nombreux élives. Une émulation conmume les animoit tons et les faisoit marcher rapidenent, enx rers l'instruction et hii vers la célébrité.

C'est un bel art que celıi de l'enseignement!

Quand en effet l'homme offrit-il à l'homme le témoignage le plus flattenr de son respect? Ce fiut sans donte lorsuru'il se tut pour éconter son semblable, pour recueillir ses paroles, pon se pénétrer de son esprit. Comme M. de Lamme s'exprimoit avec clarté et que son discours aroit du nonrement, on l'entendoit et il intéressoit tonjours. Pour agir sur l'imagination, il n'avoit pas besoin de la tronper. Il a enseigné pendant plus de quarante années, et l'on n'auroit pas à lui reprocher un seul systène.

Aux leçons d'anatomie et de plyssiologic, il ajouta successivement celles de matière médicale et de médecine pratique. Les étndians y tronroient des connoissances positires; avec Ini ils fixoient leurs idées et ils arrêtoient lenr jugennent, condition sans laquelle on ne pent faire de progrès dans une étude quelconque: car on se fatigue de beaucoup apprendre sans rien savoir, et de rassembler des faits sans s'en servir.

M. de Lamure étoit bien loin de croire que ses leçons pussent tenir lieu de tonte autre étude ; il prenoit au contraire beaucoup de peines pour diriger les lectures de ses élèves, et pour leur indiquer le meilleur usage à faire d'une grande collection de lirres. 
Parmi les diverses combinaisons dont les livres sont susceptibles, une des plus curienses, et, quoique bizarre, une des plns utiles, seroit peut-être de les distribuer, à la manière des naturalistes, en classes, ordres, genres, et espèces, de sorte que les originaux, mis en tête de leurs dérivés, dominassent sur tous ceux que l'on jugeroit avoir emprunté leur style, leurs formes, leur marche on leur's sujets. On verroit alors un petit nombre de grandes illées et de principes féconds marquer les premières places; à cres onvrages d'un petit volume, mais d'un grand sens, se rapporter les filiations les plusétendues : on verroit les grands modèles, suivis a loin du servile iroupeau des traducteurs, des imitateurs et des copistes, tenir seuls et sans cortége la route de l'immortalité; et l'œil distinguant sans peine dans ceite foule inmense les anteurs (1) d'avec les écrivains, on xe.consumeroit point, à chercher les sonrces de l'esprit et du savoir, nu temps toujours perdı lorsqu'on est éloigné d'elles.

IMalgré sa répuiation et ses talens reconuus, peutêtre même à carıse de sa réputation et de ses talens, M. de Lamure ent beaucoup de peine ì obtenir une place parmi les professeurs royaux de l'Unirersité de - médecins de Montpellier. M. Fitz-Gérald étant mort en 1748, persome ne douta qu'il ne fút nommé son successenr. Il se présenta en effet au concours (2);

(1) Autorvel auctor, ab augendo.

(a) MM. Gourraigne, Fitz-Maurice, Farjon, Petiot, Scrane et Inbert, conconrurent avec lui. 


\section{PHYSIOL. ET MÉD. - LAMURE. 393}

mais son nom ne fut pas même inscrit parni cenx des trois sujets qu'il est d'usage de présenter au roi. Le public et les étudians en gémirent, et M. de Lamure en firt tellement déconragé qu'il cessa tont travail: mais comme il avoit di caractère, il ne s'abandonna point a de vaius regrets; il partit et il vint discuter ses intérêts devant le chuncelier d'Agnessean. L'injustice étoit consonmée: M. de Lamure n'en fut pas noius éconté; persome ne parloit anssi, bien que lui de la nédecine. Séduit par ses liscours, MI. d’Aguesseau voulut être convaincu par l'cxanucn de ses écrits (1). Tontes les autorités s'étant réumies en sa fatrur, il reçut (2) la promesse de la premiere place vacante parmi les professems royanx de l'Université de médecine de Montpellier, et il partit ponr cette ville, je ne dirai pas triompliant, il avoit trop d'esprit ponles'énorgueillir d'un petit succis; mais content de voir se renoner la chaine de ses travaux et d'espérer qu'il secevroit un jour la récompense à lagnelle il avoit borné tous ses rœux.

Pendant sou séjour à Paris, M. Hilaire MIercier, l'un de ses plus anciens amis, le retrouva, l'appuya de son crédit et le força d'accepter une somme dont il n'avoit pas prérn qu'il pourroit aroir besoin. Non

(1) Quastiones medicte 12 pro cathedra vacante, anno 17 f́. II. de Lamure publia aussi alors, $10^{\circ}$ Pathologicarum de febre et palpitatione lectionum vindicice et examen responsionis d." Serane ad scriptum pracedens. 2. Examen animadversionum d. ${ }^{\circ}$ Petiot in parergon de anevrismate conscriptum.

(2) A la fin de l'année 17 名. 


\section{4 ÉLOGES HISTORIQUES.}

semlement $M$. de Lamure ne l'oublia point, mais il rendit sa reconnoissance publique en lui dédiant son meilleur ouvrage. « Tu savois, lui dit-il (1), que ma j) situation exigeroit d'autres secours que des conseils; " tli m'as cherché, et tu m'as découvert; plus tu as " pris soin de cacher ce service, plus il est indispen" sable que je le publie. Souvent, ajoute-t-il, l'adver》sité m'a fait connoître qu'il étoit doux d'être heureux " parmes anis; tu tiens, mon cher Mercier, le premier ग rang parmi eux; mais permets-leur de croire quo "tu ue le dois qu'à l'ancienneté de notre liaison ». Ami délicat il craignoit d'offenser ceux (2) qu'il avoit laissés loin de lui, et ce souvenir obligeant ne pouvoit déplaire à M. Mercier, dont il avoit accepté le bienfait et que tant d'autres motifs plaçoient le plus près de son coeur.

Plus on avance dans l'histoire de M. de Lamure, je ne dirai pas plus on l'adınire, je dirai plus ou l'aime. Cet lonme vertuenx et sensible, an sort dıquel il est impossible de ne pas's'attacher, reprit a Montpellier ses premieres liabitudes de travail et d'enseignement. M. Ridenx, doyeu des professeurs

(1) Epitre dédicatoire de l'ouvrage intitule: Recherclies sur la cause de la pulsation des artires, sur les monvemens din cerveau ct sur la couenne du sang, par M. de Lamure, à Montpellier, in-8. 1769 .

(a) MW. de Castillon, procureur-général du parlement de Provence, Venel, Monlton de Genc่e, Daumont et Lebrun, ont anssi futé ses nmis intimes. C'est le dernier qui m'n fourni les renscignemens domt je ne suis servi pour cicrire cet k̇loge. 
PHYSIOL. ET MÉD. - LAMURE. $3{ }_{9} 5$ royaux, mourpt en 1750 , et il lui succédia. Tonte la ville applandit à ce choix; les étudians allunnèrent des feux : quelques précautions qu'il ent prises pour contenir lenr joie, elle édata, ct il vit se multiplicr de toutes parts les marques de l'allégresse publique.

Ses leçons à l'Université ne l'enpêchlièrent pas d'en faire aussi de purticulieres en fuveur des étudians : il tenta de nouvean diverses expériences sur des animanx; sa pratique s'accrnt. Les jeunes médecins formés à son école le consultoient de tontes parts; il travailloit à la rédaction de plusicurs onvages, et son temps suffisoit à peine à tant d'occupations.

Pourquoi, dit froidement la critique, faire tant de choses it la fois? Mais est-on le maitre de fixer sur un scul point l'activité d'un esprit qui s'applique d tout? Qui sait s'il ne fuut pas que plusicurs efforts conconrent en même temps ì l'agrandir; si cet état violent n'est pas indispensable pour que les grandes combinaisons s'opèrent? Et pourquoi roudroit-on que la jeunesse et la vigueur de l'àme obéissent à des lois que nul n'a droit de leur dicter?

Animé par ce zèle qui produit les grands ourrages et qui mène aux graudes réputations, M. de Lamure composoit alors un Traité de médecine dont il a publié des sommaires ( 2 ) très-rechercliés, une pliysio-

(1) Tels sont les ourrages suirans:

1. Prime linect pathologicte.

2.0. Primce linece therapculice.

3. Positiones scmeioticce. 


\section{6

logie dont on connoît le compendium, qu'il dictoit à ses élèves (1), et 11 ourrage sur la matière nédicale auquel il n'a pas mis la dernière main, et que l'on a imprimé avec tånt d'imperfections (2) qu'il n'a pur se dispenser d'en faire un désaveu public.

M. Fises, praticien célèbre, étant mort en 1769 , M. de Lamure, plıs occupé que jamais de l'exercice de la médecine, fut alors enlevé pour toujours à ses travaux littéraires. Cependant il continua de remplir ses fonctions à l'Université; et lorsqu'on le félicitoit sur le plaisir qu'il faisoit toujon's à ses anditenrs, c'étoit dans ma jemnesse, disoit-il, qu'il falloit n'entendre! Riéponse très-remarquable, soit parce que cette sorte de modestie se trouve rarement dans les vicillards, soit parce 'qu'il disoit alors une vérité que l'on n'a point assez sentie.

Combien en effet cette jeunesse dont on se méfie tant n'a-t-elle pas opéré de prodiges! Combien est féconde cette chaleur qu'clle nut ì tont! Infatigable et générense, elle ne recueille que pour répandre. S'agit-il d'enseignenent: par combien de moyens le jenne homme que de grands taleus y appellent, frappe

1." Positiones medico-rhimrgice de snpunratione.

5." Positiones c.x phystologia genereli corporis humani depromplte. E11 1781 .

(1) Il dictoit à ses clères un Compendium anatomico-physiologicum qui n'a point été imprimé.

(a) Nonveanx détencus de matière médicale, cxtrails des leçons de M. de Lamure. $\Lambda$ Ansterdam el à Montpellier 1784. 


\section{PHYSIOL. ET MED. - LAMURE. 397}

at la fois l'attention de sou anditoire! Comme ou aine le contraste de son savoir avec son îge, et celni de son ardenr avec sa modestie! Sa númoire est riche en innages, que son inagination embellit; sou discours est plein d'enthonsiasme; il ne récite pas, mais il peint : avec quelle perfection il expose l'euchainement des comoissances acquises! Arec quelle furce il poursuit l'ertenr! Avec quel respect il prononce les grands noms, múme ceux de ses coutemporains! L'envie n'a point encore pénétré daus sou coenr; cehi qu'nue longne expérience a formé l'emporte sans donte par la précisiou des idées; il a rassemblé plus de taits, et la vérité lui est mienx connus; on y parvient plus difficilement avec l'autre, mais on la désire plus vivement, et il sait mienx la faire aimer. L'un, ólevé an faite de la gloire, ne voit que du repos dans l'enseignement; son langage est froid et séricux : pourquoi s'agiteroit-il? Il n'a plus de soulıait à former. L'antro est loin dn but; il se haite de l'atteindre, l'on marche et l'on avance avec lni. Ne semble-t-il pas que tous denx rempliroient lenr tìche, l'un en fixant les règles de l'art dins des écrits, l'autre en les développant dans des leçons. Disons plntôt que, dans les grandes écoles, comme daus celles de Montpellier, il importe que la rérité soit annoncée par des savans de divers âges, afuı que les élèves en commoissent tous les tons, qu'ils y tronvent des modèles de tors les genres, et que prenaut des conseils de sagesse et de conrage, ils sachent ce qu'ils doirent espérer ou craindre dans la carrière oì ils sont entrés. 
Cette facilité d'expression, cette douccur, cette sagacité, qui lui avoient concilié tous les suffrages dans l'enseignement, lui furent aussi d'un grand secours dans la pratique de la médecine. La confiance qu'il avoit inspirée étoit générale; ses talens étoient reconnus par tous les partis, par les étrangers comme par les nationaux; et c'étoit à Montpellier même, parmi les étudians qui se succédèrent en se transmettant toujours les mêmes sentimens de tendresse pour ce maître chéri: dans cette même école, où des bancs il avoit passé dans la clıaire; où du plus jeune des élèves il étoit devenu le doyen des professeurs : c'étoit dans cctte ville qu'il regardoit comme sa patrie, où, sans fatigue et sans efforts, il s'étoit environné dc bonlicur, d'estime et de gloire. Son secret avoit toujours été de ne vouloir de cette dernic̀re qu'antant qu'il en falloit pour ne pas trouver les deux autres. Il rẹ́missoit, disent ceux qui m'ont communiqué des mémoires sur sa vie, les qualités du médecin dont parle Baglivi; puissant par ses conseils, puissant par ses discours, medicus sermone potens : ct dı fond de l'Allemagne, de Haën écrivoit : Pourquoi vous adresser si loin? Consultez Lanure; c'est 1 médecin guérissenr.

Lorsqu'on cherche at se rendre compte des motifs de cette grande célébrité, on trouve qu'clle étoit due au caprice de la mode, ponr laquelle il ne fit ricu, el 'qui ne fit anssi rien pour lui; non à l'enthonsiasmo de la nouveauté; content de la place qu'il occupoil, il n'en chercha point d'autre; mais at une instruction profonde, à un esprit vraiment philosophingue, it un 


\section{PHYSIOL. ET MÉD. - LAMURE. 399}

petit nombre d'écrits, qui décèlent un talent rare et qui attesteront i jamais que leur auteur fut un grand hornme.

Ses travaux sur quelques poiuls de plysiologie ne le cedent point a ceux de Haller. Deux questions importantes smr la pulsation des arties et sur les nomvemens du cervenu étoient cucore indécises: M. de Lamure les a résolnes, et il a attaché sou nowl ì cette partie de notre histoile.

On sera peut-être ćtomné d’apprendie que le mécanișme du pouls, si sourent consulté par les médecins, lem ait été aussi long-temps inconnu. Jusqu’i V Veitbrecht, c'étoit seulenent i la dilatation des vaisseaux que l'on en avoit attribué la cause, saus la nier tontd-fait: cet anatomiste déclara qüil la regardoit connue insuffisante pour expliquer le battenuent des artères, qui, survant lui, ue fraplent le doigt quien se soulevant et en se déplaçaut daus le sens de leur louguenr.

C'est ce trarail que MI. de Lamnre a survi et perfectionuc : ses nombreuses expéricuces en ont éclairé toutes les partics. Il s'est assuré d'abord que toutes les branches artériclles battent ensemble, à moins que le ressort de quelques-nues ue soit affoibli. Son secoud résultat a été, commer MI. TTéeitbrecht l'avoit dit, qu'elles battent en se déplaçant; il a vul l'aorte se soulever par secousses le long de la colonne rertébrale; il a vu les artères des iutestius et celles des espaces intercostaux se mouvoir de mème; sur-tout il a prouvé que les pulsations des artères correspondoient aux contractions des ventricules du cœur, et 
il a dit: Le cour conserve encore ses mouvemens lorsqu'il est séparé des artères qui sont privées des leurs; dès qu'elles ne communiquent plus avec lui. D'ailleurs la pointe de cet organe se porte en devant et frappe les côtes, non lorsqu'il se dilate, mais lorsqu'il se resserre. De même, ce ri'est point la dilatation, mais le déplacement des artères qui produit le pouls, et c'est l'impulsion donnée au sang par le cœur, et modifiée dans les flexuosités des canaux où (1) il circule, qui les anime et qui les soulc̀ve.

Pour le démontrer, il a fait sur l'artère crurale d'un chien vivant deux ligatures, entre lesquelles, toutes les fois qu'il a eu soin d'y comprendre une assez grande quantité de sang, le battement, sans être ì beaucoup près aussi fort (2), a continué de se faire sentir (3).

(1) Ferrein appeloit ces sortes de déplacemens des mouremens de conversion.

(2) J'ajoute cette circonstance qui s'est toujours offerte a moi dans nes expériences. M. de Lamure n'a pas fait la mème restriction.

On lit dans Galien qu'ayant introduit un tube dans la cavité d'une artère, et ayant lié l'artère sur ce tube, il avoit toujours vu les battemens cesser an-ilessous de la ligature. Harvey et Vicussens ont répété cette expérience ave un résultat contraire. On ne pent donc lopposer aux partisans de l'explication donnćc par MI. de Lamure.

(3) Pour démontrer le soulèrement de l'urtire, il a placé un doige sous l'artere et un autre dessus : le premier n'a pas ressenti la pulsation que l'autre a éprouvéc. On a contesti is M. de Lamure lo: résultat de cote expérience, qu'il faulra répexter arant que de prononcer définitivemeat sur ce sujet. 


\section{PHYSIOL. ET MÉD. - LAMURE. 401}

M. de Lamure a bien distingué ce mourenent du vaissean d'avec le pouls prodnit par la pression du doigt, qui ne peut, selon la remarque de M. Jadelot, chánger la forme ronde de l'artiore sans rendre sil cavité plus étroite, et sans opposer $n$ obstacle à la circulation dont ce canal est l'instrument.

Malgré la précision de ces idées et l'exactitude de ces preuves, M. de Lamnre paroit avoir trop négligé la force inlıérente anx conduits arléricls qui sont musculaires (1), et trop dinimú les effets de la pression latérale, que d'antres nient absolument (2). J'ai vu, romme Haller, des artères se renfler lorsquicelles battoient; et daus plusienrs quadrupides ovipares cetto dilatation est telle qu'on ne pent la révoquer en doute.

On sait que les efforts, tels que les cris, le rire, la toux, le vomissement et l'étermenent, ponssent le sang rers la tête. Riolan avoit vin le cervears, déconrert ì la suite d'une carie de l'os pariétal s'élever et s'abaisser. Schliting s'étoit aperçu que l'ćlération de ce viscère dans les aninnaux trépanés correspondoit à lenr expiration; il aroit senti des pulsations artérielles antonr de son doigt introduit dans la subs-

(1) On trouve des fibres musculaires très-marquées dans les grosses artères des jeunes animaux. Les ossifications circulaires dé certaines parries du inbe artẻriel n'empèchent pas les battemens in s'élentre au loin ; ce qui est firorable à l'opinion de 7I. de Lamure.

(2) MAI. Jadelot et Arıaul sont de ce nombre. Toyez ce qu'ils ont écrit sur ce sujet, et la lenre de 11. Contomb sur un cours de pyisique expérinentale fait par MI. Portal en 177 .

T. 2. 
402 ÉLOGES HISTORIQUES.

rance cérébrale des animaux vivans, et il avoit terminé ses recherches en demandant si c'étoit l'air ou le sang qui se portoient ainsi vers cet organe.

M. de Lamure a répondı de la manière la plus précise à cette question intéressante.

La section des nerfs vague et grand sympathique de la trachée-artère et de l'œsophage, n'ayant apporlé aucun changement dans la correspondance des monvemens des poumons et du cerveau, M. de Lamure dirigea ses vues du côté des vaisseaux sanguins. L'artère carotide et les veines jugulaires furent lićes, et le cervean continua de se mouvoir. Il comprima fortement la poitrine de ces animaux et même, après leur mort, le cerveau s'éleva par ce procédé; il pressa la veine cave de bas en haut, et l'effet fut le mêrne: il ouvrit les veines $j u g u l a i r e s$, ct ce mouvement s'affoiblit et cessa; il ouvirit à la fois les veincsjngulaires ct les vertébrales, et le ccrveau devint aussitôt inmobilc. La veine cave on les sinus de la tête ayant été largenent incisés, le cerveau perdit encore tout son mouvement. Pour que ce viscère s'élève comme dans les expériences précédentes, il suffit qu'après avoir dilaté les pounnons on oppose, en fermant la glotte, nn obstacle invincible anx causes qui tendent à l'affaisser. Dans tous ces cas, les parois mobiles de la poitrine pressent li's poumons, par lesquels sont comprincécs les reines de cette cavité. Le sang. est reponssé dans les veines jugnlaires et dans les rertébrales; il gonfle les sinus de la base de la tête sur lesquels est soutenu le cerveau 


\section{PHYSTOL. ET MÉD. - LAMURE. 403}

qu'il soulève, et des simus il passe daus les veines de cet organe, qu'il distend : ce qui explique toutes les circonstances du fait observé par Sclıliting.

Haller avoit parlé des mouvenuens du cervean et de leurs rapports avec ceux de la poitrinc dars 111 article de sa Dissertation sur les parties irritibles (1); il réclanna avec humenr. c Je ne veux pas, dit-il, que l'ou m'impute un plagiat »; mais il voulvit bien que M. de Lamme en fût accusé (2). Les voild donc cés grands observateurs de la mature se disputaut, par ur calcurl de date, le noble patrinoine de la gloire! Les voild conuptaut les jours (3), jai prescue dit les lueures, dont l'un avoit devancé l'autre! Lá disserfation de Halter avoitété lue à la Sociétédes sciences de Gottingue,

(1) Dissertation de Mr. Haller sur les parties irritables, eic. 1.92.

(2) En lisant attentivement leurs onvrages, on roit que plnsieurs de lenrs opinions sur les phénomenes dont il s'agit different essentiellement entre elles. Suivant Haller, le sang stagne dans les veines jugulaires et dans les vertébrales pendant l'expiration; suirant IM. de Lamure, il $y$ est repoussé des veines cares, et c'est un víritable refonlement : ce qui arrive en effet dans tous les efforts un peu considérables. M. de Lanure admettoit arec Schliting un espace vidc entre la dure et la pie-mère, et ils pensoient que, dans l'état uaturel, le cerveau s'éleroit toutes les fois que l'air sortoit des pommons : ce que Haller a nié arec raison.

(3) Voyez $10^{\circ}$ la lettre de $\mathrm{MI}$. de Lamure, efc. à MI. Danmont, professeur royal en medecine à Valence, dans laquelle il fait roir qu'on ue peut pas le soupconner d'aroir copié II. de Haller au sujet de l'explication des monremens du cerveau qui paroissent daus l'hounme et dans les animaux trépanés. A Lyon 1755 , in-8.

2. Recherches sur la cause de la pulsation des artères, sur 


\section{ELOGES HISTORIQUES.}

le 22 avril 1752 ; le Mémoire de M. de Lamure l'aroit été, à l'Académie des sciences de Paris, le 2 août de la mûme année; mais Haller ignoroit que ce mémoire avoit été présenté ì la Société des sciences de Montpellier, le 4 mai (1); ce qui réduit la différence à quelques jours (2).

An reste, en repoussant les coups de son adversaire, M. de Lamure s'abstint toujours d'en porter, et il se montra dans cette défense si généreux et si fort, qu'enfin Haller lui rendit justice en publiant que c'étoit (3) à M. de Lamure qu'appartenoit l'honneur d'avoir fait connoître par de nombreuses expériences la cause de l'élévation et de l'abaissement du cerveau (4).

les mouvemens du cerreau dans l'homne et dans les animaux trépanés, et sur la couenne du sang, par M. de Launure, in-8. ${ }^{\circ}, 1769$, pag. 197,199 et 205.

(1) De Ja même année 1755 .

(2) Haller écrivit ì ce sujet une letıre it Sauvages, qui la reçut all commenceneut de l'année 1752 , et sur laquelle il fondoit en partic sa réchumation. Dans cette lettre, il aunonçoit la stagnatiou dn saug daus les veines du cou comme la cause du souldvement du cervent. M. de Launure n'a point laissé ignorer cetie circonstance en parlant, daus son Mémoire, de la vratie cause de ce soulèvement. M. de Haller, dit-il, l'a indiquée.

(3) Verium onnino ubcrius heec cum experimentis conjunxit Franciscus Lamure, 'et ctian mea cxperinenta non simum dubitare quin veram phenomeni cansam apernerit. IIalleri pliys. tom. II, lib. IV, sect. IV , et pag. 2 \{t des liecherches publices par JI. de Latlure chl $17(1)$.

(4) Il s'agit roujours ici des animanx trépanćs. 
PHYSIOT. ET MÉD. - T.AMURE. $40 . r$

Dans une antre Dissertation (1) plyysiologique sur la respiration, M. de Lamure tratita des nonvemens des côtes: on y trouve nue expéricnce de lajuelle il snit que prudant l'inspiration les espaces intercostanx augmentent. Dans l'état naturel cet accroissement est pen sensil)le; mais lorsqu'ou a fait une onverture à la poitrine la gène de la respiration devient plus grande, et les côtes s'écartent darantage. Celte expérience tres-remarquable lut faite rn 1,52 par M. de Lannre 'n présence de Sanvanges (2).

La thèse qu'il a redigíc ponr M. Salnon, alors étudiant en médecine d Montpellior. (3), contient une observation curiense. Ayant plusiens fois fint peser des personnes dn sexe immédiatement avant et apris la menstruation, il vit que le poids dn corps étoit le même à ces denx époques. Il fint encore attaqué sur cette expérience et on le forra de pronver (4) qu'il n'avoit point profité dans cetécrit des iclées de Simpson, nédecin anglais, aı nom dupuel NI. Fitz-Gerald, l'un des professenrs royaux de l'Lniversité de Miont-

(1) Dissertatio physiologica dc respiratione, respond. Joanne Cupdeviellc. Presid. Francisc. de Lamure, in-8. ${ }^{\circ}$. Montpellier, 1752.

(2) Page 2f. .

(3) Dissertatio physiologica de fluxu menstsuo respond. Nicol. Salmon. Autore de Lamure. Montpellier, 1745, pag. 11, 6 VI.

(4) Voyez Francisci Lamure, etc. Epistolu ad D.... doctorem mcdicum, qud suam de fluxu menstruo dissertationem à plagii accusatione vindicat. In $-8.0,17 .\{5$. 


\section{6 ÉLOGES HISTORIQUES.}

pellier, le poursuivoit avec chaleur. Trois sortes de personnes trouvent toujours des défenseurs zélés dans la carrière des lettres, les étrangers, les morts et les vieillards. On leur prodigue la louange, sorte de tribut que l'on aime à répandre au loin, mais que de près on paie avec regret, et que l'on refuse à ceux qui sont le plus dignes de l'obtenir.

Dans une Dissertation sur les sécrétions (1), il a indiqué la pesanteur spécifique des liumeurs animales, et il a essayé de faire voir que la force d'impulsion de leurs molécules étoit proportionnelle à la résistance des fibres des divers organes. Ici M. de Lamure a fait preuve d'liabileté dans la science de la mécanique et dans celle du calcul.

On peut en dire autant de ses réflexions sur l'inflammation (2).

Dans ses écrits sur la fièvre (3), il adopta plusieurs

(1) Dissertatio physiologica de secretionum in humano corpore mechanismo. Resp. Claudio de Chavane, in-8. ${ }^{\circ}$. Montpollier, 3748.

Jusqqu'it ce que la chimic animale ait fait des progris suffisans, nous ne saurons rien de certain sur les sécrétions.

(2) Theoria inflammationis, in-3.9, $17\{3$.

(3) Voyez $10^{\circ}$ sa thèse intitule: : Theoria febris; $20^{\circ}$ Cuostiones medica, $17\left\{9 ; 30^{\circ}\right.$ Pathologicarum de febre et palpitatione ícetionum vindicie. 1748. C'est une réponse ì une critique de M. Serane. Celui-ci répliqua par l'écrit suivant. Responsio Caroli Serane ad scriptum Francisci Lamure, cui titulus cst : P'athologicarum de fehre palpitatione lectionum vindicis.

M. de Iamure répondit une seconde fois it Mi. Scrane par un ecrie intitulé : Éxamen responsionis Caroli Scrane ad scriptunt 
PHYSIOL. E'T MÉD. - T, AMURE. 407 idées de Stahl, et il s'unit à Sauvages pour coubaltre les systèmes de Boërrhaave sur la phlogose et sur l'ubstruction ( 1 ).

Il pensoit que les palpitations opiniìtres avoient souvent pour cause la dilatation des sinus du crenr (2).

Francisci Lamure, cuitimblis est: Pathologicarum do febre, et pal-

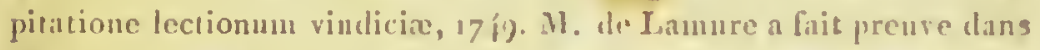
ret écrit d'uue grande élendus de counoissances en mathimutiques. Il s'exprime comune il suit, sur la fière. Fébris dici ponest morbus in quo vis cordis ad vim constamtem musculorum volmmtati sulditorum ratio major est, quim in statu samitatis: et il ajonte: Nam mathematice loquendo magnitudo pulsus est uf qusdratorum dyastoles et systoles diametrorum defferentia, qua quadrata cum medicum latcant, corum diametrorum simpliccm diffirentiam ut pote verifatiphy'sice proximam digito subjectan, indigitare sufficit.

(1) M. Garnier, médlecin, qui pratique avec rélébrité à NinulChàteau en Lorraine, soutiut ì peu prda dans le mene temps, sous lil présidence de Saurages, une thise très-conuue et irès. estimée, intitulée : Pathologia methodica, 1739, llans laquelle il défendit la théorie de Stahl.

(a) Francisci Lamure pathologicarum de febre et palpitatione lectiouum vindicict. 17ł3. Cet ourrage est terminé par un article intitule: $l^{\prime}$ arergon de ancirismate. En $17+9$ parut la critique de $\mathbf{M}$. Petiot, iutitulée : Iu Clar. Lamure parergon de anevrismale animadicrsioutes hortorati Petiot, in- $\left\{0^{\circ} 17\{9\right.$. M. de Lamure y répondit par l'écrit suivant : Examen animadversionum clarissimi Petiot, in parcrgou de anetrismate conscriptum à Francisco Lanure. Il y soutint l'opinion de Monro sur les tuniques des artères. Willis aroit indiqué la mểıne cause des anévrismes, et MI. de Lamure nous apprend que Ferrein aroit fait p'usieurs observations dans le mème genre.

iI. de Iamure a peint arec les conleurs les plus vrajes les 


\section{8 ÉLOGES HISTORIQUES}

- On connoît, sons les noms de conenne ou de croúte inflammatoire, une concrétion blanchâtre ou citrine de forme irrégulière, dont l'épaissenr varie, et qui se tronve quelquefois à la surface de la partie solide du sang refroidi. Les anciens n'en ont point parlé (1); et Sydenliam est un des premiers qui l'aient décrite avec soin (2). Lorsque M. de Lammre voulut fixer ses idées sur ce sujet, il consulta les livres et il y tronva une prodigieuse variété d'opinions sur la nature de cetle substance , et sur le pronostic que l'on doit en tirer (3). Ce que Sydenham a transmis, comme le résultat de ses observations a été nié par Triller. Celui-ci s'est assuré que la conenne recouvroit quelquefois le sang qui avoit coulé lentement le long dn bras, atıssi bien que celui qui étoit sorti par un jet rapide; et van Swieten a vu le caillot du sang des personnes saines devenir couenneux comme celui des pleurétiques et des femmes

symptômes eftrayans qui accompagnent l'inflammation de l'esiomac : Disserlatio medica de inflammatione ventriculi, resp. Ludovico Francisco dic Cair. Prats. Francisco de Lamure. in-4. $0^{\circ}$, Montpellier, ${ }^{7} 759$.

(1) A moins qu'ils ne l'aient désigné par les noms de sang cru el piruiteux claus les maladies aiguës.

(2) Tom. I de Pleuritide.

(3) On l'a regarrlée sucressivement comme le produit du clyyle (Baglivi), du pus (Trillor), de lit partie rouge du sang altéréc (Scliwenke), et de la sérnsicé (Hoflman, Haller, Borden et San-

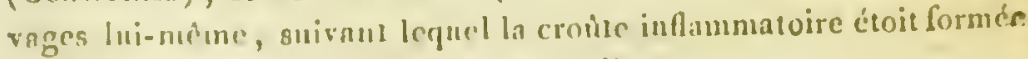
de la sćrosité avec un miasue particulier). 


\section{PIIYSIOL. ET MÉD. - LAMURE. 409}

grosses. De ces variations que MI. de Lannure rencontra près des malarles comme darss ses lectures, il couclut qu'il n'y avoit ancunc induction certaine à tiren de l'existence, mi des différentes formes de cetteconenue (1), et qu'en géuéral son cxanucu n’étoit qu'un objet de théorie rationmelle jusçu'í ce moment, peu utile à la pratique de notre art (2).

Cet exposé de ses écrits prouve qu'cu múdecine il ne jugeoit que d'après l'ubservation, comne en plysiologie il ne raisommoit que d'aprés l'cxpéricuce. Il en aroit tellencut répandu le goint que lis plupart des thèses soutrunes à cette époyuc dans l'Université de Montpellier contienuent des essais pliysiques sur quelques points de doctrine.

On peut rédurice les disscrtations que l'on public dans les différentes écoles de médecine à truis classes. Les unes sont consacrées ì des recherclues d'úrulition, les autres à des spéculations systématiques, daıs lesqijelles on range et on interprète les faits suivant le besoin qu'on en a; diuns celles de la troisiènne classe,

(1) Recherchessur la coucnne dusang, publiées in-8. , avec les recherches sur la pulsation des artères, et sur les mouremens du cerwasu, par M. de Lamure. Montpellier, 1769 .

(2) C'est, on n'en saurcit douter, par la nature et l'intensité des symptòmes fébriles et inflamnatoires que nous devons être dirigés en pareil cas; mais aussi nous pourons croire que les conclusions de MI. de Lanure auroient été moins rigoureuses si, à l'époque où il a écrit son mémoire sur la couenne du sang, on aroit su que cette croûte u'est qu'une partie de la substance albu- 


\section{TLOGES HISTORIQUES.}

on rend compte, non de ce que les antres ont dit; mais de ce que l'on a fait et de ce que l'on a vu. De ces trois procédés, le dernier senl est utile; et, soit pour hâter les progrès des sciences, soit pour tracer aux étudians une marche sûre, il seroit à soulaiter qu'ils fussent astreints à ne s'en écarter jamais. Pourquoiles professeurs, au commencement de chaque année, ne publieroient-ils pas un tablenu d'expériences, de dissections ou d'analyses, que les étndians seroient tenus de faire et dont ils discuteroient les résultats dans Jeur's thèses? Ainsi toutes les questions sur lesquelles il resteroit des dontes pourroient être éclaircies, et les actes publics, au lieu de consister dans de vaines déclamations, seroient un nouveau clıamp ouvert à la recherche de la vérité.

Pour remplir ces vues il faudroit que cliaque Faculté eût deux laboratoires, l'un d'anatomic, l'autre de climie, un jardin de botanique et un hôpital, à peu près comme on le voyoit en Espagne lorsque les arts y florissoient sous le gouvernement des Sarrasins, or

uineuse que la sérosité tient en dissolution; qu'il est possible, par la scule évaporation du sérum, de préparer une coucnue antificielle, et que c'est toujours l'excés de la chalcur qui dispose à sa formation.

Lorsqu'un se propose de dessécher la couenue du sang pour la conserver, il faut qu'elle soil mince, sans quoi elle se pourrit avant que l'ophration soit aclievéc : sourent elle se hoursoufle paree qu'il

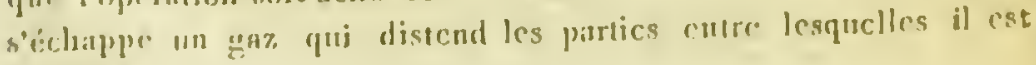
ipsimitic: 
PHYSIOL. ET MED. - LAMURE. 41:

à Bagdad sous les califes (1). Là, près des inosquées s'élevoient tonjonrs m lıôpital et nu collége de médecine, dont la réunion avec ces temples offroit trois grandes idées bien propres à naitre l'une de l'autre et at s'accompagner par-tout; celles de la scicnce, de la bienfaisance et de la divinité.

L'auroit-on pensé que l'histoire de ces peuples nous ent foumi des modèles, et que l'Europe, toute savante qu'elle est, en̂t pu y trouver des leçons? Lorsque la médecine quitta ces asiles de l'hmmanité souffrante pour prendre sa place parmi les autres corps littéraires, séduite par l'éclat de ces institutions, elle oublia tonte sa simplicití : an lien d'observer, elle disserta. Cu'on la reporte aux licux qu'elle a quittés; que son enseignement se fasse an sein des hôpitaux; les milades et les convalescens, les mourans et les morts y seront ponr elle un sujet de néditation ct d'étude. L'anatomiste ne se bornera point à décrire des organes; tontes les circonstances des maladies lni étant connues il cn rccherchera les effets et les canses; il sera facile et peu contenx d'y joindre aux instrumerrs de pharmacic cenx de chimic et de physique, dont on aura besoin dans les démonstrations; les régétanx salutaires que la médecine emploie, cultivés autour de ces demenres, y scrviront à l'instruction des

(1) Voyez page 10 de la Préface des MIémoires pour serrir a l'histoire de la Faculté de médecine de Montpellier, par II. Astruc; revus et publiés par M. Lorry, in $40^{\circ}$, Paris ${ }_{17} 67$. 
élèves; les pauvres en y entrant les contempleront avec espoir, èt ils les béniront en sortant de ces liospices pour retourner à leurs trayaux.

La pratique de M. de Lamure étoit simple et rarement active; jamais il n'entreprit de faire ce qu'il ponvoit attendre de la nature. C'est en effet aroị assez de part à ses efforts et à ses succès que de les connoître et de ne pas les troubler. Quelques-uns conclurent de cette grande circonspection qu'il ne croyoit point à la médecine. Il faut lire ses écrits pour savoir à quelle médecine il croyoit. Quant à la modération qu'il apportoit dans sa conduite, elle tenoit à celle de son caractère. Ce seroit une assez bonne manière de juger les médecins que de les considérer sous ce rapport. Mais tous les hommes ne sont pas assez sages pour le sentir. Tant de réserve déplaît à plusieurs: il en est qui veulent que leur médecin brusque la nature, comme ils brusquent eux-mêmes cenx dont ils sont environnés, et quelques-uns se persuadent que l'on pent joner sur la santé comme sur tons les antres biens de la vie.

La juste célébrité de l'école de Moutpellier et la beauté dn climat $\mathrm{y}$ attirent de tontes parts des étrangyers qui vienuent y chercher des remèdes à leurs sonffrances: M. de Lamme jout long-temps de la confiance de ces malades. Juorsque l'empercur royagea diuns le Languedoc, sous le nom de comte de Firlkenstein, il voulut reucecier M. de Jamure des soins qu'il aroit donnés à M. Ic baron de Lassy, président 
PHYSIOL. ET MED. - LAMURE. 4.3 dı conseil de guerre de sá majesté impériale. Tous m'avez rendı, lui dit-il, un des hommes qui nue sout le plus utiles et le plus chers. En véritú, MI. le comte, répondit M. de Lamure, je suis pour bieu peu de chose daus cette cure: c'est le climat de Mloutpellier qui a tout fait.

M. de Lamme épronva un accilent des plus fichenx pendant ses dernieres antées : sa roue s'affoiblit; mais il ue la perdit pas tout-itfait, comme quelpues-uns s'empressèrent de le répandre. Les médecins out besoin de tous leurs sens, et, pour eux, cosser de roir, c'est presque être forcé de cesser d'agir. MI. de Lamure, ménacé depuis loug-tenups de ce ualheur, fut atteint d'une tristesse profonde; il n'étoit plus le mème, et sa santé dépérissoit. Peu de tenups avant sa mort, un boutou gangrénenx parnt sur sa jone, et il en coumut tont le danger. Il ne dissimula point qu'il regrettoit beaucoup la vie (1). Cenx qui sareut, comme M. de Lamure, se la rendre agréable et douce doirent, comme lui, craindre de la quitter. Heureux par ses goùts et surtout par les soius de son épouse, les liens les plus attachans le retenoient; il laissa conler des larmes qu'il devoit à la tendresse et à l'amitié. Plus de résolution se troure sans doute dans ceux en qui de fortes passions se sont éteintes : ils ne tiemnent au monde que par des souvenirs; ou dans cenx qui, célèbres depuis long-temps, voient enfin se fermer pour eux la car-

(1) Il est wort le 18 mars 1737 , agé de soixante-dix ans. 
414 ÉLOGES HISTORIQUES. rière de la gloire. Ils doivent peu s'effrayer de l'avenir pour lequel ils ont vécu; ce n'est pas auprès d'eux, c'est près des hommes modestes et sensibles qu'il faut apprendre à mourir. On loue et on admire les uns; on regrette et on pleure les autres. M. de Lamure mérita ces divers tributs d'estime et d'attachement. Son nom sera long-temps cher à ses amis et à ses concitoyens; il écrivit peu, mais assez pour le transmettre à la postérité. 


\section{PHYSIOLOGISTES ET MÉDECINS. 353}

\section{LEFEVRE DESHAYES.}

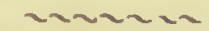

Ciest dans les colonies anglaises que, pour lit première fois, l'Anuérique a $\mathrm{m}$ des savans rémis en corps former me académie. Le Cercle des Philadelphes, établi an Capp-Français à Saint-Donningue, est la seconde institution de ce genie dont puisse se glorifier le Nonvean-Monde. M. Le chevalier Leferre Deshayes étoit mu des nucmbres les plus distingués de cette compagnie, à laquelle il a commmiqué des nuémoires sm. l'histoire naturelle et sull'économie rurale.

Ce physicien s'est fait connoìtre ì la Société par un ouvrage qui a remporté l'un de nos prix sur la topographie médicale dn Cap, et principalement sur les Albinos on nègres blancs.

On appelle dn nom d'Albinos des lommes it pean blanclie et blafarde, dont la chevelure est blonde, dunt les yeux sontiemnent difficilenuent l"éclat de la lunière, et qui sont nés d'mu père et d'mne mère de l'espèce nègre. M. Deshayes ajoute que les Indiens de l'Aunérique et les Caräbes des Autilles, dont la peau est de la conlenr dn cuivre; que les Bunbaras, dont la peau est rongeâtre, et que les blancs eux-ırêmes; porrvu qu'il u'y ait aucun mélange d'une autre couleur, 


\section{6 ÉLOGES HISTORIQUES.}

produisent aussi des Albinos. L'auteur de la Philosophie de la nature, l'abbé Richard, et plusicurs antres avec lui s'étoient trompés en écrivant que ces individus composoient un peuple particulier, soit au Sénégal, soit au royaume de Loango: ils n'offrent par-tout au contraire que des variétés accidentelles et rares, dont M. Leferre Deshayes a fait connoître les différences et les rapports.

Cliaque écrivain semble avoir pris à tâche d'ajouter un trait de plus au tableau de leur difformité.

Suivant M. de Paw, leur aspect effraie, lcur taille est cclle des Lapons; leur teiut est d'un blanc de lait, sans aucun mélange d'incarnat; souvent même, ajoute l'un des anteurs de l'Encyclopédic, il est livide et cadavérenx. Lenr chevelure est soyense, ou plutôt ils sont cliaures; les poils de leurs cils et de leurs sourcils ont été comparés au duvet dı cygne: on les peint cnfoncés dans des cåverues, et fuyant le jour dont l'impression blesse leurs organes; on répète qu'ils ne voient qu'au clair de la lume, et que leurs paupières sont tonjonr's très-rapprochées l'une de l'autre. M. de Paw regarde conme certain que le muscle releveur de ces organes mancue dans les Albinos. Plusienrs leur refusent tonte intelligence, comme aux Crćtins. Ils sont, dit-on, foibles, timides, sourds, presque avengles, imberbes, imbécilles et impuissans. Leurs mains, si l'on en croit Manpertuis, sont des especes de pattes, et Vossins les croyoit alleints de la lipre.

Ce récit montre combien la vérité sollire sons la 
PIIYSIOL. ET MED. - LEFETRE. 477 plume des meillenrs écrivains lorsquils parlent de ce yu'ils n'out point vin on de ce qu'ils n'ont pas assez vı. M. Deshayes traite dans un grand détail les articles dont je ne rapporte ici que les sommaires.

Il assure que l'aspect des Albinos u'a riende repous. sant; ils conservent, dit-il, avec nue pean blancluate les tratits de lenrs péres. Lenr teint, pendant la jeunesse est coloré diun rouge prile et puelpuefois assez vif. Ils sont d'une taille médiurre. M. Deshilyes rien a point rencontré dont le corps ent moins de cind pieds de hantenr. Plusienrs ont les chevenx crépus et mème assez rudes. Il n'y cu a peut-itre ancun qui, dans un ige arancé, soit tout-à-fait deponven de barbe. Quoique leurs yeux soient en général plus délicats que cenx des antres hommes, il ne fant pas croire quils vivent cachés ditus des antres. Une fennme ainsi conformée consoit en pleir jonr, elle entendoit tres-distinctement à voix basse. Une antre travailloit ì la moisson pendant les plus fortes chralenrs; et M. Deshayes a vu des Albinos tucr des ramiers snr la cime des arbres les plus élerés; d’ailleurs, cclte constilution n’est particnlière à ancun des parallèles du globe. On roit des Albiros à Ceylan, à Java, à Congo, à Panama, à Borneo, Madagiscar, dans la nourelle Gumce, dans lìle de Bourbors, à la Guiane, à la Janaïque, ì Saint-Doningue, à la Lonisiane, et dans quelques contrées encore plıs septentrionales de l'Antérique. Quroiqu'ils soient moins robustes que les autres habitans de ces climats, la plupart se livrent aux mêmes 


\section{ELOGES HISTORIQUES.}

travanx, et M. Deshayes ne s'est point aperçn qu'ils lenr fussent inférieurs en intelligence.

L'île de Saint-Domingue possède plusieurs sources d'eaux minérales; celles de Port-à-Piment et de Mirbalais dans la partie française, et de Banic dans la partic espagnole de cette île, ont été décrites et analysées; mais on aroit gardé le plus profond silence sur les eaux thermales de la grande Anse. M. Deshayes nous a fait parvenir un mémoire qui contient des recherches très-étendues sur leur nature. Ainsi, quoiqu'il ne fût pas médecin, il travailloit aux progrès de notre science; et la Compagnie, qui ne juge pas ses coopérateurs par leurs titres, mais par les services qu'elle en reçoit, l'admit an nombre de ses correspondans.

M. Deshayes a décrit l'art de tirer en grand nuse liqueur spirituense des baies du café; procédé đ11i pourra devenir utile aux laabitans des Mornes, dans les temps de guerre.

Enfin il a recueilli des observations sur les vers marins, que M. l'abbé Diquemarre a publices dans le Journal de physique, et il a fait sur les oisenux des recherches qu'il a envoyées à M. le conte de Buffon, dont il a reçn, connue nue récompense de son zile, le titre de correspondant du cabincet.

M. Deslıayes étoit né à Saint-Malo en 17332. Son père atvoit été nommé commandiunt de quarticr à Saint-Doningue on il éloit morl arec peu de fortune.

M. Deshayes fut placé d'aburd chez nun procurent" 
PIIYSIOL. ET MÉD. - LEFEVRE. 419 de la juridiction des Cayes, pour y apprendre ce que pent l'usage ou l'abus des formes dans le dédale des procédures. Il y conserva toute la droiture de son esprit et toute la pureté de son cucur.

Il eut bientôt une autre épreuve à subir; il fint nonımé curateur aux vacauces.

Daus un pays oì presque tons les fonds appartiennent à des proprićtaires quine grande distance en sépare, il faut bien qưil y ait un loonme public cliargé du soin de représenter les absens, qui recoive les dépôts, qui prévienne les dégradations, qui préside anx recouvremcus, qui recueille les héritages, qui devienno an besoin le parent on l'ani de tons cenx qui n'en ont point au-deld des nuers

Comme mue magistrature aussi belle est au-dessus de tont salaire, il faudroit anssi qu'une vie lungne et épronvée nuît ceux qui l'exercent an-dessus de tout sonpcon; et on derroit y attaclier tant de gloire que le citoyen vertueux, quelque fatigné qu'il fìt de ses utiles travanx, recherchât encore un emploi dont les fonctions paternelles répandroient sur les siens et sur lui les bénédictions du peuple, senl prix que l'ou puisse attendre pour tant de générosité.

M. Deshayes étoit jeune lorsqu'il fint placé dans co poste hasardeux. Il y montra autant d'intégrité que de zèle, et il s'empressa de le quitter lorsque son économie l'eut mis à portée de vivre loin du tourbillon des affaires. Il se forma dans les déserts de Plymouth une habitation oil il porta toute l'activité de sols 


\section{ELOGES HISTORIQUES.}

industrie, et il a joni du plaisir d'avoir pour ainsi dire créé les champs auxquels il confroit ses moissons.

M. Deshayes passa plusieurs années dans cette soli. tude: heureux au milieu de ses travaux, et entouré de quelques nègres qui étoient plutôt ses compagnons que ses esclaves. Une nualadie de linguzeur le força de venir au Cap demander des secours qu'il n'y trouva point. Il y mourut en 1786, après avoir légué ses livres et ses mánuscrits au Cercle des Philadelphes, et son corps aux médecins, pour qu'ils y cherchassent la cause du mal dont ils ne l'aroient point guéri. 


\section{LE ROY.}

C

Ir a N LES LE Roy, doctenr et professemr émérite do l'Université de nuérlecine de Montpellier, doctent de la Faculté de nédecine de Paris, ancien correspondant de l'Académie royale des sciences, de la Sociéte royalo de Londres, de celle des sciences de Montpellier, des Académies de Toulouse et de Ninnes, associé ordinaire de la Société royale de nuédecine, naquit ì Paris, le 12 janvier 1726 , de Julien le Roy, si cúlíbre par la r'évolution qu'il a opéréc diurs l'horlogerie, et de Jeamo Delafonds, dinne ancienne fannille dn Poiton: son grand-père, qui jonissoit ì Tours, oǹ il dentenroit, de la plus grande considération, aroit déja rendu son nom recommandable dans le mème genre.

Un art raiment ntile est sans doute celni qui, par ume suite de mourenens réguliers et non interrompns, fixe en quelque sorte la marche rapide du temps, en divise les interralles, et nontre anx hommes ce que vaut chaque instant de la journée. M. Julien le Roy, qui avoit consacré sa viè ce travail, connoissoit et faisoit connoitre ì ses enfans tout le prix du temps qu'il mesuroit si bien. Très-rersédans les sciences accessoires à cet art nutile, il jeta les premiers fondemens de leur édıcation; il lem expliqua, dès lenr plns tendre enfance, les élémens de la mécanique; il leur inspira le goùt 
des sciences exactes, et il fit naître en cuxceite ardeur pour le travail qui les a conduits à une célébrité méritée dans les différentes branches de la plyysique, dela littérature et des arts : ainsi les talens du fils ayant en lenr première source dans ceux du père, nous devions offrir à sa mémoire le premier hommage de notre reconnoissance.

M. Cliarles le Roy étoit le plus jeune de quatre fils de cet artiste illustre. Né avec une constitution trèsdélicate, la foiblesse de sa santé ne retarda point le développement de son esprit, mais elle rendit son caractère plus sérieux; et dans un âge oì les idées incohérentes se multiplient sans qu'on cherclie à en connoître les rapports, où les tableaux se dessinent en foule et se succèdent rapidement, où l'ane incertaine, neuve pour ainsi dire dans ses fonctions, et affectée de toutes parts, se répand au-dehors sans réagir sur elle-même, il avoit l'air de nuéditer ses réponses; la raison paroissoit diriger ses actions; il fuyoit les plaisirs bruyans de l'enfance, dont il n'aroit ni les gon̂ts, ni la légèreté; et ses parens le royant avec surprise tranquille an nuilien des jeux do ses frères, avoient contume de l'appeler lenr petit philosoplie.

Après avoir fait ses premières études au collége de Mazarin, il snivit an collége d'Harcont les lerons de philosophie du célébre M. le Momier de l'Acadénio royale des sciences, qui professoit encore; et il eut l'avantage alors très - rare daus les écoles, d'y recevoir les principes de celle doctrine que les académies 
PHYSIOT. ET MÉD. - LE ROY. 423 ont répandue dans le monde savant, et qui apprend à ne respecter daus les anciens que ce qui est vraiment digne de l'attention de la postérité.

IM. le Roy n'ent point à délibérer long-temps sur le choix de son état. La nućdecine convenoit à son goùt ponr le travail et ponr la méditation, et il se détermina sans balinucer. Dans quelle étude faut-il en eftet apporter plus de réllexion, plus de recucillement et de conrage que daus celle de la médecine? C'est an milien des symptônes effrinyaus que présentent les maladics les plins funcstes, c'est paruni les horremrs de la mort, c'est daus le seiu mème des cadarres ylu'il faut cn chercher les élémens. M. le Roy savoit que le plus compable de tous les lommes est celui qui, sins avol. pris la peine de šinstruire dans cet art difficile, osọ s'annoncer comme capablo de seconirir lin nature sonffrante lorsqu'il ne pent qu'angmenter ses entraves, et qui, se jouant de la vie de ses semblables, offre le tahleau lumiliant et terrible de l'humanité sonlerée coutre elle-même. Il savoit que, dans l'exercice de la nćdecine, le moindre abus, le plus léger oubli est un crime; el plus il se livroit à ces réflexions, plus il sentoit la ruécessité de se mettre, par son application, en état de ne mériter ancun reproche.

Une counoissance anssi réfléchie de tonte l'étendue de ses devoirs fit naitre cn lui le plus grand désir de les remplir. Dounant à l'étude une partie du temps qui deroit ètre destiné au repos et à la réparation des forces, il fint bientôt obligé d'interrompre absolument des travaux aussi pénibles. Mais un esprit actif pent- 
424 ELOGES HISTORIQUES.

il jamais être dans l'oisiveté? M. le Roy ne troura point de véritable délassement dans cette inaction. On lui conscilla de changer de climat, et de faire à Montpellier un nouvel essai de ses forces.

Peu de temps après son arrivée dans cettc ville, il éprouva le sentiment d'unc sorte de rérolution intérieure, dont il aimoit à parler comme de l'époque à laquellc il s'étoit senti animé par une force jusqu'alors inconnue.

Il profita de cc changement heureux pour suirre les leçons de l'Université de Montpellier; mais, loin de marquer pour le doctorat cet empressement qui est si souvent le caractère de la médiocrité, il différa le monent où ce grade devoit lui être conféré, et il résolut de faire auparavant un voyage en Itulie.

M. le Roy tint mo journal cxact de tout ce qu'il remarqua dans ce pays intéressant, où, parmi les débris de la grandenr romainc, les observatcurs tronrent à chaque pas des sujets d'étomuement et d'amiration; oir, tandis que l'artiste contemple les restes précienx de l'ancienne architecture, tandis que le littorateur cluerclic les unomumens qui lui rappellent la snémoire des grands hommes dont l'Italic a été le bercein, le pliysirien ose parconir ces monts brillans doint l'éruption a ché funcsle à 101 des plus grands naturalistes de l'antiguité : il pénitre avec respect e. attendrissement dins ces cités mallicurenses qui on disparu an milien des abimes de la terre ébranléc, et fune rontre curiosité reud ì la lumiore; il comprare enfin arec les obscrvations des ancicus l'élul actucl 
PHYSIOL. ET MÉD. - IE ROY. \25 d'un climat oì la nature semble s'ètre épnisée après avoir prodnit les maitres du monde.

M. le Roy n'onblia point de visiter la fimense grotte dn Clicu daus le royanune de Naples, et d'en sonmettre lin vapeur méphitiqune à différentes éprenves (1). Il revint par mer diftalic à Marscille. Le calme qui régrnoit, et la beaulé des nuits l'cugngèrent à restor prespunc tonjonrs sur le pout dn vaissean, oin, tantig que personnc ne songeoit à s'orcuper, il cherchoit des objets capalbles d'exercer l'activité de son esprit: il fut bientôt satisfait en observant que la prone, contre laquelle les flots venoient se briser, lançoit de petits grains brillaus daus le jour, et lumineux peudant lia muit, qui, apris aroir retounbe, praroissoient ronler sur la surface de l'cau pendant denx ou trois sccondes. L'an de incr, puisée, et exprosér à l'air pendant $u 1$ on denx jonrs, perd sa qualité phospliorique; elle on est également privée après avoir subi l'action du fen; elle la conserve plus longtemps, si l'ou bonche le rase çui la contient : l'esprit de rin, mêlé arcc l'ean de mer réccute, y prodnit dans l'obscurité un gr:und nombre d'étincelles; enfiu, si on la fillre, les corps brillans restent sur le tamis, quine légc̀re secousse rend luminenx. MI. le Roy les regardoit comme étant de rature huilense ou bitumineuse,

(1) Il a donmé il l'Aradémie royale des sciences les délails des accidens que celte vapeur til éprourer sons ses yeux a divers aui. max: ce sont ceux auxquels le méplitisme expose. II. le Roy partit pour l'Italie en 1,50 , et il communiqua en 1,75 ses observations à l'Académie, quil le nomma son correspondant. 


\section{6 ÉLOGES HISTORIQUES.}

et comme ne pouvant se dissoudre dans l'eau, puisqu'ils ne passoient point au travers du filtre. L'opinion de M. Vianelli, admise par M. l'abbé Nollet, qui attribuoit ces phénomènes à de petits vers luisans, est nuaintenant généralement adoptéc. M. Griselmini a publié en 1762 un ouvrage où il a établi le même sentiment. MM. Mauduyt et Fougeroux ont observé ces animalcules sur les côtes de Venise; et M. Rigand, correspondant de l'Académie royale des sciences, les a vus sur celles de France (1).

La santé de M. le Roy s'étoit encore fortifiéc pendant ce voyage; il a'avoit cependant point cessé de faire des recherches : mais l'esprit, livré successivement à divers travaux, éprouve plus de plaisir que de fatigue; et ce genre de délassement est le seul propre aux persomnes qui ont une véritable passion pour l'étude.

(1) L'été et l'automne sont Ícs saisons diuns lesquelles cette lunic̀re a le plus d'iutcnsitć. Boyle l'a observéc sur les còtes d'Angleterre; M. Ie chevalier ic Godehen aux ewvirous des iles Maldives, M. Secr daus la mer Baltique, et un antre pliysicien pres de Cadix. Suivant M. Ic Roy, cette propriécé est comumue it fontes les mers. Les graius qu'il avoit vus it la loupe lui avoient paru égaler en volume la tôte d’une grosse épingle. Il assuroit u'y aroir remarqué ancun des caractères des vers luisans. Certains phünomènes lumineux yroduits en pleine uer, trés-loin des còtes, sculblent tenir à l'électricitć. Des plyysiciens habiles ne sont pas éloigués d'admettre plusieurs causes capables de reudre les eaux de la mer lumineuses, et ils metent ru question si les vers luisans de MM. Vianclli, Nollet, Rigaud, ntc. ne doivent pas lenr lumicre aux molécules olscrvécs par M. le Roy, dont ils scroient plus ou ineins inprégućs. 
PHYSIOL. ET MÉD. - TE ROY. 427

Il se rendit avec empressement à Paris pour y jouir des embrassemens de son père, et pour offrir à l'Acadénuie royale des sciences les observations qu’il avoit recueillies, dont il ent la sagesse de supprimer tout ce qui étoit conmu. Il retourna ensuite à Montpellier, où il fiut reçu docteur en 1752 , et nommé professeur en 1759 .

On sait que cette place doit ètre le prix du mérite couronné dans $n$ concours oì tous cenx qui se pré. sentent sont adınis. On trouve dans les réponses anx donze quesuions qui furent proposées à MT. le Roy (1) des détails curieux sur la nature et les propriétés de l'éther nitrenx (2), alor's nouvellement déconvert par M. Navier; sur les luiles aninules; sur la manière de prévenir les inconxéniens dı sublimé corrosif daus le traitement des maladies ponr lesgunelles il est ordinairement employé, et sur plusienr's autres questions (3) importantes, relatives à la pratique de la médecine.

Il se distingua daus les fonctions de sa chaire par l'étendue et la variété de ses connoissances, par sa complaisance et par son zèle. Uniquement occupé dı

(1) Cucestiones chemicce duodccim. MIonspelii, apud Rochard, 1759 , in-k.

(a) Mímoires de l'Acadimic rọale des sciences, $17\{2$.

(3) Sur l'utilité des remèdes spécifiques, sur les substances propres a fondre les concrétious biliaires, sur l'usage des sels essentiels préparés à la manière de MI. de la Garaye, et sur les avantages que l'on peut retirer du soufre doré d'antimoine, dans le traitenent des alfections dartreuses de la peau. 


\section{4:8 ÉLOGES HISTORIQUES.}

soin de former ses élèves, et no songeant jamais à $\mathbf{s a}$ propre gloire, il ne mêloit dans ses instructions rien d'étranger, rien qui fît capable de distraire; il cn écartoit sur-tout cette érudition si difficile à acquérir, mais si facile ì feindre, dout le faste est toujours déplacé dans l'enseignement, et il ne présentoit aux étudians que ce qu'ils pouvoient et ce qu'ils devoient apprendre. Ses lecons étoient autant de traités simples è élémentaires que les jeunes médecins écoutoient avec avidité, qu'ils écrivoient et qu'ils se transmettoient avec cmpressement. Celles qu'il faisoit sur les fières, que l'on savoit avoir été pendant long-teınps lobjet de ses méditations, étoi.nt principalement recherchées. Il lui est un joul arrivé, ne pouvant s'ouvsir un passage au milieu des élèves nombrenx dont l'école étoit remplie, d'être porté sur leurs épaules jusqu'à la chaire, qu'ils entomroient et dont ancun ne vonloit conrir les risques de s'écarter. Ses collègues lui rendoient justice à cet égard. “ En sor》tant de nues leçons, disoit le célébre M. Venel, les ) tudians sont surpris de toute la climie güils ont " entendue; en sortant de celles de M. le lioy, ils sont э) étonnés de tout ce qu'ils out compris et retenu. ग On doit attribucr me partie de ses succi's daus ce genre à ce qu’il enseignnit en français : Ia nétlodo contraire a l'inconvénicnt d'ètre nowns intelligible, et de servir, soit par des conlonrs liamonienx, à flatter loreille, suns ajouter ail sens, et yuelquefois mome sans rien dire it la pensée, soit par des tonrumes iusidienses et consacrécs au soplrisme, ad domner de la 


\section{PIIYSIOL. ET MED. - I,E ROY. 429}

vraisemblance à l'errenr: de sorte que sourent il sulfiroit de traduire la lecon du latin en françus pour en faire sentir toute la médiocrité.

M. le Roy a toujours mis dans son étude beanconp de sagesse et d'écononic. Ne perdant jumatis de vau le but qu'il s'étoit proposé, il faisoit servir au succés de son entreprise toutes les parties de son iraviil. La pratique do la médecine étoit le point vers lequel il dirigeoit tous ses efforts, ot il ne se livroit anx scicuces accessoires qu'autant qu'elles pouvoient lui servir de guide dans la route difficile oi il se proposoit de marcher. Le tableau de ses ouvrages, cu justifiunt cetto partie de son éloge, et cn domnat an public nue idée de ce qu'il est indispensable de firire pour mériter sa confiance, offrira peut-ètre le plan le mieux entendu qu'un nédecin puisse concevoir de sa propre éducafion. Nous trouverons successivenent en lui un pliysicien sage, nu anatonuste instruit, un climiste lıbile, et un praticien éclairé, qu`une santé délicate a souvent troublé daus ses recherches, qu'un caractère fioid et sérieux a plus d'une fois arrèté dans ses succis, et que la cıuelle euvie u'a point épargué, quoique sa réputatiou alit presque toujours été inférieure à ses talens.

La physique pent seule faire connoitre les rapports qui existent entre la température des saisons et la nature des maladies. M. le Roy, en s'occupant de cette recherche utile, a fait, sur la suspension de l'eau dans l'atnıosphère (1), des expériences qui l'ont con-

(1) Musschenbroeck, art, 1455, n. 3 de son Essai- Bouillet, 


\section{3o ELOGES HISTORIQUES.}

duit à une explication très-ingénieuse de ce phénomène. Tous les physiciens savent qu'un vase rempli de glace se couvre extérieurement de petites gonttes d'eau dans le temps le plus chaud et le plus sec. Un ballon rempli d'air et bouché exactement se mouille en dedans lorsqu'on l'expose à une température plus froide; si on l'échauffe, l'humidité disparoît. M. le Roy conclut de ces faits que l'air de l'atmosphère est toujours chargé de molécules d'eall, sans que sa transparence en soit troublée; que cette eau est vraiment combinée, et qu'à un certain degré l'air ne ponvaut en dissoudre une quantité nouvelle, ce point est celui d'une saturation partaite; que l'eau dissonte dans l'atmosphère devient visible en se précipitant, lorsque la variation des vents (1), ou quelque antre

Mémoires de l'Académic, 3741 ; et M. Barberet dans le Mercure de novembre 752 , ont parlé de la dissolution de l'eau dans l'air; mais ils n'ont rien dit de plus. M. le Roy en a développé le mécanisme.

(1) Lorsque le vent du nord souffle, l'nir conticnt moins d'can en dissolution que daus le temps où le rent du nord-ouest domine. Dans un beau jour d'été, l'air en contient plus que pendant l'hirer; les couches les plus élevées sout plus froides et en contiennent moins. La dissolution des molécules aqueuses daus l'air, se faisant souvent d'une manière iućgale, et les conches de l'atmosplièce n'en étiun pas antant cliargées les nues que les aures, il doit s'ensuirre, sur-tout aupris des mers, une agitation dans ce fluide; aussi, sur les còtes de la Méditerrancic, il s'clève pendaut le jout un vent qui futit vers le soir.

I. a throric: te la suspensiun de l'eall dims l'atmosphère aroit conduit M. le Roy i celle de la furnumion de la rosére. Il all a distingué de trois espices. I'une est dne au refroidissement de 


\section{PHYSIOL. ET MÉD. - LE ROY. 行}

circonsconslance fout changer le point de saturation; et que, pour donncr à cette théoric tonte l'étendue dont clle est susceptible, de mème que l'ean, lorsption l'échanffe, dissont plus de sel, l'air, lorsque la liqueur du thermomètre est frltıs élevéc, dissont anssi une plus grande quantité d'ean.

Le mémoire dans lequel M. le Roy a exposé ces principes a rémil les stulfinges de lous les pllýsicierss de l'Europe (1). Occupé des phénomènes relatil's anx différentes températures de l'atmosphire, il n'a prentetre pas fait assez d'attention à la densité del'arr, regurdéc par plusiems physiciens comme une des cätises qui ajontent ì sa propriété dissolvante, puisque l'on voit

l'nir, qui, perdant aux approches de la nuit une parlie de sa propriéte dissolvante, reud it la terre l'ea un qu'il lui a enleve pelldaut le jour; l'autre esı une vapeur épusse qui s'élève il la haneur de quelques pieds an-dessus du sul, et clont l'air ne peut se charger, son degré de saturation ayan baissé : lia troisiènte est l'eflet de l'humidite locale de cerlains ellurvils vil l'eau est flins aboudinte. Des pliutes arrachies on élé couvertes de ruscie, et les observations de M. le hoy sur la première espèce ayant été faites ì des hantenrs très-consillérables, il étoit fondé à con. clure, contre Mussclienbroeck et Dulay, que toute la rosée ne s'élève point de la terre ou des pliutes. Il a vu l'eau répandue arcc un arrosoir sur ces denières se risscubler en gouttelettes aux extrémités de leurs feuilles: il ne faut douc pas, a-t-il dil, inférer de celte disposition que la rosée est toujours le produit sle la trauspiration végétale.

(1) MI. Franklin a adopté les principes de MI. le Roy dans les Tran. sactious philosopliques, anné 175 . Un professenr de Dublin a mublié la même theorie plusieurs années apris, sans citer MI. le
lịoy. 


\section{2 ÉLOGES HISTORIQUES.}

chaque même jour l'une ct l'autre croître et diminucr en proportion. Un savant moderne pense que l'air ne peut acquérir le moindre degré de chalcur sans abandonner une partie de l'eau avec laquelle il est combiné; mais ce plyysicien ( 1 ), dont on attend l'ourrage avec impatience, a reconnu la vérité des faits avancés par M. le Roy. Il se contente de les interpréter d'une manière analogue à ses propres observations.

Le mécanisme par lequel l'œil s'accommode aux différentes distances des objets exerce depuis long-temps la sagacité des plrysiciens. Le sentiment de M. de la Hire qui, rejetant l'allongement de l'œil et les mouremens du cristallin, faisoit tout dépendre de l'ouverture de la prunelle, n'avoit plus de partisans; et les objections de M. de Porterfield paroissoient saus réplique lorsque M. le Roy entreprit d'y répondre dans denx mémoires. Il a comparé l'œil à une chambre obscure dans laquelle, si l'image n'est pas bien terminéc, parce que l'objet est placé trop près, il suffit, pour détruire la confusion, de mettre devant le verre lenticularire un carton percé d'un trou fort étroit : ainsi la prunelle, suivant qu'elle se rétrécit ou qu'elle se dilate, accommorle l'œil à tontes les distances.

Si le sentiment de M. de la Hire pouroit être soutenı, ce scroit sans donte par les moycus sur lesquels M. le Roy s'est appuyé : nua is comment se dissimuler sa

(1) M. Ic chevalier de la Marck, de l'Acarlemic royale des sciences, jui a bien roulu me communiquer ses Ménores sur cc sujet. 


\section{PHYSIOL. ET MÉD. - LE ROY.}

toiblesse lorsqu'on réfléchit qu'un diaphlirĭğme placé devant le verre lenticulaire d'une chambre obscure retrécit l'innige, et qu'il rend la confusion moins sensible sans la détrnire; que l'objet étant placé trèsprès de l'œil, les rayons lumineux se réunissent tonjours an-delit de la rétine; et que si l'on aperçoit double ou triple un objet vin de trop prè's, par denx ou trois fentes rapprochées daus un espace qui un'excide point celui de la pruncl te, on ne duit l'attriluer yu'it ce que les rayous qui passent par chaque onverture, et qui tendent it se rémuir an-delì de la rétine, en sont empecchés par cette expansion dent ils affeetent plusienrs points dans lesquels ils nunltiptient les images et les sensations ( 1 )?

(1) La trop grande ouverture de la prunelle rend la vision confinse lorsque l'objet esI très-près de l'ouil. Dans ce cas, les rayons de lunitre qui partent de l'objet et qui tombent sur la circonférence de la prumelle, se brisent en entrant dans l'œil; mais ils ne se brisent pas assez pour que le point de reunion puisse ton:ber sur la rétiue: ce point se trouve au-deli, et le còne intéricur de lumière est conpé par la rétine mème, entre le sommet et la prunelle : la section qui en résulte est large, et la peinture du poiut visible, au lieu d'ètre un point unique, occupe un espace trop éteudu. On prévient cet inconvénient en diminuant artificicl. lement. l'ourerture de la prunelle, c'est-à dire en regardant l'objet au travers d'uu petit trou percé dans une carte, parce qu'alors la base du còne que les rayons de lunière forment en entrant daus l'œeil étant très-petile, Ia section de ce còne par la rétine est cucore plus petite, et est prise pour un point unique, quoique cette section ne soit pas faite an sommet; mais la clarté de $l_{a}$ vision est beancoup diminnée, à canse du petit nombre de rạ̧ons qui, dans ce cas, agissent sur la rétine.

Lors donc que l'on regarde à nu un point placé très-près de l'œil,
T. 2. 
Deux Mémoires lus à l'Académie royale des sciences en $17^{51}$, sur la respiration de la tortue et sur la struc-

son image est amplifiée et nal terminée; mais si l'on place audevant de l'œil, et très-près, un petit obstacle moindre que le dianètre de la prunelle, on, ce qui revient an même, si on regarde le même objet au travers de deux fentes très-rapprochiécs l'une de l'antre, pratiquées dans une carte, la bande intermédiaire intercepte les rayons de lumière qui tomberoient sur le milieu de la prunelle : les faisceaux qui passent par les deux fentes tendent, après leur entrée dans l'oeil, à se réunir au même point que. si l'obstacle n'y étoit pas, c'est-à-dire au-delà de la rétine, et chaque faisceau rencontrant cette mentbrane dans un point particulicr, it en résulte deux peintures, et par conséquent la même sensation que s'il y aroit deux points. De plus clacune de ces peintures est nette, parce que chacune est dans le cas éuoncé plus luaut; et la clarté est moindie pour chaque image qu'elle ne le seroit pour l'image confuse si l'œil regardoit à nu.

Si au lieu de denx fentes on en pratique trois dans une carte, mais de manidre que les trois fentes et leurs intervalles n'occupent pas une largeur plus grande que l'ouverture de la prunelle, et qu'on regarde au traters de ces trois lentes un point placé trèsprès de l'ocil, on verra, par la même raison, trois imagges assez distinctes. En général, si on fitit un nombre quelconque de fentes, pourvu que l'espace total qu'elles occrupent en largeurne soit pas plus grand que l'ouverture de la prunelle, on verra autaut d'inages qu'il y aura de fentes, en regardant mn point tres-proche au travers de toutes les fentes; mais clitcune de ces innges sera d'autant moins vive et moins claire, que la finte correspondaute sera plus i:troite, c'est-a-dite qu'il y aura moins de rayous de lunière culployés à la peindre sur la rétine.

Lorsqu'un oljet est placé is 1.1 portce de la vision distincte, tous les rayons de lumiore qui partent de claaque point et qui toulwut sur la prunelle, se réfracteut, "rout se réunir sur un point de la rétine, ou ils forment une peiuture très-nette, parce

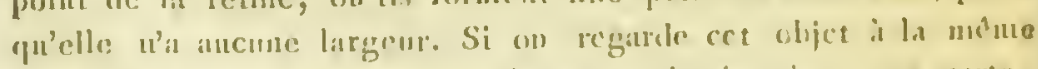
distance, au travers de deux fiutes pratiquées dans une carte. 


\section{PHYSIOL. ET MED. - LE ROY.}

ture de l'organe de l'onïe, amoncent les progries que M. le Roy avoit faits dans l'étude de l'anatomie humaine et comparéc.

ou ne voit qu'une intage, parce que les rayons de lumière qui traversent l'uue et l'autre fente se réunisseut tous sur nu mèue point de la rítine, coume ils le fervient si l'aul regardvit librement et it $11 \mathrm{ll}$.

Les choses étant daus cet état, lorsqu'ou place i pen près sur la mèue direction un secoul objet très-visible et trds-petit, mais beanconp plus loin, et que l'un fixe toujours le premier objet, ou voit deux iunges du second, parce que les rayons de lumicre qui viennent du second objet itant moins iloignes dn parallelisuce que ne le sont ceux du preuire, sont plus brises en eutrat dans l'xil; leur poiut de réuniou est alors compris eutre la rétine et la prunelle; ils se croisent lì et se prolungene jusqu’a ce qu’ils ri’ncoutreut la rétine, ce qui se fait eu deux poiuts distiucts : cenx qui viennent de la lente qui est i gaucle reucontreut la réline i droite, et réciproquement.

Si, sans changer de place, ou fixe le seconil point, ces deux inilges se confondront; il u'y en aura plus qu'une qui sera distiucte; mais on en retra deux du premier.

Or il est exident que dans ce cas tout est le mème pour la prumelle que dans le précédent; sa largeur artificielle est constante, puisque c'est toujours par les mèmes fentes que passent les rayons de lunière, dont les routes sont les memes, soit avant d'arriver à l'oeil, soit après avoir traversé la prumelle dans l'un et l'autre cas. Si les impressious sur la rétine sont différentes, il faut donc que cette membrane ait change de position parrapport aux rayons de luniere.

Dans le second cas, le second point ne peut ètre ru distinctement que la rẻtine ne se soit portée rers la prunelle pour se placer daus l'intersection des rayons qui viennent de ce second point; mais ceux du premier sont rencontrés par la rétine eutre le somnet et la prunelle : il doit douc arricer le mème phénomène dont on a déja parlé, c'est-i-dlire que les deux faisceaux qui vienuent. 


\section{‘36 ELOGES HISTORIQUES.}

C'est à l'analyse des eaux minérales qu'il a principalement appliqué ses connoissances en clinie. Dans nun précis très-bien fait (1), il les divise en salines martiales et sulfureuses. Il expose et discute ce que les auteurs en ont écrit, et il détermine leur nature et leur's effets d'après l'expérience et l'observation. Ce traité, d'abord uniquement destiné aux étudians, est maintenant regardé comme un des meilleurs ouvrages qui aient paru sur cette matière.

Les eaux de Balaruc étant pen éloignées de Montpellier, M. le Roy s'en est spécialeinent occupé (2). Outre l'analyse qu'il en a faite, et qui est plus exacte que celle de Régis, Deidier (3), et même que celle de

des denx fentes doivent être coupés par la rétine en des points diffẻrens.

Il résulte de ces réflexions que, par une diminution naturclle ou artificielle de l'onverture de la prunelle, on pent, aux dépens de la clarté, rendre la vision moins confuse, mais que celte diminution ne peut pas seule détruire la coufusion.

(1) De aquarum mineralium natura et usu, MIousp. apul Rocliard, 1758 , in-3..$^{\circ}$ en français : Précis sur les caux minérales : dans les Mélanges de plyysique, de climie et de médecine.

(2) M. le Roy a indiqué les précautious qu'il est indispensable de prendre relativement a la clialenr extrême du bain de sonrce, qui est de qu à $q$ degrés, i la manicre de la modifier dans le bain de cuve et daus l'étuve, et aux remedes auxiliaires. Ces obscrvations mtiles sont contennes daus denx Mcimoires sur les eaux de Balarue, dont M. Ie Roy attribue l'efficacite is las grande quansité dre sel marin quelles conticuncut, et à la chaleur dont elles bont péucitreses.

(3) Acalćmie des sciences, 1699. 


\section{PHYSIOL. ET MEDD. - IE ROY.}

Bolduc (1), il en a déterminé les vertus avec une sitgesse et me nodération nalhemensement trop rares parni cenx qui écrivent sur les eanx minćrales, dont l'intérêt et l'entlonsiasme exagèrent si sonvent les a vantages.

En cherchant à composer des canx mincénles artificielles, il est nn des preniers qui anient essilyé tons les moyens que la chinic fommit pon y snspendre le sonfie; ancun ne lui a parn anssi propre à cet nusage que la magnésie on base du sel d'epsonn. C"est d'après co principe que sont dictées les formules ntiles qüil a publiées dans nu mémoire particulier sur la manièe d'innter les eamx minérales sulfirenses.

Quel médecin étoit plus dignue que M. le Roy de succéder à M. Venel dans le travail important que le gonvernement a ordonné sur les eaux minérales de France? Quel médecin rénnissoit ì mu plus lıant degré les connoissances nécessaires an succès de celte cntreprise? M. le lioy, nulgré ses nombrerses occupations, a mis les observations de M. Venel en ordre; il y a ajouté des réflexions; et nons avons lien d'espérer que cet ourráge, commencé par deux médecins célèbres, et confié maintenant à $11 n$ chiniste habile (2), acquerra enfin le degré de perfection dont les progrès de la chimie le rendent susceptible.

Il étoit temps que M. le Roy fit lapplication de ses

(1) Voyez différentes analyses de Bolduc, Acadéın. des sciences, 1726 et 1729 .

(2) M. Tourenal, associè régnicole de la Société royale. 
travanx à la pratique de la médecine. Lorsqu'il essaya de se rendre compte à lui-même des connoissances qu'il aroit acquises, il s'aperçut que la nature de certaines maladies, telles que la petite-vérole, la rougeole, la pleurésie, les fièvres intermittentes simples, etc. étoit exactement déterminée; mais il vit avec peine que les auteurs les plus recommandables étoient d'une opinion différente sur la division et la nomenclatıre des fièvres; que Boërrhaave a souvent donné le nom d'ardentes aux fièvres appelées inalignes par d'autres médecins; que Villis, Morton et Fizes ne sont point d'accord sur l'idée qu'on doit avoir de la fièvre putride, regardée par Willis comme n'ayant point de redoublemens, et par Morton comme étant rémittente.

L'incertitude de ces opinions engagea $M$. le Roy à se faire une méthode particulière, fondée sur l'observation des fièvres dans le clinat qu'il habitoit. Il avoit remarqué que tons cenx qui ont écrit sans établir lenrs travanx sur une base semblable ont avancé beancoup de propositions vagues, et dessiné des tableanx sans modele et sans ressemblance. Il ne reconnoissoit gue deux classes de fièvres, qu'il distingnoit, suivant le danger dont les jours du malade sont menacés, en béniguses ct malignes (1), el qu'il subdivisoil chacune en qualre espèces (2). La fiève accompaguéc d'un érysipucle it

(1) Cente premiche division paroît un pen vague; mais, consideréc dans ses dérails, elle est exacte. Voyez le Mémoirc de M. Ie Ruy sur les tiievres.

(a) Colles de la premidre classe sone 1.0 la fivere cominue, beni- 


\section{PHYSIOL. ET NED. - I.E ROY. 439}

la face, qu'il rangeoit dans la prenière classe; la fierre soporeuse des vieillards et la fievre charbounense qu'il rapportoit i la seconde, sont des nualadies assez fréquentes dans le Langnedoc: il les a décrites d'mne maniore nonvelle, et il en a tracé la métlode curative d'après les indicalions les mienx présentées.

On ne rloit point confondre les maladies popmlaires avec les épilténiques. Les premiieres ne doivent ètre

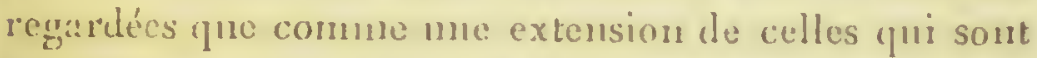
propres ì un clinat dans leynel des circonstances parliculicres en angunentent le numbre et l'intensitó. Les sccoules se propagent dans an pays vir cllessont étrangìres, el oil clles unt élé apporlées d'nure antre région yni est leur bercean. Ainsi la fievre miliaite et la cataruhale maligne, dont Hoffizan a domé la description, sont propres it plusienrs provinces de l'Alle-

gur ; $2 .^{\circ}$ la fidre quotilienne; $30^{\circ}$ la ficre lierce dégénérie en continue; $40^{\circ}$ la fière acromugagnéc d'un érysipèle i la facc.... Celles de la seconde classe sont $10^{\circ}$ lil fière maligne des ricil. lards; $20^{\circ}$ la fière maligne cies jemes gens; $3 .^{\circ}$ la fière maligne cliarbonncuse, endénique en Languedoc; $4^{\circ}$ la fièrre malignc rles nccouchées. Daus quelques fic̀res malignes, M. le Rny a observé que le pouls ne baltoit que quarante à cinquante fois par minute. Ces fierres n’éloicut pas les plus dangereuses. Il est en général plus facile d'exciter la nature trop lenic, que de la modérer lorsque ses monvemens se lont arec trop l'énergie. Voyez NIémoires et observalions de médecine. I. ${ }^{\text {ro }}$ parlie, contenant deux mémoires sur les fières aignës: it Montpcllier 1766 , in-8. ${ }^{\circ}$. Mélanges de physique, de chimic et de médecine : a Paris, chez Cavelier, ${ }^{1773}$, in-8. ${ }^{\circ}$; et Mélanges de médecine, I. ${ }^{\circ}$ partie, etc. chez Didot, 1776 in $-8^{\circ}$. 


\section{0 ÉLOGES HISTORIQUES.}

magne; les fièvres pétéchiales règnent presque sans interruption dans la basse Hongrie ; les fièvres intermittentes semblent appartenir anx lieux humides, vaseux, et dans lesquels il y a des débris de végétaux en fermentation. La fièvre jaune que M. Lind a vie quelquefois épidémique dans les ports d'Angleterre, y est toujours répandue par les vaisscaux venant d'Amérique, où la petite-vérole étoit inconnue avant la conquête ou plutôt l'invasion de cette partie du monde. Enfin, quelques contrées du Levant sont assez mallıeureuses pour être le foyer du plus terrible des fléaux: le commerce a rémni les individus les plus éloignés ; le Nord et le Midi se sont communiqué leurs maladies: productions funestes que l'homme semble cultiver par ses cxcès; et les peuples ont vu s'accroître en même temps leurs besoins et lcurs mallienrs.

Cette distinction des maladies populaires et épidćmiques a conduit $M$. le Roy à une réflexion anssi utile qu'elle est simple ct vraie. La connoissance de la naturc ct du traitement des maladies propres ì cliaquie contrée doit nécessairement apprendre dans un antre pays où ellcs sont répandnes et épidénniques, à en détcrmincr la nature et le traitcment : d'où il résulte que le moyen le plus snir pour avoir un tablean de tontes les épidémies proprentent ditcs, soit existantes, soit môme possibles, scroit de se procurer, par nue correspondance cxacte et très-ćtendue, ainsi que la Société l'a projecté, la description des maladics populaires particulicres à changue contréc. Et en effet l'illustre 
PHYSIOL. ET MED. - LE ROY. 441 Sydenham anroit-il méconnu la fievre miliaire en 1684 s'il avoit été instruit de son apparition a Leipsick, plus de trente années auparavant, en 1652?

On donne le nom de crise anx efforts organiques qui tendent à fare sortir les snbstances irritantes dont la maladic est la canse on l'elf't. Sédnits pent-ĉtre, comme Celse l'a présnmé, par l'harmonie des nombres, les anciens ont admis des jours divisc's par septenaires et demi-septenaires, lesyuels doient, selon enx, destimés aux crises: d'autres indiquoient lenrs approches, et 111 petit nombre permettoit l'usage des médicamens. M. le Roy parle de celte disposition avec érudition et impartialite. Ontre que Galien, Archigine et Dioclès different sur plusicurs points importans de cette doctrinc ( 1 ), il y a beanconp de circonstances dans lesquelles les premières munces de la maladie se confondent tellement aréc l'état de santé, qu'il est presque impossible d'indiquer le jour qui doit être le premier dans l'ordre de ce calcul (1). L'existence et l'ntilité des crises n'en sont pas moins démontrées; elles sont indiquées par des redoublemens, par des efforts, qu'nn médecin instruit et exercé sait rcconnoître et qu'il ne trouble jamais. C'cst donc plutôt anx mouvemens qui les annoncent, qu'aux jours qui les précèdcut, que l'on doit dommer son attention.

(1) Les uns regardoient le 20 , les autres le a1, comme critiques. Quelques-uns accordoient à ces deux jours les mêmes préroga-
tives.

(2) On éprouve, sur-tout dans les fièrres des femmes cn cauche cette difficulté pour le compte des jours. 


\section{2 ÉLOGES HISTORIQUES.}

L'art du pronosstic est fondé sur la connoissance de ce qui s'est passé, de l'état actuel du malade, et de toutes les circonstances qui l'enviroment. Hippocrate ayant jeté les fondemens de cette science, M. le Roy a réuni (1) tous les jugemens épars dans les ouvrages de ce médecin illustre; il les a rapprochés, analysés et comparés avec les observations des modemes; mais en même temps qu'il a donné cette preuve de son respect pour la mémoire et de sa confiance dans les écrits d'Hippocrate, il s'est élevé avec force contre la sounission aveugle de certains auteurs à la doctrine des anciens. Il a montré de quelles erreurs une admiration anssi peu éclairée a été la source, et combien elle a prolongé ces siècles d'ignorance, dans lesquels les écrivains de l'antiquité étoient révérés comme des dieux dont on se permettoit.quelqnefois d'interpréter les oracles, mais que l'on n'osoit jamais contredire. M. le hoy a au contraire établi que, daus une science de faits, l'antorité la plus respectable pent et doit mêtne toujours être tradaite au tribumal de l'expérience (2).

Une suite de travaux anssi utiles lni açuit la réputation la mieux méritée; il la vit bientôt s'étendro

(1) Du pronostic dans les maladios aignës, dans les Melanges de mélecinc, II." partic, cliez Dirlot, in-8.".

(*) On lira aussi avec plaisir, 1. "un Mémoire ale MI. Ic Rny sur le scorburt, dans Inquel cette maladie est considéréc comme accidentalle et comme coustituinnnelle. On y trouve, sur ce dernier genre de scorlun, des réflexions tres-jurlicicusos; $20^{\circ}$ une Dissertation latine de l'urgantibus, anctore d.." le lloy. Monsp. 175y, in-4.* 


\section{PHYSIOL. ET MED. - LE ROY. 443}

vers la capitale, qu'il n'avoit quittée qu’à regret; il manquoit à une famille dans lixquelle les taleus sembloient être lıéréditaires, et qui, possédaut qutatre fréres également célébres en divers genres (1), devoit être empresséc de les voir réunis, el d'offrir à lis capitale mo phénomène littéraire anssi rare qu’il étoit intéressilut. Le plaisir de vive dans sa pattrie, et lat solli-

(1) M. Pierre le Roy l'aine parcont arec succes la carritre il-

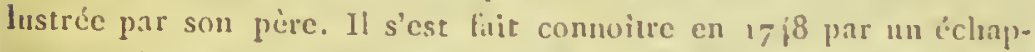
pement d'une nourelle invention. En 3755 , il a présenté a l'Aca. démie royale des sciences ume pendule d'une construction tries. ingenicuse, en ce qu'elle n'at pas besoin de rouage, et que de petits grains de plomb qui tombeut d'un revervoir dans des augets donnent à la machine l'impulsion qui hui est nécessaire. En 17 Gy et 1771 il a reuporté les deux prix proposés par l'dradémie royale des sciences sur les moutres marines. M. Jeam. Baptiste le Roy, le second des quatre frères, est complé parmi les membres les plus distingnés de l'Acadénic royale des sciences. On lui doit, sur li mécanique, sur la physique, el principalenent sur l'électricité, des ménoires tris-iutéressans. M. Julien-Darid, le troisième, après arois voyage dans la Grice, et y aroir contemplè les monumens qui ont échappé à la barbaric, en a décrit les ruines dans un bel ourrage. Il a succédé au rélchbre Blonılel, dont il est élève, dans sa place de professcur à l'Acalénie d'architecture. Celle des inscriptions et belles-lettres l'a associè ì ses travaux; il a communiqué ì cette Compagnie des mémoires très-curicux sur la marine des anciens penples, expliquée et considéréc par rapport anx Inmières qu'on peut en tirer pour perfectionner la marine moderuc. MI. Charles le Roy, auquel cet ćloge cst consacré, étoit le plus jerne des quatre fières. Tant de connoissances ct de talens rẻunis dans me mème famille doirent être regardés comne le frutit d'une édncation dirigée par un père que le bruit de sa propre renonuce n'a point détourné du plus sacré de tous les deroirs, celni de former le cœur et l'esprit de ses enfans. 


\section{ELOGES HISTORIQUES.}

citation des personnes les plus distinguées, invitoient depuis long-temps M. le Roy à y revenir : il céda enfin, et il se fixa à Paris dans le mois de février $\mathbf{1 7 7 7}$.

Quel changement! une ville immense à parcouri. chaque jour; un grand nombre de concurrens à balancer; tont le monde à la fois à satisfaire; répondre à la foule des curienx, dont l'amour de la nouveauté dirige la confiance et les goûts: résister an torrent des importuns; déconcerter Ia critique; braver l'envie : telle est la tâche pénible qu'un médecin s'impose lorsque, appelé dans la capitale, ses talcns le portent aussitôt au faîte de la célébrité, sans qu'il ait eu la peine d'en parcomir les routes et les détours. M. le Roy n'avoit pour se soutenir dans un rôlc aussi difficile que sa probité et son expérience en médecinc. On ne trouvoit en Ini ni cette agréable urbanité qui, cn donnant des graces aux talens, scmble alléger le poirs des infirmités, et sait répandre à propos quelques fleurs sur la fin de notre carrière; ni celte assurance qui persuade, cntrainc et porte la conviction dans los esprits; encore moins cette adiesse qui comnoit l'art de subjugner le public avec une force dont on sait varier les nuances suivant le besoin et la trempe des esprits. On reprochoit à M. le Roy me froideur, quel quefois mêne une taciturnité bien excusables saus donte, puisque, produite par l'attention profonde qu'il domoit à l'état de ses malades, elles ne pouvoient que tourner ì leur profit.

Nous ne devons pas oublier de domer me prenrede sa délicatcsse, en rapportant les moyeus qu'il a choisis 


\section{PHYSOIL. E'T MÉD. - LE ROY.}

pour acquérir le droit de pratiquer la médecine à Paris. Il lui anroit été en mềue temps facile et commode d'obtenir nne place qui lui en anroit domé le privilége; mais il aima mienx se présenter à la Faculté de.nédecine; et, aprís avoir professé pendant vingt amnées, s'exposer an désagrément et à l'ennui d'un examen et d'une tlièse, persuadé qu'mu nuédecin ne peut offrir à cette illustre Compagnie trop de témoignages dle son déronement, et an public trop de titres pour nuériter sa confiance.

Les occupations fitigantes anxquelles il se livroit sans réserve épuiscirent bientùt ses forces; elles s'affoiblirent sensiblement dés le milien de l'amée $177^{8}$. Dans les prenniers nois de l'année snivante, il connmença à romir aprés ses repas; il ent némmons le comrage de continner son travail arec la mème ardenr, jusqu'ì la fin dn nois de septembre de la mène aunće. A cette époque, ses doulenrs devintent plus vives, et ses vomissenens se rapproclı̀ıent. MI. le Roy vit sans étonnement les progrès d'm mal dont il soupçonnoit depuis loug-ternps la nature et le siége. Son art ne lui fournissant anculle ressource pour éloigner une mort inévitable, son conringe lui donna la force nécessaire pour n'en être point effrayé. II ne fatigua point ses confrères, en leur demiandaut des avis qui auroient été inutiles. Il s'empressa de mettre en ordre les cahiers de feı M. Vencl qui lui aroient été confiés; il pria M. Lorry de déposer au bureau de la Société les mémoires dont il aroit été nommé commissaire ; et il attendit dins les bras de ses frères, et au milieu do 


\section{ELOGES HISTORIQUES.}

ses anis, l'instant où il devoit cesser de souffrir et de vivre. Il mourut des suites d'nn squirre an pylore, le 10 du mois de décembre 1779 , âgé de cinquantequatre ans moins quelques jours.

Avec moins d'amour pour l'étude et pour la célébrité qui en est la récompense, M. le Roy auroit peutêtre passé des jours plus longs et plus paisibles; mais le bonheur tient-il de si près à cette tranquillité dont quelques-uns se font une froide idole? et ne doit-on pas plutôt l'estimer, en raison des jouissances qu'un homme instruit et vertueux sait se procurer? Quel état en rémit plus dans ce genre que celui d'un professeur liabile, qui répand et fait circuler les rérités parmi les honimes, et d'un inédecin savant, qui, sans cesse occupé de leur conservation, est assez heureux pour diminuer la somme des maux quiles accablent? M. le Roy a eu le plaisir d'être utile sous ce donble aspect, et il a joui dn véritable bonheur dont la foible humanité est susceptible : on ne doit donc ni le blitner., ni le plaindre, mais faire ses efforts pour l'initer.

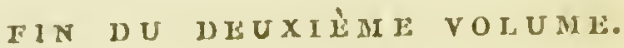




\section{TABLE}

\section{DES ÉLOGES HISTORIQUES}

\section{CONTENUS DANS CE VOLUME.}

Híroo e de l'oulletior de la Sulle, de Sihéle.

page 1

- de Spieluann.

de Watelet.

_- de Vergennes. $\begin{array}{lr}\text { Notice historique sur le's principales Académies. } & 141 \\ \text { Rieflexions sut les sciences. } & 153\end{array}$

Discours prononcé devant le prince Henri de Prusse. 163 Eloge d'Aruaud de Nublerille.

- de Barbeu Dubourg.

- de Bouillet.

- de Fothergill.

- de Gaubius.

- de Girod.

- de Haller.

- de Hunter (Guilluune).

- de Lamure (de).

- de Lefcrre Dishayes.

- de Le Roy. 



Wur-8) a

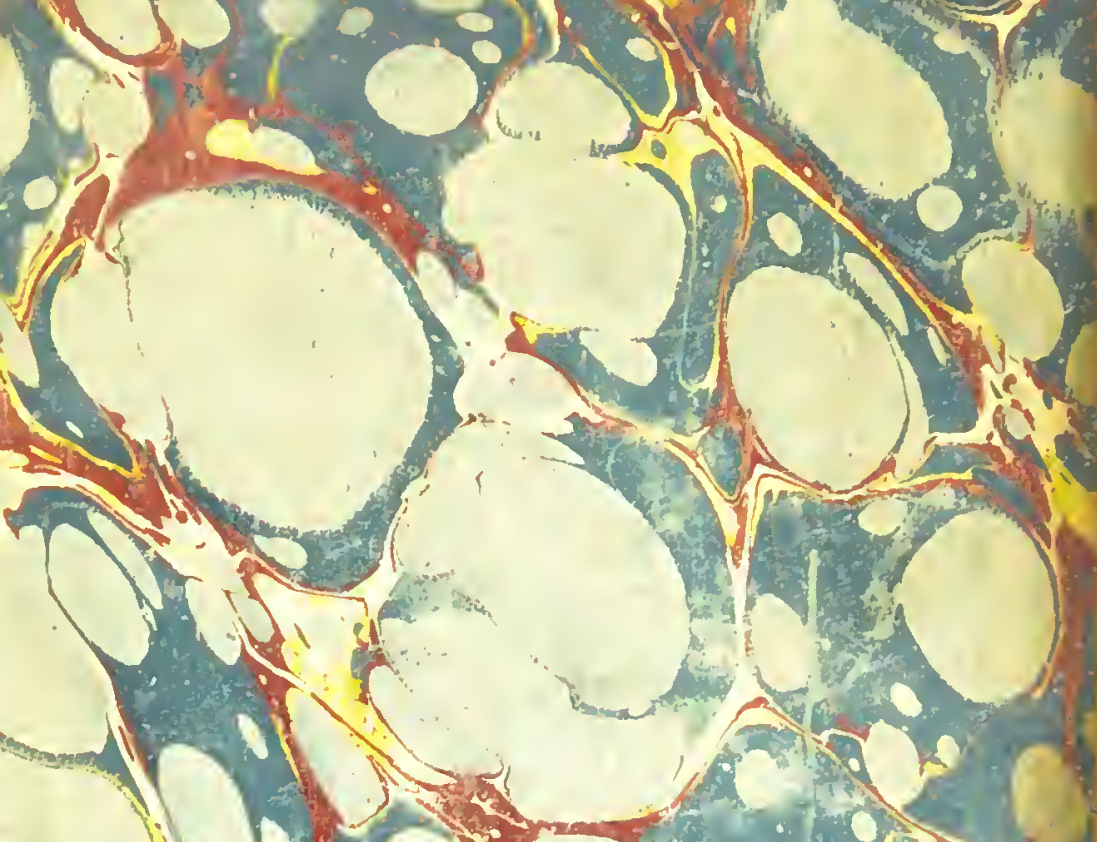

in $10: 10$
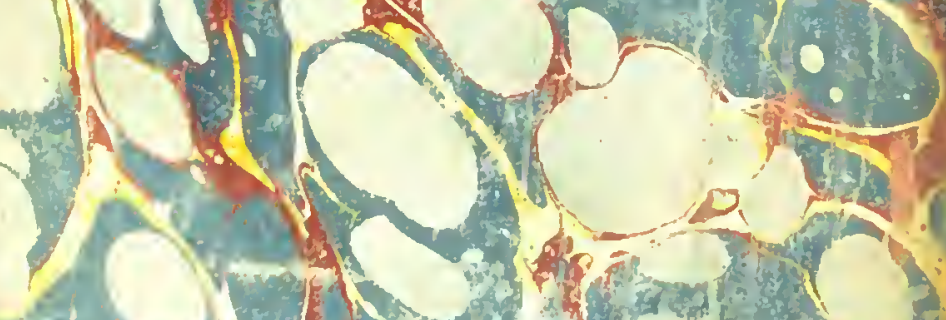

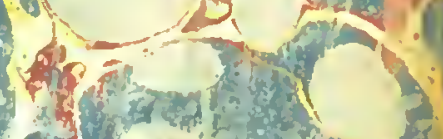

